\title{
Intracranial Fluids Dynamics: \\ A Quantitative Evaluation by Means of \\ Phase-Contrast Magnetic Resonance Imaging
}

Yudy Natalia Flórez Ordónez

Valencia (Spain), 2009 
The research described in this thesis was carried out at the Polytechnic University of Valencia (Universitat Politècnica de Vàlencia), Valencia, Spain in a close collaboration with the Radiology Department of the Hospital Quirón, Valencia, Spain. The project was financially supported by the Generalitat Valenciana through a CTBPRB/2004/342 FPI (Formació de Personal Investigador) grant and by the Spanish Medical Radiologic Society (SERAM, Sociedad Española de Radiología Médica) grant. 


\title{
Intracranial Fluids Dynamics: \\ A Quantitative Evaluation by Means of Phase-Contrast Magnetic Resonance Imaging
}

\section{Yudy Natalia Flórez Ordónez}

\author{
Dissertation submitted \\ in partial fulfillment of the requirements \\ for the degree of \\ Doctor of Philosophy
}

Supervisors: Dr. Luís Martí-Bonmatí

Radiology Department

Hospital Quirón, Valencia, Spain

Dr. David Moratal-Pérez

Electronic Engineering Department and

Center for Biomaterials and Tissue Engineering

Universitat Politècnica de València, Valencia, Spain

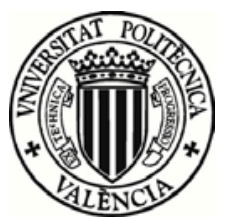

Polytechnic University of Valencia 

A mis padres Cecilia y Justo Pastor, por todos los principios éticos y morales impartidos; que prevalecerán durante toda mi vida.

Al mayor regalo que Dios trajo a mi familia, María del Pilar. Gracias por enseñarme a valorar el sentido de la vida.

A Elvis por toda la paciencia, amor y comprensión que día a día me fortalecieron. 



\section{Acknowledgments}

During the development of this thesis, I have met many people and I learnt from all of them. Besides this, many people helped indirectly to the realization of this thesis helping me to feel at home in this foreign country. I hope I can express my gratitude to all of them and apologize in case I forget somebody.

I will start this acknowledgment by thanking my two Ph.D advisors: Dr. David Moratal and Dr. Luís Martí-Bonmatí for all their effort and the never-ending flow of ideas and energy. Looking back, I am very happy that I decided to work in the field of image processing and therefore the chance to do research with Dr. David Moratal Dr David Moratal who became not only my teacher but also my friend. He always supported and encouraged me during the five years of study and research. Thank you David.

Dr. Luís Martí-Bonmatí, first of all I would like to thank him for offering me the opportunity to do research with him. Over time I have collected lots of "paper tablecloths" of the Italian restaurant, where we discussed step by step the different points that allowed the development of this thesis. I feel great admiration because he is able to transmit and share his knowledge in a polite way and I am especially thankful that he shared it with me during all these years.

I would also like to express my gratitude to Dr. José Millet-Roig and Dr. Antonio Mocholí, for offering me the opportunity to begin this research in their Bioengineering, Electronic and Telemedicine group (BET) of the Polytechnic University of Valencia. The time I worked in their group was very pleasant. Thanks to my colleagues of the BET: María, Cibeles, Fili, Paco, Cuentin, Vicent, Robin.

Lots of people were very important during my stay in the Service de médicine nucléaire et traitement de l'image in Amiens, France. Dr. Olivier Baledent, Dr. Roger Bouzerar and Dr. Marc-Meyer. I am especially grateful to Dr Olivier for his direct, concise and very interesting contributions and discussions that helped the development of this thesis. J'aimerais jouer encore pétanque. J'ai de très bonnes mémoires de mon étape en France.

Special thanks go to my friends who joined me at coffee breaks: Silvia, Isabel, Jacqueline, Nina, Ana and Rocío. Your company throughout these years 
was an escape to routine and everyday problems, helping me to endure work without complaining.

Radiology Department staff of the Clinica Quirón-Valencia, and especially to Dr. Juani, Dr. Estanis, Dr. Salva, Dr. Cristina, Dr. Enrique, Dr. Rosario, Dr. Vicente, Dr Enrique, Eva, Noelia, Ángel, Pedro, Roberto, Gracián, Ángel and Clara. Thank you for guiding me and helping me during this time and especially when I had doubts about how to proceed.

To the staff of the Spanish division of Philips Medical System: Han and Javier.

To the MR Unit staff of the Hospital Universitario Dr. Peset, and especially to Dr. Cecilio for his fruitful comments about the cerebral hydrodynamics.

To my volunteers, "my heads": Angel, Catalina, Silvia, Isabel, Elvis, Leila, Tatiana, Oneira, Fabian, Ida, Salin, Mauricio, Milangela, Nidya, Sofía, Carolina and finally my colleage Fabian "El tigre". Thanks, for their valuable collaboration.

Finally, I thank my parents, Cecilia and Justo, my sister, María del Pilar and my boyfriend Elvis for instilling in me confidence and a drive for pursuing my $\mathrm{PhD}$.

All of you have helped me to carry out this work, in one way or in another, and maybe without being aware of it. You have been my lifemates during these last years, and I thank you for all of this. 


\section{Abstract}

The intracranial volume is made up by the cerebrospinal fluid (CSF) volume, the blood flow volume and the brain parenchyma. The inflow blood to the skull in systole temporary increases the intracranial volume. According to the Monroe-Kellie doctrine an increase in one volume should cause a decrease in one or both of the remaining two volumes in order to maintain volume constant. The imbalances that occur in this process of cerebral homeostasis have been linked to neurodegenerative and cerebrovascular diseases. Therefore, adequate methodologies in order to analyze the dynamic of the intracranial fluids (LCR and blood) are necessary.

The cine sequences of phase contrast magnetic resonance imaging (PCMRI) with cardiac synchronism allow to quantify the CSF and blood flows during a cardiac cycle. Flow measurement with PC-MRI is accurate and reproducible if an adequate acquisition protocol is used. The reproducibility and accuracy of the measures also depend on the use of adequate post-processing techniques that allow to segment the regions of interest (ROI), with great consistency and independency of the operator and to correct the residual systematic errors caused by imperfect suppression of eddy currents and the contributing to the signal of small movements that the brain presents due to the transmission of the vascular pulse as well as the aliasing reflected as an abrupt change and opposed to the original sense of flow. These techniques also must take into account the errors associated with the partial volume effect (PVE), caused by the presence of stationary tissue and flow inside the voxels of the periphery of the region under study.

The overall objective of this thesis was to develop a reproducible methodology to quantitatively evaluate the intracranial fluids dynamics within CSF spaces (aqueduct of Sylvius, prepontine cistern and subarachnoid space C2C3) and main cerebral blood vessels (carotids and vertebral arteries, jugular veins, straight and sagittal superior sinus) by means of PC-MRI. This methodology includes semiautomatic segmentation techniques by thresholding and K-means clustering that allow to delineate the ROI with great independency of the observer and to apply background and aliasing correction.

Amplitude parameters (increase of flow volume in systole, mean flows, pulsatility, compliance indexes and supratentorial CSF) and temporal parameters 
(delay respect to the inflow blood to the brain) were quantified. The distribution of the pulsatibility of the CSF flow between the ventricular and subarachnoid spaces was measured as the ratio of aqueductal to C2C3 cervical stroke volume.

The commitment between the acquisition protocol and the used methodology to calculate each one of the parameters has helped to establish reliable and reproducible normality ranges for each one of them. The evaluated control subjects were asymptomatic and they had no history of intracranial hypertension, neurological disease, vascular events or relevant risks factors allowing to generalize the measures. They were studied at the same hourly stripe to avoid influences of the circadian cycle. All acquisitions were carried with a 3.0T MR unit to avoid the influence of the field strength on parameters.

In conclusion an adequate methodology was developed to carry out quick and reproducible quantitative blood and CSF flow analysis useful in clinical practice. This new approach to study cerebral fluid interactions should help to improve the understanding about the physiopathology of several cerebral diseases caused by CSF, blood and intracranial pressure alterations.

Keywords- Phase contrast MRI, CSF, cerebral flow, segmentation, image processing, k-means 


\section{Resum}

El volum intracranial l'integren el volum de líquid cèfalo-raquidi (LCR), el de la sang i el del parènquima cerebral. L'entrada de sang al crani en la sístole incrementa el volum intracranial. Segons la llei de Monroe-Kellie deu ocórrer una descompensació als volums restants per mantindre constant el volum total. Els desequilibris que es produeixen en aquest procés de la homeostasi cerebral s'han associat tant a malalties neurodegeneratives com a cerebrovasculars. Per tant, és necessari contar amb metodologies adequades per analitzar la dinàmica dels fluids intracranials (LCR i sang).

Les seqüències dinàmiques de ressonància magnètica en contrast de fase (RM-CF) amb sincronisme cardíac permeten quantificar el fluxe de LCR i de sang durant un cicle cardíac. La mesura de fluxe mitjançant seqüències de RM-CF és precisa i reproduïble sempre que s'utilitze un protocol d'adquisició adequat. La reproduïbilitat i exactitud de les mesures depén també de l'ús de tècniques adequades de posprocés que permeten segmentar les regions d'interés (ROI) independentment de l'operador i admeten corregir els errors de fons introduïts per la supressió imperfecta de les corrents induïdes i la contribució al senyal dels xicotets moviments que presenta el mesencèfal per la transmissió del pols vascular així com el submostreig (aliasing), reflectit amb un canvi abrupte i oposat del sentit original del fluxe. Aquestes tècniques d'anàlisi deuen també tindre en compte els errors relacionats amb l'efecte de volum parcial (EVP, causat per la presència de teixit estacionari i de fluxe a l'interior dels vóxels de la perifèria de la regió a estudiar.

L'objectiu principal d'aquesta tesi consisteix a desenvolupar una metodologia reproduïble per avaluar quantitativament la dinàmica dels fluids intracranials dins d'espais de LCR (aqüeducte de Silvio, cisterna prepontina i espai perimedular C2C3) i principals vasos sanguinis cerebrals (artèries caròtides internes i vertebrals, venes jugulars, sinus recte i sinus sagital superior) utilitzant imatges de RM-CF. Aquesta metodologia integra tècniques de segmentació semiautomàtiques per umbralització i classificació K-mitges que permeten delinear les regions d'interés independentment de l'observador amb correccions de fons i submostreig. 
S'han quantificat paràmetres d'amplitud (increment de volum de fluxe en sístole, fluxes promig, índex de pulsatibilitat, índex de compliança i producció supratentorial de LCR) i temporals (retrasos front a l'entrada de fluxe arterial al cervell). La distribució de la pulsatibilitat del LCR entre l'espai ventricular i el sac dural espinal es va calcular com la relació de volum per cicle entre l'aqüeducte de Silvio i l'espai perimedular en C2C3.

El compromís establert entre el protocol d'adquisició i la metodologia emprada per calcular cadascun dels paràmetres ha permés establir rangs de normalitat fiables i reproduïbles per cadascun d'ells. Els subjectes estaven assimptomàtics i no havien presentat mai un quadre d'hipertensió intracranial ni patit traumatisme cranioencefàlic, permetent generalitzar la normalitat de les mesures. Tots els subjectes foren examinats durant la mateixa franja horària per evitar influència del cicle circadià, i baix la mateixa intensitat de camp magnètic per evitar la seua influència.

En conclusió, s'ha desenvolupat una metodologia adequada per dur a terme de forma ràpida i reproduïble anàlisis quantitatius de fluxe de LCR i sanguini d'utilitat en la pràctica clínica. Aquesta metodologia per estudiar les relacions dinàmiques dels fluxes intracranials contribuirà a comprendre la fisiopatologia de varies malalties cerebrals causades per alteracions del fluxe de LCR i sanguini..

Paraules clau- Ressonància magnètica en contrast de fase, LCR, fluxes cerebrals, segmentació, posprocés d'imatges, k-mitges 


\section{Resumen}

El volumen intracraneal lo integran el volumen de líquido cefalorraquídeo (LCR), el de la sangre y el del parénquima cerebral. La entrada de sangre al cráneo en la sístole incrementa el volumen intracraneal. Según la ley de Monroe-Kellie debe ocurrir una descompensación en los volúmenes restantes para mantener constante el volumen total. Los desequilibrios que se producen en este proceso de la homeostasis cerebral se han asociado tanto a enfermedades neurodegenerativas como a cerebrovasculares. Por tanto, es necesario contar con metodologías adecuadas para analizar la dinámica de los fluidos intracraneales (LCR y sangre).

Las secuencias dinámicas de resonancia magnética en contraste de fase (RM-CF) con sincronismo cardíaco permiten cuantificar el flujo de LCR y de sangre durante un ciclo cardíaco. La medición de flujo mediante secuencias de RM$\mathrm{CF}$ es precisa y reproducible siempre que se use un protocolo de adquisición adecuado. La reproducibilidad y exactitud de las medidas dependen también del uso de técnicas adecuadas de posproceso que permitan segmentar las regiones de interés (ROI) independientemente del operador y admitan corregir los errores de fondo introducidos por la supresión imperfecta de las corrientes inducidas y la contribución a la señal de los pequeños movimientos que presenta el mesencéfalo por la transmisión del pulso vascular así como el submuestreo (aliasing), reflejado como un cambio abrupto y opuesto del sentido original del flujo. Estas técnicas de análisis deben también tener en cuenta los errores relacionados con el efecto de volumen parcial (EVP), causado por la presencia de tejido estacionario y de flujo en el interior de los vóxeles de la periferia de la región a estudiar

El objetivo principal de esta tesis es desarrollar una metodología reproducible para evaluar cuantitativamente la dinámica de los fluidos intracraneales dentro de espacios de LCR (acueducto de Silvio, cisterna prepontina y espacio perimedular $\mathrm{C} 2 \mathrm{C} 3$ ) y principales vasos sanguíneos cerebrales (arterias carótidas internas y vertebrales, venas yugulares, seno recto y seno sagital superior) usando imágenes de RM-CF. Esta metodología integra técnicas de segmentación semiautomáticas por umbralización y clasificación K-medias que permiten delinear las regiones de interés independientemente del observador con correcciones de fondo y submuestreo. 
Se han cuantificado parámetros de amplitud (incremento de volumen de flujo en sístole, flujos promedio, índices de pulsatibilidad, índices de complianza y producción supratentorial de LCR) y temporales (retrasos frente a la entrada de flujo arterial al cerebro). La distribución de la pulsatibilidad del LCR entre el espacio ventricular y el saco dural espinal se calculó como la relación de volumen por ciclo entre el acueducto de Silvio y el espacio perimedular en C2C3.

El compromiso establecido entre el protocolo de adquisición y la metodología empleada para calcular cada uno de los parámetros ha permitido establecer rangos de normalidad fiables y reproducibles para cada uno de ellos. Los sujetos estaban asintomáticos y no habían presentado nunca un cuadro de hipertensión intracraneal ni padecido traumatismo craneoencefálico, permitiendo generalizar la normalidad de las medidas. Todos los sujetos fueron examinados en la misma franja horaria para evitar influencia del ciclo circadiano, y bajo la misma intensidad de campo magnético para evitar su influencia.

En conclusión se ha desarrollado una metodología adecuada para llevar a cabo de manera rápida y reproducible análisis cuantitativos de flujo de LCR y sanguíneo de utilidad en la práctica clínica. Esta metodología para estudiar las relaciones dinámicas de los fluidos intracraneales contribuirá a comprender la fisiopatología de varias enfermedades cerebrales causadas por alteraciones del flujo de LCR y sanguíneo.

Palabras clave- Resonancia magnética en contraste de fase, LCR, fluidos cerebrales, segmentación, posproceso de imágenes, k-medias 


\section{Contents}

$\begin{array}{ll}\text { Acknowledgments } & 7\end{array}$

$\begin{array}{ll}\text { Abstract } & 9\end{array}$

$\begin{array}{ll}\text { Resum } & 11\end{array}$

$\begin{array}{ll}\text { Resumen } & 13\end{array}$

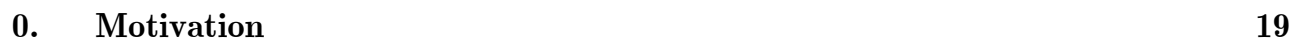

1. Thesis Objectives and Structure $\quad 21$

2. Introduction $\quad 25$

2.1 Central Nervous System 25

$\begin{array}{lll}2.1 .1 & \text { Brain } 25\end{array}$

$\begin{array}{ll}2.1 .2 & \text { Spinal Cord }\end{array}$

$\begin{array}{lll}2.1 .3 & \text { Meninges } & 26\end{array}$

2.2 Cerebrospinal Fluid 28

2.2.1 Localization 28

2.2.2 CSF Physiology: Production, Absorption and Circulation 30

2.3 Vascular System 32

2.3.1 Arterial Blood Supply to the Brain and Spinal Cord 33

$\begin{array}{lll}2.3 .2 & \text { Capillaries } & 35\end{array}$

2.3.4 Venous Blood Drainage From the Brain and Spinal Cord 36

2.4 Intracranial Dynamic $\quad 37$

2.5 Noninvasive Imaging Techniques for Flow study 39

2.6 Physical Principles of Nuclear MR 41

2.6.1 Origin of the MR Signal 42

2.6.2 Nuclear Spins in a Magnetic Field 43

2.6.3 Response of the Magnetization to a Radiofrequency Pulse 44 
2.6.4 Basic Characteristics of the Magnetic Resonance Signal

2.6.5 Longitudinal and Transversal Relaxation 48

2.6.6 Spatial Encoding of the MR Signal $\quad 51$

2.6.7 The $k$-space and the Matrix Image 55

2.7 Flow Quantification from Phase Contrast MR Imaging 55

2.7.1 Construction of the Image 56

2.7.2 Flow Sensitivity Adjustment 58

$\begin{array}{lll}\text { 2.7.3 Cardiac Synchronization } & 60\end{array}$

$\begin{array}{lll}2.7 .4 & \text { Flow Quantification } & 62\end{array}$

2.7.5 Errors in the MR Volumetric Flow Measurements 63

$\begin{array}{lll}\text { 3. } & \text { Methods } & 69\end{array}$

$\begin{array}{lll}3.1 & \text { Segmentation Techniques } & 70\end{array}$

$\begin{array}{lll}3.1 .1 & \text { Threshold Method } & 73\end{array}$

$\begin{array}{lll}3.1 .1 .1 & \text { Aqueduct of Sylvius } & 75\end{array}$

$\begin{array}{lll}\text { 3.1.1.2 Vascular Vessels } & 79\end{array}$

3.1.2 K-means Method $\quad 81$

$\begin{array}{lll}3.2 & \text { Aliasing Correction } & 88\end{array}$

$\begin{array}{lll}3.3 & \text { Background Correction } & 91\end{array}$

3.4 PC-MRI Acquisition Protocols $\quad 93$

3.5 Quantitative Analysis $\quad 96$

3.5.1 Velocity Amplitude Parameters $\quad 97$

$\begin{array}{lll}\text { 3.5.2 Flow Amplitude Parameters } & 97\end{array}$

$\begin{array}{lll}\text { 3.5.3 Flow Temporal Parameters } & 97\end{array}$

$\begin{array}{lll}\text { 3.5.4 Intracranial Dynamic } & 98\end{array}$

$\begin{array}{lll}3.6 & \text { Statistical Analysis } & 102\end{array}$

3.6.1 One-Way Analysis of Variance 102

3.6.2 Bland and Altman Plot 104 
3.6.3 Intraclass Correlation Coefficient

3.6.4 Coefficient of Variation 104

$\begin{array}{lll}\text { 3.6.5 Percent Error } & 105\end{array}$

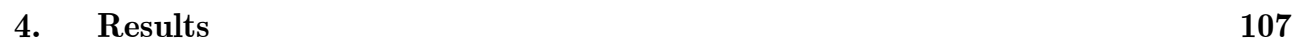

$\begin{array}{lll}4.1 & \text { Threshold Method } & 107\end{array}$

4.1.1 Reproducibility and Comparison with other Methods 107

4.1.2 Estimation of the Background and Aliasing Correction 109

$\begin{array}{lll}4.2 & \text { K-means Method } & 112\end{array}$

4.2.1 Reproducibility and Comparison with other Methods 112

4.2.2 Estimation of the Background and Aliasing Correction 116

$\begin{array}{lll}\text { 4.2.3 Measurements } & 117\end{array}$

4.3 Factors that Influence on the PC Quantitative Analysis of CSF 120

4.3.1 Influence of the MR Field Strength and Circadian Rhythm 121

$\begin{array}{ll}\text { 4.3.2 Influence of the Age and Gender } & 127\end{array}$

$\begin{array}{ll}\text { 4.3.3 Normality Parameters } & 130\end{array}$

4.4 Clinical Applications 131

4.4.1 Aqueductal CSF Flow in White Matter Disease and NPH 131

$\begin{array}{lll}\text { 4.4.2 Intracranial Dynamic } & 138\end{array}$

$\begin{array}{lll}\text { 4.4.2.1 In Healthy Volunteers } & 138\end{array}$

$\begin{array}{lll}\text { 4.4.2.1 In Neurological Disorders } & 143\end{array}$

$\begin{array}{lll}\text { 5. Discussion } & 147\end{array}$

$\begin{array}{lll}5.1 & \text { Threshold Method } & 147\end{array}$

$\begin{array}{lll}5.2 & \text { K-mean Method } & 149\end{array}$

5.3 Factors that Influence on the PC Quantitative Analysis of CSF 153

5.3.1 Influence of the MR Field Strength and Circadian Cycle 153

5.3.2 Influence of the Subject's Age and Gender 154

$\begin{array}{lll}5.4 & \text { Clinical Application } & 155\end{array}$ 
5.4.1 Aqueductal CSF Flow in White Matter Disease and NPH

5.4.2 Intracranial Dynamic

158

6. Conclusions $\quad 163$

6.1 Reviews of Thesis Objectives 163

6.2 On the Future Work 165

$\begin{array}{ll}\text { Glossary } & 167\end{array}$

$\begin{array}{lr}\text { References } & 169\end{array}$

$\begin{array}{lr}\text { Thesis related publications } & 189\end{array}$

$\begin{array}{lr}\text { APPENDIX } 1 & 195\end{array}$ 


\section{Motivation}

\section{Motivation}

Neurological diseases are disorders that affect the central nervous system (CNS). These disorders are varied and frequently severe, affecting a large portion of the population. Their manifestations and treatments are quite diverse. These disorders include, for example, epilepsy, hydrocephalus, Alzheimer's disease, dementia, cerebrovascular diseases, migraine, multiple sclerosis, Parkinson's disease, neuroinfections and brain tumours.

Hundreds of millions of people worldwide are affected by neurological disorders. A report of 2007 of the World Health Organization (WHO) [1] reveals that 50 million people have epilepsy; 62 million are affected by cerebrovascular disease; 326 million people suffer from migraine; 24 million are affected by Alzheimer's disease and dementias globally. An estimated 7 million people die every year as a result of neurological disorders.

Alzheimer's disease (AD), vascular dementia (VD) and normal pressure hydrocephalus (NPH) are the most important causes of dementia in the elderly population. It is often the case that it is clinically very difficult to differentiate these diseases. All three forms of dementia share the same risk factors, which for the most part are vascular in origin. Therefore it is necessary to establish biomarkers that add reliability and accuracy to the diagnosis.

Adequate knowledge of the dynamics of the intracranial fluid could help to establish biomarkers that allow the improvement of clinical diagnosis and treatment of disorders such as the hydrocephalus, which is associated with decreasing of the intracranial compliance, or vascular dementias which is characterized by problems on the supply of blood within the brain.

The use of neuroimaging techniques has resulted in outstanding progress in the diagnosis and management of neurological diseases. The most frequently used brain imaging technique is magnetic resonance imaging (MRI). This technique has several advantages, some of them unique between the existing medical imaging modalities. The foremost advantage of MR imaging is that it can produce high 


\section{Motivation}

quality medical images without submitting the patient to harmful ionizing radiation.

Other advantages of MRI are associated with its capability to measure different parameters. The cine sequences in phase contrast (PC-MRI) provide a powerful clinical tool for the non-invasive evaluation and quantification of fluids. This technique allows to carry out qualitative as well as quantitative analysis of fluid dynamics within all the major arteries, veins, and CSF spaces during the cardiac cycle when it is used together with cardiac synchronization [2-8]. Quantitative assessment of the changes in the homeostatic mechanism using PCMRI has important implications in the development of imaging biomarkers of neurological diseases.

The broad distribution of MR systems makes these measurements readily available for a large number of patients in many institutions. Unfortunately, the flow quantification using PC-MRI is subject to different sources of variability and inaccuracy. The manual segmentation of the region to analyze is one of the main sources of variability. The partial volume effect, the intravoxel phase dispersion, aliasing and the residual systematic errors [9] are the main sources of inaccuracy. These factors justify the development of adequate methodologies that allow analyzing the dynamic of the intracranial fluid in a reproducible and a reliable way in order to obtain reference models that could serve as a diagnostic aid to different neurological diseases. 


\section{Chapter1}

\section{Thesis Objectives and Structure}

Several neurological disorders such as hydrocephalus, vascular dementia, leukoaraiosis, vascular thrombosis, ruptured aneurysm, intracranial hypertension, cerebral ischemia and Chiari malformation are characterized by abnormal intracranial fluid dynamics. These disorders can be assessed and may benefit by studying the dynamic relationships of flow inside and outside the skull.

As stated previously in the motivation, PC-MRI allows the non-invasively quantification of pulsatile CSF flow and blood flow in the main vascular structures. This is done by acquiring data at multiple time points throughout the cardiac cycle using cardiac synchronism. Nevertheless, this image technique is mainly subject to variability of results introduced by the segmentation method used to define the region to analyze, and to inaccuracies occasioned by several MR related artifacts.

The overall objective is to develop a reproducible methodology to quantitatively evaluate the intracranial fluids dynamics within CSF spaces and main vascular vessels by means of PC-MRI as an aid to a clinical diagnose of different neurological and cerebrovascular disorders. In order to achieve this biomarker, it is necessary to carry out the following consecutive tasks:

1. To develop reproducible semiautomatic segmentation techniques to define the ROIs integrated with background phase correction and aliased pixels detection and correction. Therefore it is important:

- To reduce the intra and inter-observer variability in the measurements, mainly occasioned by the delineation of the regions to analyze.

- To study the influence of the localization of the background region necessary to correct the errors introduce by imperfect suppression of eddy currents and brain motion. 


\section{Chapter 1: Thesis objectives and Structure}

- To develop an aliasing correction to automatically detect and correct the aliased pixels without repeating the image sequence acquisition.

2. To analyze the influence of the MR field strength, subject's age and gender on the quantitative analysis of CSF within the aqueduct of Sylvius.

3. To analyze the CSF fluids dynamic in control subject and neurological patients.

4. To establish spatiotemporal relationships between the blood flow in the internal carotid arteries (ICA) and vertebral arteries (VA), the CSF flow in the aqueduct of Sylvius (S) and spinal CSF (C2C3), and blood flow in the jugular veins (JV), straight sinus (STS) and superior sagittal sinus (SSS)

that provide information about the cerebral hemodynamic and hydrodynamics.

5. Finally, to develop a friendly image processing tool for the clinicians to carry out quantitative analysis of the flow dynamics.

The following chapters of this thesis are organized as follows:

Chapter 2 summarizes the anatomy of the central nervous system, modern concepts about the CSF physiology, physical principles of MRI, quantitative flow imaging using PC-MRI and a summary of the main imaging artifacts that introduce errors in the measurements.

Chapter 3 describes the segmentation methods as well as the background and aliasing correction techniques developed in this thesis in order to analyze the flow dynamics in a reliable and reproducible way. The PC-MRI acquisition protocols and the statistical tests used in the different studies are also described.

Chapter 4 summarizes the main obtained results: reproducibility of the developed segmentation methods and comparison with other method, the influence of the MR field strength, subject's gender and age on the quantification of the flow parameters, the intracranial dynamic models and clinical applications.

Chapter 5 briefly discusses the obtained results. 


\section{Chapter 1: Thesis objectives and Structure}

Finally, in Chapter 6, the objectives of this thesis are reviewed, summarizing the presented results in this thesis, and making some suggestions for future works.

After the last chapter there is a glossary that contains and explains the main terms used in this thesis. The references used in this research are also included as well as the list of publications derived from this work, carried out by the author during the development of this thesis.

Finally, in Appendix 1, the developed software tool containing all the developed algorithms and needed processing tools, is briefly described. 


\section{Chapter 2}

\section{Introduction}

\subsection{Central Nervous System}

The central nervous system (CNS) is one of the two parts of the nervous system. The other is the peripheral nervous system which includes nerves in the organs, muscles, arms, and legs. The CNS consists of the brain and spinal cord. The brain is surrounded by the cranium, and the spinal cord is protected by the vertebrae. The brain is continuous with the spinal cord at the foramen magnum. In addition to bone, the CNS is surrounded by connective tissue membranes, called meninges, and by cerebrospinal fluid (CSF).

\subsubsection{Brain}

The brain is located inside the cranium. The cranium is a set of bones which makes up the skull, and protects and holds the brain. The brain is an extremely complex organ composed of interdependent parts each having its own specific functions and properties. However, all of these individual parts can be grouped into three fundamental segments: the forebrain, midbrain, and hindbrain (Figure 2.1). The hindbrain and midbrain are mainly concerned with basic life support functions such as blood pressure and respiration. On the other hand, the forebrain is responsible for the majority of higher brain functions such as memory and language. Brain tissue is classically divided into two structures: gray matter and white matter. Gray matter is made up of cell bodies while the white matter is composed of nerve fibers. 


\section{Chapter 2: Introduction}

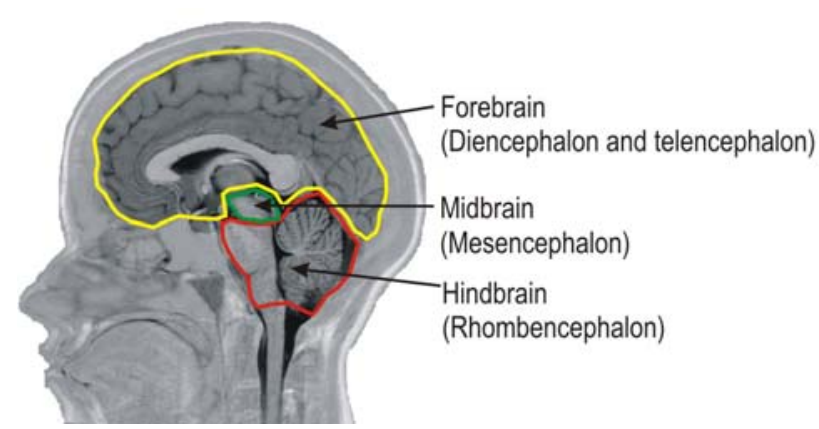

Figure 2.1 Segments of the brain on a sagittal image of MRI

\subsubsection{Spinal Cord}

The spinal cord is a long, thin, tubular bundle of nerves that is an extension of the central nervous system from the brain. It is enclosed in and protected by the bony vertebral column. The spinal cord extends from the foramen magnum at the base of the skull and continues through the conus medullaris near the first or second lumbar vertebrae, terminating in a fibrous extension known as cauda equina. The spinal cord is divided into cervical, thoracic, lumbar, sacral and coccygeal regions (Figure 2.2).

Like the brain, the spinal cord is surrounded by meninges and CSF. The interior of the cord contains the grey matter and is surrounded by a cylindrical mass of white matter, organized into discrete areas relating to the specific body functions they control. The main function of the spinal cord is transmission of neural inputs between the periphery and the brain.

\subsubsection{Meninges}

The brain and spinal cord are enclosed in three layers of connective tissue. The outer most (dura mater) consists of dense connective tissue. Underlying the dura is the arachnoid layer made of dense connective tissue. The space under the arachnoid, the subarachnoid space, is filled with CSF and contains blood vessels. The inner most layer, the pia mater, consists of loose connective tissue on the 


\section{Chapter 2: Introduction}

surface of the brain and lining channels which penetrate the brain carrying the vascular system (Figure 2.3). The primary function of the meninges and of the CSF is to protect the central nervous system.

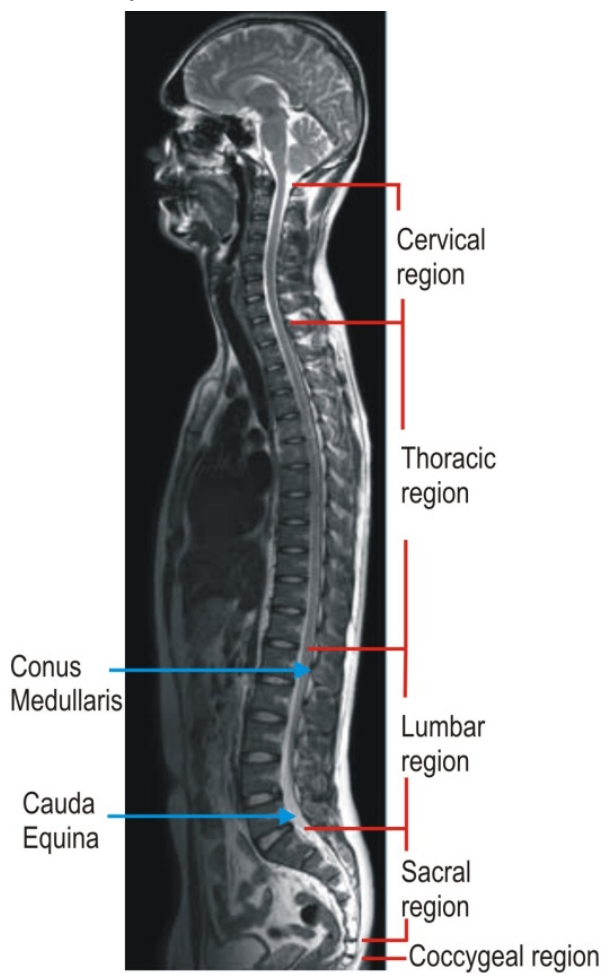

Figure 2.2 Regions of the spinal cord (nerves exit) on an MR sagittal image.

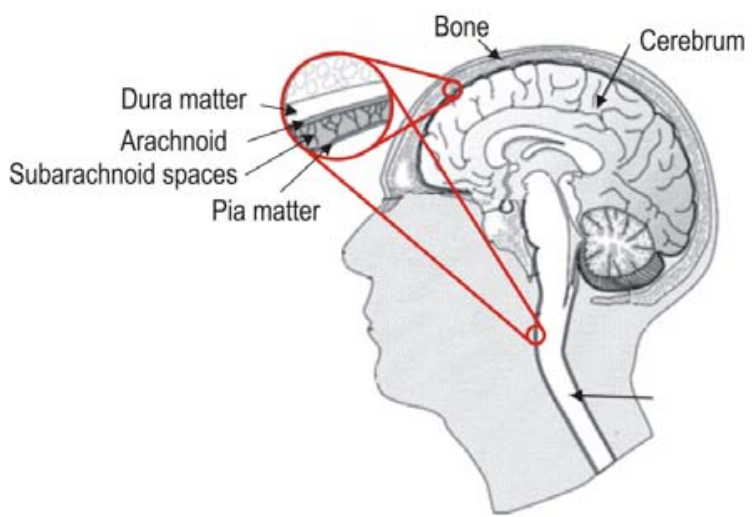

Figure 2.3 Meninges around the brain and spinal cord. Adapted from [10]. 


\section{Chapter 2: Introduction}

\subsection{Cerebrospinal Fluid}

CSF is the liquid that surrounds the brain and spinal cord and fills the spaces in between. It is a clear liquid which is very similar to the liquid portion of blood (plasma), and contains various salts and products such as sodium, calcium, bicarbonate, chloride, magnesium and glucose.

Because the brain and spinal cord are immersed in the CSF, it cushions the CNS and protects it from traumatic injury. CSF also plays a major role in the maintenance of the homeostasis of the CNS. The CSF filters nutritious substances from the blood and transports them towards the encephalon and the spinal cord, and evacuates waste products and toxic substances produced by cells of the CNS.

The CSF also may play a role in signal transduction. It may provides a route for hormones to move within the brain, as well as a route of communication from the brain to the rest of the body. The bulk flow of CSF along the optic and olfactory nerves drains through lymphatic tissue, and antigenic material in the CSF may produce a systemic immune reaction.

In addition to its nutritive and protective effects, the basic function of the CSF resides in dynamic equilibration of pressure fluctuations caused by volume changes in the three compartments contained within the rigid skull cavity: brain tissue, blood and cerebrospinal fluid.

\subsubsection{Localization}

The CSF is distributed into three spaces: the ventricular system inside the brain, the cranial subarachnoid space around the brain and the spinal subarachnoid space around the spine (Figure 2.4). These compartments communicate with one another but differ regarding resistance and compliance.

The ventricular system is composed of two lateral ventricles and two midline ventricles referred to as the third and fourth ventricles. The ventricles are connected to allow the flow of the CSF which is mainly produced by the choroid plexuses located in the walls and roofs of the ventricles. 


\section{Chapter 2: Introduction}

The lateral ventricles are in the cerebral hemispheres, one in each hemisphere. Each lateral ventricle communicates with the third ventricle by the interventricular foramen (also called the foramen of Monro). The third ventricle is connected with the fourth ventricle by means of the cerebral aqueduct (also called the aqueduct of Sylvius). From the fourth ventricle the CSF flows into the subarachnoid space through the foramina of Luschka (there are two of these) and the foramen of Magendie (only one of these) (Figure 2.4).

The total volume of CSF in normal human adults is about $140 \mathrm{~mL}$. The volume of the ventricular system is close to $30 \mathrm{~mL}$. Most of the total CSF is contained in the subarachnoid spaces of the brain and spinal cord (110 mL). The volume of CSF surrounding the spinal cord is at least $30 \mathrm{~mL}$. Thus, the largest compartment of CSF is nearly $80 \mathrm{~mL}$ contained in the subarachnoid spaces and cisterns that envelop the cerebral and cerebellar hemispheres [11].

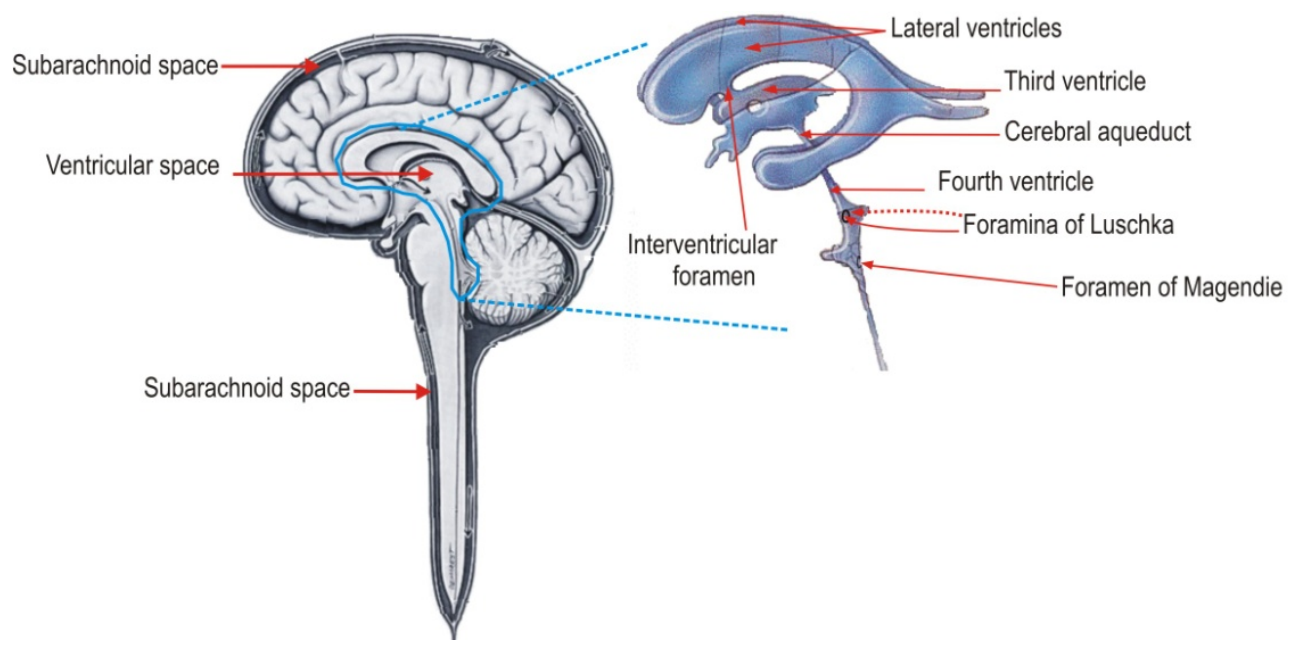

Figure 2.4 The CSF is distributed into the ventricular space inside the brain, the cranial subarachnoid space around the brain and the spinal subarachnoid space around the spinal. Adapted from [12]. 


\subsubsection{CSF Physiology: Production, Absorption and Circulation}

The traditional view of CSF physiology has focused on the concept that the CSF flows from its source, the choroid plexus, to its absorption site, the arachnoid granulations. This theory known as the bulk flow model [13;14] has been criticized and new hypothesis have been proposed due to observations made using MRI and radionuclide cisternography [15-19] which include also transparenchymal production and absorption.

\section{- Production}

CSF is a mixture of a secretion of the choroid plexus plus interstitial fluid derived from parenchymal capillaries and cellular metabolic processes $[20 ; 21]$. Under normal conditions, $40 \%$ to $70 \%$ of CSF has been estimated to come from the choroid plexus and $30 \%$ to $60 \%$ from the interstitial fluid that derives from transport across the blood vessels [22].

The choroid plexus are branched structures made up of numerous villi which project into the ventricles of the brain. Each villus is composed of a single layer of epithelial cells overlying a core of connective tissue and blood capillaries (Figure 2.5). The blood vessels of choroid plexus are fenestrated capillaries hence provide little resistance to the movement of small molecules, ions and water [23]; so, plasma freely goes out from the capillaries into the interstitium and meets the ependymal cells which are connected by tight junctions (zonula occludens). Therefore, the choroid plexus epithelial cells form what is known as the blood-CSF barrier (BCB) 


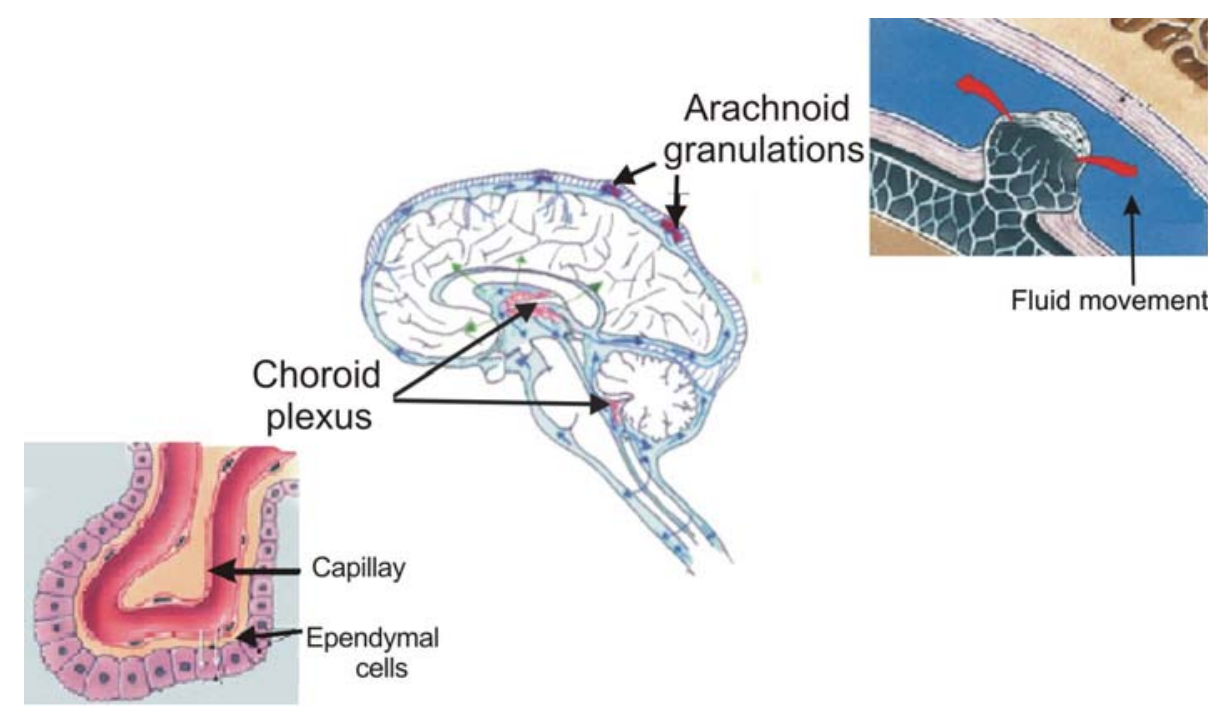

Figure 2.5 Choroid plexus and arachnoid granulations. Adapted from [24]

The CSF is produced by an active process that requires energy; it is not simply a filtration process. There is an active transport of sodium $\left(\mathrm{Na}^{+}\right)$from the interstitium to the ventricles. $\mathrm{Na}^{+}$is accompanied by clorure $\left(\mathrm{Cl}^{-}\right)$and $\mathrm{HCO} 3$, and they are followed by water [25].

The CSF secretion has not been accurately reported. Invasive methods and imaging-based approaches have reported a large range of results $(0.35-0.7$ $\mathrm{ml} / \mathrm{min}$ ) [26-30].

The circadian cycle and subject's age also influence the CSF production rate; Nilsson et al. [31] found, for healthy volunteers, a variation of $30 \mathrm{ml} / \mathrm{h}$ between the minimum and maximum production period at 18:00 pm and 2:00 am respectively. May et al. [27] found in elderly healthy individuals a significantly lower CSF production compared with healthy young subjects.

\section{- Absorption}

The CSF absorption always has been attributed to the arachnoid granulations into the venous system; however, this view does not support the 


\section{Chapter 2: Introduction}

normal CSF hydrodynamic in early childhood where the pacchionian granulations have not developed [17].

The effectiveness of third ventriculostomy for the treatment of communicating hydrocephalus also put in doubt the commonly accepted CSF absorption theory; producing a communication between the third ventricle and the subarachnoid space should have no effect on abnormal ventricular dilatation. Dandy et al. [18] recognized that decreased bulk flow across the pacchionian granulations could not cause communicating hydrocephalus.

Many investigators have presented experimental evidence that the CSF is also reabsorbed outside the granulations of Pacchioni. Greitz et al. $[15 ; 17 ; 32]$ confirms the existence of CSF absorption in the brain capillaries, the absorption mechanism is the same as the one happening in capillaries in the other part of the body absorbing interstitial fluid.

\section{- Circulation}

CSF circulation is generated by continued secretion and absorption of CSF, by the cardio-respiratory variations transmitted by the plexus, the arteries, the veins, as well as by the gradients of pressure.

The CSF mainly formed by the plexuses of the lateral ventricle passes through the interventricular foramina into the third ventricle, and then via the cerebral aqueduct of Sylvius into the fourth ventricle. Here the fluid exits through two lateral apertures (foramina of Luschka) and one median aperture (foramen of Magendie) into the subarachnoid space around the brain and spinal cord (Figure 2.4). CSF presents a pulsate motion through the pathways; the pulsatibility of this motion can be consider as a biomarker of the intracranial dynamics.

\subsection{Vascular System}

The blood vessels or vascular system form a tubular network throughout the body that allows blood to flow from the heart to each body cell and then back to the heart. The capillaries are microscopic vessels which enable the exchange of 
water and chemicals between the blood and the tissues, while the conduit vessels, arteries and veins, carry blood away from the heart and through the capillaries or back towards the heart, respectively.

\subsubsection{Arterial Blood Supply to the Brain and Spinal Cord}

Arteries are elastic vessels that transport oxygen-rich blood away from the heart. The arteries branch into small, eventually becoming very small vessels called arterioles which connect with even smaller blood vessels called capillaries.

Arteries and arterioles have relatively thick muscular walls because blood pressure in them is high and because they must adjust their diameter to maintain blood pressure and to control blood flow. An artery has three layers of tissue: an outer layer, a muscular middle, and an inner layer of epithelial cells. The muscle in the middle is elastic and very strong. The inner layer is very smooth so that the blood can flow easily with no obstacles in its path. The muscular wall of the artery helps the heart pump the blood.

The blood leaves the heart by an artery of large diameter called the aorta. The brain receives blood from two sets of branches from the dorsal aorta, the internal carotid arteries, which arise at the point in the neck where the common carotid arteries bifurcate, and the vertebral arteries. The internal carotid arteries branch to form two major cerebral arteries: the anterior and the middle cerebral arteries. The right and left vertebral arteries come together at the level of the pons on the ventral surface of the brainstem to form the midline basilar artery. The basilar artery joins the blood supply from the internal carotids in an arterial ring at the base of the brain (in the vicinity of the hypothalamus and cerebral peduncles) called the circle of Willis (Figure 2.6)[33]. 


\section{Chapter 2: Introduction}

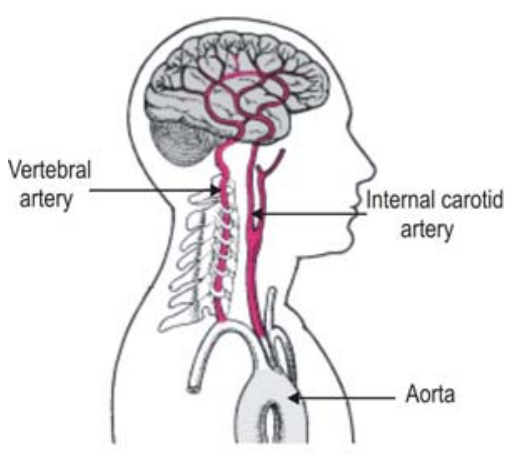

a

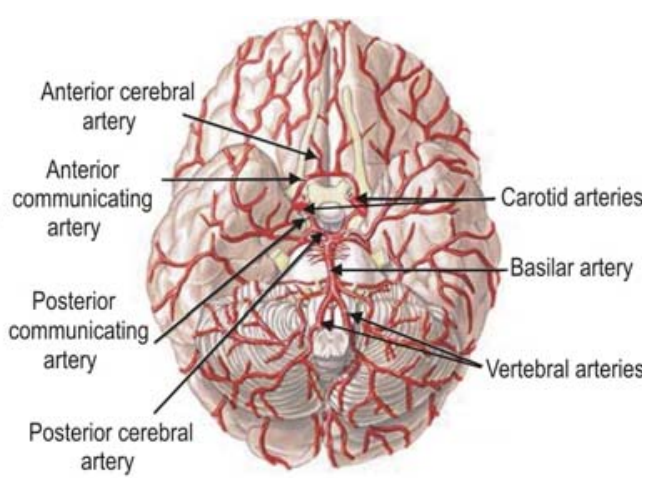

b

Figure 2.6 a) Blood is supplied to the entire brain by two main arteries: the internal carotid artery and the vertebral artery. b) Ventral horizontal section of brain, showing the join of the basilar artery to the blood supply of the internal carotid arteries in a ring at the base of the brain called the circle of Willis. Adapted from $[34 ; 35]$

The blood supply to the spinal cord comes in the form of a single anterior spinal artery and paired posterior spinal arteries. The anterior spinal artery arises from the vertebral arteries and extends from the level of the lower brainstem to the tip of the conus medullaris. It supplies the ventral surface of the medulla and the anterior two-thirds of the spinal cord. The posterior spinal arteries supply the dorsal third of the spinal cord, and also take their origin from the vertebral arteries. At certain sites along the spinal cord there are a number of reinforcing inputs from other arteries (Figure 2.7)[33].

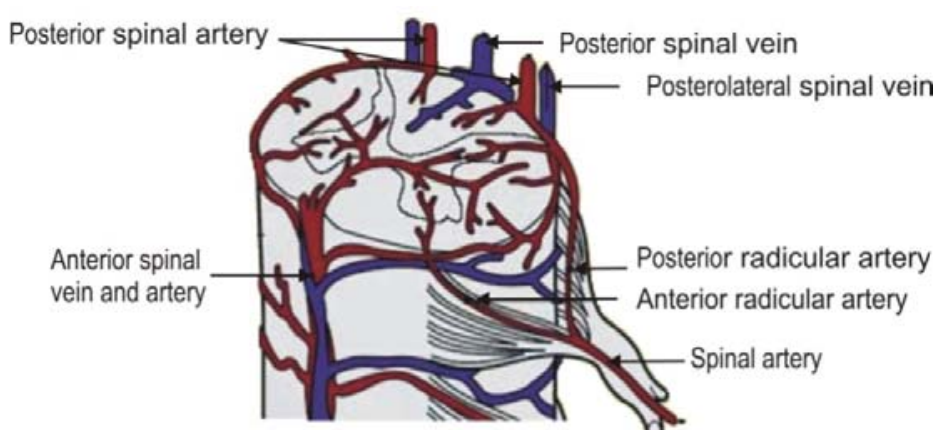

Figure 2.7 Vascularization of the spinal cord. Adapted from [36] 


\section{Chapter 2: Introduction}

\subsubsection{Capillaries}

Capillaries are tiny blood vessels, (about 10 micrometers in diameter) which connect arterioles and venules. Their thin walls composed of endothelial cells act as semipermeable membranes allowing the interchange of molecules between the blood and interstitial fluid. Oxygen and nutrients move from the blood to interstitial fluid, while carbon dioxide and waste substances move in the opposite direction.

Three types of capillaries can be distinguished based on features of the endothelium: continuous, fenestrated, and discontinuous. Continuous capillaries are the most abundant type and are found in skin, muscle, lungs, and the CNS. They have low permeability and therefore allow only limited passage of substances across the capillary wall. Fenestrated capillaries are much more permeable than continuous capillaries; their walls contain circular pores or fenestrae closed by a thin diaphragm. Discontinuous capillaries, also called sinusoids, have gaps between endothelial cells that are large enough to allow even erythrocytes to pass through the capillary wall. They are found in the liver, spleen, and bone marrow, as well as some endocrine glands [37].

\subsubsection{Transcapillary Fluid Exchange}

Substances pass through the capillaries wall by diffusion, filtration, and osmosis. The main forces that govern this exchange are the hydrostatic pressure which is the force per unit area exerted by blood fluid against a vessel wall and the osmotic pressure that is the pressure required to prevent osmosis of fluid across a semipermeable membrane.

The filtration and absorption of CSF and interstitial fluid in the brain capillaries is governed by the Starling principle [38]. Starling [38] identified the interrelationship between the hydrostatic pressure and the osmotic forces within the capillary. Hydrostatic pressure tends to cause fluid to leave the plasma, and osmotic pressure pulls it back. These two forces tend to balance each other. In a 


\section{Chapter 2: Introduction}

normal capillary bed, fluid gain and loss from the plasma are closely balanced, so there is little or no net change in plasma and interstitial fluid volumes.

At the arterioles the blood pressure is greater than the osmotic pressure of blood and the result is a net movement of fluid (blood plasma) from the capillary into the tissue fluid surrounding cells. This fluid delivers dissolved oxygen and nutrients such as glucose and aminoacids that are taken up by cells. Blood proteins and formed element (blood cells) are too big to leave the capillary.

In the middle of a capillary bed, blood pressure is equal to the osmotic pressure of blood and there is no net movement of fluid from blood to the tissues. In this area, nutrients and wastes move with their concentration gradients. Oxygen gas (from the lungs) and nutrients (from the liver) are in high concentration in the blood and diffuse into the tissue fluid through the walls of the capillary. Carbon dioxide (produced by cellular respiration) and other cell waste products are in high concentration in cells and tissue fluid and diffuse into the blood through the walls of the capillary. At the venules the osmotic pressure of the blood is greater than blood pressure and there is a net movement of tissue fluid back into the blood.

\subsubsection{Venous Blood Drainage From the Brain and Spinal Cord}

The majority of veins in the body carry low-oxygen blood from the tissues back to the heart; the exceptions being the pulmonary veins which carry oxygenated blood. The venous system begins with the merging of capillaries into venules, venules into small veins, and small veins into larger veins. Veins transport blood at a lower pressure; they are not as strong as arteries. Like arteries, veins have three layers: an outer layer of tissue, muscle in the middle, and a smooth inner layer of epithelial cells. However, the layers are thinner, containing less tissue, and that is why veins may dilate to accommodate increased blood volume.

Cerebral venous system can be divided into a superficial and a deep system. The superficial system comprises of sagittal sinuses and cortical veins, draining superficial surfaces of both cerebral hemispheres. The deep system comprises of transverse sinus, straight sinus and sigmoid sinus along with draining deeper cortical veins. Both systems mostly drain themselves into the internal 


\section{Chapter 2: Introduction}

jugular veins. The veins draining the brain do not follow the same course as the arteries that supply it. Generally, venous blood drains into the nearest venous sinus or, in the case of blood draining from the deepest structures, into deep veins (Figure 2.8) [39].

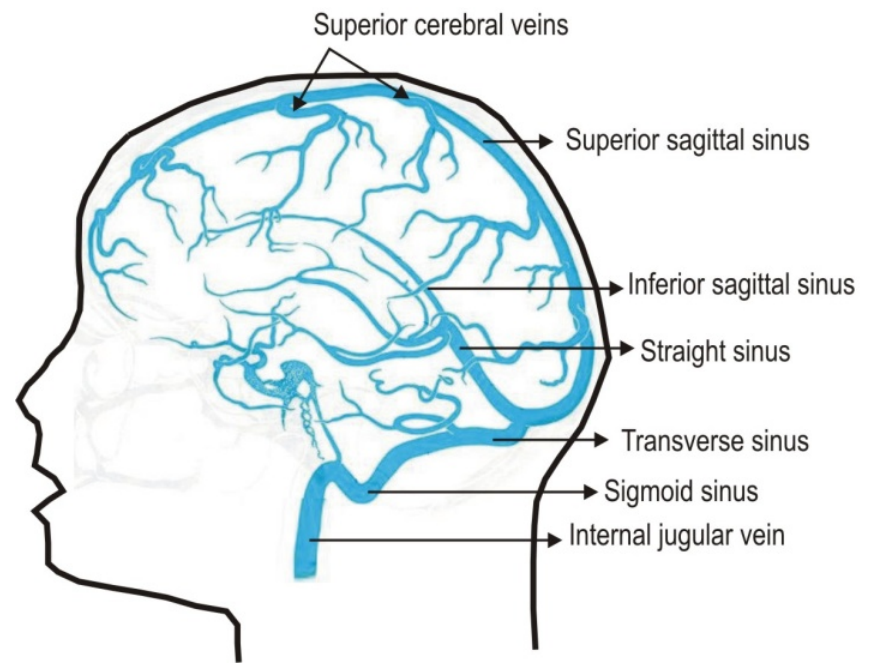

Figure 2.8 Superficial and deep cerebral venous systems.

The venous drainage of the spinal cord follows the arterial system. Like the arterial system, the veins are also segmentally organized into anterior and posterior systems. The anterior spinal vein is situated in the anterior sulcus, adjacent to the anterior spinal artery while the posterior spinal veins are situated close to the posterior spinal arteries. The veins form a pial plexus that drain blood from the posterior, lateral, and anterior spinal cord (Figure 2.7).

\subsection{Intracranial Dynamic}

Intracranial dynamics is defined as the interaction between solid brain tissue, CSF flow and blood flow throughout the central nervous system. Therefore, the dynamic relationships of the fluid inside and outside the skull reflect the state of the cerebral dynamic. 


\section{Chapter 2: Introduction}

The brain is probably the most complex known structure of the human body. The brain motion and the redistribution of cerebrospinal fluid (CSF) pulsations within the craniospinal axis in response to rhythmic cerebral blood volume variations during the cardiac cycle have been the focus of a great number of investigations in order to clarify different neurological disorders such as hydrocephalus $[8 ; 40-44]$

Intracranial pressure (ICP), is that which is exerted on to the brain tissue by external forces, such as CSF and blood. ICP at rest is normally around 7-15 $\mathrm{mmHg}$ for a supine adult [45]. The relationship between ICP and intracranial volume (compliance) is described by the non-linear pressure-volume curve obtained inserting known volumes into the CSF space and measuring the corresponding rise in pressure [46]. Compliance expresses the capability to buffer an intracranial volume increase while avoiding a rise in ICP. At low levels of pressure, the compliance is maximum, and relatively large increases of volume can be tolerated with small increases in the ICP. At high initial pressure, the compliance is reduced and small volume additions will results in large increases in pressure. Currently, ICP is obtained by invasive monitoring devices; the analysis of the blood and CSF flow dynamics by means of PC-MRI within the brain has allowed to calculate the intracranial volume change and to make attempts to simulate or evaluate the intracranial compliance and pressure noninvasively $[47 ; 48]$.

The Monroe-Kellie [49] doctrine states that the total volume of the three main intracranial components: the brain, the CSF and the arterial and venous blood, is constant and that any volume increase in one component causes a matching decrease in the other components. Dynamic relationships between the input and output of blood to the brain allow an estimation of the cerebral compliance (Figure 2.9).

In systole the inflow of arterial blood during cardiac systole increases the intracranial volume; there is an expansion of the arterial tree and brain, which occurs both toward the ventricles and toward the subarachnoid space. This increase of volume is compensated by immediate craniocaudal CSF displacement to the spinal canal and venous egress. The brain expansion toward the ventricles causes aqueduct CSF flow, and the expansion outwards causes a shift of CSF, out of the 
skull, and compression of the venous structures. The outflow of blood during the diastole decreases the intracranial volume and promotes the caudocranial CSF displacement from spinal canal into the cranium. The degree of inward/outward displacement depends on the relative intracranial compliance.

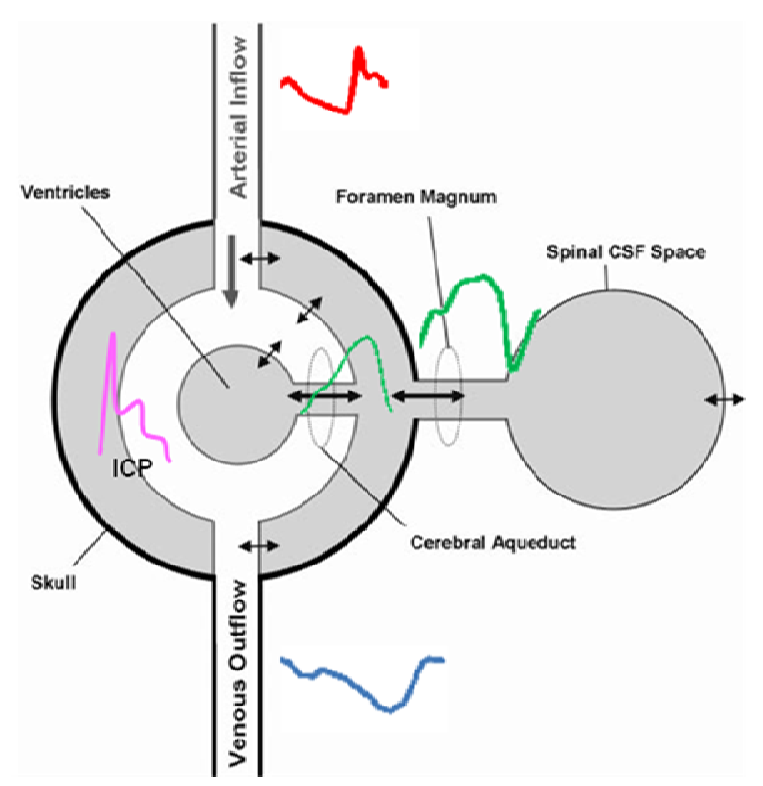

Figure 2.9 Intracranial components. The small bidirectional arrows represent inward/outward displacement. ICP: intracranial pressure. Adapted from[50]

\subsection{Noninvasive Imaging Techniques for Flow study}

Noninvasive techniques do not involve direct insertion of a sensor into the flow but provide sensing capability through either access to the flow at the flow boundary or through the use of some form of electromagnetic radiation (EMR) transfer or propagation. Next, the main techniques commonly used are briefly described.

- Doppler ultrasound is used to evaluate blood flow and pressure by bouncing high-frequency sound waves (ultrasound) off red blood cells. During Doppler 


\section{Chapter 2: Introduction}

ultrasound, a handheld instrument (transducer) is passed lightly over the skin above a blood vessel. The transducer sends and receives sound waves that are amplified through a microphone. The sound waves bounce off solid objects, including blood cells. The movement of blood cells causes a change in pitch (frequency) of the reflected sound waves (called the Doppler effect). If there is no blood flow, the pitch does not change. The ultrasound techniques have difficulties in some applications due to intervening bone or air.

There are several forms of depiction of blood flow in medical Doppler imaging:

- Color Doppler provides an estimate of the mean velocity of flow within a vessel by color coding the information and displaying it superimposed on the gray-scale image. The flow direction is arbitrarily assigned the color red or blue, indicating flow toward or away from the transducer, respectively.

- Power Doppler is a newer ultrasound technique that is up to 5 times more sensitive in detecting blood flow than color Doppler. Power Doppler can obtain some images that are difficult or impossible to obtain using standard color Doppler. However, power Doppler is most commonly used to evaluate blood flow through vessels within solid organs. Power does not provide directional information.

- Spectral Doppler is a form of ultrasound image display in which the spectrum of flow velocities is represented graphically on the $\mathrm{Y}$-axis and time on the X-axis; both pulse wave and continuous wave Doppler are displayed in this way. Spectral Doppler provides a quantitative analysis of the velocity and direction of blood flow.

- Magnetic Resonance Imaging is a radiology technique that uses magnetism, radio waves, and a computer to produce images of body structures. MR measurements of flow are based either on the effect of flow on the signal intensity of the longitudinal magnetization (time-of-flight techniques) or on the influence of flow on the phase dispersion of the transverse magnetization (phaseshift techniques).

- Time of Flight technique (TOF) is dependent on the flow and the movement of protons in blood through the imaging plane. To accomplish 
this, the technique involves saturating the signal in the slice that is to be imaged with rapid radiofrequency (RF) pulses. Background or stationary tissues will be suppressed by the RF pulse, whereas fresh-moving blood entering the slice after the RF pulse will retain its signal intensity and create contrast between blood and background tissue. This technique allows a qualitative evaluation of the flow.

- Phase-contrast techniques utilize velocity differences and phase shifts in moving blood to provide image contrast. The phase of the MRI signal is manipulated by special gradients (varying magnetic fields) in such a way that it is directly proportional to velocity. Thus, quantitative measurements of blood and CSF flow are possible. In order to quantitatively analyze the intracranial dynamic this imaging technique was used in this thesis.

\subsection{Physical Principles of Nuclear MR}

In 1946, the phenomenon of nuclear MR was first observed independently by Felix Bloch and Edward Purcell. MR is a phenomenon exhibited by atoms with an odd number of protons or neutrons which possess nuclear spin angular momentum. In the classical description the phenomenon can be described as spinning charged spheres which produce a small magnetic moment. Developments in MR over the decades that followed, including the spin echo and different RF pulse sequences, led to widespread use of MR spectroscopy, a method of analyzing the composition of chemical samples. In 1970, Raymond Damadian discovered the basis for using MR as a tool for invivo cancer diagnosis. In 1973, Paul Lauterbur proposed the use of gradient magnetic fields for spatial encoding of MR signals to form the first magnetic resonance images. MRI has since developed rapidly into a widely used clinical imaging modality, and is now used to image virtually every part of the body in clinical practice. MRI also allows arbitrary selection of the scan plane and true three-dimensional (3D) imaging. Unlike any other medical imaging modalities, image contrast in MRI is based on multiple physical parameters, resulting in the 
unique ability to generate excellent soft-tissue contrast that can be tailored for specific applications.

\subsubsection{Origin of the MR Signal}

MR imaging is based on the electromagnetic activity of atomic nuclei. The nucleus of an atom is composed of a number of protons and neutrons, the nucleus with an odd number of protons or neutrons possesses a property known as spin-angular moment, as it is the case of the ${ }^{1} \mathrm{H}$ (hydrogen- 1 ) ${ }^{15} \mathrm{~N}$ (nitrogen15), ${ }^{19} \mathrm{~F}$ (fluorine-19), ${ }^{13} \mathrm{Na}$ (sodium-23) and ${ }^{31} \mathrm{P}$ (phosphorus-31).

Spin can be visualized as a rotating motion of the nucleus around its own axis and commonly symbolized by a vector directed along the axis of rotation. In quantum mechanics spin is represented by a magnetic spin quantum number that represents the intensity of rotational motion. A spinning charged particle possesses a characteristic magnetic moment and can be described as a magnetic dipole creating a magnetic field similar to a bar magnet (Figure 2.10). The strength of the magnetic moment is a property of the type of nucleus. The hydrogen, with just one proton $\left({ }^{1} \mathrm{H}\right)$ is a good isotope for imaging because of its great natural abundance in the living matter and because it has a larger nuclear magnetic moment than any other atom, resulting in an easily detectable signal.

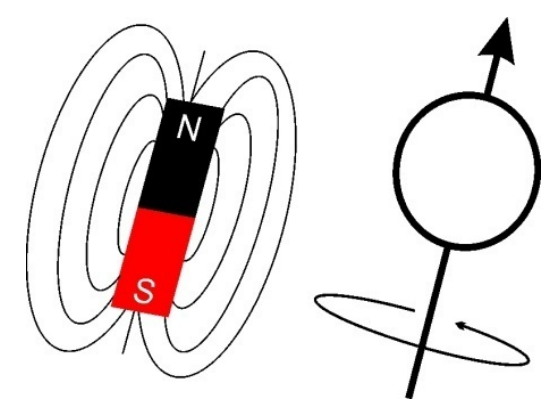

Figure 2.10 A charged, spinning nucleus creates a magnetic moment which acts like a bar magnet (dipole). 


\subsubsection{Nuclear Spins in a Magnetic Field}

In the absence of an externally applied magnetic field, the proton (hydrogen nuclei) spins in a substance, such as the tissues of the human body, moves in response to thermal energy exchange and are oriented in random directions (Figure 2.11a). The vector sum of their magnetic moments is called the net magnetization (M). For the randomly oriented spins $\mathbf{M}$ equals zero.

When the spins are placed in a strong magnetic field $\mathrm{B}_{\mathrm{O}}$, the spins align parallel or anti-parallel respect to $\mathbf{B}_{\mathbf{0}}$ (Figure $2.11 \mathrm{~b}$ ). The spin axes are not exactly aligned with $\mathbf{B}_{\mathbf{0}}$, they precess around $\mathbf{B}_{\mathbf{0}}$ with a frequency known as the Larmor frequency (Figure 2.11c). The Larmor equation expresses the relationship between the strength of a magnetic field, $\mathrm{B}_{\mathrm{O}}$, and the precessional frequency, $\omega_{o}$, of an individual spin.
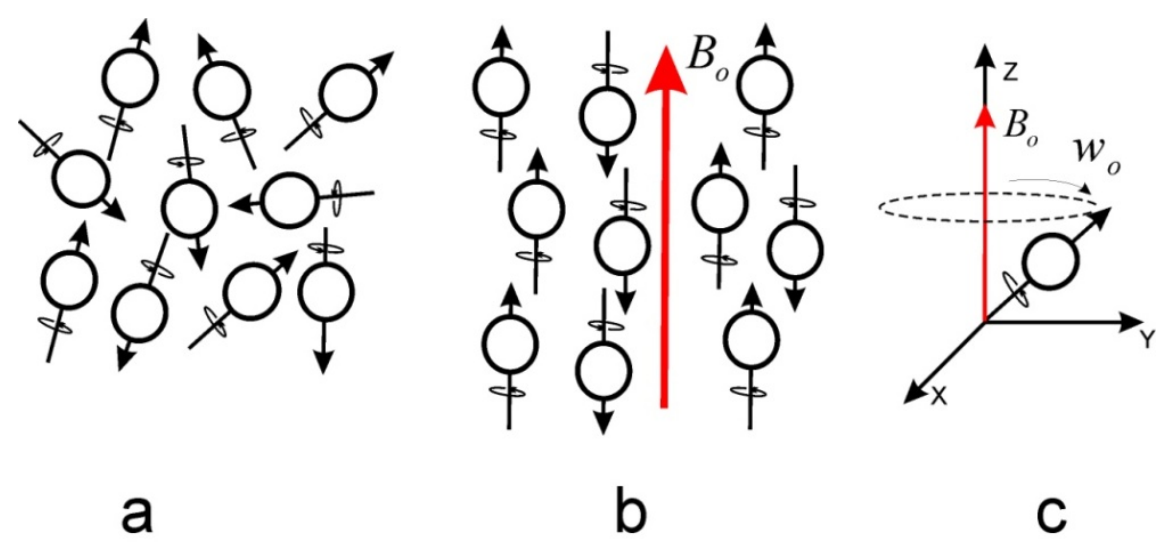

Figure 2.11 Alignment of protons with the $B_{o}$ field. (a) Without external magnetic field, hydrogen protons are oriented randomly. (b) An external magnetic field $\boldsymbol{B}_{0}$ is applied which causes the protons align parallel or anti-parallel respect to $\boldsymbol{B}_{\boldsymbol{O}}$. (c) Precession of a spin around an externally applied magnetic field $\boldsymbol{B}_{\boldsymbol{O}}$, by convention the applied $\boldsymbol{B}_{\boldsymbol{O}}$ is directed along the positive z-axis. The angular frequency of precession is $\omega_{0}$. The dashed oval shows the path that is traced by the spins as it precesses about the z-axis. 


$$
\omega_{o}=\gamma B_{o}
$$

The proportionality constant to the left of $\mathbf{B}_{\mathbf{0}}$ is the gyromagnetic ratio of the nucleus which is a constant for every atom at a particular magnetic field strength. For a hydrogen nucleus, the gyromagnetic ratio is $4257 \mathrm{~Hz} /$ Gauss. Thus at 1.5 Tesla (15,000 Gauss), $\omega_{o}=63.855$ Megahertz [51].

The quantum physic tells that a nuclear spin in a uniform static magnetic

field $\mathbf{B}_{\mathbf{0}}$ has a discrete number of measurable energy levels, equal to twice the nuclear-spin value plus one. The hydrogen proton has two energy levels (nuclear spin value $=1 / 2$ ): the upper energy level if the spin is aligned antiparallel to $\mathbf{B}_{\mathbf{0}}$, and the lower energy level if the spin aligns parallel to $\mathbf{B}_{\mathbf{0}}$. Overall, the hydrogen spins tend to align with $\mathbf{B}_{\mathbf{0}}$ by a very small number of spins in the lower energy level providing a net magnetization. This magnetization vector will be the basis of the signal in MR.

The energy difference $(\Delta \mathrm{E})$ between the two levels increases linearly with the magnetic field strength, as does the population difference of protons $\left(\mathrm{p}_{1}\right.$ and $\left.\mathrm{p}_{2}\right)$. A spin can jump from the lower energy level to the upper energy level absorbing the energy difference (excitation) or from the upper energy level to the lower energy level emitting the energy difference (relaxation).

\subsubsection{Response of the Magnetization to a Radiofrequency Pulse}

Radiofrequency (RF) energy is created due to the movement of electrical charges in antennas. In a MR system, this RF energy is transmitted by an RF transmit coil (eg, body coil, head coil, knee coil). Typically, the RF is transmitted for a short period of time; this is called an RF pulse. This transmitted RF pulse must be at the precessional frequency of the protons (calculated via the Larmor equation) in order for resonance to occur and for efficient transfer of energy from the $\mathrm{RF}$ coil to the protons. RF energy, like all electromagnetic radiation, has electric and magnetic field components, although only the magnetic component is interesting in MR (produces the excitation of the tissue under study). The electric component will be deposit on the tissues under excitation in the form of heat. 


\section{Chapter 2: Introduction}

The magnetic field is typically represented by a vector named $\mathbf{B}_{\mathbf{1}}$.

A standard Cartesian x-y-z coordinate system is known as stationary frame of reference, along with the rotating frame of reference, which has axes labeled x', y', z' (Figure 2.12). The z and z' axes are coincident; relative to the stationary frame of reference, the rotating frame of reference revolves about the $\mathrm{z}$-axis with a constant angular velocity, typically equal to the Larmor frequency, $\omega_{o}$.

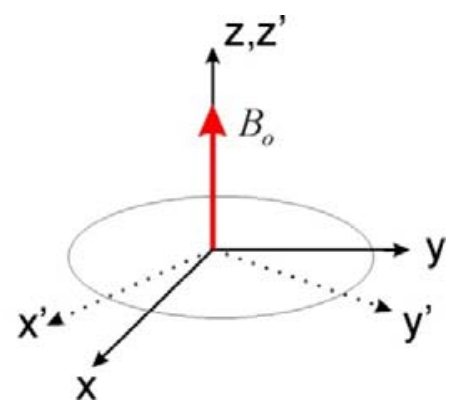

Figure 2.12 The stationary ( $x, y, z)$ and rotating $\left(x^{\prime}, y^{\prime}, z^{\prime}\right)$ frames of reference.

In absence of $\mathbf{B}_{1}$, the magnetization lies along the longitudinal axis or $\mathbf{z}$ axis. Once the RF pulse is turned on, the magnetization $\mathbf{M}$ flips by a certain angle, and produces two magnetization vector components, longitudinal magnetization, $\mathbf{M}_{\mathrm{z}}$ and transversal magnetization $\mathbf{M}_{\mathrm{xy}}$ (Figure 2.13a). In the stationary frame, $\mathbf{M}$ precesses around $\mathbf{B}_{\mathbf{o}}$ and $\mathbf{B}_{1}$ simultaneously generating a spiraling movement called nutation of $\mathbf{M}$ toward the $\mathrm{x}-\mathrm{y}$ plane (Figure 2.13b). In the rotating frame, only the precession around $\mathbf{B}_{1}$ is seen (Figure 2.13c). The angle through which $\mathbf{M}$ has rotated away from the $\mathrm{z}$-axis is known as the flip angle.

The most common RF pulses used in MRI are $90^{\circ}$ and $180^{\circ}$ pulses. A $90^{\circ}$ pulse converts the longitudinal magnetization into transverse magnetization and a $180^{\circ}$ pulse rotates the longitudinal magnetization from positive $\mathrm{z}$-axis to the negative z-axis (Figure 2.14). 


\section{Chapter 2: Introduction}

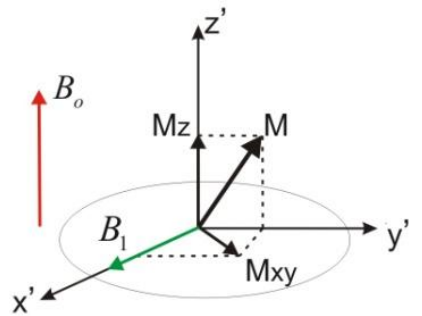

a

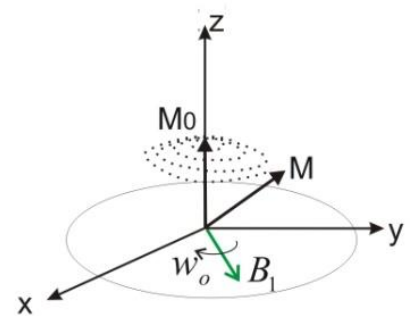

$\mathrm{b}$

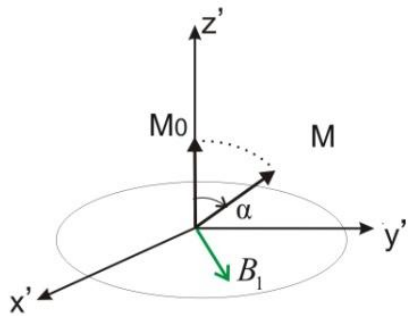

C

Figure 2.13 Effects of a RF pulse on the magnetization vector. The field $B_{0}$ (red arrow) is the same for the three cases. (a) The magnetization $M$ can be represented by a component parallel to the z-axis, called longitudinal magnetization $\left(M_{z}\right)$ and a component that lies in the $x^{\prime}-y$ ' plane, called transversal magnetization $\left(M_{x y}\right)$. (b) In a stationary frame of reference $M$ precesses around both $B_{0}$ and $B_{1}$, the dotted line shows the path that is traced out by the tip of the magnetization vector. (c) In a rotating reference frame $M$ preccesses with $B_{1}$. The angle between the z-axis and the magnetization measured at the end of the RF pulse is called the flip angle.

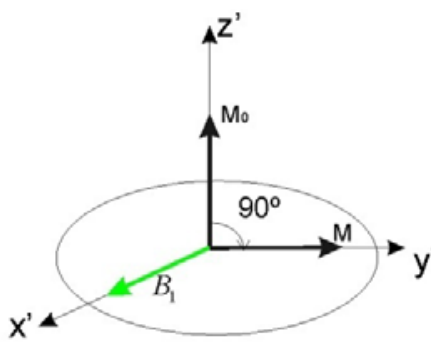

a

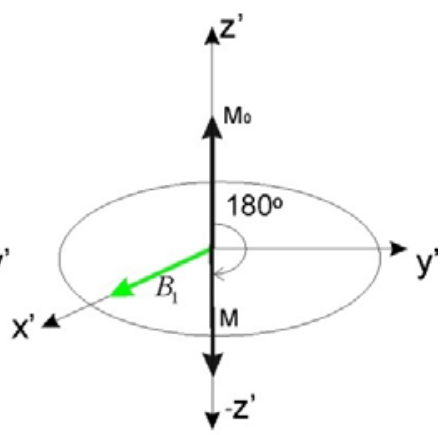

b

Figure 2.14 Commons types of RF pulses used in MRI: (a) $90^{\circ}$ RF pulse. (b) $180^{\circ}$ RF pulse. $M_{0}$ is the start magnetization. 


\subsubsection{Basic Characteristics of the Magnetic Resonance Signal}

Once the RF pulse is removed, the magnetization precesses about the $\mathbf{B}_{\mathbf{o}}$ in the Larmor frequency. The MR signal is detected as a voltage in a receiver coil, induced by the precessing transverse magnetization. $\mathbf{M}_{\mathrm{xy}}$ induces an electromotive force in a receiver coil according to Faraday's law of electromagnetic induction. This law states that if a conducting coil is in a magnetic field and the magnetic field changes relative to the coil, then a voltage is induced across the coil. This is the principle of the NMR signal detection.

The signal that is measured just after an excitation RF pulse is called free induction delay (FID) (Figure 2.15). The term "free" refers to the fact that after the $\mathbf{B}_{1}$ field is turned off at the end of the RF pulse, the magnetization precess freely in the applied static magnetic field. The term "induction" is used because the precessing magnetization induces a voltage across the coil. The term "decay" is used because of the magnitude of the transverse magnetization, and thus the signal strength, gradually decreases. The amplitude of the FID signal becomes smaller over time as net magnetization returns to equilibrium.

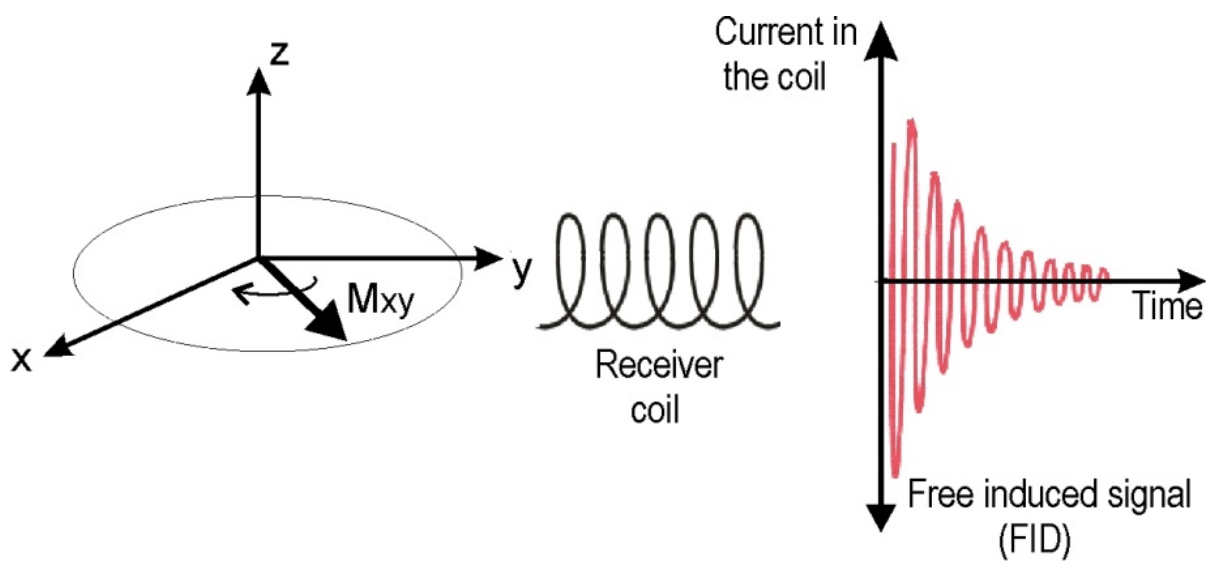

Figure 2.15 After a $90^{\circ} \mathrm{RF}$ pulse, $M$ lies in the $x$-y plane and rotates about the $z$ axis. The component of $M$ in the $x$-y plane decays over time. An alternating current is induced in the receiver coil. 


\subsubsection{Longitudinal and Transversal Relaxation}

The return of the magnetization to its equilibrium state (that is, aligned parallel to the $\mathrm{x}$-axis) is known as relaxation. Between the $\mathrm{RF}$ pulse and restablishment of the equilibrium two things occur:

- Longitudinal relaxation. Restoration of longitudinal magnetization to its equilibrium value ( $\mathrm{T}_{1}$ or "spin lattice" relaxation).

- Transversal relaxation. The net magnetization leaving the transverse plane ( $\mathrm{T}_{2}$ or "spin-spin" relaxation).

Immediately following a RF pulse, the longitudinal magnetization is zero and the number of spins in the high energy state equals that in the low energy state. As longitudinal relaxation occurs, the number of spins in the upper energy level decreases and the energy is transferred from the spin system to its environment, which is referred to as the "lattice". The recovery of the longitudinal magnetization follows an exponential curve described by the following equation:

$$
M_{z}(t)=M_{0}+\left(M_{z}(0)-M_{0}\right) \times \ell^{-\frac{t}{T_{1}}}
$$

where $\mathbf{M}_{\mathbf{Z}}(0)$ and $\mathbf{M}_{\mathbf{Z}}(\mathrm{t})$ are the longitudinal components of the magnetization at the start and the end of the interval, $\mathbf{M}_{\mathbf{0}}$ is the equilibrium magnetization, and $\mathrm{T}_{1}$ is the longitudinal relaxation time constant. After time $\mathrm{T}_{1}$, longitudinal magnetization has returned to $63 \%$ of its final value (Figure 2.16a).

Transverse relaxation results from spins getting out of phase. As spins move together, their magnetic fields interact (spin-spin interaction), slightly modifying their precession rate. These interactions are temporary and random. Thus, spinspin relaxation causes a cumulative loss in phase resulting in transverse magnetization decay. Transverse magnetization decay is described by the following equation:

$$
M_{x y}(t)=M_{x y}(0) e^{-\frac{t}{T_{2}}}
$$




\section{Chapter 2: Introduction}

where $\mathbf{M}_{\mathrm{xy}}(0)$ and $\mathbf{M}_{\mathrm{xy}}(\mathrm{t})$ are the transverse magnetization at the start and end of the interval, and $\mathrm{T}_{2}$ is the transverse relaxation time constant. After a time $\mathrm{T}_{2}$, transverse magnetization has lost $63 \%$ of its original value (Figure 2.16b).

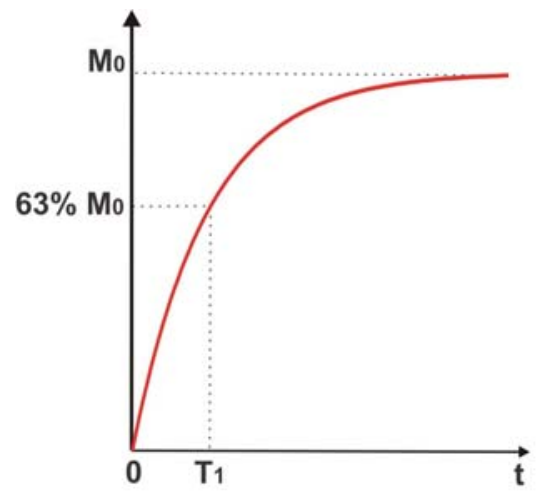

a

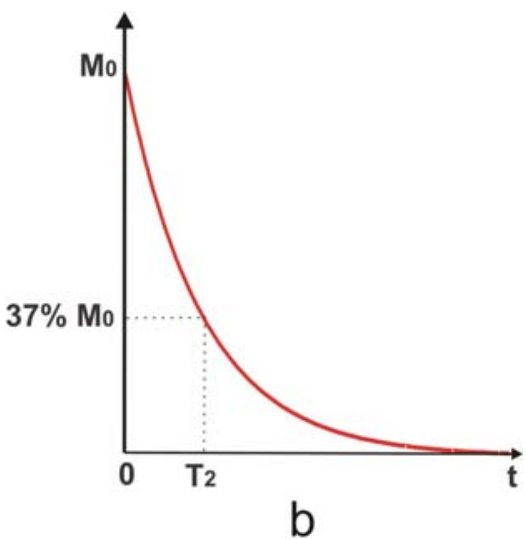

b

Figure 2.16 Plots of the time course of the longitudinal (a) and transverse (b) components of the magnetization following a $90^{\circ} \mathrm{RF}$ pulse.

The $T_{1}$ and $T_{2}$ time are an intrinsic property of any given tissue; different types of tissue typically have different time values (see Table 2.1), the T1 and T2 value depends on the details of the tissue's molecular structure. The difference in relaxation times between different tissue types is frequently exploited as a mechanism of generating contrast between different tissues in imaging.

The Larmor equation allows determining the precessional frequency of a proton as the product of the gyromagnetic ratio and main magnetic field strength. The gyromagnetic ratio is a constant; however, the main magnetic field is not perfectly homogeneous across the image volume due to imperfect instrumentation. Thus, protons precess at slightly different Larmor frequencies.

Considering both T2 and the effect of field inhomogeneities, the signal FID decays at a rate faster than that which results from T2 time alone. This decay is characterized by another, shorter, relaxation time parameter known as $\mathrm{T} 2 *$. Unlike the $\mathrm{T} 1$ and $\mathrm{T} 2$ relaxation times, the $\mathrm{T} 2 *$ time is not necessarily an intrinsic property of a given tissue; $\mathrm{T} 2 *$ may depend on factor other than the tissue structure itself. 


\begin{tabular}{|l|c|c|}
\hline Tissue & $\mathbf{T}_{\mathbf{1}}$ & $\mathbf{T}_{\mathbf{2}}$ \\
\hline CSF & $2719 \pm 405$ & $166 \pm 74$ \\
\hline Blood & $1441 \pm 120$ & $290 \pm 30$ \\
\hline White matter (WM) & $778 \pm 84$ & $79 \pm 8$ \\
\hline Cortical Grey matter (CGM) & $1124 \pm 50$ & $95 \pm 8$ \\
\hline Skeletal muscle & $1060 \pm 155$ & $35 \pm 4$ \\
\hline Thalamus & $609 \pm 34$ & $55 \pm 2$ \\
\hline
\end{tabular}

Table 2.1 Relaxation times, $T_{1}$ and $T_{2}$, for different body tissues in milliseconds [52-55].

\section{- $\quad$ Spin Echoes}

In order to obtain signal with a $\mathrm{T}_{2}$ dependence rather than a $\mathrm{T}_{2}{ }^{*}$ dependence, a pulse sequence known as the spin-echo had been designed which reduce the effect of $\mathbf{B}_{0}$ inhomogeneity on $\mathbf{M}_{\mathrm{xy}}$. After a $90^{\circ} \mathrm{RF}$ pulse, protons that were in phase begin to dephase in the transverse plane (represented by some spins going faster than the average and some spins going slower than the average). Whether a $180^{\circ} \mathrm{RF}$ pulse is applied a time after, the spins will rotate over to the opposite axis. Now, rather than the spins continuing to dephase, the spins will begin to rephase. The rephasing of the spins forms an "echo" (Figure 2.17).
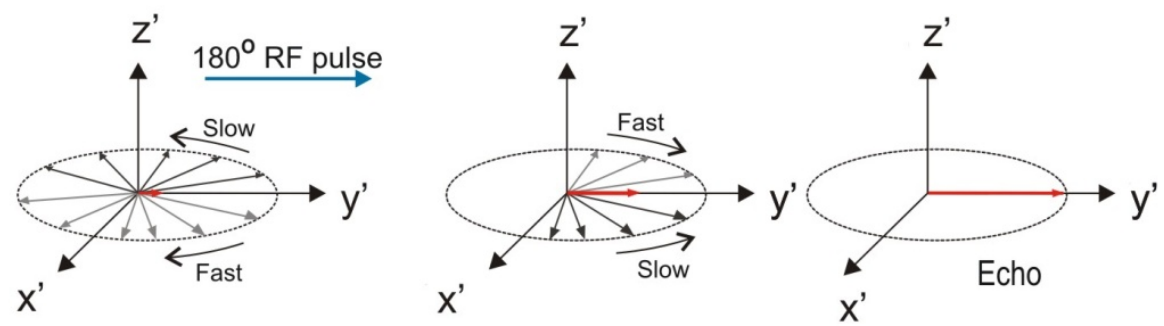

Figure 2.17 After transverse magnetization has begun to dephase in the transverse plane, application of a $180^{\circ} \mathrm{RF}$ pulse will rotate the proton spins to the opposite axis. This rotation will allow the spins to rephase and form an echo. 
The time between the peak of the $90^{\circ} \mathrm{RF}$ pulse and the peak of the echo is called echo time (TE). The symmetry of the spin echo process requires that the refocusing RF pulse $\left(180^{\circ}\right)$ be applied at the time TE/2. The curve formed by connecting the peaks of the echoes represents decay by T2 effects (spin-spin interactions), whereas the initial faster decay observed immediately after the $90^{\circ}$ $\mathrm{RF}$ pulse or during echo formation is due to $\mathrm{T}_{2}{ }^{*}$ effects. (Figure 2.18)

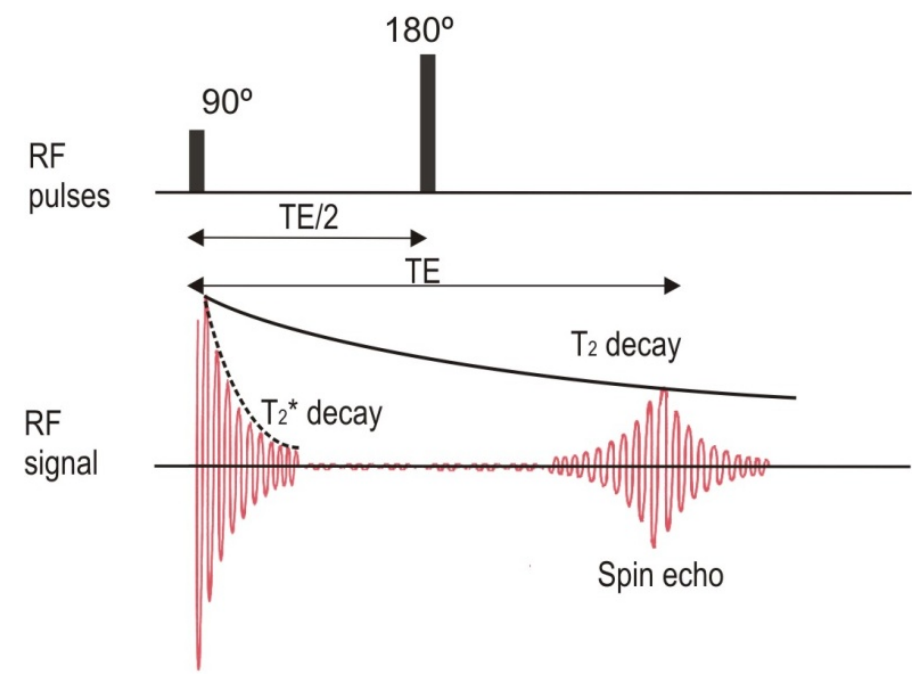

Figure 2.18 Mechanism of spin echo. Application of the $90^{\circ} R F$ pulse results in an immediate signal that decays with a time constant $T_{2}{ }^{*}$ due to the presence of field inhomogeneities. The $180^{\circ}$ RF pulse applied at TE/2 will allow formation of an echo at a time TE.

\subsubsection{Spatial Encoding of the MR Signal}

Spatial localization is based on magnetic field gradients, applied successively along different axes. A magnetic field gradient is a magnetic field that increases in strength along a particular direction. Magnetic field gradients are generated using gradient coils (Figure 2.19). They operate in pairs in the magnet, with opposite polarities (one coil increases the static magnetic field, the other 


\section{Chapter 2: Introduction}

reduces it), resulting in a linear change of the magnetic field in the direction of the gradient. An MRI scanner uses three gradients in the $\mathrm{x}, \mathrm{y}$ and $\mathrm{z}$ direction called $\mathrm{G}_{\mathrm{x}}$, $\mathrm{G}_{\mathrm{y}}, \mathrm{G}_{\mathrm{z}}$ respectively. These gradients are employed for slice selection, phase encoding and frequency encoding.

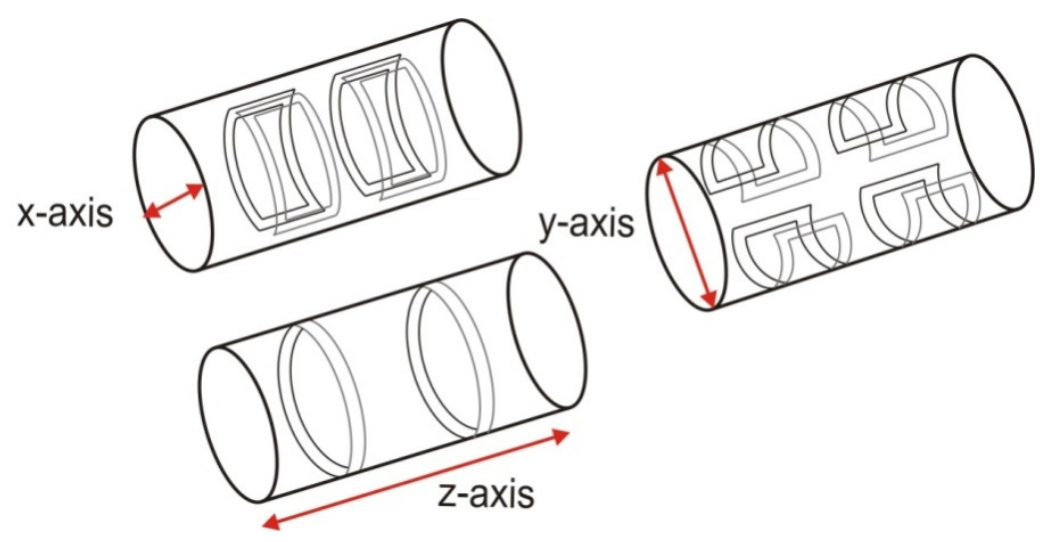

Figure 2.19 To cover all spatial dimensions ( $x, y$ and $z$ ), three sets of gradient coils are installed in the bore of the MR scanner. By changing the current flow relative to each other, planes in any direction can be laid trough the patient body.

\section{- $\quad$ Slice Selection}

Slice selection combines a magnetic field gradient and a specially shaped RF pulse to restrict MR signals to a slice instead of the entire region influenced. A magnetic field gradient is applied perpendicular to the desired slice plane. As the magnetic field varies in the direction of the gradient, all the planes perpendicular to the direction of the gradient have different precessional frequencies. Then, an RF pulse is applied at the resonance frequency of the spins on the desired slice plane. The protons on either side of the slice will be at different precessional frequencies so that only the protons of the desired slice will be excited (Figure 2.20). The width of the slice (slice thickness) can be decreased either by increasing the amplitude of the gradient field or by decreasing the bandwidth of the RF pulse. 
Once a slice has been selectively excited, the protons of this slice must be localized on an x-y plane.

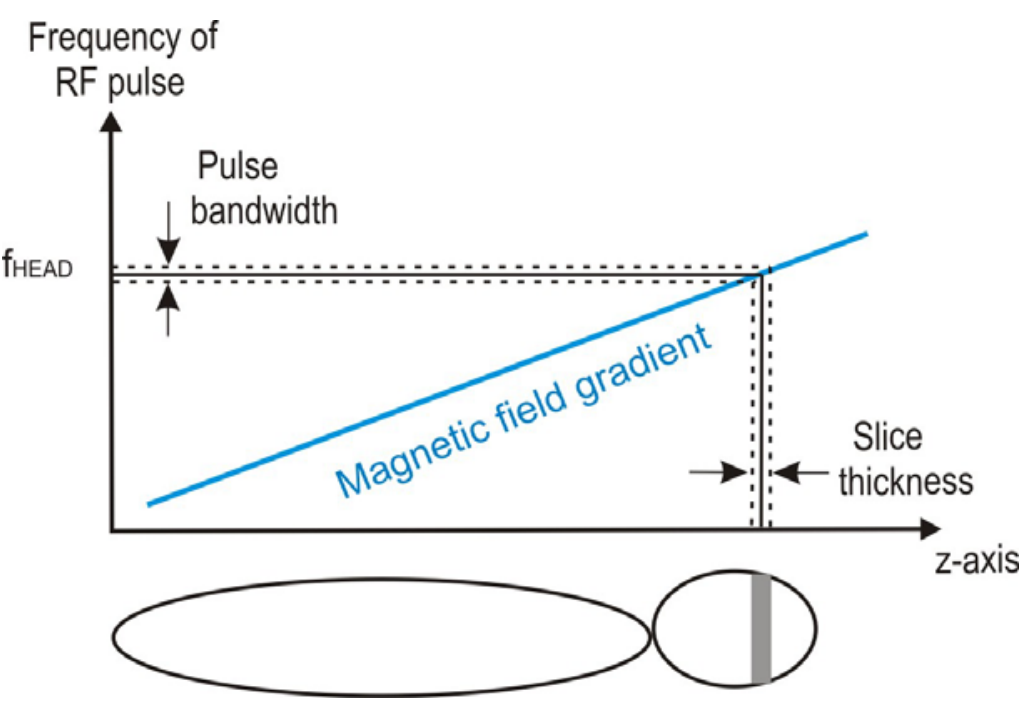

Figure 2.20 Slice selection. A slice of tissue can be excited applying an RF pulse that has the frequency of the profile known in presence of a linear magnetic field gradient. The RF pulse bandwidth and the strength of the gradient determine the slice thickness.

\section{- $\quad$ Phase Encoding}

Once a slice has been selectively excited, the protons of this slice must be localized on an $\mathrm{x}-\mathrm{y}$ plane. Phase is encoded into MR signal by pulsing a magnetic field gradient briefly ( $1 \mathrm{~ms}$ to $5 \mathrm{~ms}$ ) before each echo. As the change in frequency is very brief, when the gradient is switched off, it causes a change in phase that is proportional to the distance. If the phase encoding direction is the $y$-axis the protons in the same row have the same phase while that the protons in the same column have different phases (Figure 2.21). 


\section{- $\quad$ Frequency Encoding}

Frequency encoding resolves spatial information along one direction of an MR image keeping a magnetic field gradient on while each MR signal is being measured. The magnetic field gradient is called the frequency encoding gradient, read out gradient, or measurement gradient. The direction of the space that is encoded is called the frequency encoding direction and is perpendicular to the phase encoding direction. This gradient is applied during data acquisition.

The frequency encoding gradient spread the Larmor frequency over a range wide enough to distinguish the number of locations (pixels in an MR image) along one direction. If the $\mathrm{x}$-axis is the frequency encoding direction, the Larmor frequency of columns of nuclear spins varies in the direction of the frequencyencoding gradient (Figure 2.21).

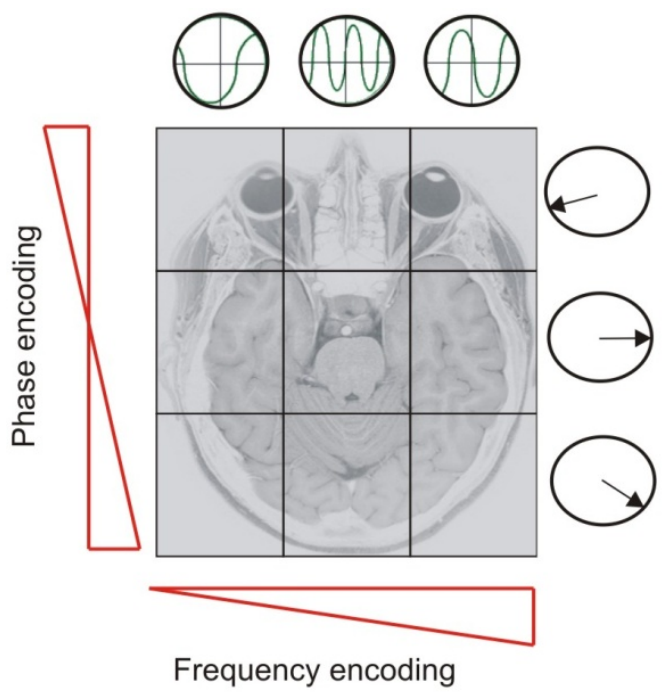

Figure 2.21 Phase and frequency encoding. 


\subsubsection{The $k$-space and the Matrix Image}

Images can be decomposed into thousands of sine and cosine waves of different frequencies and orientations. The Fourier transform of an MR image is its spatial frequency spectrum ( $k$-space), which specifies the amount of each of the various spatial-frequency components that make up the image. The MR image is a representation of the anatomy of interest in physical space, whereas its spectrum is a representation of the same information in $\mathrm{k}$-space. The $\mathrm{k}$-space is a matrix in which the horizontal axis (x-axis) usually corresponds to the frequency encoding, and the vertical axis (y-axis) corresponds to the phase encoding. The data in the central region of the $k$-space are the low spatial frequency components which represent the gross structure and contrast in the image. The data in the outer regions of the $k$-space are the high spatial frequency components which represent the detail of the structures and edges of the objects in the image.

\subsection{Flow Quantification from Phase Contrast MR Imaging}

The need to better understand the physiology of different neurological diseases and its application to diagnosis and treatment has motivated the application of MR imaging for in vivo flow measurements. PC-MRI technique permits to quantify different parameters that characterize the dynamic of the fluids. The principle of phase contrast is based on phase differences of flowing spins compared to spins of stationary tissue when a bipolar gradient is applied. These bipolar gradients are used in imaging sequences in the slice and frequency directions in order to prevent dephasing caused by the gradient itself. The phase difference will be then only present for the moving spins.

In combination with various gating algorithms, reasonable temporal resolution can be achieved allowing characterization of flow dynamics throughout all the cardiac cycle. The reproducibility and reliability of flow quantization using 
PC-MRI greatly depends in both the post-processing method used to accurately delineate the area to be analyzed and in the image acquisition protocol.

\subsubsection{Construction of the Image}

The quantity imaged in MRI is the transverse magnetization in each voxel defined by both magnitude and phase. PC velocity mapping is based on the underlying principle that the signal from moving tissue will undergo a phase shift, relative to that from stationary tissue, if a bipolar magnetic field gradient is applied in the direction of motion.

Figure 2.22 shows the effect of a bipolar gradient on stationary and moving spins. The stationary spin at position $\mathrm{X}_{0}$ experiences a magnetic field strength that causes the transversal magnetization to precess through an angle $\alpha$ during the application of the positive lobe of the bipolar gradient. The same stationary spin at position $\mathrm{X}_{0}$ experiences a field strength of the same intensity but opposite polarity during the application of the negative lobe of the bipolar gradient. This causes that it precesses through an angle $-\alpha$ during this time. The bipolar gradient has no effect on the phase of the magnetization from stationary spins. The effects of the positive and negative lobes of the gradient are cancelled $\alpha+(-\alpha)=0$. Whether the spin is moved to a new location $\mathrm{X}_{0}+\mathrm{x}^{\prime}$ during the negative lobe, it experiences a different magnetic field strength and precesses through a new angle $\alpha$ '. Thus there is a phase difference between the flowing and stationary spins. The accumulated phase $\alpha-\alpha$ ' is determined by the strength of the magnetic field gradient and the duration of time it is applied.

Phase information is affected not merely by velocity but also by other factors such as magnetic field inhomogeneities, Eddy currents and phase sequence tuning. To eliminate phase changes due to sources other than the encoding gradient, it is necessary to acquire two different phase images, with two different encoding gradients. Subtraction of these two images eliminates any phases that remain constant from the first image to the second one. An example of a PC gradient echo pulse sequence is shown in Figure 2.23. 

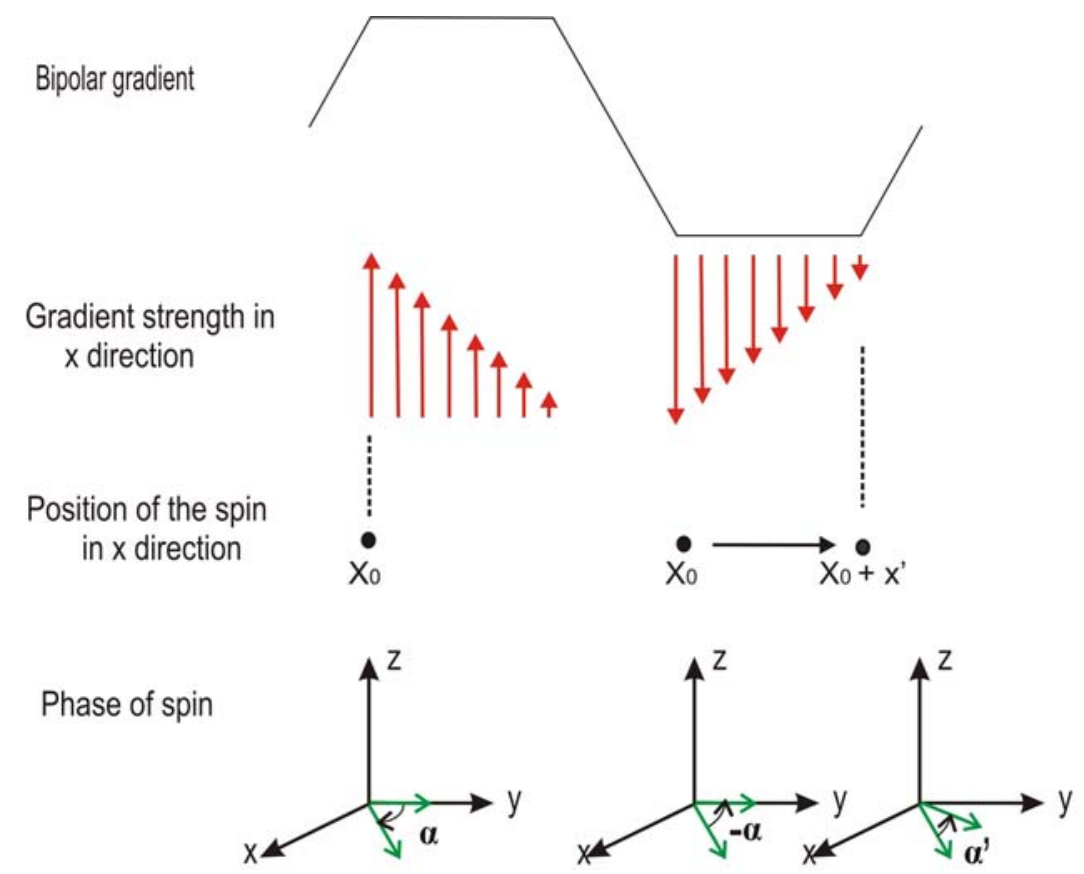

Figure 2.22 Effect of the bipolar gradient on the phase of stationary and moving spins. The application of a bipolar gradient has no net effect on the phase of stationary spins $\alpha+(-\alpha)=0$, but if the spin is displaced to a new position $X_{0}+x^{\prime}$ there is a phase difference between the stationary and moving spins, $\alpha-\alpha$ '. This phase shift is proportional to the distance moved and hence the velocity.

The two data sets with different velocity encoding gradient first order moments of the gradient waveform (which contain the information concerning the gradient moment of the moving spins) along one direction are acquired in an interleaved fashion. The pixel-by-pixel difference of the phase in two images, $\Delta \alpha$, reflects the velocity in the slice selection direction:

$$
\Delta \alpha=\gamma \mathrm{v} \Delta \mathrm{M}_{1}
$$

where $\Delta \mathrm{M}_{1}$ is the change of first moment, $\gamma$ is the gyromagnetic ratio, and $\mathrm{v}$ is the velocity component traveling in the direction of $\Delta M_{1}$. 


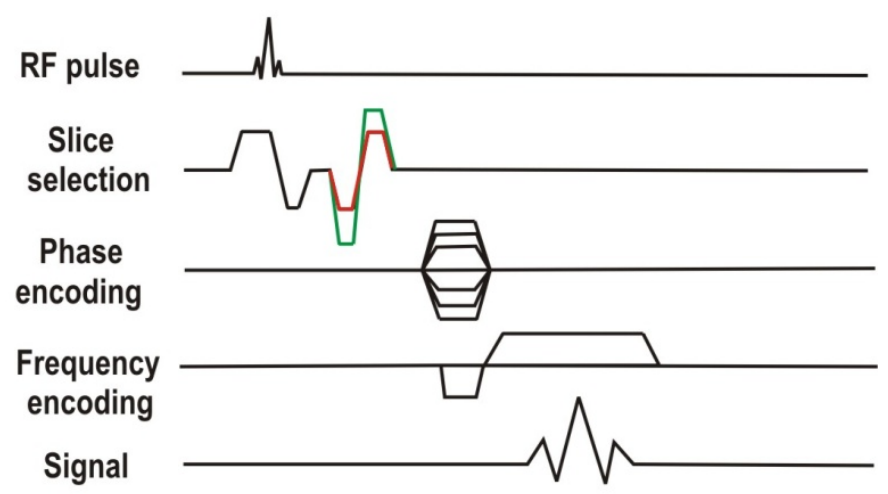

Figure 2.23 A timing diagram for a PC imaging sequence that would be sensitive to motion in the slice selection direction. Subtraction of the images acquired with two bipolar encoding gradients (red and green) eliminates phase changes due to sources other than the encoding gradient.

To detect motion in all directions a bipolar gradient must be applied on each of the three gradient axes in subsequent TRs avoiding that positive phase from the component of velocity along one axis may cancel negative phase from the component of velocity along another axis.

\subsubsection{Flow Sensitivity Adjustment}

The strength of the flow encoding gradient and hence the sensitivity of the $\mathrm{PC}$ technique to flow is controlled by $\Delta \mathrm{M}_{1}$. It can be characterized by the phase change per unit velocity and expressed as radians per cm/s. A more intuitive parameter is the velocity encoding $\left(\mathrm{V}_{\text {enc }}\right)$ value. It is defined as the velocity that produces a phase shift of $\pm 180^{\circ}$ :

$$
\mathrm{V}_{\mathrm{enc}}=\frac{\pi}{\gamma \Delta \mathrm{M}_{1}}
$$




\section{Chapter 2: Introduction}

A phase shift of $\Delta \alpha$ is converted to velocity as

$$
\mathrm{V}=\Delta \alpha\left(\frac{\mathrm{V}_{\mathrm{enc}}}{\pi}\right)
$$

Hence $\mathrm{V}_{\text {enc }}$ controls the dynamic range of velocities that can be measured. Pixel intensities on the image depend of the manufacturer; in Philips for example, when the measured velocity in the positive gradient direction has reached the chosen $\mathrm{V}_{\text {enc }}$, then the phase difference $\Delta \alpha$ has reached its maximum positive angle $\left(180^{\circ}\right)$ and therefore the pixel intensity is the higher. Or, when the measured velocity in the negative gradient direction has reached the chosen $V_{\text {enc }}$, then the phase difference has reached its maximum negative angle $\left(-180^{\circ}\right)$ and therefore the pixel intensity is the lowest possible one. When the phase is zero the velocity is zero and the intensity is grey (Figure 2.24).

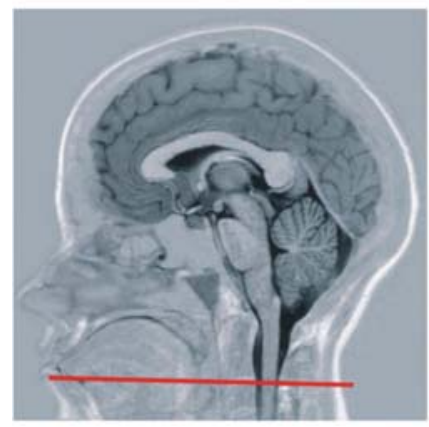

a

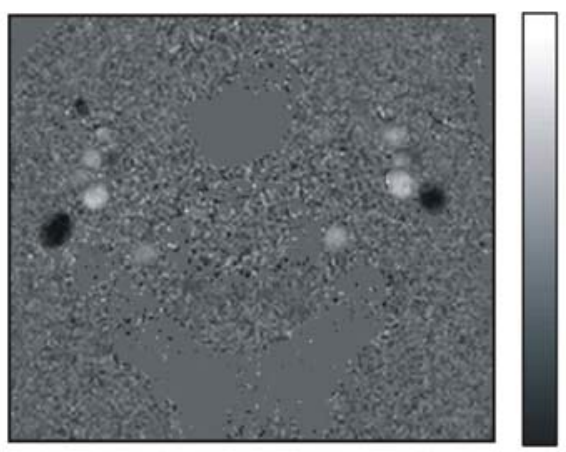

$180^{\circ}$

Venc $=80 \mathrm{~cm} / \mathrm{s}$

$0^{\circ}$

$-180^{\circ}$

$V_{\text {enc }}=-80 \mathrm{~cm} / \mathrm{s}$

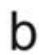

Figure 2.24 Image of vascular flow at C2C3 level. a) Sagittal slice of a T1 weighted turbo inversion recovery sequence used to determine flow acquisition level. b) The phase has a direct relationship with the velocity and the intensity of the image. The white intensities represent arterial flow and black intensities venous flow. The $\pm V_{\text {enc }}$ value represents a phase shift of $\pm 180^{\circ}$. 


\section{Chapter 2: Introduction}

\subsubsection{Cardiac Synchronization}

The PC-MRI allows to carry out detailed analysis of CSF and blood flows' variations during the cardiac cycle when it is used with cardiac synchronization [8;29;40;56-65](Figure 2.25). Electrical sensing (leads) or peripheral pulse (PP) devices are used to electrocardiogram (ECG) gating during the scan. There are two types of synchronization methods commonly used to carry out flow studies. Following will be briefly explained.

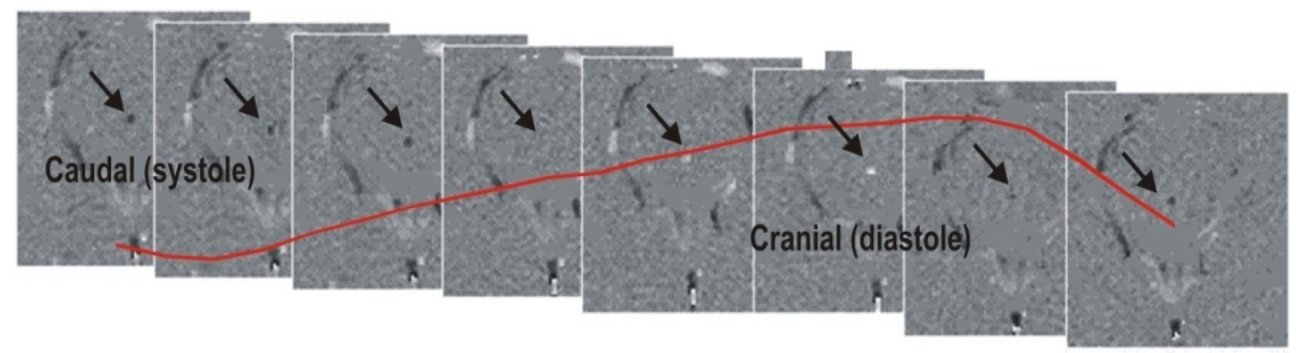

Figure 2.25 PC-MRI sequence obtained with PP. The sequence represents the dynamic of CSF flow through the aqueduct of Sylvius (arrows) during a cardiac cycle. In the reconstructed waveform the two directions that the CSF flow presents can be observed: caudal direction during systole and cranial direction during diastole.

\section{- $\quad$ Prospective Triggering}

Prospective triggering uses the ECG R-peak to determine the starting point of the acquisition. Data collection is acquired a time after each new R-peak in successive RR intervals; this time is known as the delay time (DT). The cardiac frequency determines the length of the RR interval and therefore how much time is available for scanning (Figure 2.26).

Commonly, the acquisition is stopped within $200 \mathrm{~ms}$ of next R-peak to allow for respiratory variation [66] and for accurate detection of the trigger. By this, the flow in the diastolic phase is not well evaluated. This technique can be 
used to analyze flow over the whole RR interval although at the penalty of an increased acquisition time.

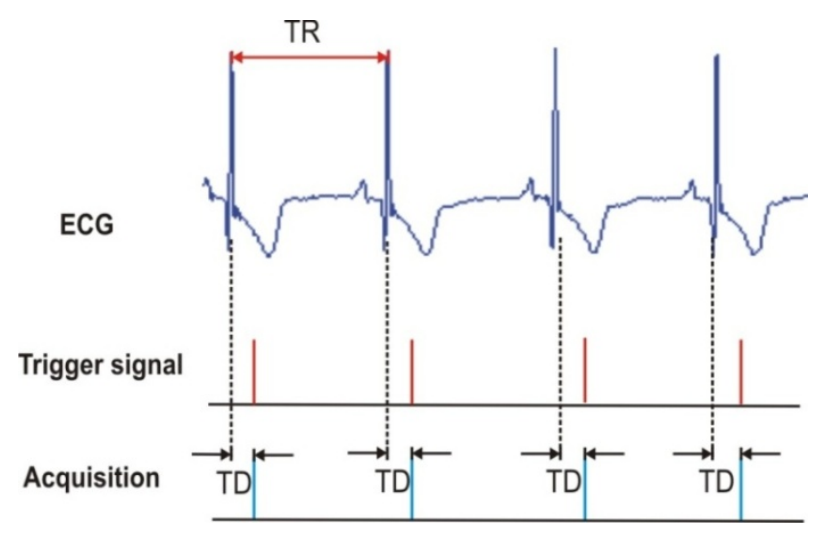

Figure 2.26 Prospective synchronization. TR: repetition time, TD: delay time.

\section{- $\quad$ Retrospective Triggering}

Retrospective triggering measures data continuously and stores the ECG timing with each acquired measurements. Afterward, the acquired data are reordered, so the images for different phases of the heart cycle can be reconstructed without an increase in scan time. The TR is constant for each measurement and is independent of the $\mathrm{RR}$ interval. As the $\mathrm{R}$-peak is recorded the data are retrospectively stored according to position within the RR interval. These values are used to interpolate the images in predetermined positions within the cardiac cycle [66] (Figure 3.27). This technique is often associated with some blurring (motion artifact). 

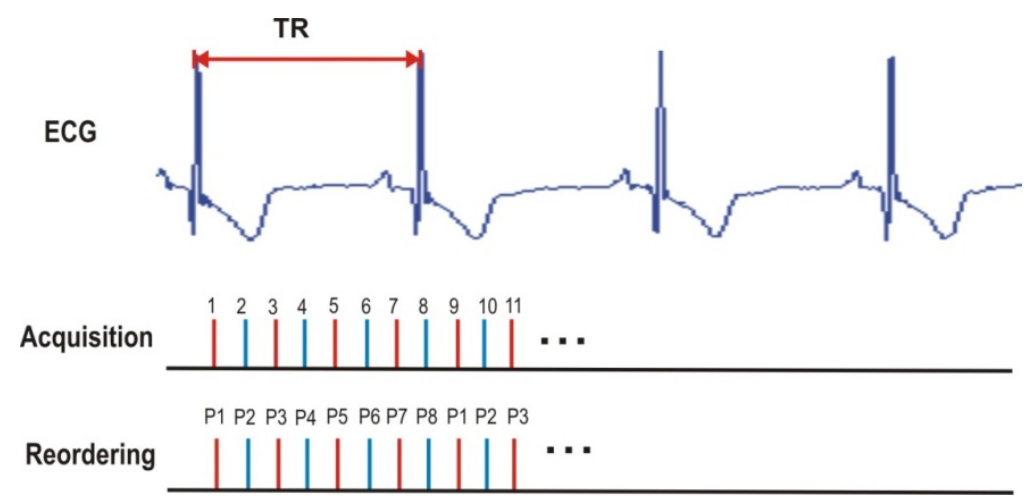

Figure 2.27 Retrospective synchronization. TR: repetition time.

Cardiac synchronization must be used with arrhythmia rejection to avoid mistakes when the heart rate of the patient is very irregular.

\subsubsection{Flow Quantification}

The sensitivity of PC-MRI to motion allows to analyze the dynamic of the intracranial fluids and therefore to have a more appropriate knowledge of the pathophysiology of different neurological diseases, increasing the reliability in the diagnosis. A detailed analysis of flow dynamics can be expected from volumetric fluid flow evaluation in defined regions.

The volume flow rate is determined by acquiring a phase image oriented perpendicular to the direction of flow and applying the velocity-encoding gradient along the slice selection axis. From this image, both the velocity of the flow through the plane of the image and the area of the region to analyze can be determined. The area of each pixel is known, because the area is a function of the field of view (FOV), the encoding steps, and the number of pixels in the image.

The rate of flow through a pixel is obtained multiplying its velocity value by the pixel area. The sum of all such values for all pixels on a region of interest (ROI) that includes the entire vessel, or equivalently the product of the average velocity within the region and the ROI area, is the volume flow rate, $\mathrm{Q}$, through the vessel: 


$$
\mathrm{Q}=\mathrm{A}_{\text {pixel }} \sum_{\mathrm{i}=1}^{\mathrm{N}} \mathrm{v}_{\mathrm{i}}=\mathrm{A}_{\mathrm{ROI}}\left(\frac{1}{\mathrm{~N}} \sum_{\mathrm{i}=1}^{\mathrm{N}} \mathrm{v}_{\mathrm{i}}\right)
$$

where $A_{\text {pixel }}$ and $A_{R O I}$ are the pixel and ROI areas, respectively. The ROI has $\mathrm{N}$ pixels in it, and $v_{i}$ is the velocity in the $i$-th pixel.

When the image sequence is not synchronized with the cardiac cycle, the measured volume flow rate corresponds to an average volume flow rate over time. Whether image acquisition is synchronized with the cardiac cycle, the flow volume displacement that has passed through the vessel from the beginning of the first time frame until the end of the image sequence is:

$$
\mathrm{VOL}_{\mathrm{j}}=\Delta \mathrm{t} \sum_{\mathrm{i}=1}^{\mathrm{j}} \mathrm{Q}_{\mathrm{i}}
$$

where, $\Delta \mathrm{t}$ is the time interval between frames, $j$ is the number of frames in the image sequence and $\mathrm{Q}_{\mathrm{i}}$ is the flow rate in the $i$-th frame.

\subsubsection{Errors in the MR Volumetric Flow Measurements}

Analyses of PC-MRI measurements are subject to variability and inaccuracy. The placement of the ROI is highly user-dependent and therefore is the main source of variability in the measurements. The main sources of inaccuracy are intravoxel phase dispersion, the partial volume effects, the misalignment of the flow axis and the flow encoding gradient, aliasing, the residual systematic errors caused by imperfect suppression of eddy currents or brain motion and the background phase shift caused by Maxwell or concomitant gradients [9].

The contribution of the PC-MRI to clinical research is based on the possibility to quantify parameters that can be used as biomarkers of disease. The reliability and reproducibility of these biomarkers can be increased by using an adequate protocol of acquisition and segmentation methods that reduce the interobservers' measurements variability [67]. Some of the main sources of error in the volumetric flow measurements will be described below. 


\section{Chapter 2: Introduction}

\section{- Partial Volume Effects}

Partial volume effects arise at the edge of a lumen when voxels contain signal from both stationary and moving spins. This leads to two counteracting effects: an underestimation of the velocity and an overestimation of the vessel size [68].

The presence of signal from stationary and moving spins in a voxel causes that the measured phase of the total signal is lower than the phase given to moving spins (Figure 2.28). The vessel area is overestimated because even if some of the pixels near the edge of the vessel are only partially filled with moving spins, the whole pixel contributes to the area calculation. In the calculus of volume flow rate, these two effects compete with one another and partially compensate each other. The underestimation of the velocity in the edge pixels tends to decrease the calculated volume flow rate, whereas the overestimation in area tends to increase it. The net effect on the calculated volume flow rate depends on which of these effects dominate.

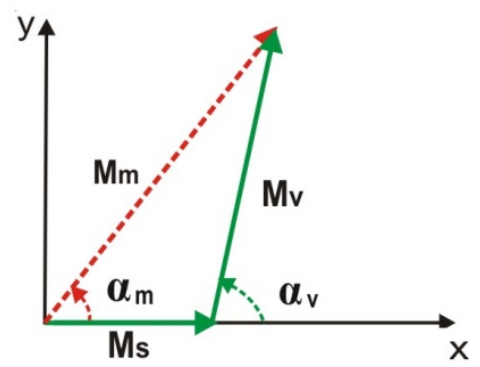

Figure 2.28 Illustration of the partial volume effects. $M_{s}$ and $M_{v}$ represent the magnetization vectors for stationary and moving spins within a voxel respectively, and $M_{m}$ is the total magnetization vector. The measured phase angle, $\alpha_{m}$, is smaller than the actual phase angle for moving spins, $\alpha_{v}$. The extent of the discrepancy between actual and measured phase depends on the difference size of the magnetization vectors $M_{s}$ and $M_{v}$. 


\section{Chapter 2: Introduction}

Partial volume effects occur when the voxel size is large and the imaging plane is not perpendicular to the vessel $[9 ; 69]$. The errors depend on the number of pixels across the vessel, on the ratio of slice thickness to vessel diameter, and also on the distribution of velocities across the vessel, being smaller for laminar flow than for plug or turbulent flow profiles [69].

Partial volume errors can be minimized by using a higher spatial resolution, imaging planes perpendicular to the flow direction and a carefully defined ROI [69]. Thin slices, higher matrix, and small flip angles will reduce the errors but will also decrease the signal to noise ratio (SNR) [9].

\section{- Intravoxel Phase Dispersion}

Phase errors can also occur when one voxel contains many different velocities which cannot be accurately represented by a single phase, as occurs with partial volume e This is known as intra voxel phase dispersion, and can lead to quantitative velocity errors in voxels that encompass a wide range of phases, such as in areas of turbulent flow or at the edges of a lumen.

Voxel velocity is the average of all isochromat velocities within the voxel, therefore the voxel phase would reflect mean isochromat phases within the voxel in order to accurately represent the voxel velocity. However, average voxel phase is not always equivalent to voxel phase derived from the vector sum of isochromat magnetization. This occurs when the phase distribution is asymmetric and/or the modulus of each isochromat are not identical (Figure 2.29).

The errors occasioned by intra voxel phase dispersion can be reduced increasing the spatial resolution and the $\mathrm{V}_{\text {enc }}$ value, and also by decreasing the echo time $[70]$. 


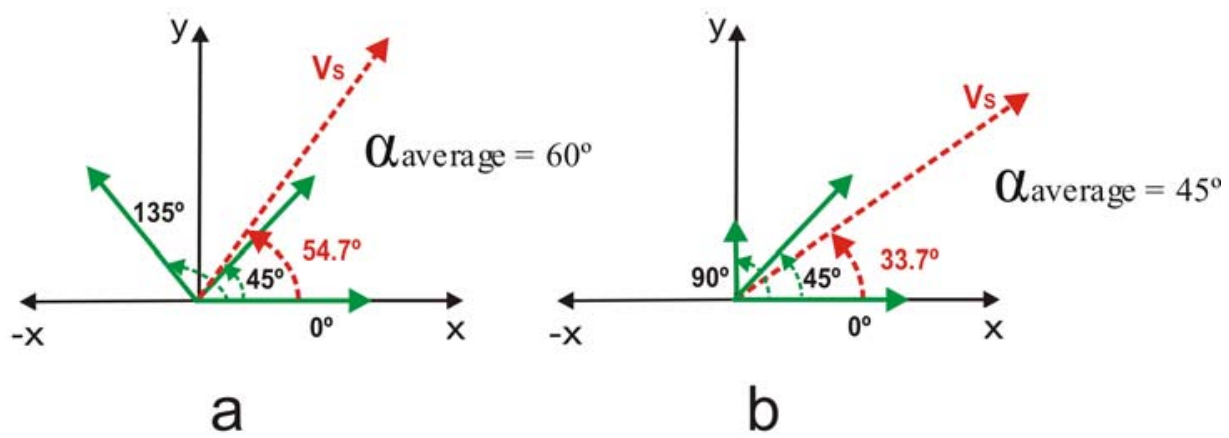

Figure 2.29 (a) When the phase distribution is asymmetric (phase $=0^{\circ}, 45^{\circ}, 135^{\circ}$ ) and the modulus of each isochromat is identical the phase derived from vector sum, $V_{s}$ is $54.7^{\circ}$ and the average phase is $60^{\circ}$. (b) If the phase distribution is symmetric (phase $\left.=0^{\circ}, 45^{\circ}, 90^{\circ}\right)$, and the modulus of one isochromat differs from the other the average phase and the phase derived from sum vector, $V_{s}$, again are different: $45^{\circ}$ and $33.7^{\circ}$ respectively.

\section{- Misalignment of Flow and Flow Encoding Axes}

If the flow and slice encoding directions are misaligned by an angle $\theta$, the velocity will be underestimated by $\cos (\theta)$ and the area will be overestimated by $1 / \cos (\theta)$. If the slice is thin with respect to vessel diameter, the volume flow rate is not affected, because the effect on velocity and area tend to cancel one another. If the slice is thick with respect to the vessel diameter, the partial volume effects begin to influence the results because the area is increased as the slice thickness increases due to the greater misalignment between the position where the vessel enters and exits the slice as the slice increases (Figure 2.30). The reliability of the measurements is therefore optimized by orienting the slice perpendicular to the direction of blood flow. 


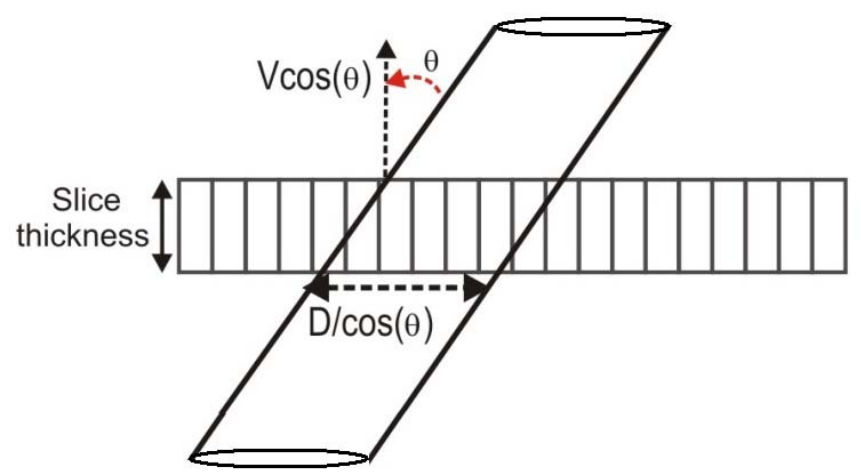

Figure 2.30 The velocity is underestimated by $\cos (\theta)$ and the area of the vessel in the image increase by $1 / \cos (\theta)$ as $\theta$, the angle between the vessel and the imaged slice, increases. $D$ is the diameter of the vessel.

\section{- $\quad$ Aliasing}

The $\mathrm{V}_{\text {enc }}$ value is the velocity that produces a phase shift of $\pm 180^{\circ}$. When the accumulated phase exceeds $\pm 180^{\circ}$ the reconstruction algorithm no longer represents the phase correctly, and the velocity information cannot be properly determined from the image; this is known as aliasing. The reconstruction algorithm ignores how the magnetization arrived at its final orientation. Spins accumulating phases greater than $\pm 180^{\circ}$ are assigned the wrong phase. In an image, the aliased pixels appear as a change from black to white signal intensity, or viceversa (Figure $2.31)$.

To avoid the aliasing, $\mathrm{V}_{\text {enc }}$ value should always be chosen to exceed the expected maximum velocity within the vessel of interest. However, $\mathrm{V}_{\text {enc }}$ should not be chosen too high, because it is inversely proportional to the signal to noise ratio (SNR) [71].

\section{- $\quad$ Eddy Current Effects}

Flow measurements with PC-MRI make use of velocity induced phase shifts. This means that phase offsets which may not disrupt an anatomical image 


\section{Chapter 2: Introduction}

may create a considerable bias in the measured velocity. When magnetic field gradients are turned on and off very rapidly, they tend to induce currents in the housing that surrounds the gradient coils. The induced currents are called eddy currents.

Even if the final phase contrast image is composed of the difference between two separate images, so as to cancel out field inhomogeneities, not all unwanted contributions to the phase can be completely eliminated this way. The eddy currents induced by these different gradients cannot be identical, so subtraction leaves a net value that is not equal to zero.

The velocity offset within the vessel can be estimated by examining the apparent velocity in static region surrounding the vessel and subtracted from the vessel to correct for possible errors. The baseline regions should be as close as possible to the vessel being analyzed and should exclude vascular structures. It is important to be careful with low signal regions as they have very high phase noise.
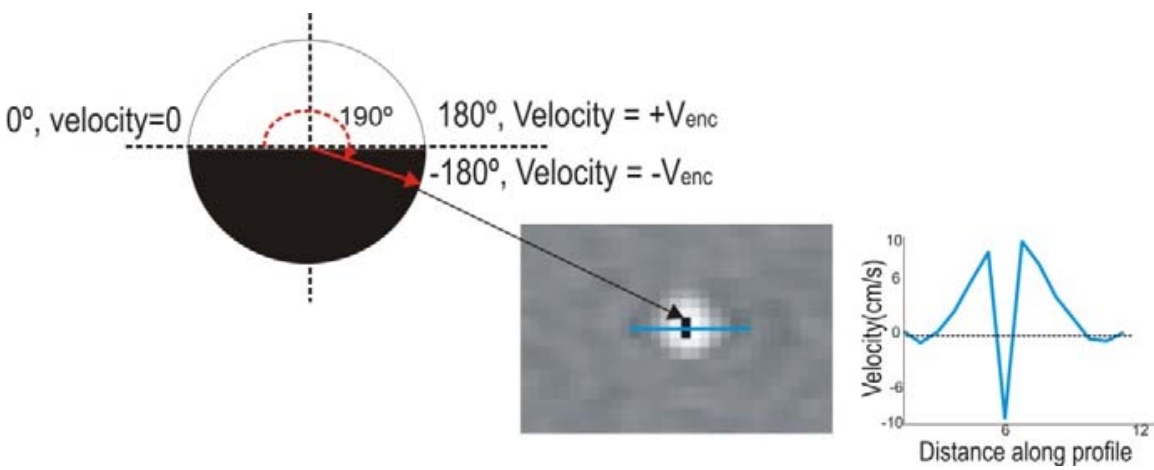

Figure 2.31 Aliasing presents in a frame of the image sequence acquired at the aqueduct of Sylvius. The $V_{\text {enc }}$ value used during the acquisition of this image was 10 $\mathrm{cm} / \mathrm{s}$. The spin represented was moving in the positive direction with a velocity greater than $10 \mathrm{~cm} / \mathrm{s}$ accumulating a phase of $190^{\circ}$. The reconstruction algorithm assigns a wrong phase of $-170^{\circ}$; the aliased pixels appear black rather than white. If a velocity profile is drawn across the aqueduct on this frame, the aliasing velocity value is near the maximum value in the opposite direction. 


\section{Chapter 3}

\section{Methods}

Flow measurements with PC-MRI provide a powerful clinical tool for the non-invasive evaluation of flowing fluids. However, analyses of PC-MRI measurements are subject to variability and inaccuracy. The partial volume in the surrounding of the region to analyze, the residual errors caused by imperfect suppression of eddy currents and even brain motion, and the presence of aliasing are the main sources of inaccuracy. The reproducibility and reliability of flow quantization greatly depend upon the post-processing method used to accurately delineate the area to be analyzed. Variability and inaccuracy generates artefactual measurements that are not representative of real values.

In this chapter the developed methodology in order to analyze the flow dynamic of reliable and reproducible way is described. This methodology integrates semiautomatic segmentation techniques with background phase correction and aliased pixels detection and correction, when necessary. All the methods were implemented using MATLAB R7 (The MathWorks Inc., Natick, MA, USA) and were included into a graphical user interface to facilitate its use.

\section{Adapted from:}

- YN Flórez, D Moratal, J Forner, L Martí-Bonmatí, E Arana, U GuajardoHernández, J Millet-Roig. Semiautomatic analysis of phase contrast magnetic resonance imaging of cerebrospinal fluid flow through the aqueduct of Sylvius. Magn Reson Mater Phy 2006; 19;78-8\%.

- N Flórez, R Bouzerar, D Moratal, ME Meyer, L Martí-Bonmatí, O Balédent. Quantitative analysis of cerebrospinal fluid flow by means of unsupervised clustering k-means using phase contrast magnetic resonance imaging. Submitted to Medical Image Analysis 


\subsection{Segmentation Techniques}

Image segmentation is defined as the partitioning of an image into regions that are homogeneous with respect to one or more characteristics or features. Segmentation is a powerful tool used in several applications: face and fingerprint recognition, automatic traffic controlling systems, machine vision and medical image processing.

In medical imaging, segmentation plays a crucial role; it is important for the detection of micro-calcifications on mammograms [72], multiple sclerosis lesion quantification [73], for the detection of tumors [74], to measure tissue volumes [75], for computer-guided surgery and diagnosis [76], for treatment planning [77], for the study of anatomical structures, for the quantification of the intracranial volume [47] and for heart image extraction from cardiac cine-angiograms [78], among many other applications.

A wide variety of segmentation techniques has been proposed [79]; however, there is not one standard method that can produce satisfactory results for all imaging applications. The complexity of the human body structures complicates this task; specific segmentation algorithms are necessary to study the behavior of its main organs and fluids. The definition of the goal of the segmentation varies according to the goal of the study and the image data.

Quantification of fluid from PC-MR examinations requires a postprocessing step to segment the regions to analyze. The most commonly applied postprocessing method is the manual segmentation; it is tedious, time-consuming, and leads to significant inter and intra-observer variabilities. The accuracy and reproducibility highly depend on the skills of the user, as well as on the image display parameters such as window width and level and image resolution.

The main manufacturers of MR equipments provide software with limited options to analyze the dynamic of the flow. Some of them only allow manually defined circular and elliptic ROIs justifying the development of reliable and reproducible computer assisted automatic methods. The Q-FLOW package of the ViewForum workstation of Philips Medical Systems (Best, The Netherlands) allows 


\section{Chapter 3: Methods}

defining adaptable ROIs using active contours; however in small vessels or complex regions it is not possible to quickly and reproducibly define the ROI.

Several approaches to automatic or semiautomatic segmentation of PC-MR images have been described. In 1998 Yuan et al. [80] used active contour (Snakes) to identify the inner and outer boundaries of the blood vessel wall in MR images. The selection of the initial Snake points was critical for the successful execution of the algorithm. The user defined a circle closer to the desired vessel boundary by specifying the center and the radius manually; then 16 initial Snake points were uniformly created along the circle. Once the initial points were selected, a Canny edge detector and weighted distance transform (WDT) were used to create a contour map. Finally, the Snake algorithm was iterated until convergence using the defined contour. The entire process was supervised by the operator who might manually reposition any Snake points that have been erroneously positioned.

In 1999 Kozerke et al. [81] also used active contours for an automatic vessel segmentation. Eleven steps were carried out in order to delineate the vessel of interest. The segmentation depends of the selection of the start frame processing (image corresponding to the early systolic acceleration of the blood flow) and therefore of the contrast to noise ratio on image. This method was used in the ascending aorta, a large vessel in comparison to the vessels evaluated for the intracranial dynamic (jugular veins, internal carotid, basilar and vertebral arteries).

In 2001 Baledent et al. [82] developed a semiautomatic method, based upon fast Fourier transform of the time velocity series, to segment both vessels and CSF spaces. They used the fundamental frequency amplitude of the pixel velocity variations during the cardiac cycle in order to create a parametric image. Next, a threshold was applied to the entire parametric image to extract all of the pixels with a velocity at the cardiac frequency above a visually selected threshold. This method highly depends on the skills of the user. The definition of the ROI is tedious due to the manual selection of the threshold value.

In 2003 Box et al. [83] proposed two automatic segmentation algorithms (a static and a dynamic approach) to define small vessel. The methods assumed the cross section of the vessel to be circular and the velocity profile to be parabolic. The automatic segmentation was based on the fitting of a three dimensional 


\section{Chapter 3: Methods}

parabolic velocity profile to the actual velocity data. In the static method, the velocity profiles were averaged over the complete cardiac cycle, whereas the dynamic method takes into account the velocity data of each cardiac time bin individually. In the first iteration the segmented ROI is always a circle, but a threshold procedure after the fitting improves the result.

In 2003 Alperin and Lee [84] used both temporal and spatial information for lumen boundary identification and a cross-correlation unbiased threshold method to improve reproducibility. Once a threshold has been applied, the boundary of a region containing connected pixels with values above this threshold is obtained using a simple boundary tracking method (nearest neighbor search). This method was applied to the CSF spaces and vessels' segmentation. Marshall et al. [85] in a recent study stated that they did not find this technique useful for determination of CSF flow jets presents in Chiari I malformation patients [86]. A jet consists of a spatially concentrated region of high velocity that is embedded in a surrounding region of lower velocity. Quigley et al. [86] found that the CSF flow in the foramen magnum is highly complex both spatially and temporally, even in healthy subjects.

The degree of the correlation is attributed to shape, not magnitude, the limitation of the segmentation method in this flow behavior may be associated to the unbiased threshold value (0.75) proposed in order to segment CSF flow. By using this high threshold value, regions with inhomogeneous pulsatile flow probably are discarded.

The performance of the segmentation techniques can be improved by combining images from several sources (multispectral segmentation) or integrating images over time (dynamic or temporal segmentation).

In this thesis two dynamic semiautomatic segmentation methods have been developed to analyze the dynamics of the intracranial flow in the main vessels and CSF spaces with independence of the operator allowing studying the dynamic relationship of the intracranial fluids.

The first method was implemented to analyze the flow in regions with parabolic and plane flow velocity profiles as the aqueduct of Sylvius and main 


\section{Chapter 3: Methods}

vascular structures; this method uses the temporal information of each pixel along all the images sequence followed by a reproducible thresholding method.

The second method developed in this thesis allows studying the flow in regions with complex shapes and inhomogeneous pulsatile flow patterns as in the pontine cistern and subarachnoid spaces. Our method was developed based upon the segmentation algorithm presented by Alperin et al. [84]. In the designed method a threshold value is individually calculated for every segmentation and the simple boundary tracking method (nearest neighbour search) used in the last step is replaced by an unsupervised k-means classification method to increase the robustness of the algorithm.

\subsubsection{Threshold Method}

Thresholding is a non-linear operation that converts a gray-scale or color image into a binary image where the two levels are assigned to pixels that are below or above the specified threshold value. Each pixel in the image is compared with the chosen threshold value. If the pixel's intensity is higher than the threshold, the pixel is set to white in the output image. If it is lower than the threshold, it is set to black. This segmentation technique was used to analyze the flow dynamic in the aqueduct of Sylvius and in the main vascular structures.

Fluid flow in pipes can be either laminar or turbulent. Laminar flow occurs at low flow rates. This flow is streamlined and without turbulence. The flow has a maximum possible value at the centre and diminishes towards the periphery; this makes that the laminar flow describe a parabolic velocity profile.

The turbulent flow occurs at higher flow rates than the laminar one, and it is not streamlined; there is a lot of swirling (eddies) of the fluid. The turbulent flow does not have a maximum value at the centre, and thus the velocity profile of turbulent flow is flatter than the one caused by laminar flow (Figure 3.1). 


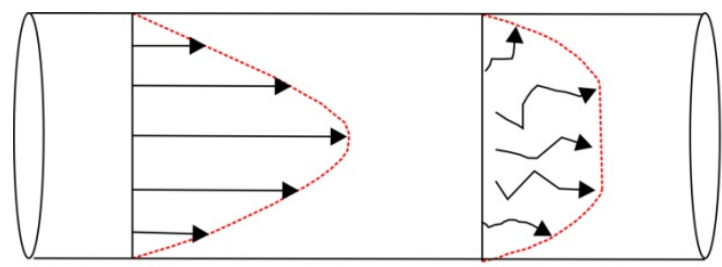

a

b

Figure 3.1 Comparison of laminar (i) and turbulent (ii) velocity profiles in a pipe.

The factor that determines which type of flow is present is the ratio of inertia forces to viscous forces within the fluid, expressed by the nondimensional Reynolds number:

$$
R=\frac{\rho d v}{\eta}
$$

where, $\rho$ is the density of the flow, $\eta$ is the viscosity of the flow, $d$ is the diameter, and $v$ is the flow velocity.

Laminar flow occurs at low Reynolds numbers $(<2000)$, where viscous forces are dominant, and is characterized by smooth, constant fluid motion, while turbulent flow, on the other hand, occurs at high Reynolds numbers $(>4000)$ and is dominated by inertial forces, which tend to produce random eddies, vortices and other flow fluctuations. Between 2000 and 4000, the flow is in transition between laminar and turbulent, and it is possible to find subregions of both flow types within a given flow field.

It is assumed that the regions to analyze (cerebral aqueduct and different vascular structures) are characterized by a parabolic velocity profile (laminar flow) or a plane velocity profile (turbulence flow) is considered in order to automatically select the threshold values. The CSF flow in the aqueduct of Sylvius, because of its small size should present a velocity profile purely laminar, nonetheless under pathological conditions the laminar flow pattern becomes turbulent as is the case for NPH patients, for which a hyperdynamic CFS flow occur [58;87]. Regarding the blood flow, it is also generally laminar; under conditions of high flow the laminar 


\section{Chapter 3: Methods}

flow can be disrupted and becomes turbulent. This turbulence also occurs in large arteries at branch points, in diseased and narrowed arteries, and across stenotic heart valves [88;89]. But even slow flow coming from a large orifice can be turbulent; an increase in diameter without a change in velocity also increases Reynolds number and the likelihood of turbulence.

In a first step, the method is manually initialized by selecting a seed point inside the region to analyze on the magnitude or phase image. Afterward, the method creates a new mean working matrix with an area in accordance with the region to study to minimize the computational burden.

\subsubsection{Aqueduct of Sylvius}

The created mean working matrix has an area of $81 \mathrm{~mm}^{2}$ around the seed point marked by the user; the aqueduct, having a diameter smaller than $4 \mathrm{~mm}$ [87], will be surely contained in that $81 \mathrm{~mm}^{2}$ working area. In this visualization matrix, each pixel intensity reflects the mean intensity of the pixels all along the magnitude images sequence (Figure 3.2a). To reduce the interobserver variability, a new mean matrix is created, centered in the highest mean intensity pixel $\left(I_{\max }\right)$. Next, two ROIs are automatically defined using this temporal information by means of a reproducible thresholding method. The first ROI surrounds the aqueduct; it is used to calculate flow parameters. The second one, disregarding the periphery of the aqueduct, is used to calculate velocity parameters without influence of peripheral laminar flow. If the ROI is drawn just surrounding or slightly larger than the aqueduct or vessel, the mean velocity will then be slightly less, but the area of the ROI is larger. The result is that flow remains the same. Nevertheless, if this same ROI is used to calculate velocity parameters, the value will be underestimated due to the accidental inclusion of pixels containing surrounding tissue.

The first threshold value is obtained from an intensity profile built using the maximum intensity found in each column of the mean working matrix. Next, the points where the calculated profile begins to increase are automatically detected. The intensity profile could presents a dicrotic morphology due to the physiology of the aqueduct, the own pathology and the acquisition protocol (Figure 


\section{Chapter 3: Methods}

3.3). Taking this into account, the upper half of the intensity profile is discarded to avoid mistakes to the automatically detect the points (Figure $3.2 \mathrm{~b}$ ).

Next, the lower part of the intensity profile is analyzed. The changes of trend of decreasing to increasing are selected. The points where the last change of trend occurs are selected. The threshold value is calculated as the average of the maximum intensity values found to the left and right of the detected points (Figure $3.2 \mathrm{~b})$.

The second threshold value is calculated as $\left(I_{\max }-I_{\min }\right) / 2$, where $I_{\max }$ is the highest mean intensity and $I_{\text {min }}$ is the smallest mean intensity of the working matrix. Two binary working matrices are then constructed based on the threshold values; these thresholds give reproducibility to the method. From these binary working matrices, two ROIs are defined as the boundary that contains the pixels with a velocity higher than the selected thresholds (Figure 3.2d).

These two ROIs will then have a variable shape, depending on the subject. The temporal information of each pixel was chosen from the magnitude sequence instead of the phase sequence to assure the definition of the ROIs. In some patients the mean working image built from the phase sequence does not allow to automatically define the threshold values. Nevertheless, the magnitude sequence facilities the definition of the ROIs and therefore the respective flow waveform that characterize the CSF flow dynamic (Figure 3.4). 


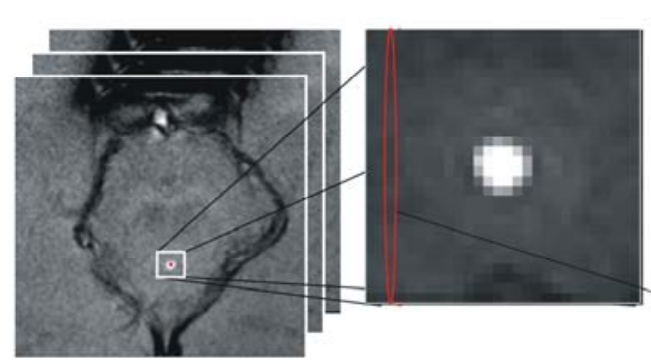

a

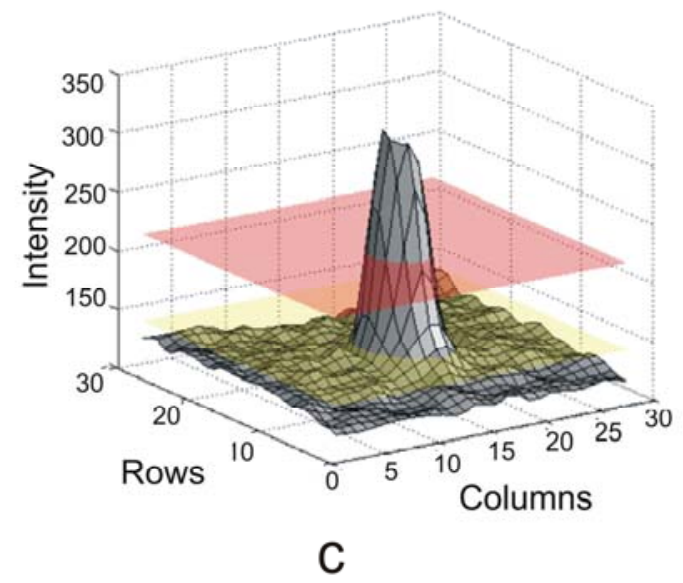

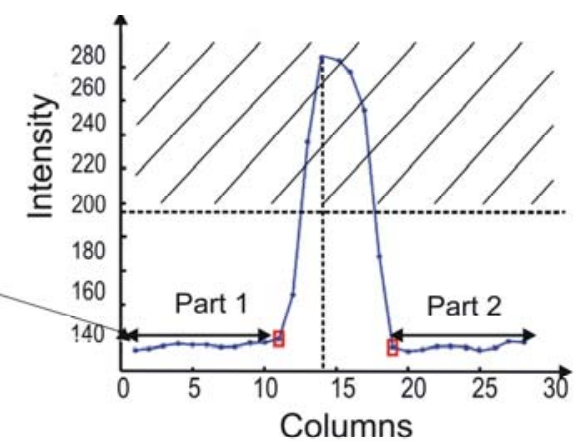

b

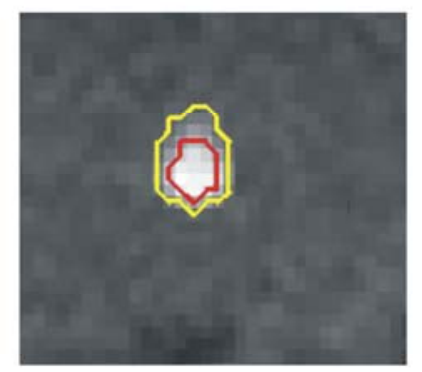

d

Figure 3.2 Threshold method used to delineate the Aqueduct of Sylvius. a) Magnitude images sequence of the aqueduct of Sylvius and the mean working matrix built around the seed point marked by the user. Afterward a new mean matrix is created again, centered in the maximum intensity pixel in order to reduce the interobserver variability. b) Intensity profile that represents the maximum intensities found in each column of the mean working matrix. The upper half of the intensity profile is discarded to avoid mistakes to the automatically detect the points. The changes of trend of the lower part of the profile are analyzed. The threshold value is calculated as the average of the maximum intensity values found to the left and right of the detected points. The green line represents the part of the profile where the maximum intensity values are looked for. c) 3D plot of the mean matrix where the obtained threshold values are represented. The threshold value (red layer) is calculated as $\left(I_{\max }{ }^{-} I_{\min }\right)$ /2. d) Defined ROIs used to analyze velocity parameters (red ROI) and flow parameters (yellow ROI). 


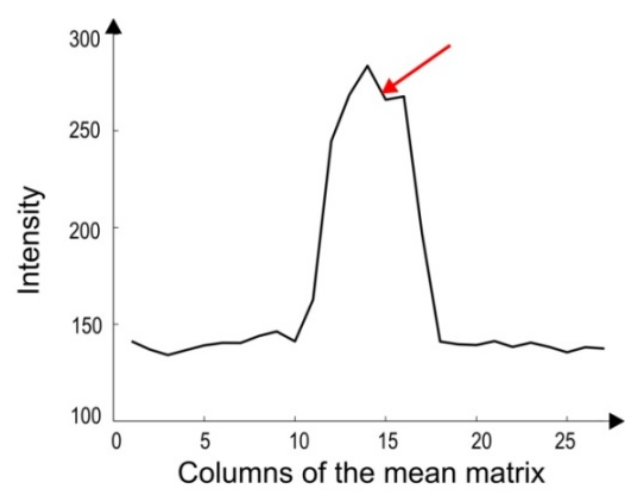

Figure 3.3 Intensity profile. The red arrow indicates the presence of a dicrotic wave, which could make difficult the automatic definition of the points used to calculate the second threshold value.

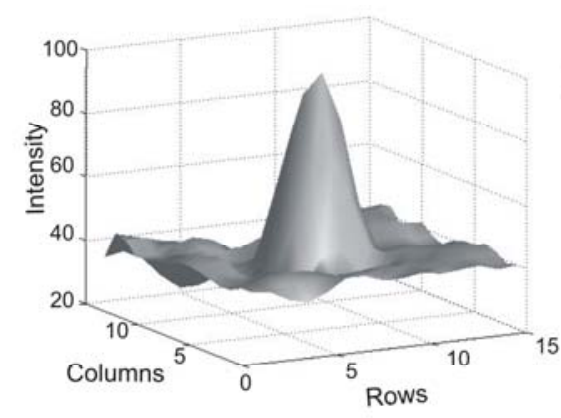

a

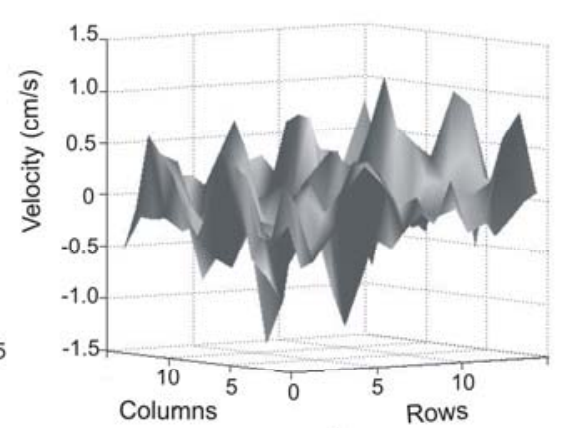

b

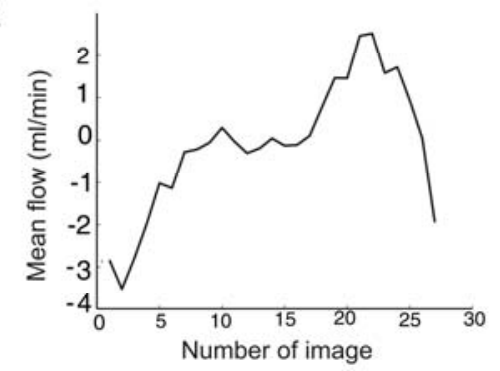

C

Figure 3.4 Mean working matrices obtained from a white matter disease patient of 57 years old. a) Mean matrix built using the magnitude images sequence. b) Mean matrix built using the phase images sequence. c) CSF flow waveform. 


\section{Chapter 3: Methods}

\subsubsection{Vascular Vessels}

In order to segment vascular structures (arteries and veins), the previously described method to delineate the aqueduct was modified. The mean working matrix was built using the mean velocity of the pixels all along the phase images sequence instead of the magnitude images sequence (Figure 3.5a). It will be possible to differentiate arteries and veins as blood vessels are encoded on the image with opposite pixel intensities, representing the direction of the flow (Figure 3.5b).

The area of the working matrix was increased to $225 \mathrm{~mm}^{2}$ to ensure that relevant arteries or veins were included. Next, a first binary working matrix is created depending on the vessel to analyze. For example, if the region to analyze is an artery and it has been encoded with positive velocities (white pixel intensities), the greatest velocities and equal to zero are selected. Then, the resulting mask is multiplied by the mean working matrix (Figure 3.5c). If the vessel to analyze was encoded with negative velocities, these are converted to positive velocities to generalize the following steps.

Unlike the previously described method, where the first threshold value is calculated using a velocity profile, the first threshold value is calculated as $\left(\mathrm{V}_{\max }\right.$ $\left.\mathrm{V}_{\min }\right) / 10$, where $\mathrm{V}_{\max }$ is the highest mean velocity and $\mathrm{V}_{\min }$ is the absolute minimum mean velocity. The absolute $\mathrm{V}_{\min }$ is used to assure that the calculated threshold value allows to define the ROI without influence of background tissue. The threshold value depends on the maximum flow velocity; on this way, reproducible parameters are obtained. The velocity profile is not used to calculate the threshold value due to the presence of several vascular structures on the image (Figure 3.5d).

Next, the region that contains the marked point by the user is automatically selected; in this region the second threshold value, $\left(\mathrm{V}_{\max }\right) / 2$, is calculated (Figure 3.5e). From the binary matrices obtained using the two thresholds values, two ROIs are defined as the boundary that contains the pixels with velocities higher than the selected thresholds (Figure 3.5f). The ROI enclosing the entire vessel was used to calculate the flow parameters, and the other ROI was used to calculate the velocity parameters. Several arteries or veins can be selected by marking different seed points within the vessels to segment. 


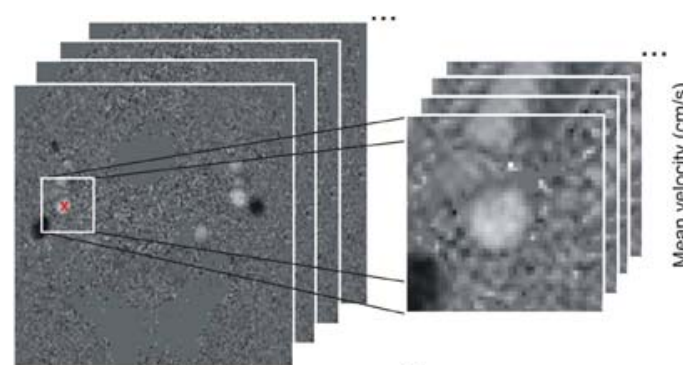

a

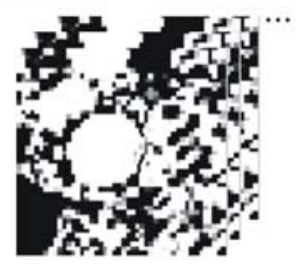

C

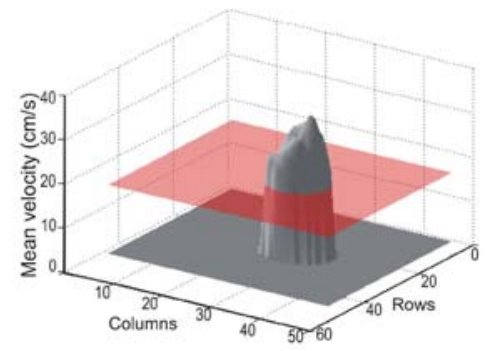

e

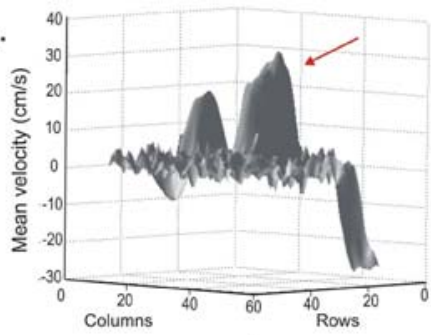

b
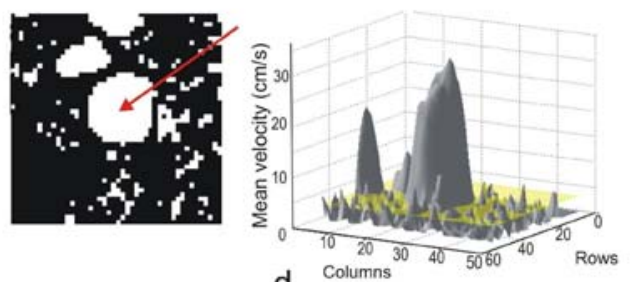

d

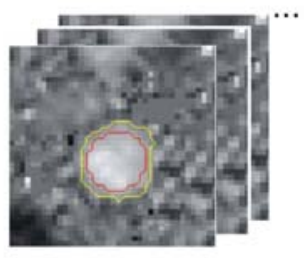

f

Figure 3.5 Threshold method used to delineate blood vessels. a) Phase image sequence and working matrix built after the selection of an initial seed point (" $x$ ") inside the vessel of interest. b) 3D plot of the mean velocity matrix, the red arrow point out the artery to segment. c) Mean working matrix multiplied by the first binary matrix, which is created depending on the vessel to analyze; in this example the matrix contains positives velocities. d) The first threshold value is calculated as Vmax/10. This value facilitates to eliminate almost all the background and to extract the vessel that transports blood in the same direction. The red arrow points out the region that contains the seed point marked by the user. This region is automatically selected. e) Next, in the region that contains the seed point, the second threshold value, Vmax/2, is computed. f) From the binary matrices obtained using the two thresholds values, two ROIs are defined as the boundary that contains the pixels with velocities higher than the selected thresholds. The red ROI is used to calculate velocity parameters and the yellow ROI is used to calculate flow narameters. 


\subsubsection{K-means Method}

$\mathrm{K}$-means clustering is an unsupervised way to classify or to group a given data set based on attributes (features) into $\mathrm{K}$ number of group. $\mathrm{K}$ is a positive integer number. The grouping is done by minimizing the sum of squares of distances between data and the corresponding cluster centroid.

The k-means clustering algorithm can be described in the next steps (Figure 3.6):

1. K points are placed into the space represented by the objects that are being clustered. These points represent initial group centroids (Figure 3.6a).

2. Each object is assigned to the group that has the closest centroid (Figure 3.6b).

3. When all objects have been assigned, the positions of the $\mathrm{K}$ centroids are recalculated (Figure 3.6c).

4. Steps 2 and 3 are repeated until the centroids no longer move (Figure 3.6d).

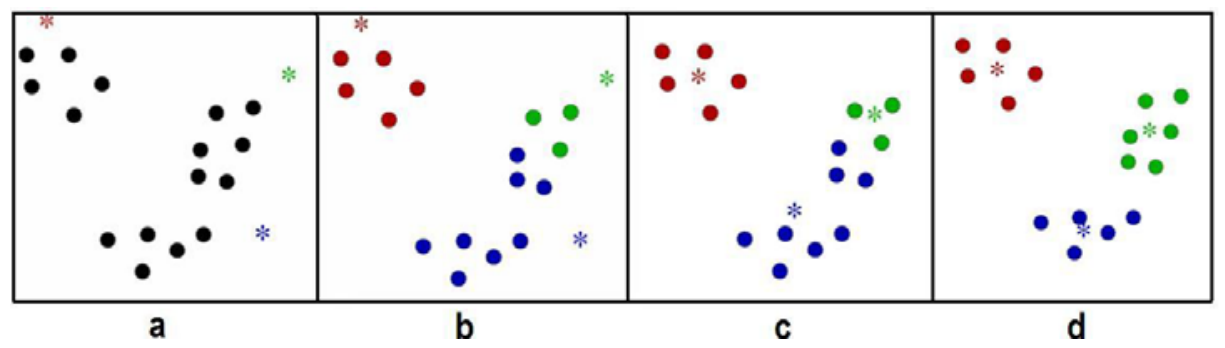

Figure 3.6 K-means clustering method. The red, green and blue asterisks represent the centers of the respective cluster (centroids).a) $K$ points are placed into the space represented by the objects that are being clustered. b) Each object is assigned to the group that has the closest centroid. c) When all objects have been assigned, the positions of the $K$ centroids are recalculated. $d)$ The cluster converges. 


\section{Chapter 3: Methods}

The segmentation process is manually initialized by selecting a point in the CSF spaces to be studied in a phase image with pixels of high intensities. The method creates a fixed window, with a size in accordance with the level, so that computational burden is minimized (Figure 3.7a). Before applying the k-means clustering in order to select CSF flow pixels, the number of pixels to analyze was reduced (reduction of the working matrix), increasing the reliability of the method.

First, a correlation map is created. For this, a reference velocity waveform is defined using the selected point. This waveform describes velocity as a function of time during the cardiac cycle (Figure 3.7b). The correlation map is built obtaining the correlation coefficients between the defined velocity profile and the profiles from other pixels of the working matrix (Figure 3.7c). The correlation coefficient $(\mathrm{CC})$ is defined as:

$$
C C_{x y}=\frac{\sum_{k=1}^{n}\left(R_{k}-\bar{R}\right)\left(V_{x y k}-\bar{V}_{x y}\right)}{\sqrt{\sum_{k=1}^{n}\left(R_{k}-\bar{R}\right)^{2} \sum_{k=1}^{n}\left(V_{x y k}-\bar{V}_{x y}\right)^{2}}}
$$

where, $k$ is the time index, $n$ is the total images number, $R$ is the reference velocity profile and $\overline{\mathrm{R}}$ its mean value, $V_{x y}$ is the velocity value at $x y$ pixel and $\bar{V}_{x y}$ its mean value, and $C C_{x y}$ is the $\mathrm{CC}$ coefficient at that location.

Second, a CC threshold value is calculated in a reproducible and automatic way in order to extract flow pixels. With this aim in view, the curve representing the number of segmented pixels is computed as a function of $\mathrm{CC}$ threshold values, ranging from 0.3 to 0.9 in steps of 0.02 as suggested by Alperin et al. [84]. They proposed unbiased correlation threshold values of 0.7 and 0.75 for the segmentation of blood vessel lumens and CSF places respectively. Nevertheless, in the developed method, the mean slope values between consecutive points on the curve are calculated in order to choose the threshold value, set as the first threshold value that coincides with the first slope of the curve whose value is below the average slope (Figure $3.7 \mathrm{~d}$ ). 


\section{Chapter 3: Methods}

This threshold value is automatically selected in a reproducible way for each segmentation procedure avoiding underestimate the region of interest and therefore improving the method robustness. Figure 3.8 shows the pixels to cluster after applying the threshold values ranging from 0.3 to 0.9 in steps of 0.02 ; with the unbiased threshold value of 0.75 suggested by Alperin the region to analyze (ROI) will be underestimated because pixels containing flow probably are removed. The threshold value calculated with the proposed method was 0.4 . This threshold value allows to define the ROI using k-means clustering. Using this method, it is possible to extract the pixels containing flow based on attributes

After the threshold value was applied to the correlation map and the resulting mask was multiplied by the sequence of images (Figure 3.7e), it was assumed that almost all pixels with CSF flow behavior were marked in the resulting image. In order to clearly delineate the desired region of interest, a kmeans clustering method was applied in the last step of the segmentation procedure [90].

The $\mathrm{k}$-means cluster implemented was defined with $\mathrm{k}=2$ classes. A class contains pixels with CSF flow behavior while the other class contains pixels with blood flow or background tissue behavior. Initially, the position of the cluster centroids was randomly selected from the data and the distance between each object and the centroids was calculated using a squared Euclidean distance. The Euclidean distance, $d$ between the points $\mathrm{P}=\left(\mathrm{p}_{1}, \mathrm{p}_{2}, \ldots, \mathrm{p}_{\mathrm{n}}\right)$ and $\mathrm{Q}=\left(\mathrm{q}_{1}, \mathrm{q}_{2}, \ldots \mathrm{q}_{\mathrm{n}}\right)$ in the Euclidean n-space is defined as:

$$
d=\sqrt{\sum_{i=1}^{n}\left(p_{i}-q_{i}\right)^{2}}
$$

Classification using cluster analysis is based on a fixed number of attributes per pixel. Three temporal attributes, explained below, were chosen in our study. These attributes were selected taking in account the flow behavior.

- In order to calculate the first attribute, a mean velocity curve characterizing CSF flow over the cardiac cycle was defined in the highest area region 


\section{Chapter 3: Methods}

extracted from the matrix obtained after image thresholding and binarization. Indeed, this region must contain a large number of CSF pixels; therefore, the temporal velocity curves in this area were averaged. The first attribute corresponds to the total number of agreements in signs obtained from the comparison between the averaged curve and the pixels velocity profile. A positive sign represents a velocity value higher than 0 , while a negative represents a velocity value smaller than 0 (Figure 4.8). The amplitudes are not compared. Therefore, it is possible to discard unidirectional flow as the blood flow.

- The second attribute is obtained from the spectral decomposition of the velocity signal obtained during one cardiac cycle in each pixel. The flow displacement during a cardiac cycle can be considered as a continuous periodic function. The PC-MRI allows obtaining $\mathrm{N}$ discrete values of flow velocity during a period $\mathrm{P}$ equal to the length of the cardiac cycle $(\mathrm{RR})$; therefore the frequency components of this function can be estimated with a fast discrete Fourier transform (FFT) analysis. Using N discrete sampling points the Fourier transform gives $\mathrm{N} / 2$ harmonic frequencies. The zeroth harmonic is equal to the arithmetic mean of the $\mathrm{N}$ sampled values. The first harmonic or fundamental frequency has a wavelength equal to the cardiac cycle $\mathrm{P}$. This frequency component allows to exclude nonpulsatile regions and background noise; therefore; it is used as second attribute for the k-means clustering (Figure 4.8).

- The third and last attribute was defined as the mean absolute velocity value calculated from the phase image sequence in each pixel (Figure 4.8). Thus intermediate velocities of LCR flow are differentiated of higher velocities of blood flow and lower velocities of nonpulsatile regions and background noise. 


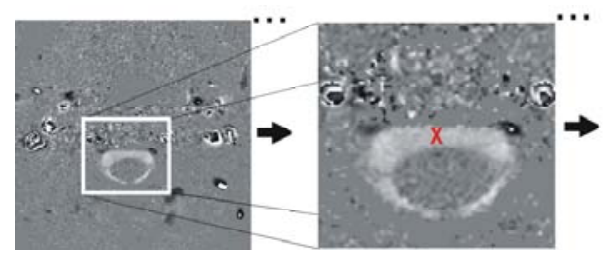

a

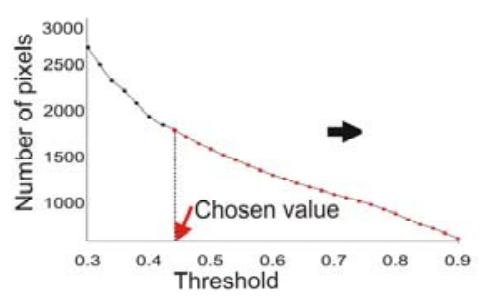

d

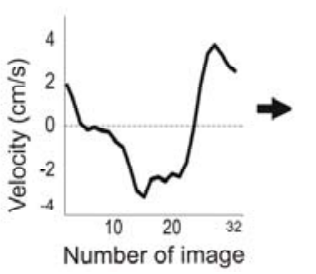

b

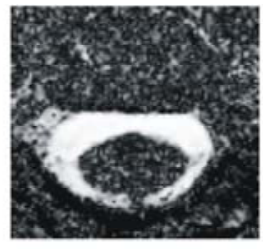

C

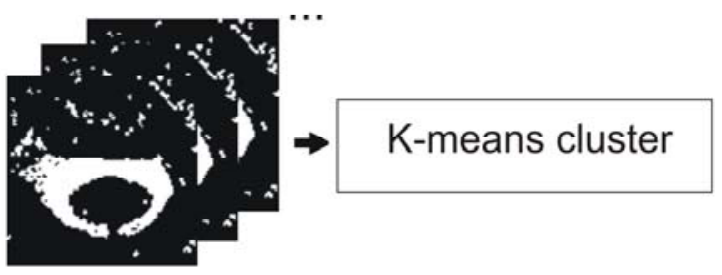

e

f
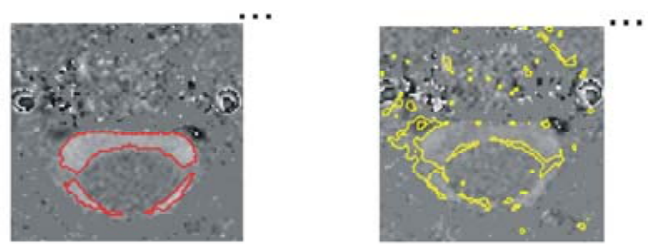

g

Figure 3.7 CSF segmentation algorithm applied to the subarachnoid spaces at C2C3 level. (a) Region of interest defined after the selection of an initial seed point inside the CSF spaces to be studied. (b) Using the selected point ("x"), a reference velocity profile is obtained in order to create a correlation map (c). (d) From this correlation map, a curve representing the number of segmented pixels above the threshold values ranging from 0.3 to 0.9 is obtained; the slopes between two consecutive points on the curve are calculated and the threshold value is the first value that coincides with the first slope of the curve whose value is below the average slope. (e) The threshold value is applied to the correlation map and the resulting mask is multiplied by the sequence of images. After the implementation of the $k$ means clustering (f), the 2 obtained classes correspond to pixels with CSF flow and pixels containing blood flow or background tissue. The red contour delineates the automatically selected ROI while the yellow contour the discarded regions $(\mathrm{g})$. 


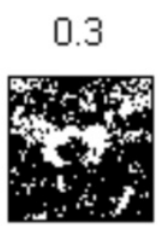

0.42

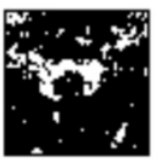

0.54

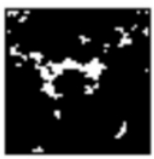

0.66

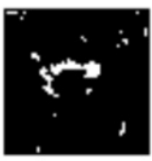

0.78

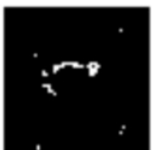

0.9
0.32

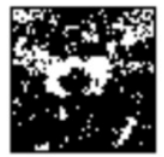

0.44

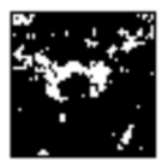

0.56

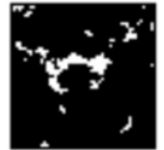

0.68

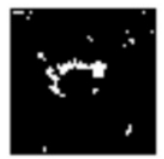

0.8

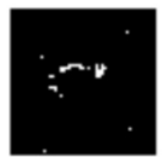

0.34

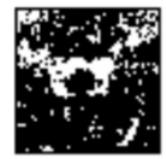

0.46

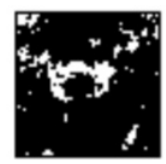

0.58

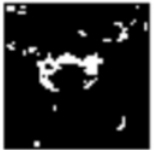

0.7

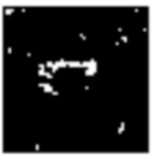

0.82

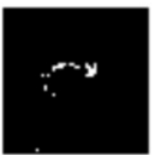

0.36

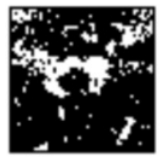

0.48

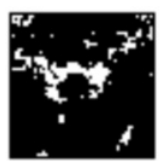

0.6

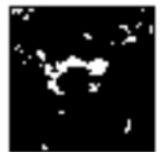

0.72

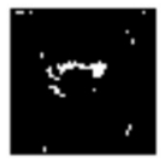

0.84

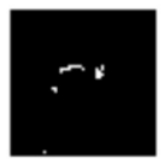

0.38

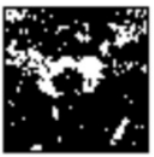

0.5

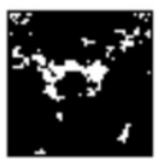

0.62

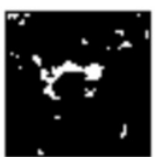

0.74

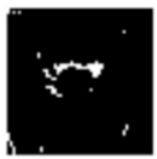

0.86

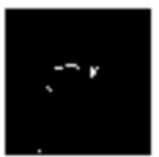

0.4

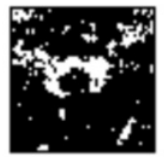

0.52

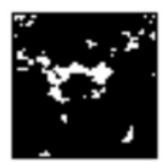

0.64

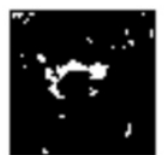

0.76

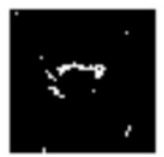

0.88

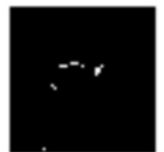

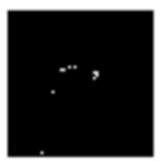

Figure 3.8 Threshold values ranging from 0.3 to 0.9 in steps of 0.02 applied to the correlation map obtained in order to define the CSF region at level C2C3. With the threshold value of 0.75 suggested by Alperin the region to segment will be underestimated. The threshold value calculated with the proposed method was 0.4. With this threshold, the number of pixels to cluster is not reduced and therefore the segmented region is not underestimated. 


\section{Chapter 3: Methods}

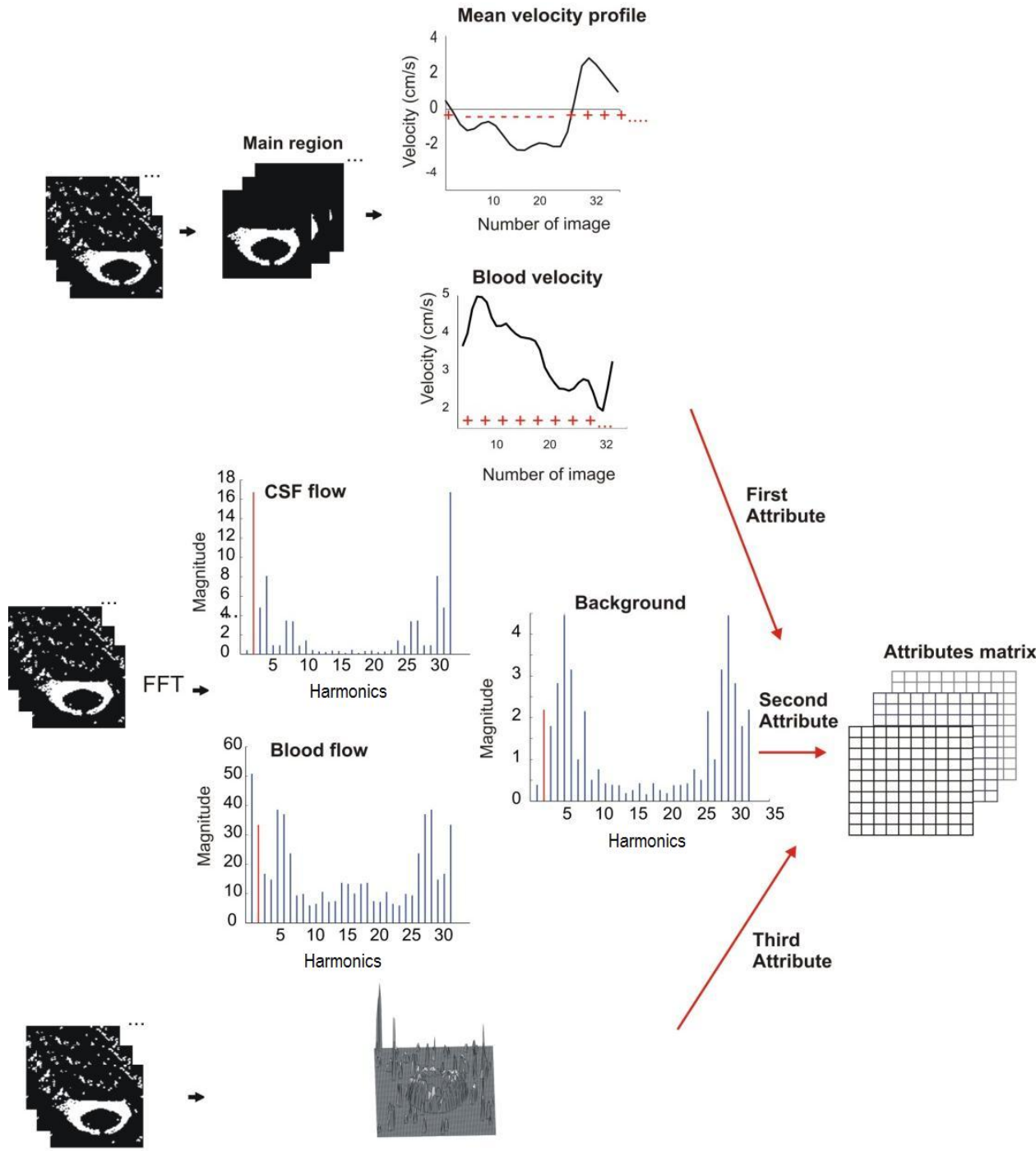

Mean absolute
velocity matrix

Figure 3.9 Attributes used in the k-mean clustering. The first attribute is the total number of agreements in sign obtained from the comparison between the averaged curve and the pixel velocity profile. The second attribute is the magnitude of the fundamental frequency component, which corresponds to the heart rate of the subject. The third attribute is defined as the mean absolute velocity value calculated from the phase image sequence in each pixel. 


\section{Chapter 3: Methods}

Once these attributes have been calculated, the k-means cluster was then applied and the class that contains the highest number of pixels was automatically chosen as the representation of the ROI to be analyzed (Figure $3.7 \mathrm{~g}$ ).

The combination of these attributes permits to exclude partial volume effects near the region edges and to facilitate the extraction of rachidian nerves that divide the cervical CSF region into several compartments (Figure 3.10). The user can check the discarded class and select it in case of an erroneous ROI delineation.
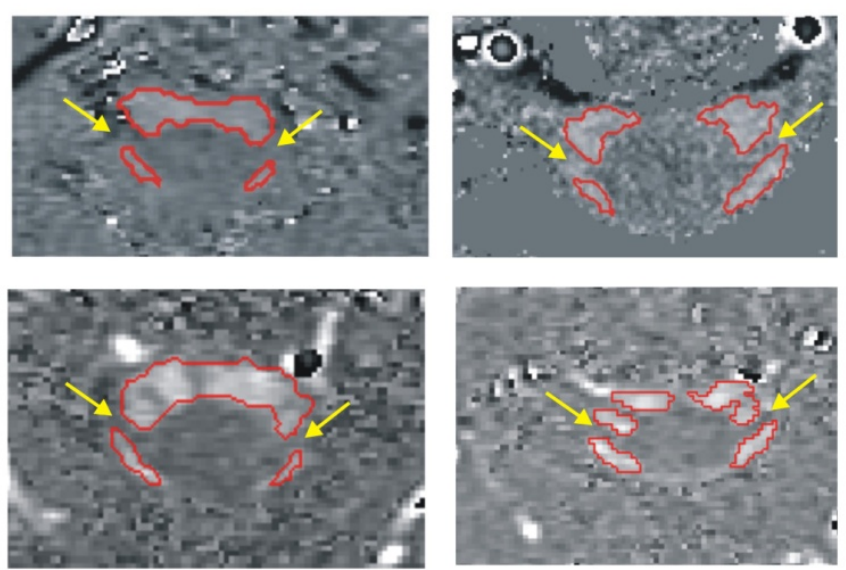

Figure 3.10 Different ROIs determined for cervical CSF regions divide into compartments. The presence of rachidian nerves (arrows) in the plane of the image is excluded from the segmentation.

\subsection{Aliasing Correction}

The presence of aliased pixels through the sequence of images depends on the adequacy of the $\mathrm{V}_{\text {enc }}$ value chosen at the moment of the MR acquisition. The most accurate flow measurements are obtained when the $V_{\text {enc }}$ is just slightly greater than the maximum observed flow velocity. However, in some pathologic cases with high flow rates, the selected $\mathrm{V}_{\text {enc }}$ can be inadequate [67;91]. Previous authors have 


\section{Chapter 3: Methods}

taken into account this artifact during the flow quantification, nevertheless the aliased frames are manually detected and subsequently corrected [82].

Two methods to automatically detect aliased pixels with velocities smaller than $180 \%$ of $\mathrm{V}_{\text {enc }}$ were developed (Figure 3.11). Based on the flow behavior, the aliased pixels are automatically detected using the temporal information of the flow within the defined ROI.

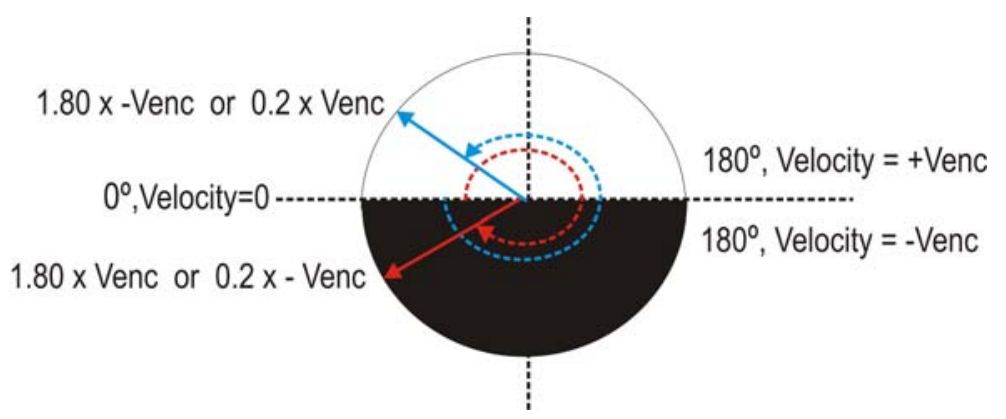

Figure 3.11 Aliasing correction. The developed methods are designed to detect aliased pixel with velocities smaller than $1.80 \times V_{\text {enc }}$.

The first method was designed to detect aliased pixels in regions with bidirectional flow as the CSF flow. In this method, the trend of the flow movement through the ROI during the whole cardiac cycle is determined by the sign of the mean flow within the ROI. The aliased pixels in every frame are identified by choosing the pixels with values higher than $0.2 \times \mathrm{V}_{\text {enc }}$ or smaller than $-0.2 \times \mathrm{V}_{\text {enc }}$ depending on the trend of the motion flow (if the trend is negative the considered aliased pixels are those with a value higher than $0.2 \times \mathrm{V}_{\text {enc }}$ [namely smaller than $\left.1.80 \times \mathrm{V}_{\text {enc }}\right]$ and if it is positive, those with a value smaller than $-0.2 \times \mathrm{V}_{\text {enc }}$ [namely higher than $1.80 \times \mathrm{V}_{\text {enc }}$ ) $($ Figure $3.12 \mathrm{a})$.

The second method allows detecting aliased pixels in regions with unidirectional flow as the vascular structures. To achieve this, every pixel is analyzed and the aliased pixels are detected if they comply with the following condition:

$$
\left(\left(V_{\text {profile }} \times V_{\text {pixel }}\right)<0\right) \&\left(\left|V_{\text {pixel }}\right|>V_{\text {enc }} \times 0.2\right)
$$




\section{Chapter 3: Methods}

where $\mathrm{V}_{\text {profile }}$ represents the mean velocity of the pixel along the whole sequence (Figure 3.12b).

After detecting the aliased pixels, the velocity value is corrected using the following equation [82]:

$$
V=\left(2 \times V_{\text {enc }}\right)-\left|V_{\text {aliasedpixel }}\right| \times\left(-\frac{\left|V_{\text {aliasedpixel }}\right|}{V_{\text {aliasedpixel }}}\right)
$$

where $V_{\text {aliasedpixel }}$ represents the velocity value measured in the aliased pixel.
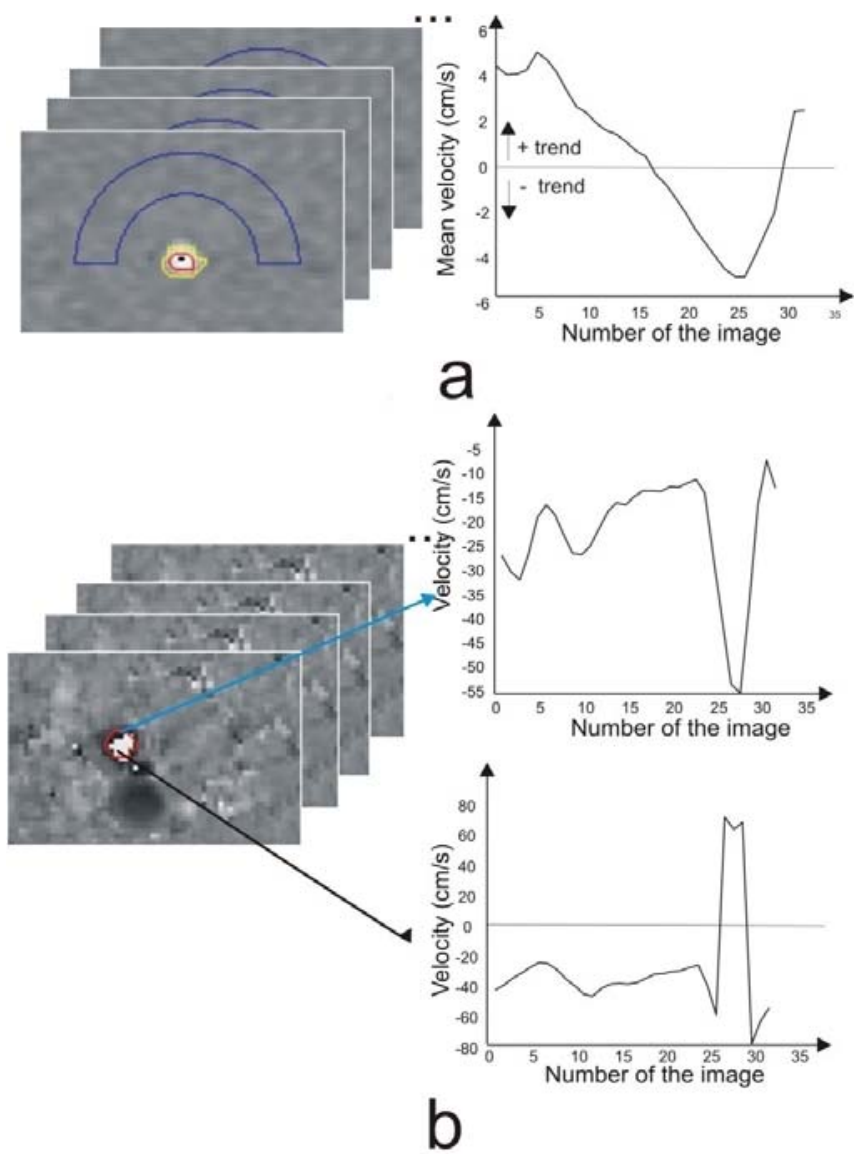

Figure 3.12 Detection of aliased pixels. a) In bidirectional flows the aliased pixels are detected analyzing the trend of the flow through the ROI during the whole cardiac cycle. b) In unidirectional flows, the velocity of each pixel along all sequence is analyzed. The blue arrow represents the velocity profile of a pixel without aliasing and the black line shows the velocity profile of an aliased pixel. 


\section{Chapter 3: Methods}

So, the aliased pixels are automatically detected and corrected, if necessary, throughout the whole sequence. This process is automatically applied without the user intervention. A 3D visualization of the movement of the CSF through the aqueduct allows a visual analysis of the aliasing correction. Figure 3.13 shows a PC frame before and after the aliasing correction.

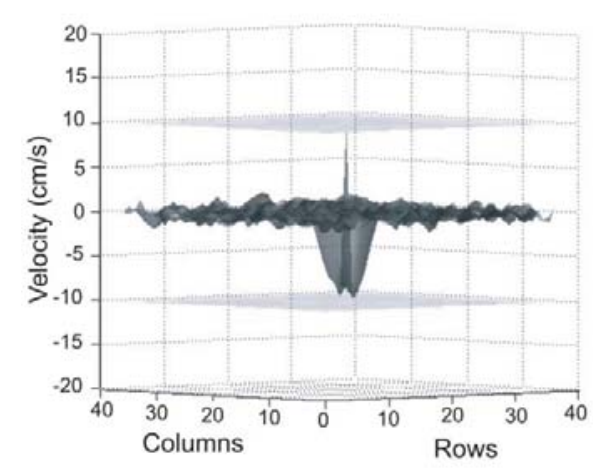

a

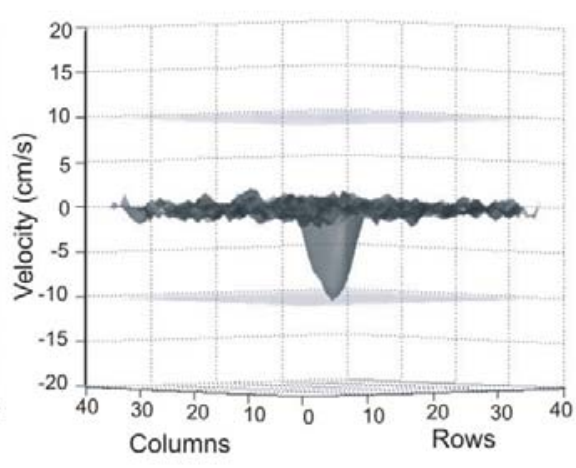

b

Figure 3.13 a) Frame with presence of pixels with aliasing. b) Same frame after applying an aliasing correction. The velocity encoding value for this acquisition was $10 \mathrm{~cm} / \mathrm{s}$.

\subsection{Background Correction}

Flow studies are prone to systematic errors caused by imperfect suppression of eddy currents or brain motion [92;93]. The main source of error is the null background offset due to long term eddy currents.

To correct the residual systematic errors, an average value of offset per frame is measured in background baseline regions where brain motion is minimal or nearly absent during the cardiac cycle in order to subtract this value from the apparent velocities in the ROI $[9 ; 62 ; 92-94]$. As data filtering is not introduced in the reconstruction of the phase maps by the manufacturer's software, at least in 


\section{Chapter 3: Methods}

the equipments used in this thesis, a background correction method must be implemented.

Depending on the position slice and the anatomic distribution on the image of the structures to analyze, the background region is selected by means of two methods.

The first one allows to automatically define the background region. A half moon region is automatically selected surrounding the upper part of the ROI, where the half moon region inner radius equals $3 * \mathrm{R}_{\mathrm{ROI}}$ and the outer radius equals to inner radius plus $2 \mathrm{~mm}$, being $\mathrm{R}_{\mathrm{ROI}}$ an hypothetical $\mathrm{ROI}$ radius calculated as half the diameter of the ROI in the horizontal direction (Figure 3.14). This method was designed to correct the measurements of isolated region as the cerebral aqueduct.

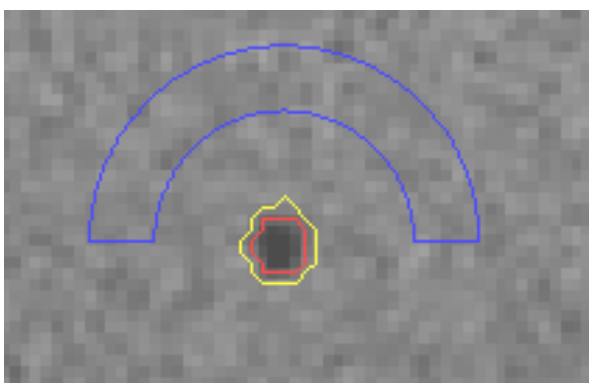

a

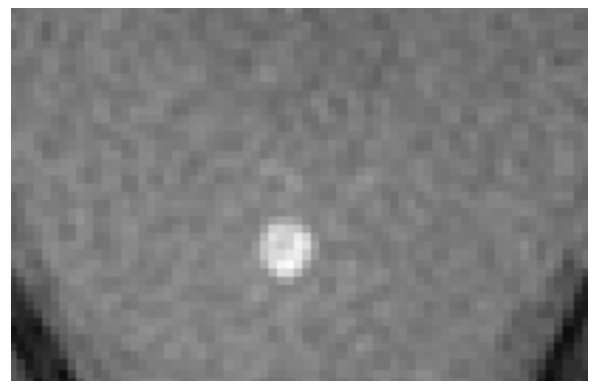

b

Figure 3.14 Automatic background correction. a) Velocity map of the aqueduct of Sylvius. The blue halfmoon is the background region where the inner radius equals $3^{*} R_{R O I}$ and the outer radius equals to inner radius plus $2 \mathrm{~mm}$, being $R_{R O I}$ an hypothetical ROI radius calculated as half the diameter of the yellow ROI in the horizontal direction. b) Modulus image.

For the second method, the observer selects a point in the soft tissues. A circular ROI will then be formed with $42 \mathrm{~mm}^{2}$ area using that selected point as its centre. This semiautomatic method is used to correct measurements obtained from regions where exists influence of close structures. For this reason the user chooses the region that will be used to do the correction (Figure 3.15). 


\section{Chapter 3: Methods}

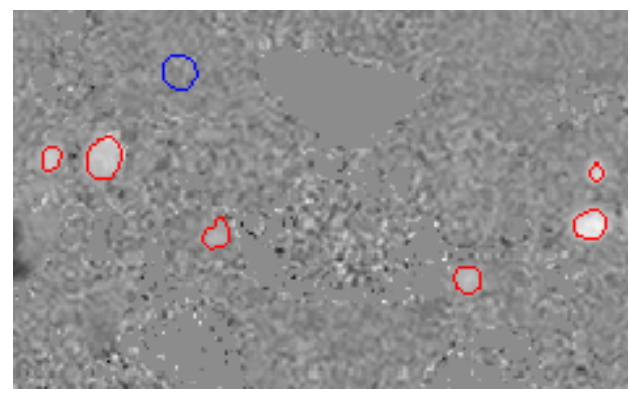

a

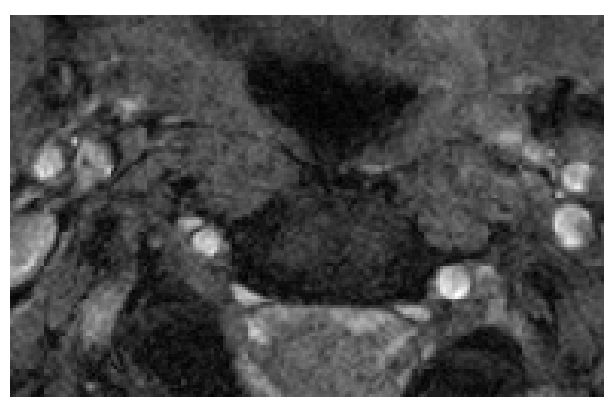

b

Figure 3.15 Semiautomatic background correction. a) Velocity map of vascular flow at level C2C3. The red ROIs are the different arteries and the blue region is the region considered for the background correction. b) Modulus image.

\subsection{PC-MRI Acquisition Protocols}

The PC-MR images sequences analyzed with the developed methods were acquired using four different MR acquisition protocols.

\section{- Protocol 1:}

A PC sequence in an oblique-transversal plane perpendicular to the aqueduct of Sylvius at its midpoint was obtained using a 1.5 Teslas unit (Gyroscan Intera MR scanner, Philips Medical Systems, Best, The Netherlands) (Figure 3.16).

Main image parameters included a gradient echo sequence with a fixed velocity encoding $\left(\mathrm{V}_{\text {enc }}\right)$ of $20 \mathrm{~cm} / \mathrm{s}$, field of view (FOV) of $160 \times 160 \mathrm{~mm}, 3 \mathrm{~mm}$ slice thickness, matrix size of $256 \times 256$, yielding an image resolution of $0.62 \times 0.62$ $\times 3 \mathrm{~mm}$ per pixel. $\mathrm{TR}=53 \mathrm{~ms}, \mathrm{TE}=11 \mathrm{~ms}, \mathrm{NSA}=2$, flip angle $=15^{\circ}$ and 23 frames per cardiac cycle with use of peripheral pulse retrospective gating. Velocities in craniocaudal direction are encoded with negative values. 


\section{Chapter 3: Methods}

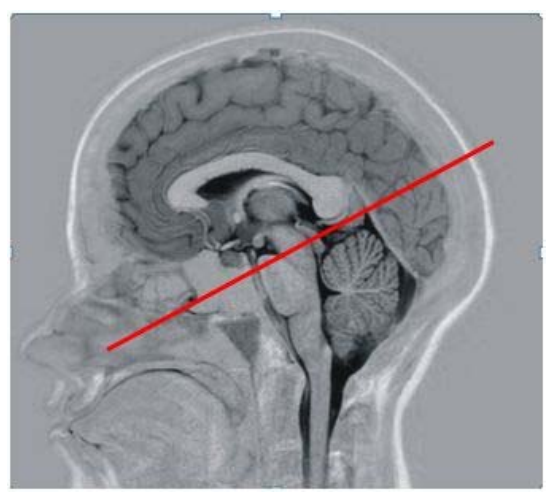

Figure 3.16 Sagittal slice of a T1 weighted turbo inversion recovery sequence used to determine flow acquisition level for the cerebral aqueduct.

\section{- Protocol 2:}

Three PC sequences were obtained: perpendicular to the flow direction on mid-sagittal planes at the aqueduct of Sylvius, C2C3 subarachnoid spaces (SAS) and pontine cistern level (Figure 3.17) using a 3 Teslas MR unit (Signa HDx General Electric Healthcare, WI, USA).

Images were acquired using retrospectively gated cine phase-contrast pulse sequences with the following parameters: FOV $=140 \times 140 \mathrm{~mm}$, matrix size $=256$ $\times 256$, slice thickness $=5 \mathrm{~mm}$, yielding an image resolution of $0.54 \times 0.54 \times 5 \mathrm{~mm}$ per pixel, $\mathrm{TR}=12 \mathrm{~ms}, \mathrm{TE}=7 \mathrm{~ms}$, flip angle $=30^{\circ} . \mathrm{V}_{\text {enc }}$ value was set to $10 \mathrm{~cm} / \mathrm{s}$ at the aqueduct level, $5 \mathrm{~cm} / \mathrm{s}$ at the pontine cistern level and $5 \mathrm{~cm} / \mathrm{s}$ at the $\mathrm{C} 2 \mathrm{C} 3$ SAS level and 32 images were equally distributed throughout the cardiac cycle. Velocities in craniocaudal direction are encoded with positive values. 


\section{Chapter 3: Methods}

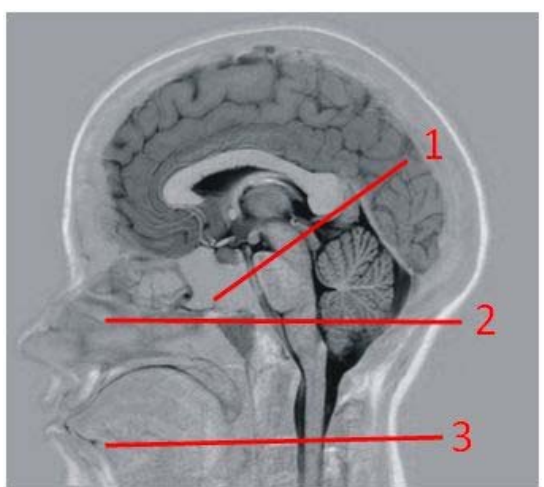

Figure 3.17 Sagittal slice of a T1 weighted turbo inversion recovery sequence used to determine flow acquisition level for the cerebral aqueduct (1), lower pontine cistern (2) and C2C3 space (3).

\section{- Protocol 3:}

PC sequences in an oblique-transversal plane perpendicular to the aqueduct of Sylvius at its midpoint were obtained using a 1.5 Tesla unit (Gyroscan Intera MR scanner, Philips Medical Systems, Best, The Netherlands) and 3.0 Teslas unit (Intera Achieva, Philips Medical Systems, Best, The Netherlands) (Figure 3.16).

Main image parameters were the same for both MR equipments. The sequence was a gradient echo with a fixed $\mathrm{V}_{\text {enc }}$ of $15 \mathrm{~cm} / \mathrm{s}, \mathrm{FOV}=170 \mathrm{~mm}, 5 \mathrm{~mm}$ slice thickness, matrix size $=512 \times 512$, yielding an image resolution of $0.33 \times 0.33$ $\times 5 \mathrm{~mm}$ per pixel, $\mathrm{TR}=18 \mathrm{~ms}, \mathrm{TE}=10 \mathrm{~ms}$, flip angle $=15^{\circ}$, and 27 frames per cardiac cycle with the use of a peripheral pulse retrospective gating. Velocities in craniocaudal direction are encoded with negative values.

\section{- Protocol 4:}

Four PC sequences were obtained using a 3.0 Teslas unit (Intera Achieva, Philips Medical Systems, Best, The Netherlands). The first sequence was acquired in an oblique-transversal plane perpendicular to the aqueduct of Sylvius with $\mathrm{V}_{\text {enc }}=$ $15 \mathrm{~cm} / \mathrm{s}$; two sequences were acquired axial at the level of C2C3 with $\mathrm{V}_{\text {enc }}=7 \mathrm{~cm} / \mathrm{s}$ 


\section{Chapter 3: Methods}

for subarachnoid CSF flow (Figure 3.18a) and $V_{\text {enc }}=80 \mathrm{~cm} / \mathrm{s}$ for vascular flow in the internal carotid, vertebral arteries and jugular veins (Figure 3.18b); and the last sequence was acquired in a plane localized to intersect the superior sagittal sinus (SSS) and the straight sinus (STS) with $\mathrm{V}_{\text {enc }}=80 \mathrm{~cm} / \mathrm{s}$; above the confluence of the sinuses (Figure 3.18c). Main image parameters included FOV $=170 \mathrm{~mm}$, $5 \mathrm{~mm}$ slice thickness, matrix size $=512 \times 512$, yielding an image resolution of $0.33 \times$ $0.33 \times 5 \mathrm{~mm}$ per pixel, $\mathrm{TR}=16 \mathrm{~ms}, \mathrm{TE}=8 \mathrm{~ms}$, flip angle $=10^{\circ}$, and 25 frames per cardiac cycle with use of peripheral pulse retrospective gating. Velocities in craniocaudal direction are encoded with negative values.

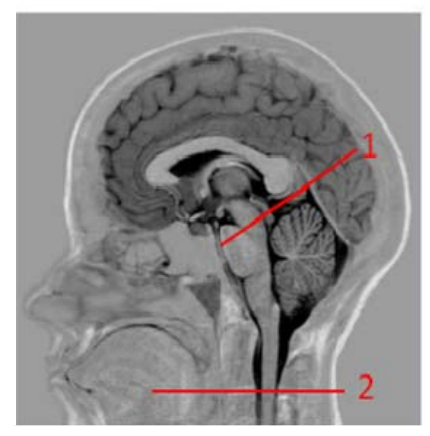

a

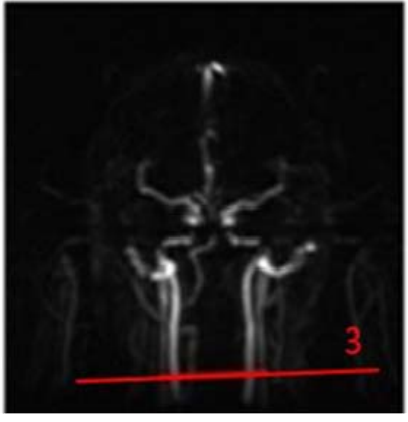

b

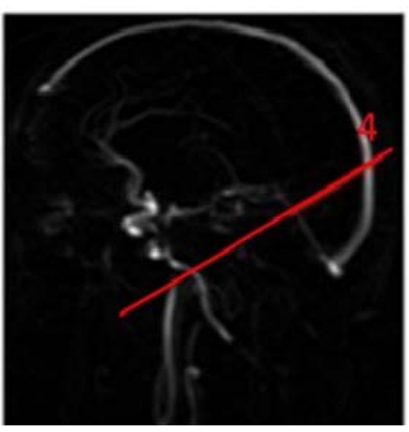

C

Figure 3.18 a) Sagittal slice of a T1 weighted turbo inversion recovery sequence used to determine flow acquisition level for the cerebral aqueduct (1) and C2C3 space (2). b) Fast coronal angiography used to determine the acquisition level for the internal carotid, vertebral arteries and jugular veins (3). c) Fast sagittal angiography to determine the acquisition level for the straight and superior sagittal sinuses.

\subsection{Quantitative Analysis}

Amplitude and temporal parameters were quantified in healthy subjects and NPH patients. Reproducible normality parameters were calculated considering the influence of age, gender, circadian cycle and MR field strength. 


\subsubsection{Velocity Amplitude Parameters}

- Maximum velocity (cm/s), moving both craniocaudally and caudocranially

- Mean velocity $(\mathrm{cm} / \mathrm{s})$ obtained as the mean of the absolute velocities measured along all the cardiac cycle.

\subsubsection{Flow Amplitude Parameters}

The flow rate $(\mathrm{ml} / \mathrm{min})$ was obtained as the product of the ROI area $\left(\mathrm{cm}^{2}\right)$ by the mean velocity $(\mathrm{cm} / \mathrm{s})$ within the region to analyze. Five parameters were calculated:

- Maximum craniocaudal and caudocranial flow.

- Mean absolute flow $(\mathrm{ml} / \mathrm{min})$, computed as the mean of the absolute flow measured along all the cardiac cycle.

- Mean flow amplitude ( $\mathrm{ml} / \mathrm{min})$, extracted from the flow curve as the difference between maximum and minimum flow.

- $\quad$ Stroke volume $(\mu \mathrm{l} /$ cycle), defined as the mean volume of CSF passing through the aqueduct during both systole and diastole (obtained integrating the area under the flow waveform)

- At the aqueduct of Sylvius, an estimation of the supratentorial CSF production $(\mathrm{ml} / \mathrm{min})$ was calculated as the difference between the volume of craniocaudal and caudocranial flow displaced by cardiac cycle.

\subsubsection{Flow Temporal Parameters}

All temporal parameters are expressed as percentages of the cardiac cycle (Figure 3.19).

- The craniocaudal and caudocranial flow onset,

- Craniocaudal flow duration

- Duration from R-wave to maximum craniocaudal and caudocranial flow. 


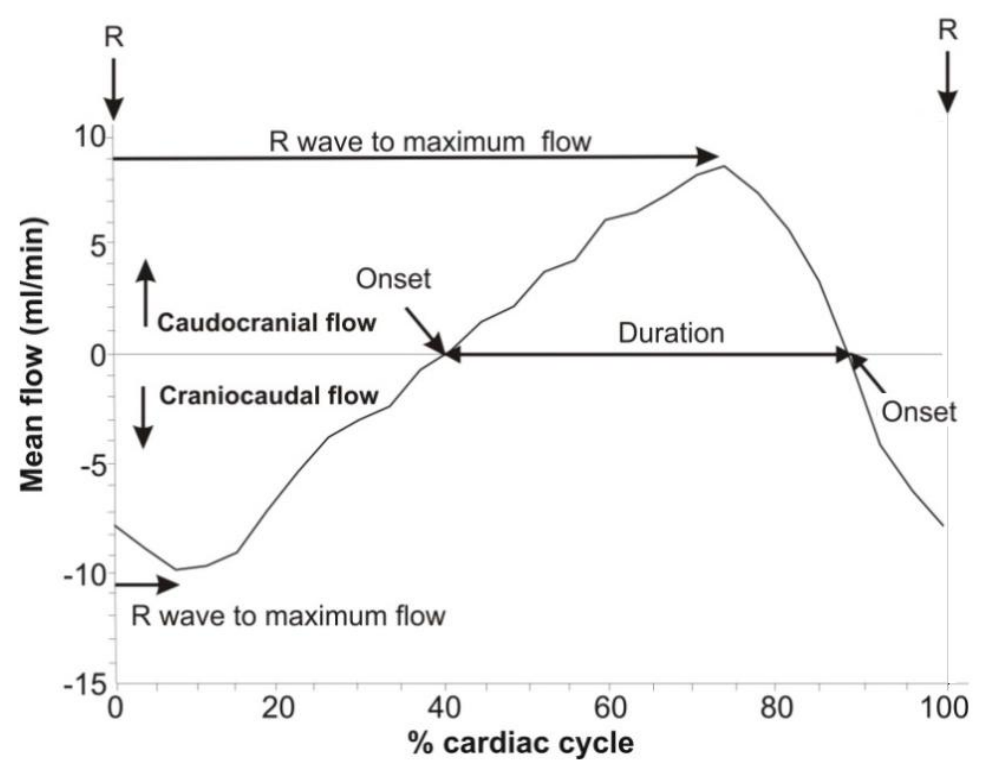

Figure 3.19 CSF waveform obtained from a healthy volunteer at the aqueduct of Sylvius. The positive values represent caudocranial flow. The first register is synchronized with the $R$-wave. The craniocaudal and caudocranial flow onset, the duration of the craniocaudal flow and the duration from $R$-wave to maximum craniocaudal and caudocranial flow are expressed as a percentage of the cardiac cycle.

\subsubsection{Intracranial Dynamic}

An overall evaluation of the intracranial dynamic is possible by means of quantification of various amplitude and temporal parameters from different vascular structures and CSF spaces. These parameters reflect the state of the intracranial dynamic.

In a first study of the intracranial fluids, the internal carotid arteries (ICA), vertebral arteries (VA), aqueduct of Sylvius (AS), C2C3 space and jugular veins (JV) were included. Amplitude parameters were measured in all the regions: mean flow and mean flow amplitude. The supratentorial CSF production was 


\section{Chapter 3: Methods}

estimated at the aqueduct. The ratio of aqueductal to cervical subarachnoid stroke volume was calculated as a measure of the distribution of CSF flow between the ventricular and subarachnoid spaces. The percentage of cardiac cycle between the different flow waveforms respect to the systolic peak allows to establish the temporal relationships of the craniospinal fluid (Figure 3.20).

The $\mathrm{T} 1$ and $\mathrm{T} 2$ percentages of cardiac cycle were defined taking into account the vascular anatomy. The vertebral arteries are close to the spinal CSF flow; they course through the cervical until cervical level $\mathrm{C} 1$ and form the basilar artery before getting into the brain. On the other hand the carotid arteries are the main arteries that supply blood to the brain (Figure 2.6). A better estimation of the pulsatibility within the craniospinal axis is reflected.

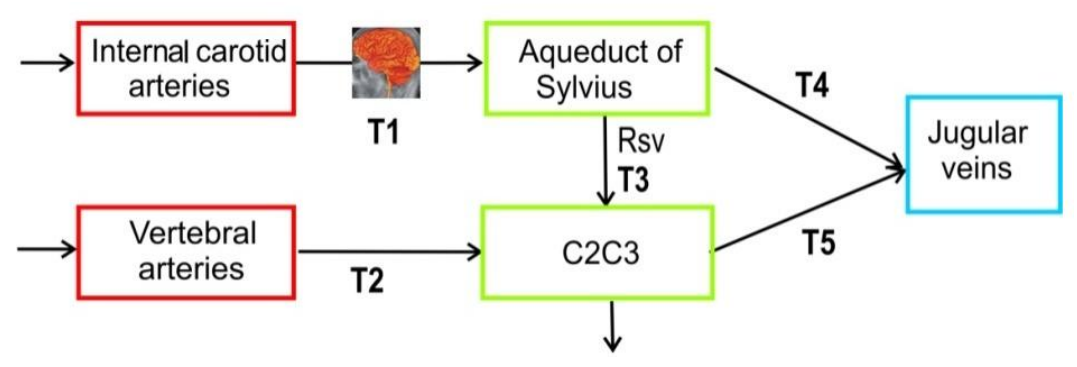

Figure 3.20 Model of temporal and amplitude relationships. Rsv: ratio of stroke volume. T1-T5: time between systolic peaks of the related flow waveforms.

This study was limited due to the difficulty to acquire adequate images to measure the jugular flow. This inconvenient can be attributed to the variation of the diameter and low rigidity of its walls. For this reason, the study was re-stated and a second one was proposed, where rigid venous structures as the straight and superior sagittal sinuses were analyzed.

The arterial flow input to the brain was considered as the sum of flows in the ICA and VA. The displacements of flow volume that occur as consequence of the cerebral expansion were analyzed in the aqueduct of Sylvius, spinal space C2C3, straight sinus (STS), and superior sagittal sinus (SSS) (Figure 3.21). This 


\section{Chapter 3: Methods}

study included temporal and amplitude parameters that allow to have a detailed estimation of the cerebral dynamics.

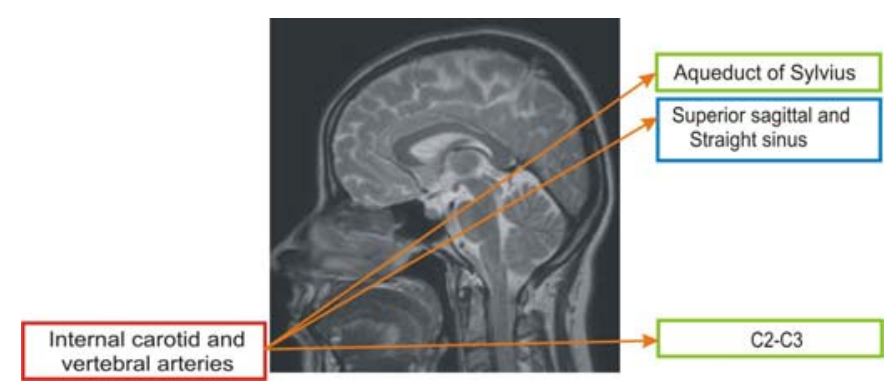

Figure 3.21 Model of temporal and amplitude relationships.

The following parameters were calculated in each one of the regions:

- Mean flow reflects the mean caudal during all the cardiac cycle.

- Systolic volume is the increment of flow volume that occurs during the systole. This value represents the degree to which the arterial tree and brain expand in systole above the mean flow (obtained integrating the area under the flow waveform) (Figure 3.22).

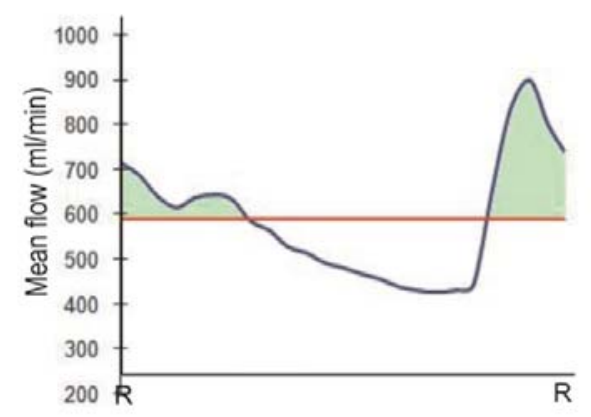

a

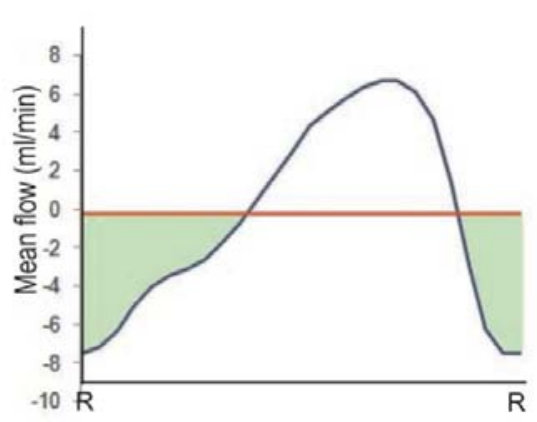

b

Figure 3.22 Mean flow waveforms obtained from a) the ICA and VA and b) the Aqueduct of Sylvius. The horizontal lines represent the mean flow across the entire heartbeat $(R-R)$. The green area is the increment of flow volume during the systole. 


\section{Chapter 3: Methods}

- The pulsatility of the fluids was quantified using the pulsatility index (PI) derived by subtracting the peak diastolic flow from the peak systolic flow and dividing by the mean flow $[95 ; 96]$.

$$
P I=\frac{P F_{\text {systolic }}-P F_{\text {diastolic }}}{\text { Mean flow }}
$$

- Amplitude pressure gradient was derived of changes of the velocity using the equations of Navier-Stokes for incompressible fluid (flow with constant density and null divergence of velocity equal cero) in a rigid tube [47;97]. With this method the absolute pressure variations over the cardiac cycle in the flow and therefore on the wall are measured. The Navier-Stokes equations describe how the velocity, pressure, temperature, and density of a moving fluid are related. The equation describing an incompressible flow is:

$$
\begin{gathered}
\nabla P=-\delta\left(\frac{\partial v}{\partial t}+v \cdot \nabla v\right)+\mu \cdot \nabla^{2} v \\
v \cdot \nabla v=0
\end{gathered}
$$

where $\delta$ the fluid density, $\mu$ is the fluid viscosity and $v$ and $P$ are the velocity vector and pressure, respectively. The first and the second terms on the right-hand side represent the transient (pulsatile) and convective accelerations (related to velocity changes with a change in position), respectively. The third term is the viscous term, which is the momentum loss due to viscous effects. For CSF, $\delta=1.0007 \mathrm{~g} / \mathrm{cm}^{3}$, and $\mu=1.1 \mathrm{cP}$; for blood, $\delta=1.0007 \mathrm{~g} / \mathrm{cm}^{3}$, and $\mu=4.3 \mathrm{cP}$.

- Cerebral compliance is the ability of the brain to adapt to changes in volume inside the cranium in order to reduce changes in pressure. A brain is described as compliant if a large change in ventricular volume results in a small change in intracranial pressure. The arterio-cerebral compliance was estimated by means of two compliance indexes (CI) measured in 
respect to arterial volume input. These indexes were obtained by subtracting the aqueductal or cervical systolic flow volume from the arterial systolic volume and dividing by the aqueductal or cervical systolic volume [56].

$$
C I=\frac{S V_{\text {arterial }}-S V_{\text {region }}}{S V_{\text {region }}}
$$

Where, $S V_{\text {region }}$ is the systolic flow volume in the aqueduct of Sylvius or C2C3 space.

The supratentorial CSF production was estimated at the aqueduct. The ratio of aqueductal to cervical subarachnoid stroke volume was calculated as a measure of the distribution of CSF flow between the ventricular and subarachnoid spaces.

The delays between the systolic arterial peak and each one of the systolic peaks from the different flow waveforms are calculated in percentages of cardiac cycle. This permits to describe the distribution of the pulsatility of the fluids along the craniospinal axis.

\subsection{Statistical Analysis}

The purpose of a statistical analysis is to investigate causality, variability, and in particular to draw a conclusion on the effect of changes in the values of predictors or independent variables or dependent variables on response. The Statistical Package for the Social Sciences SPSS 13 (SPSS, Inc., Chicago, IL, USA) and MATLAB R7 (The MathWorks Inc., Natick, MA, USA) were used to perform the statistical analysis. The statistical procedures applied in this thesis are briefly explained next.

\subsubsection{One-Way Analysis of Variance}

Analysis of variance (ANOVA) is a statistical technique used for comparing the means of groups of measurement data with a normal distribution. One-way 


\section{Chapter 3: Methods}

ANOVA, also called single factor ANOVA, analyses two or more independent groups on the dependent variable. The $p$-value answers the null hypothesis $\left(\mathrm{H}_{0}\right)$ tested by one-way ANOVA: two or more populations means are equal. The $p$-value is determined from the F-statistic.

Variation is the sum of the squares of the deviations between a value and the mean of the values. ANOVA measures two sources of variation in the data:

- Variation between groups: for each data value the difference between its group mean and the overall mean from data set is obtained.

- Variation within group: for each data value the difference between that value and the mean of its group is calculated.

The F-statistic is the ratio of the between groups variance and the within group variance. These variances are obtained by dividing the variation by the degrees of freedom (df). The between group $\mathrm{df}(\mathrm{B})$ is one less than the number of groups. The within group $\mathrm{df}(\mathrm{W})$ is the sum of the individual df's of each group.

The $\mathrm{F}$ test statistic has an $\mathrm{F}$ distribution with $\mathrm{df}(\mathrm{B})$ numerator and $\mathrm{df}(\mathrm{W})$ denominator. The $p$-value is the area to the right of the test statistic. If the variance caused by the interaction between the samples is much larger when compared to the variance that appears within each group, then it is because the means are not the same.

The results of a one-way ANOVA can be considered reliable as long as the following assumptions are met:

- Observations are independent.

- Variances on the dependent variable are equal across groups.

- The dependent variable is normally distributed for each group.

Multiple comparisons tests allow to analyze the reasons that made ANOVA reject the null hypothesis. These tests are globally known as a posteriori or posthoc tests. The Newman-Keuls test is one of these kinds of tests. The result of the test is a series of pairs of groups, the means in each pair being considered significantly different by the test at a chosen significance level. 


\subsubsection{Bland and Altman Plot}

The Bland and Altman plot [98] is a graphical method that allows to compare two measurements techniques. The differences between the two techniques are plotted against the averages of the two techniques. The obtained plot allows investigating the agreement between the methods and any possible relationship between the measurement error and the true value. If the differences are normally distributed, $95 \%$ of differences will lay between the limits defined for the mean data \pm 1.96 times the standard deviation.

\subsubsection{Intraclass Correlation Coefficient}

The intraclass correlation coefficient (ICC) is a measure of correlation, consistency or conformity for a data set when it has multiple groups. The calculation is based on the ANOVA model and measures the variability in the means relative to the total variability.

The ICC is large when there is little variation within the groups compared to variations among group means, where groups consist of replicate measurements. A small ICC occurs when within-group variation is large compared with betweengroup variability, indicating that some unknown variable has introduced nonrandom effects in the different groups. The maximum value of the ICC is 1 , and the minimum value is theoretically 0 .

The Fleiss scale was used to interpret the level of agreement that reflects the ICC values. An ICC value $>0.90$ is very good, $0.71-0.90$ is good, $0.51-0.70$ is acceptable, $0.31-0.50$ is insufficient and $<0.30$ is poor [99].

\subsubsection{Coefficient of Variation}

The coefficient of variation (CV) is a normalized measure of dispersion of a probability distribution. It is defined as the standard deviation (SD) of a data set, divided by the mean of the same data set multiplied by 100 . 


$$
C V=\frac{S D}{\text { Mean }} \times 100
$$

\subsubsection{Percent Error}

Percent error expresses the magnitude of the error (or deviation) between two measurements. The percent error is determined when the true value is compared to the measured value according to the equation below:

$$
\% \text { error }=\frac{\mid \text { Value }_{\text {measured }}-\text { Value }_{\text {true }} \mid}{\text { Value }_{\text {true }}} \times 100
$$




\section{Chapter 4}

\section{Results}

\subsection{Threshold Method}

Twenty one healthy subjects (10 men and 11 women) with a mean age of $40.8 \pm 18.7$ years (range 3-70) were examined using the acquisition protocol 1.

\subsubsection{Reproducibility and Comparison with other Methods}

Interobservers' measurement variations were evaluated as the most important way to analyze the reproducibility of the proposed method. To evaluate the interobservers' measurement variations, two observers made independent analysis with the developed method and a manual method in every patient. In the manual method the observer selects, between the modulus or phase images, the image with the highest contrast between CSF and mesencephalon. Next, the user marks two points: the first one will be the centre of the ROI and the second will determine its radius. Finally, this circular ROI is copied to all frames of the phase series. The stroke volume and mean flow were calculated at the aqueduct of Sylvius.

The agreement of the measurement methods was investigated using the ICC, standard deviation and ANOVA test.

ANOVA test and Bland and Altman method were used to compare the values obtained with background correction and no correction. The two described background corrections in the previous chapter were used in order to analyze which correction introduces more variability in the measurements. Null hypothesis that the obtained measurements are equal was verified using a one-way test, and $p$ values smaller than 0.05 were considered significant. 
The measurements carried out by two observers using the manual method showed much higher interobservers variability than the measurements carried out by the same observers using the developed method. The mean flow, stroke volume, standard deviation, ICCs and p-value for both methods are presented in Table 4.1 and Table 4.2. The ICCs indicate that the reproducibility was significantly better with the developed method than with the manual one.

\begin{tabular}{|c|c|c|c|c|}
\hline $\begin{array}{l}\text { Stroke volume } \\
\qquad(\mu \mathrm{l} / \text { cycle })\end{array}$ & $\begin{array}{l}\text { Mean (SD) } \\
\text { Observer } 1\end{array}$ & $\begin{array}{l}\text { Mean(SD) } \\
\text { Observer } 2\end{array}$ & ICC & $p$ \\
\hline C. Half moon & $39.19(20.13)$ & $39.19(20.13)$ & $1.00(-1.00,1.00)$ & 1.00 \\
\hline C. Midbrain & $38.19(18.55)$ & $38.25(18.53)$ & $1.00(-0.99,1.00)$ & 0.99 \\
\hline No correction & $40.83(20.09)$ & $40.83(20.09)$ & $1.00(-1.00,1.00)$ & 1.00 \\
\hline $\begin{array}{l}\text { Mean flow } \\
(\mathrm{ml} / \mathrm{min})\end{array}$ & & & & \\
\hline C. Half moon & $3.81(2.17)$ & $3.81(2.17)$ & $1.00(-1.00,1.00)$ & 1.00 \\
\hline C. Midbrain & $3.71(2.00)$ & $3.71(2.01)$ & $1.00(-0.99,1.00)$ & 0.99 \\
\hline No correction & $3.96(2.17)$ & $3.96(2.17)$ & $1.00(-1.00,1.00)$ & 1.00 \\
\hline
\end{tabular}

Table 4.1 Measurements obtained at the aqueduct of Sylvius. Interobserver's variability using the developed method to define the ROI and applying different background corrections. ICC: intraclass correlation. p-value ANOVA test. 


\begin{tabular}{|c|c|c|c|c|}
\hline $\begin{array}{l}\text { Stroke volume } \\
\qquad(\mu \mathrm{l} / \text { cycle })\end{array}$ & $\begin{array}{l}\text { Mean (SD) } \\
\text { Observer } 1\end{array}$ & $\begin{array}{l}\text { Mean (SD) } \\
\text { Observer } 2\end{array}$ & ICC & $p$ \\
\hline C. Half moon & $27.56(16,53)$ & $21.90(9.66)$ & $0.46(-0.078,0.736)$ & 0.072 \\
\hline C. Midbrain & $28.03(17.18)$ & $22.08(9.43)$ & $0.45(-0.063,0.728)$ & 0.068 \\
\hline No correction & 30.49 (18.17) & $23.66(9.71)$ & $0.40(-0.019,0.702)$ & 0.055 \\
\hline $\begin{array}{l}\text { Mean flow } \\
\text { (ml/min) }\end{array}$ & & & & \\
\hline C. Half moon & $1.47(0.78)$ & $1.51(0.59)$ & $0.65(-0.320,0.846)$ & 0.750 \\
\hline C. Midbrain & $2.08(1,54)$ & $1.54(0.59)$ & $0.43(-0.042,0.716)$ & 0.054 \\
\hline No correction & $1.63(0.87)$ & $1.65(0.62)$ & $0.60(-0.237,0.819)$ & 0.905 \\
\hline
\end{tabular}

Table 4.2 Measurements obtained at the aqueduct of Sylvius. Interobserver's variability using the manual method to define the ROI and applying different background corrections. ICC: intraclass correlation. p-value ANOVA test.

\subsubsection{Estimation of the Background and Aliasing Correction}

Table 4.1 and Table 4.2 summarize the obtained measurements by two observers using the developed and manual method with and without background correction.

The Bland and Altman plots (Figure 4.1 and Figure 4.2) reflect the interobserver's variability of the measurements using the developed method with half moon (automatic) and midbrain (semiautomatic) correction. 

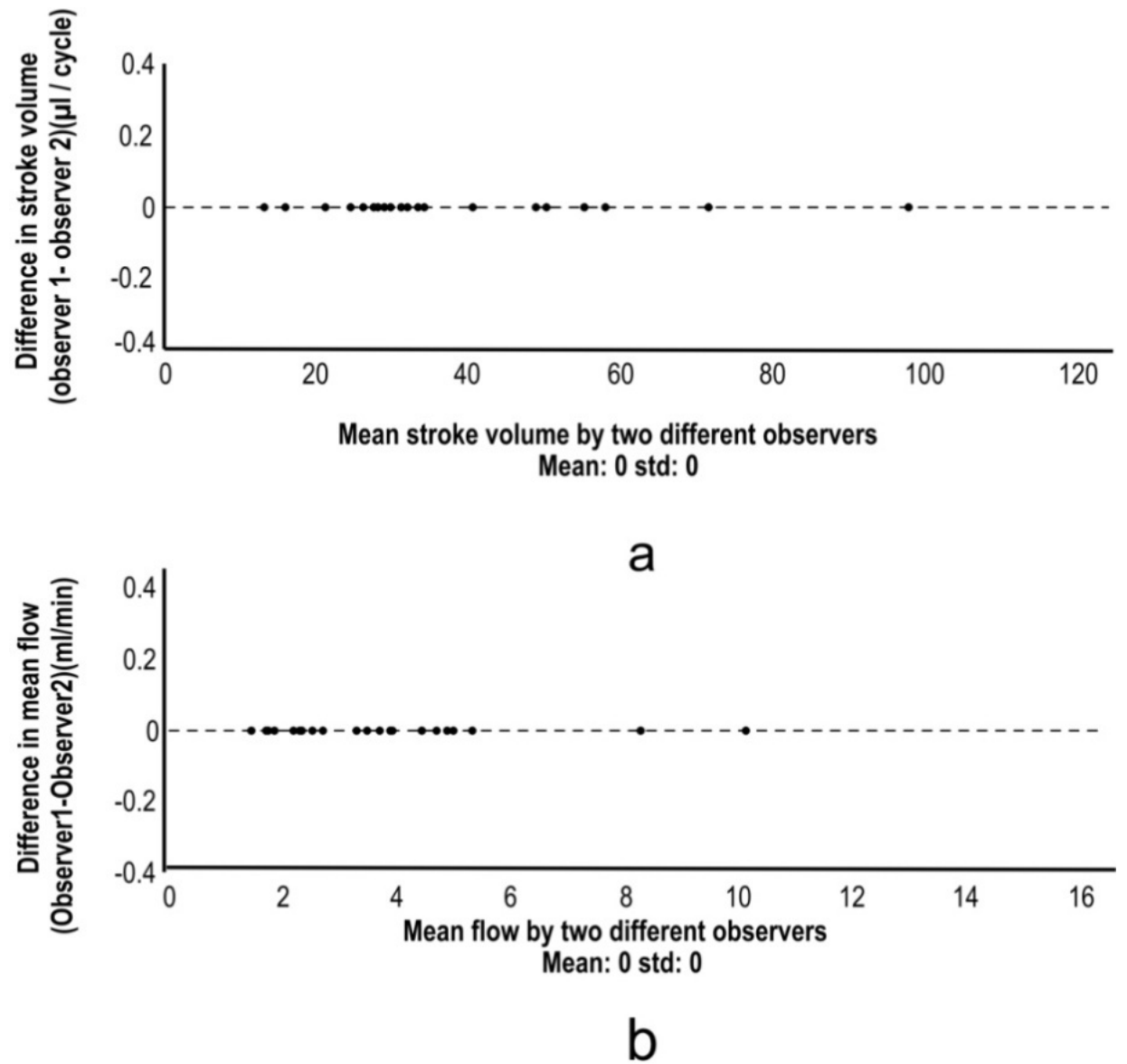

Figure 4.1 Plot of the difference between measurements carried out by two observers using the half moon background correction at the aqueduct of Sylvius. Dotted line: $95 \%$ confidence interval for agreement. a) Measurements of mean stroke volume. b) Measurements of mean flow. 

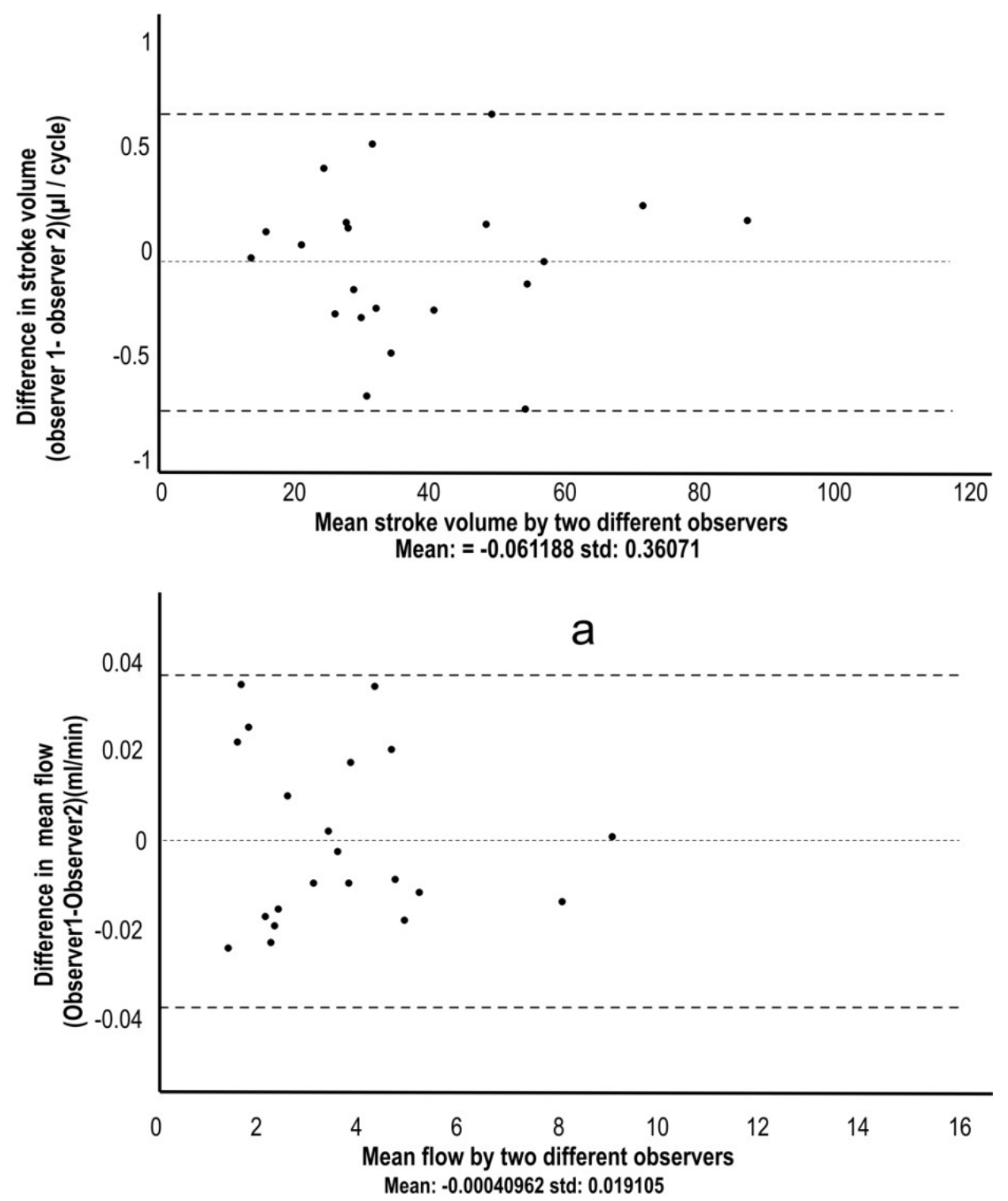

b

Figure 4.2 Plot of the difference between measurements carried out by two observers using the midbrain correction at the aqueduct of Sylvius. Dotted line: 95\% confidence interval for agreement. a) Measurements of mean stroke volume. b) Measurements of mean flow. 


\section{Chapter 4: Results}

There was considerable agreement between the two observers using the developed method for every flow and stroke registry, with half moon, midbrain offset correction and no correction. However, the method presented more dispersion when midbrain correction was used. The ANOVA test did not show statistical differences among the two background corrections and without correction for neither stroke volume $(\mathrm{p}=0.90)$ nor mean flow $(\mathrm{p}=0.92)$.

It was not necessary to apply an aliasing correction to any of the normal subjects' data of the present study due to the low flow velocities compared to the chosen Venc although all subjects' data was completely analyzed.

\subsection{K-means Method}

Twenty six volunteers (10 women and 16 men) with an age of $29 \pm 7$ (mean \pm standard deviation) years (range: 22-37) were explored using the acquisition protocol 2. In 16 of those 26 volunteers the CSF flow at the pontine cistern level was studied.

Five parameters were calculated in the aqueduct of Sylvius, C2C3 SAS, and in the pontine cistern: the net mean flow $(\mathrm{ml} / \mathrm{min})$; the stroke volume ( $\mu \mathrm{l} /$ cycle); the maximum craniocaudal and caudocranial velocity $(\mathrm{cm} / \mathrm{s})$ and the ratio of aqueductal to cervical subarachnoid stroke volume representing the distribution of CSF flow between the ventricular and subarachnoid spaces.

The segmentation of the three regions was carried out using the method developed in this work and the method described in [82]. A comparison of the mean stroke volume and the segmented area was performed.

\subsubsection{Reproducibility and Comparison with other Methods}

The reproducibility of the developed CSF segmentation algorithm was determined varying the initially selected seed point. One observer carried out ten times the segmentation of the cervical CSF images in 5 subjects (Figure 4.3); stroke volume and area values were computed for each subject. The variability of the obtained measurements was assessed calculating the percentage of the $\mathrm{CV}$ defined 


\section{Chapter 4: Results}

as the ratio of standard deviation of each group of measurements to the mean value of the group.

ANOVA test, ICC and Bland and Altman method were used in order to compare the obtained measurements with the two segmentation methods. Null hypothesis were verified using a one-way test and $p$-values smaller than 0.05 were considered significant. The ratio between aqueductal and cervical stroke volumes was analyzed using a linear regression analysis for which the equation and the regression coefficient were extracted.

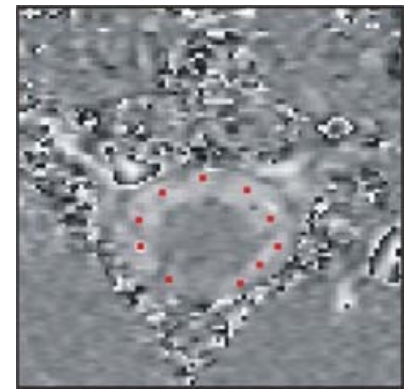

Figure 4.3 Initial seed points set to evaluate the reproducibility of the CSF segmentation algorithm. This process was repeated in five subjects.

The mean CV values obtained for the cervical CSF area and stroke volume in healthy subjects demonstrate that the reproducibility of the developed method is not affected by the initially selected seed point. Mean CV $(3 \pm 1.5 \%$ and $4 \pm 2.4$ $\%$ ) were obtained for the mean stroke volume and area, respectively.

The method presented here and the method described in [82] did not show statistical differences in the aqueduct for neither stroke volume $(\mathrm{p}=0.70)$ nor area $(p=0.26)$. In the same way, measurements obtained at the $\mathrm{C} 2 \mathrm{C} 3$ level did not show statistical differences for neither stroke volume $(p=0.14)$ nor area $(p=$ 0.64). Nevertheless, the measurements obtained in the pontine cistern presented statistical differences for both the stroke volume $(p=0.02)$ and the area $(p=$ $0.00)$.

ICC values showed a very good level of agreement $(>0.90)$ in the aqueduct. At $\mathrm{C} 2 \mathrm{C} 3$ level, results showed a very good level of agreement for the stroke volume 
$(\mathrm{ICC}=0.96)$ and a good level of agreement for the area $(\mathrm{ICC}=0.89)$. At the pontine cistern level, the results showed a good level of agreement (0.71 - 0.90). Stroke volumes, areas, standard deviations, ICCs and levels of significance are presented in Table 4.3.

\begin{tabular}{|c|c|c|c|c|c|c|}
\hline \multirow{2}{*}{ Region } & \multirow{2}{*}{ Parameters } & \multirow{2}{*}{$\mathbf{n}$} & \multicolumn{2}{|c|}{ Mean (SD) } & \multirow{2}{*}{ ICC } & \multirow{2}{*}{$p$} \\
\hline & & & Method 1 & Method 2 & & \\
\hline \multirow{2}{*}{ Aqueduct } & $\begin{array}{l}\text { Stroke volume } \\
(\mu \mathrm{l} / \text { cycle })\end{array}$ & \multirow{2}{*}{26} & $33(20)$ & $36(21)$ & $\begin{array}{c}0.99 \\
(0.98-0.99)\end{array}$ & 0.70 \\
\hline & $\begin{array}{l}\text { Area } \\
\left(\mathrm{mm}^{2}\right)\end{array}$ & & $3.8(1.6)$ & $3.3(1.6)$ & $\begin{array}{c}0.94 \\
(0.86-0.97)\end{array}$ & 0.26 \\
\hline \multirow{2}{*}{$\mathrm{C} 2 \mathrm{C} 3$} & $\begin{array}{l}\text { Stroke volume } \\
(\mu \mathrm{l} / \text { cycle })\end{array}$ & \multirow{2}{*}{26} & 383 (133) & $438(132)$ & $\begin{array}{c}0.96 \\
(0.90-0.98)\end{array}$ & 0.14 \\
\hline & $\begin{array}{l}\text { Area } \\
\left(\mathrm{mm}^{2}\right)\end{array}$ & & $93(31)$ & $88(46)$ & $\begin{array}{c}0.89 \\
(0.77-0.96)\end{array}$ & 0.64 \\
\hline \multirow{2}{*}{$\begin{array}{l}\text { Pontine } \\
\text { cistern }\end{array}$} & $\begin{array}{l}\text { Stroke volume } \\
(\mu \mathrm{l} / \text { cycle })\end{array}$ & \multirow{2}{*}{16} & $148(75)$ & $224(91)$ & $\begin{array}{c}0.82 \\
(0.50-0.93)\end{array}$ & 0.02 \\
\hline & $\begin{array}{l}\text { Area } \\
\left(\mathrm{mm}^{2}\right)\end{array}$ & & $108(41)$ & $71(31)$ & $\begin{array}{c}0.78 \\
(0.37 .0 .92)\end{array}$ & 0.00 \\
\hline
\end{tabular}

Table 4.3 Comparison of obtained measurements with the new method (method 1) and the method described in [82] (method 2) in the aqueduct, C2C3 level and in the pontine cistern. n: number of studies, SD: standard deviation, ICC: intra-class correlation. p-value from ANOVA test.

In the Bland and Altman plots depicted in Figure 4.4, it can be observed that the differences between the 2 methods for stroke volume measurements in the three regions lie within the agreement limits; only one point is set outside this range at the aqueduct and two points at $\mathrm{C} 2 \mathrm{C} 3$ level.

For the sixteen subjects, the pontine cistern was properly segmented with the developed method without any inclusion of additional region: the basilar artery present in the measurement plane was clearly removed (Figure 4.5a). Nevertheless, the operator had to manually exclude the fourth ventricle area from the segmented 
region in 5 subjects where the flow behavior in this area was very close to the one observed in the pontine cistern (Figure 4.5b).
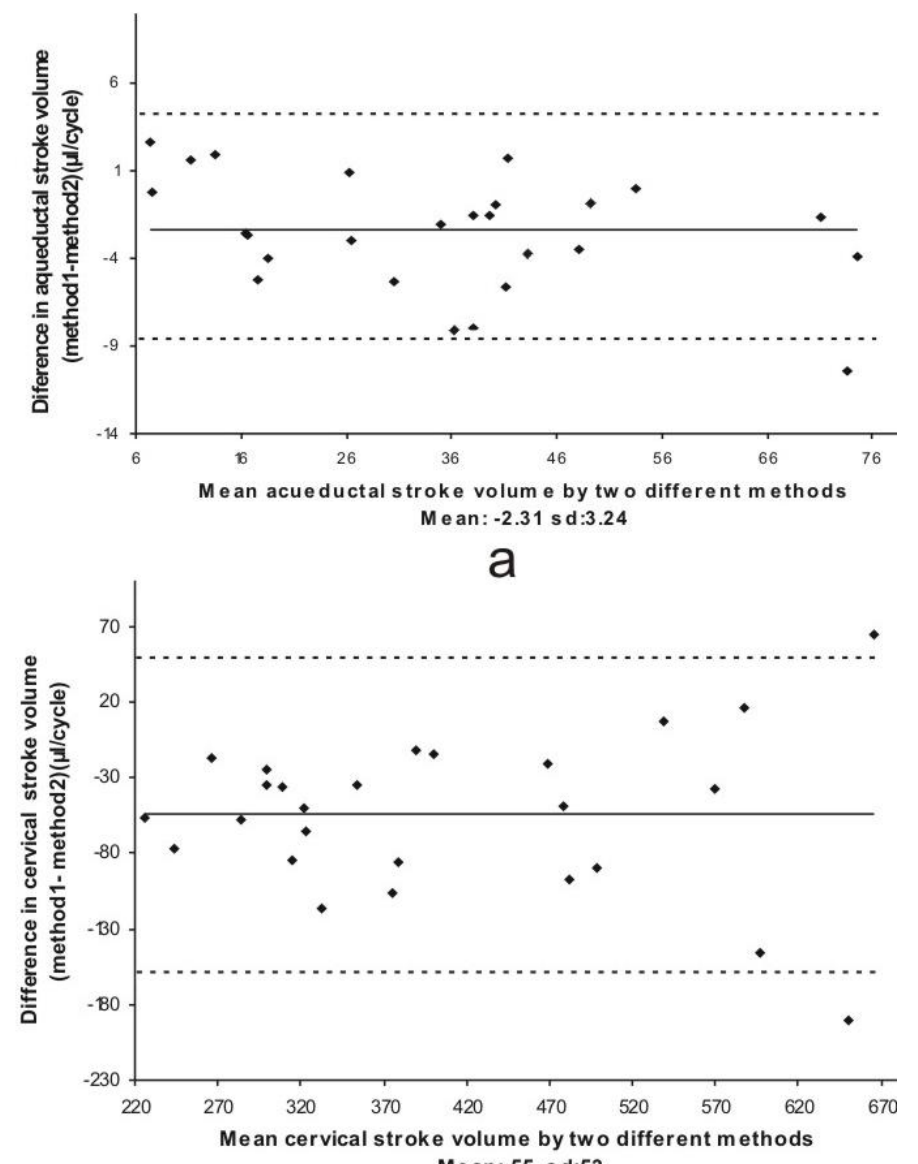

Mean:-55 sd:53

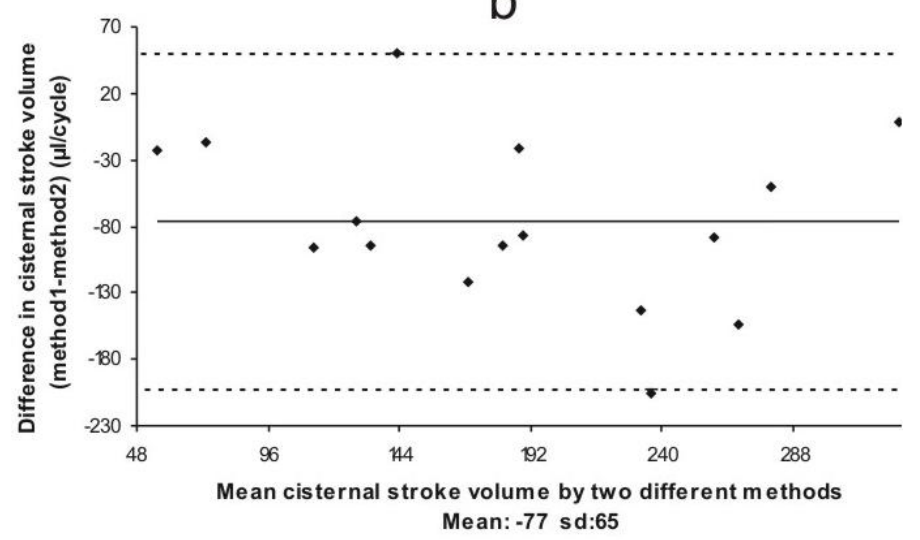

Figure 4.4 Bland and Altman plots of the difference between the measurements obtained with the method presented in this work (method 1) and the method described in [82] (method 2). Dotted line: $\quad 95 \%$ confidence interval for agreement.

Measurements of aqueductal stroke volume.

Measurements cervical stroke volume.

(c) Measurements of stroke volume at the pontine cistern level. 
Agreement limits are drawn with dotted line.

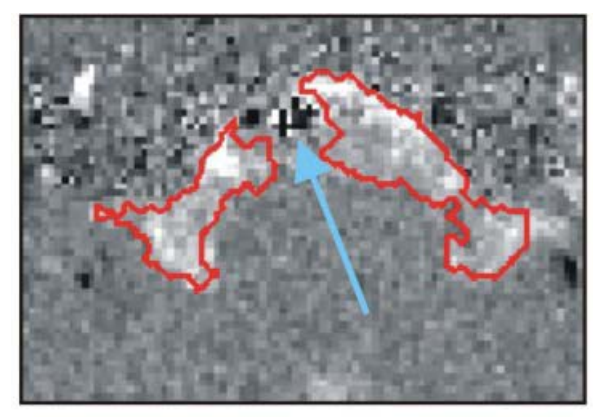

a

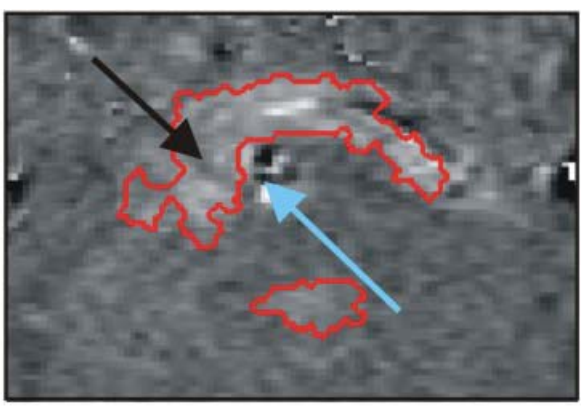

b

Figure 4.5 (a) Automatically segmented pontine cistern. (b) The observer intervention was needed in order to correctly segment the pontine cistern. The observer had to select the region to be analyzed (black arrow selects the considered region among the two areas); the little region corresponds to CSF outflow through the fourth ventricle, blue arrow indicates the basilar artery exclusion from the segmented region.

\subsubsection{Estimation of the Background and Aliasing Correction}

ANOVA test, ICC and Bland and Altman method were used in order to investigate the agreement of the obtained values at the $\mathrm{C} 2 \mathrm{C} 3$ level with and without background correction.

The one-way ANOVA test did not show statistical differences neither for the mean stroke volume $(p=0.32)$ nor for the CSF net mean flow $(p=0.69)$ calculated with and without background correction at the cervical level using the new method.

The stroke volume and the net mean flow measured using background correction were respectively $383 \pm 133 \mu \mathrm{l} /$ cycle and $-0.17 \pm 7 \mathrm{ml} / \mathrm{min}$. The obtained measurements without background correction were $421 \pm 146 \mu \mathrm{l} /$ cycle for the stroke volume and $-1.01 \pm 7 \mathrm{ml} / \mathrm{min}$ for the mean flow. The ICC value 
provided a very good level of agreement $(\mathrm{ICC}>0.90)$. These results are summarized in the Table 4.4 .

\begin{tabular}{|c|c|c|c|c|c|}
\hline \multicolumn{2}{|c|}{ Parameters } & Mean (SD) & Range & ICC & $p$ \\
\hline \multirow{2}{*}{$\begin{array}{l}\text { Stroke volume } \\
\qquad(\mu \mathrm{l} / \text { cycle })\end{array}$} & C. Background & $383(133)$ & 198,697 & \multirow{2}{*}{$\begin{array}{c}0.99 \\
(0.96-0.99)\end{array}$} & \multirow{2}{*}{0.32} \\
\hline & No correction & $421(146)$ & 208,771 & & \\
\hline \multirow{2}{*}{$\begin{array}{l}\text { Net Mean flow } \\
\qquad(\mathrm{ml} / \mathrm{min})\end{array}$} & C. Background & $-0.17(7)$ & $-15,13$ & \multirow{2}{*}{$\begin{array}{c}0.98 \\
(0.97-0.99)\end{array}$} & \multirow{2}{*}{0.69} \\
\hline & No correction & $-1.01(7)$ & $-18,12$ & & \\
\hline
\end{tabular}

Table 4.4 Measurements obtained with and without background correction at C2C3 level. SD: standard deviation, ICC: intra-class correlation. p-value from ANOVA test. Negative net mean flow represents flow in caudocranial direction.

Figure 4.6 plots measurement's variability calculated with and without background correction using the Bland-Altman method. Though the agreement between the two measurements was very good, the stroke volume plot presented more scattering than the net mean flow.

\subsubsection{Measurements}

Mean stroke volumes, net mean flows, maximum craniocaudal and caudocranial velocity and areas calculated at the aqueduct, $\mathrm{C} 2 \mathrm{C} 3$ and pontine cistern levels are showed in Table 4.5. An example of CSF flow waveforms for a healthy subject at the three levels can be observed in Figure 4.7 . 


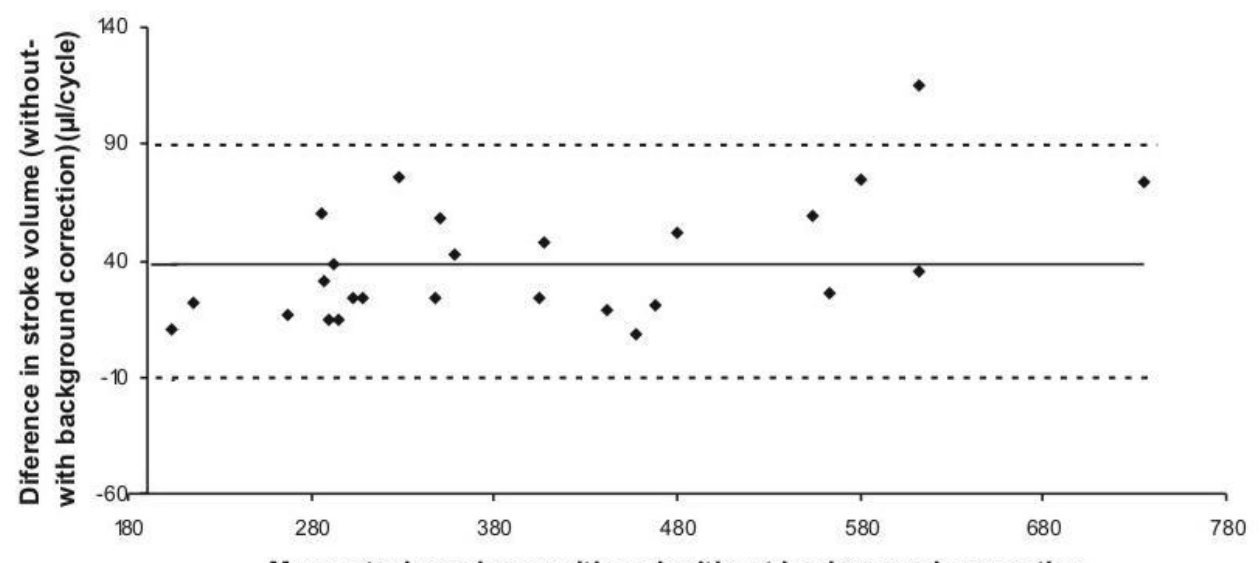

Mean stroke volume $w$ ith and $w$ ithout background correction

Mean: 39 sd: 26

a

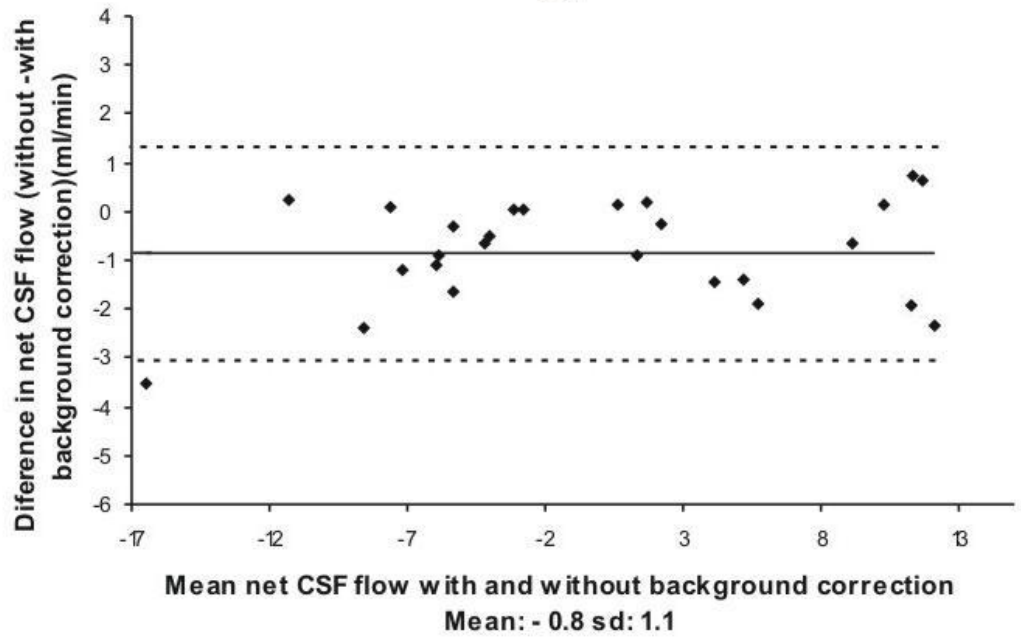

b

Figure 4.6 Bland and Altman plots of the difference between the measurements obtained with and without background correction at C2C3 level. Dotted line: 95\% confidence interval for agreement. a) Stroke volume measurements, b) net mean flow measurements. 


\begin{tabular}{|l|c|c|c|c|c|c|}
\hline \multirow{2}{*}{ Parameters } & \multicolumn{2}{|c|}{ Aqueduct } & \multicolumn{2}{c|}{ C2C3 } & \multicolumn{2}{c|}{ Pontine cistern } \\
\cline { 2 - 7 } & $\begin{array}{c}\text { Mean } \\
\text { (SD) }\end{array}$ & $\begin{array}{c}\text { Range } \\
\text { min, max }\end{array}$ & $\begin{array}{c}\text { Mean } \\
\text { (SD) }\end{array}$ & $\begin{array}{c}\text { Range } \\
\text { min, max }\end{array}$ & $\begin{array}{c}\text { Mean } \\
\text { (SD) }\end{array}$ & $\begin{array}{c}\text { Range } \\
\text { min, max }\end{array}$ \\
\hline $\mathrm{n}$ & \multicolumn{2}{|c|}{26} & \multicolumn{2}{|c|}{26} & \multicolumn{2}{c|}{16} \\
\hline $\begin{array}{l}\text { Stroke volume } \\
(\mu \mathrm{l} / \text { cycle })\end{array}$ & $33(20)$ & 7,73 & $383(133)$ & 208,772 & $148(75)$ & 43,326 \\
\hline $\begin{array}{l}\text { Net mean flow } \\
(\mathrm{ml} / \mathrm{min})\end{array}$ & $1.30(0.9)$ & $-0.4,3.5$ & $-0.17(7)$ & $-15,13$ & $4(5)$ & $-2,15$ \\
\hline $\begin{array}{l}\text { Craniocaudal } \\
\text { velocity }(\mathrm{mm} / \mathrm{s})\end{array}$ & $75(28)$ & 41,146 & $70(20)$ & 38,96 & $32(16)$ & 14,71 \\
\hline $\begin{array}{l}\text { Caudocranial } \\
\text { velocity }(\mathrm{mm} / \mathrm{s})\end{array}$ & $-51(22)$ & $-119,-24$ & $-52(23)$ & $-89,-23$ & $-27(17)$ & $-83,-11$ \\
\hline Area $\left(\mathrm{mm}{ }^{2}\right)$ & $3.8(1.6)$ & 1,8 & $93(31)$ & 41,157 & $108(42)$ & 28,190 \\
\hline
\end{tabular}

Table 4.5 Mean value and standard deviation of CSF flow parameters measured in twenty six volunteers at the aqueduct, C2C3 and pontine cistern levels. The negative net mean flow represent flow in caudocranial direction.

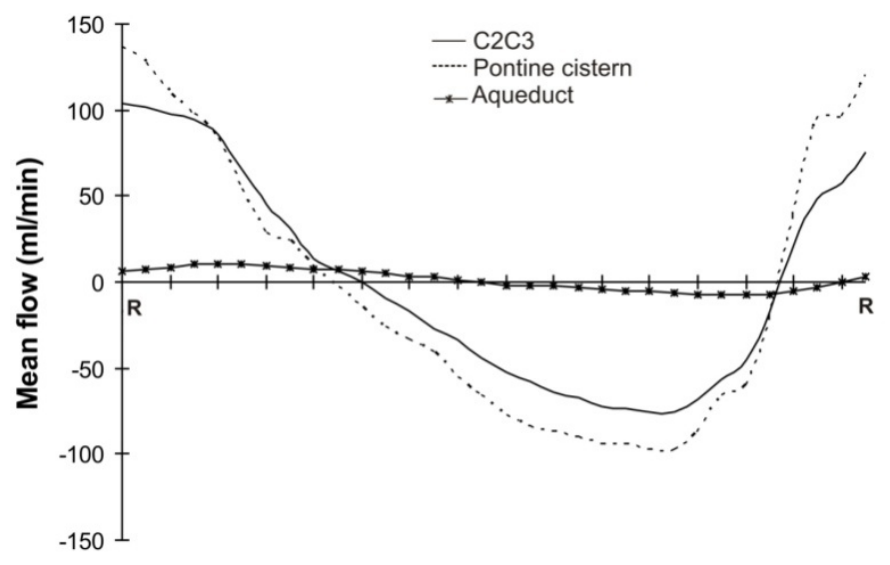

Figure 4.7 Cerebrospinal fluid flow waveforms measured in a healthy subject during a cardiac cycle at C2C3, pontine cistern and aqueduct levels. 
The average ratio of cervical stroke volume to ventricular stroke volume was 8 $\pm 4 \%$ (range $[2 \%-16 \%]$ ). The scatter plot in figure 4.8 shows a poor fit and low correlation between the aqueductal and cervical stroke volumes: aqueductal stroke volume $=0.08 \times \mathrm{C} 2 \mathrm{C} 3$ stroke volume $+1.23, \mathrm{r}^{2}=0.35, p<0.001$.

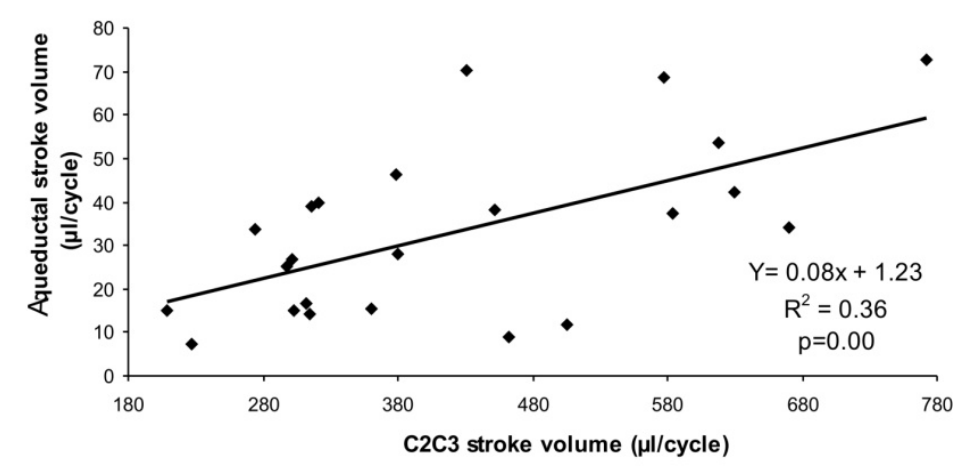

Figure 4.8 Correlation between the mean aqueductal and mean cervical stroke volumes.

Aliased pixels were detected and corrected in: two subjects for aqueductal flow, two subjects for cervical CSF flow and three subjects for pontine cistern flow.

\subsection{Factors that Influence on the PC Quantitative Analysis of CSF}

The study of the behavior of the intracranial fluids is of great relevance in the follow-up of neurological and cerebrovascular pathologies. Adequate postprocessing methods are crucial in this kind of analysis; nonetheless it is also necessary to have knowledge about the different factors that may influence on the measurements obtained in order to set up reproducible reference values.

The influences of the MR field strength, age and gender on the PC quantitative analysis of CSF within the aqueduct of Sylvius were analyzed. 


\subsubsection{Influence of the MR Field Strength and Circadian Rhythm}

\section{Adapted from:}

- N Flórez, D Moratal, J Forner, E Arana, L. Martí-Bonmatí. Influence of the MR field strength on the PC quantitative analysis of cerebrospinal fluid flow within the aqueduct. European Society for Magnetic Resonance in Medicine and Biology -23st Annual ESMRMB Meeting, Warsaw, 2006.

Among many advances in MRI, the increase of the magnetic field strength is perhaps one of the most significant one. High field MRI at 3.0T has rapidly gained acceptance in the MR community for both research and clinical applications in the last years. Many clinical applications for high field MRI that were investigated showed potential benefits over 1.5T [100-103]. The field strength of the magnet influences on the quality of the MR image regarding chemical shift artifacts, the signal to noise ratio (SNR), motion sensitivity and susceptibility artifacts $[101 ; 104]$. The main advantage of very high field MRI is that the signal to noise ratio $(\mathrm{S} / \mathrm{N})$ scales approximately linearly with field strength $\mathrm{B}_{0}$ [105]. This $\mathrm{S} / \mathrm{N}$ improvement is illustrated by figure 4.9, which shows a PC-MRI comparison on a normal volunteer between the field strength of $1.5 \mathrm{~T}$, and 3.0T. All acquisition parameters were identical. Note the improved appearance of the cerebral aqueduct at $3.0 \mathrm{~T}$.

Reliable quantitative analysis of the CSF flow dynamics within the aqueduct of Sylvius is of great aid in the MR evaluation of fluid abnormalities characterization in patients with probable hyperdynamic states [4;32;58]. The normal values of control subjects may also reflect the influence of field strength on signal.

Therefore, it seems quite relevant to study the influence of magnetic field strength on the quantification of the different parameters related to the motion of CSF flow as determined by PC-MRI at the aqueduct of Sylvius. 


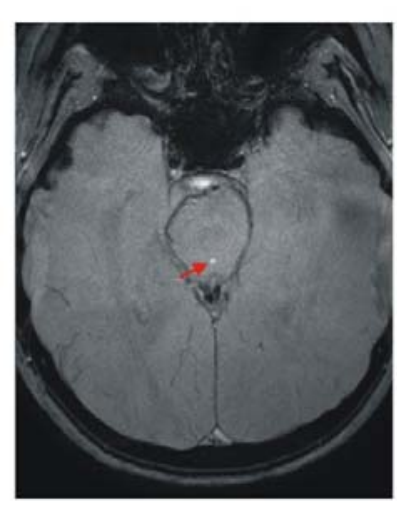

a

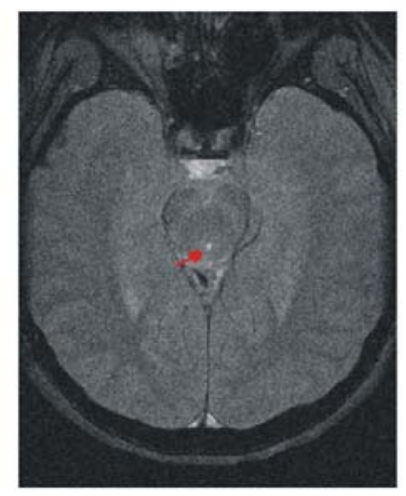

b

Figure 4.9 PC-MRI from a healthy volunteer of 25 years old obtained in a perpendicular plane to the aqueduct of Sylvius (arrow) with a $3.0 \mathrm{~T}$ (a) and $1.5 \mathrm{~T}$ (b) magnetic field strength. $S / N$ is higher on the $3.0 T$ image.

CSF flow PC-MR measurements were obtained from the same subject (healthy woman, 25 years old) with two different MR field strengths machines (1.5 $\mathrm{T}$ and $3.0 \mathrm{~T}$ ) of the same manufacturer (Philips Medical Systems, Best, The Netherlands). Globally, $33 \mathrm{MR}$ studies were carried out on the same subject, 22 in a $1.5 \mathrm{~T}$ unit (Philips Gyroscan Intera) and 11 in a $3.0 \mathrm{~T}$ unit (Philips Intera Achieva) in four different hourly stripes within two months. The Table 4.6 summarizes the distribution of the studies carried out in every MR unit in the different hourly stripes and the mean heart rate (HR) of the subject recorded during the acquisitions. All MR examinations were obtained using the protocol previously described 3 .

The quantitative analysis involved calculation of velocity and flow amplitude parameters. All variables presented a normal distribution (test KolmogorovSmirnov, $p \geq 0.05)$. Afterward, the ANOVA test was used to evaluate:

- The influence of the circadian rhythm on the mean flow. For this the obtained measurements during the different hourly stripes with the $1.5 \mathrm{~T}$ magnetic field strength machine were analyzed. 


\section{Chapter 4: Results}

- The influence of the field strength on the different parameters. For this the obtained measurements during the hourly stripes between the 15:00 16:00 h. and 17:00 -17:30 h. were compared.

- There are significant differences in the mean flow obtained with two different $1.5 \mathrm{~T}$ scanners of the same model and manufacture.

Null hypotheses were verified using a one-way test. All $p$-values smaller than 0.05 were considered significant.

\begin{tabular}{|l|c|c|}
\hline & $\mathbf{1 . 5} \mathbf{~ T}$ & $\mathbf{3 . 0} \mathbf{~ T}$ \\
\hline 9:00 - 9:30 & 4 & \\
HR $($ mean $\pm \mathrm{SD})$ & $(50 \pm 0.5)$ & \\
\hline 15:00 - 16:00 & 8 & 8 \\
$\mathrm{HR}($ mean $\pm \mathrm{SD})$ & $(60 \pm 3)$ & $(53 \pm 1)$ \\
\hline 17:00 - 17:30 & 7 & 3 \\
HR (mean $\pm \mathrm{SD})$ & $(55 \pm 4)$ & $(52 \pm 0.5)$ \\
\hline 19:00 - 20:00 & 3 & \\
HR $($ mean $\pm \mathrm{SD})$ & $(56 \pm 4)$ & \\
\hline TOTAL & $\mathbf{2 2}$ & $\mathbf{1 1}$ \\
\hline
\end{tabular}

Table 4.6 Number of studies carried out in the different hourly stripes and the respective $H R$ of the subject during the acquisitions.

Figure 4.10 shows the mean flow waveforms obtained in the different hourly stripes. The ANOVA test showed significant differences in the mean flow ( $p$ $=0.012$, Table 4.7).

All the curves present similar morphologies; nonetheless in the flow curves obtained in the extreme hourly stripes (9:00 - 9:30 and 19:00 - 20:00), two peaks and one peak were respectively observed at the beginning of the curve. Figure 4.11 graphically shows the Student-Newman-Keuls test results. The mean CSF flow measured at extreme hourly differs from the other hourly stripes. 


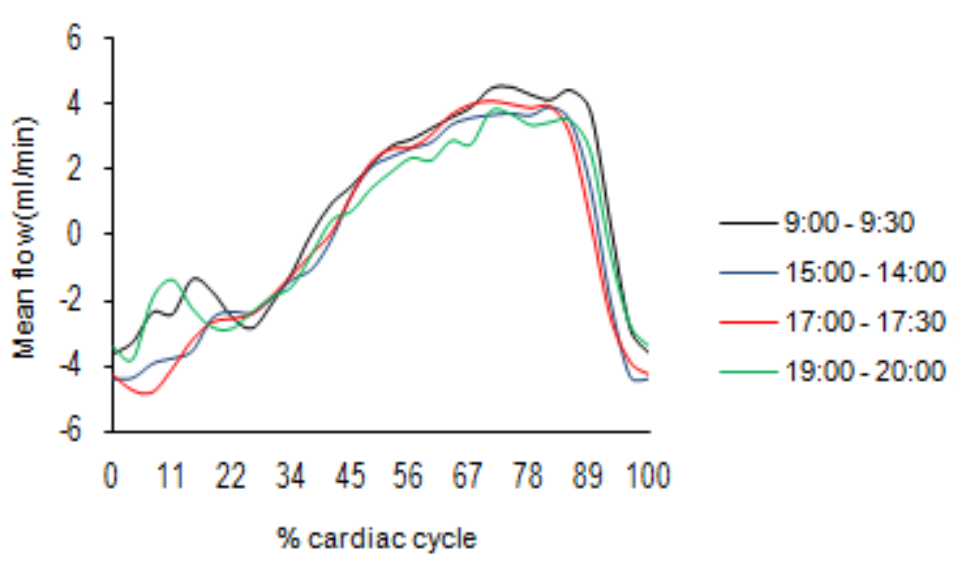

Figure 4.10 Aqueductal CSF flow waveforms obtained from a healthy volunteer of 25 years in different hourly stripes with a 1.5 magnetic field strength machine.

\begin{tabular}{|l|c|c|c|}
\hline \multicolumn{1}{|c|}{ Hourly strip } & n & Mean (SD) & $\boldsymbol{p}$ \\
\hline 9:00 - 9:30 & 4 & $2.61(0.26)$ & \\
15:00 - 16:00 & 8 & $2.84(0.20)$ & \\
h17:00 - 17:30 & 7 & $2.87(0.27)$ & 0.012 \\
19:00 - 20:00 & 3 & $2.34(0.10)$ & \\
\hline
\end{tabular}

Table 4.7 Aqueductal mean CSF flow measured with a $1.5 T$ magnetic field strength machine. $n$ : number of studies. SD: standard deviation. p-value from ANOVA test. 


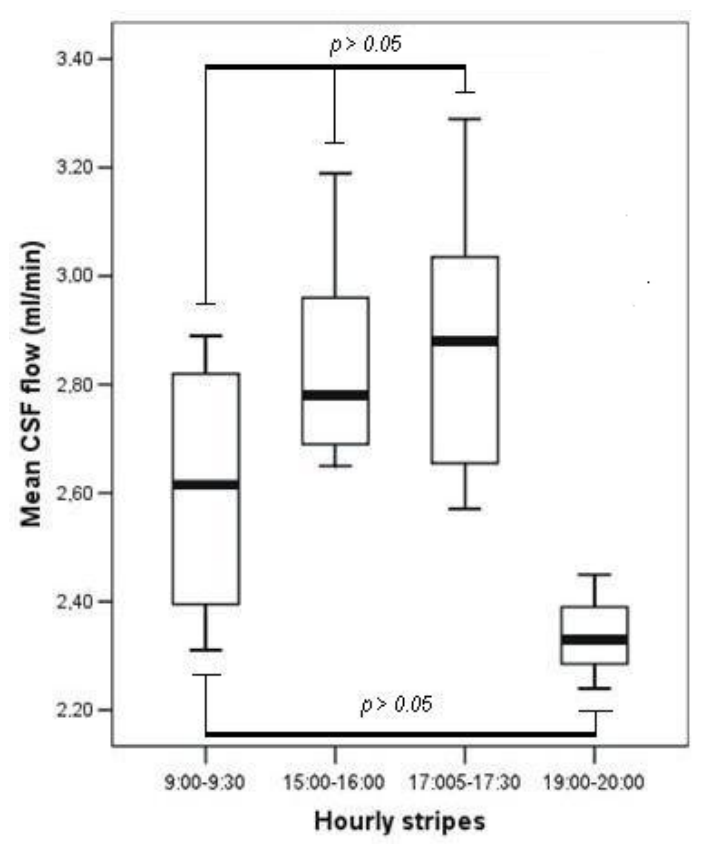

Figure 4.11 Student-Neuwman-Keuls test for mean Aqueductal CSF flow measured in four hourly stripes using a 1.5 T magnetic field strength machine.

Almost all the parameters that characterize the CSF flow were slightly higher when obtained in the $3.0 \mathrm{~T}$ than at the $1.5 \mathrm{~T}$ MR equipments. The ANOVA test showed statistical differences in all parameters to exception in the CSF production $(p=0.155)$ (Table 4.8).

The Figure 4.12 shows the mean flow waveforms obtained from two studies carried out in consecutive days at 16:00 with different $1.5 \mathrm{~T}$ scanners of the same model and manufacture (Philips Gyroscan Intera). The ANOVA test did not show significant differences in the mean flow $(p=0.20)$. 


\begin{tabular}{|c|c|c|c|}
\hline \multicolumn{2}{|l|}{ Parameters } & \multirow{2}{*}{$\frac{\text { Mean (SD) }}{2.84(0.44)}$} & \multirow{3}{*}{$\frac{p}{0.002}$} \\
\hline \multirow{2}{*}{ Maximum craniocaudal velocity $(\mathrm{cm} / \mathrm{s})$} & $1.5 \mathrm{~T}$ & & \\
\hline & $3.0 \mathrm{~T}$ & $3.42(0.38)$ & \\
\hline \multirow{2}{*}{ Maximum caudocranial velocity $(\mathrm{cm} / \mathrm{s})$} & $1.5 \mathrm{~T}$ & $2.58(0.34)$ & \multirow{2}{*}{0.020} \\
\hline & $3.0 \mathrm{~T}$ & $2.90(0.28)$ & \\
\hline \multirow{2}{*}{ Mean flow (ml/min) } & $1.5 \mathrm{~T}$ & $2.85(0.22)$ & \multirow{2}{*}{0.000} \\
\hline & $3.0 \mathrm{~T}$ & $3.41(0.20)$ & \\
\hline \multirow{2}{*}{ Maximum craniocaudal flow $(\mathrm{ml} / \mathrm{min})$} & $1.5 \mathrm{~T}$ & $4.93(0.47)$ & \multirow{2}{*}{0.001} \\
\hline & $3.0 \mathrm{~T}$ & $5.65(0.40)$ & \\
\hline \multirow{2}{*}{ Maximum caudocranial flow $(\mathrm{ml} / \mathrm{min})$} & $1.5 \mathrm{~T}$ & $4.37(0.50)$ & \multirow{2}{*}{0.010} \\
\hline & $3.0 \mathrm{~T}$ & $4.87(0.34)$ & \\
\hline \multirow{2}{*}{ Stroke volume $(\mu \mathrm{l} /$ cycle $)$} & $1.5 \mathrm{~T}$ & $24.87(3.63)$ & \multirow{2}{*}{0.000} \\
\hline & $3.0 \mathrm{~T}$ & $32.17(2.32)$ & \\
\hline \multirow{2}{*}{ CSF production (ml/min) } & $1.5 \mathrm{~T}$ & $-0.20(0.12)$ & \multirow{2}{*}{0.155} \\
\hline & $3.0 \mathrm{~T}$ & $-0.29(0.23)$ & \\
\hline
\end{tabular}

Table 4.8 Velocity and flow amplitude parameters from a healthy volunteer of 25 years measured during the hourly stripes between the 15:00 -16:00 h. and 17:00 17:30 h (15 and 11 measurements obtained with a 1.5T and 3.0T scanner, respectively). Negative CSF production represents flow in craniocaudal direction. SD: standard deviation. p-value from ANOVA test. 


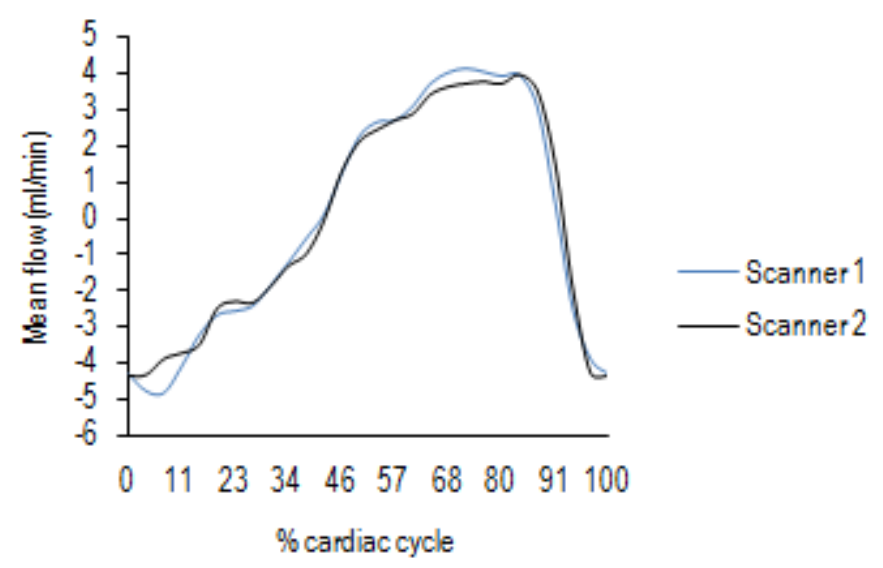

Figure 4.12 Aqueductal CSF flow waveforms from a healthy volunteer obtained in two consecutive days at 16:00 using two different 1.5 T MR scanners.

\subsubsection{Influence of the Age and Gender}

\section{Adapted from:}

- N Flórez, L. Martí-Bonmatí, J Forner, E Arana, D Moratal. Normal values of the cerebrospinal fluid flow dynamics in the Aqueduct of Sylvius by means of an optimized analysis of phase contrast magnetic resonance imaging. Radiología, 51:38-44, 2009.

Both age and gender are variables that must be considered in the analysis of the intracranial dynamic. The aging process damages blood vessels; biomechanical changes can lead to structural breakdowns in the aging arterial wall even when conventional risk factors such as cardiovascular disease and blood pressure are within normal ranges. The brain supports some changes as enlargement of the ventricular system, reduced brain weight and brain volume; these changes are probably caused by the loss of neurons. Throughout aging, the ability of choroid plexus epithelium to produce CSF also undergoes a continual decline [106-108]. 


\section{Chapter 4: Results}

Differences between men and women are constantly remarked; previous studies have evaluated the influence of the gender in different fields [109-111]. The purpose of this study was to obtain references values of the aqueductal CSF flow considering the influence of these two variables in order to provide reliable and reproducible information as diagnostic aid to the neurological evaluation.

The influence of age and gender was analyzed in 42 healthy subjects (16 men and 26 women) with age ranging from 25 to 78 years old $(44 \pm 19$ years, mean \pm standard deviation). They were examined using a $1.5 \mathrm{~T}$ MR scanner (Gyroscan Intera, Philips Medical Systems, Best, The Netherlands) in the same hourly stripe (11:00 to 18:00 hours) to avoid possible circadian variations in the measurements. The PC-MRI sequences were acquired perpendicular to the aqueduct of Sylvius at its midpoint using the acquisition protocol 1. Velocity and flow amplitude parameters were obtained.

The selected subjects did not present neurological disturbers, hydrocephalus neither cerebrovascular illnesses. They had never presented a picture of intracraneal hypertension neither they had suffered cranioencephalic traumatism. All variables presented a normal distribution (test Kolmogorov-Smirnov, $p \geq 0.05$ ). The influence of the gender and the age (categorized as $\leq 25,26-50$, and $>50$ years old) on the measures was evaluated with the one-way ANOVA test. All $p$-values smaller than 0.05 were considered significant.

Neither sex nor age influenced significantly any parameter $(p>0.05)$. Nonetheless both variables presented tendencies. As regard age almost all the parameters decreased while the age increased (Table 4.9); with the gender almost all parameters were higher in women than in men (Table 4.10). 


\begin{tabular}{|c|c|c|c|c|}
\hline Parameters & $\begin{array}{r}\leq 25 \text { years } \\
\text { Mean } \pm \text { SD }\end{array}$ & $\begin{array}{c}26-50 \text { years } \\
\text { Mean } \pm \text { SD } \\
\end{array}$ & $\begin{array}{c}>50 \text { years } \\
\text { Mean } \pm \text { SD }\end{array}$ & \multirow[t]{2}{*}{$p$} \\
\hline $\mathrm{n}$ & 7 & 19 & 16 & \\
\hline $\begin{array}{l}\text { Maximum caudocranial } \\
\text { velocity }(\mathrm{cm} / \mathrm{s})\end{array}$ & $4.57 \pm 1.98$ & $4.09 \pm 1.51$ & $4.04 \pm 0.84$ & 0.67 \\
\hline $\begin{array}{l}\text { Maximum craniocaudal } \\
\text { velocity }(\mathrm{cm} / \mathrm{s})\end{array}$ & $5.14 \pm 1.72$ & $5.59 \pm 1.89$ & $5.19 \pm 1.32$ & 0.72 \\
\hline $\begin{array}{l}\text { Mean velocity } \\
(\mathrm{cm} / \mathrm{s})\end{array}$ & $4.86 \pm 1.80$ & $4.84 \pm 1.53$ & $4.61 \pm 0.98$ & 0.87 \\
\hline $\begin{array}{l}\text { Maximum caudocranial } \\
\text { flow }(\mathrm{ml} / \mathrm{min})\end{array}$ & $12.44 \pm 8.27$ & $8.70 \pm 3.95$ & $8.09 \pm 2.99$ & 0.14 \\
\hline $\begin{array}{l}\text { Maximum craniocaudal } \\
\text { flow }(\mathrm{ml} / \mathrm{min})\end{array}$ & $13.36 \pm 7.11$ & $11.64 \pm 4.68$ & $10.85 \pm 3.97$ & 0.53 \\
\hline $\begin{array}{l}\text { Mean flow } \\
(\mathrm{ml} / \mathrm{min})\end{array}$ & $6.89 \pm 4.20$ & $5.58 \pm 2.54$ & $5.21 \pm 2.03$ & 0.39 \\
\hline $\begin{array}{l}\text { CSF production } \\
(\mathrm{ml} / \mathrm{min})\end{array}$ & $-0.54 \pm 0.42$ & $-0.48 \pm 0.40$ & $-0.39 \pm 0.21$ & 0.59 \\
\hline $\begin{array}{l}\text { Stroke volume } \\
(\mu \mathrm{l} / \text { cycle })\end{array}$ & $44.97 \pm 22.24$ & $41.13 \pm 21.35$ & $35.20 \pm 11.17$ & 0.44 \\
\hline
\end{tabular}

Table 4.9 Influence of the age on the PC quantitative analysis of aqueductal CSF in healthy subjects. n: number of studies. Negative CSF production represents flow in craniocaudal direction. SD: standard deviation. p-value from ANOVA test. 


\begin{tabular}{|c|c|c|c|}
\hline Parameters & $\begin{array}{c}\text { Female } \\
\text { Mean } \pm \mathrm{SD}\end{array}$ & $\begin{array}{c}\text { Male } \\
\text { Mean } \pm \text { SD }\end{array}$ & $\mathbf{p}$ \\
\hline $\mathrm{N}$ & 26 & 16 & \\
\hline Maximum diastolic velocity $(\mathrm{cm} / \mathrm{s})$ & $4.24 \pm 1.44$ & $4.00 \pm 1.26$ & 0.58 \\
\hline Maximum systolic velocity $(\mathrm{cm} / \mathrm{s})$ & $5.52 \pm 1.47$ & $5.10 \pm 1.89$ & 0.42 \\
\hline Mean velocity $(\mathrm{cm} / \mathrm{s})$ & $4.88 \pm 1.32$ & $4.55 \pm 1.45$ & 0.45 \\
\hline Maximum diastolic flow $(\mathrm{ml} / \mathrm{min})$ & $9.53 \pm 5.44$ & $8.38 \pm 3.36$ & 0.45 \\
\hline Maximum systolic floe $(\mathrm{ml} / \mathrm{min})$ & $11.91 \pm 4.98$ & $11.16 \pm 4.75$ & 0.63 \\
\hline Mean flow (ml/min) & $5.85 \pm 2.96$ & $5.34 \pm 2.25$ & 0.55 \\
\hline CSF production $(\mathrm{ml} / \mathrm{min})$ & $-0.43 \pm 0.33$ & $-0.50 \pm 0.36$ & 0.54 \\
\hline Stroke volume $(\mu \mathrm{l} /$ cycle $)$ & $40.46 \pm 18.39$ & $37.97 \pm 18.40$ & 0.67 \\
\hline
\end{tabular}

Table 4.10 Influence of the gender on the PC quantitative analysis of aqueductal CSF in healthy subjects. n: number of studies. Negative CSF production represents flow in craniocaudal direction. SD: standard deviation. p-value from ANOVA test.

\subsubsection{Normality Parameters}

After analyzing the influences of the MR field strength, age and gender on PC-MRI measurements at the cerebral aqueduct, normality parameters which can be used as reference values were established. To achieve this, 36 healthy volunteers were analyzed using the optimized acquisition protocol 3. Velocity and flow amplitude parameters were obtained.

Eighteen of them (15 men and 3 women) with a mean age of $32 \pm 12$ years old were examined in the $1.5 \mathrm{~T}$ unit. The rest (13 men and 5 women), with a mean age of $38 \pm 17$ years old were examined in the 3.0T unit. The MR examinations were carried out in the same hourly stripe (11:00-18:00) to avoid circadian influence. The age did not presented significant differences $(\mathrm{p}=0.07)$. The Table 4.11 shows the normality parameters obtained. 


\begin{tabular}{|l|c|c|}
\hline \multicolumn{1}{|c|}{ Parameters } & $\begin{array}{c}\mathbf{1 . 5} \mathbf{~ T} \\
(\mathbf{m e a n} \pm \mathbf{~ S D})\end{array}$ & $\begin{array}{c}\mathbf{3 . 0} \mathbf{~ T} \\
(\mathbf{m e a n} \pm \mathbf{~ S D})\end{array}$ \\
\hline Maximum caudocranial velocity $(\mathrm{cm} / \mathrm{s})$ & $4.01 \pm 1.15$ & $4.20 \pm 1.79$ \\
\hline Maximum craniocaudal velocity $(\mathrm{cm} / \mathrm{s})$ & $4.51 \pm 1.78$ & $5.05 \pm 1.59$ \\
\hline Mean velocity $(\mathrm{cm} / \mathrm{s})$ & $3.88 \pm 1.60$ & $4.08 \pm 1.44$ \\
\hline Maximum caudocranial flow $(\mathrm{ml} / \mathrm{min})$ & $9.85 \pm 5.61$ & $8.45 \pm 4.16$ \\
\hline Maximum craniocaudal flow $(\mathrm{ml} / \mathrm{min})$ & $9.95 \pm 4.40$ & $10.61 \pm 4.05$ \\
\hline Mean flow (ml/min) & $5.04 \pm 2.59$ & $5.57 \pm 2.60$ \\
\hline CSF production $(\mathrm{ml} / \mathrm{min})$ & $-0.25 \pm 0.22$ & $-0.29 \pm 0.23$ \\
\hline Stroke volume $(\mu \mathrm{l} / \mathrm{cycle})$ & $36.26 \pm 15.09$ & $38.22 \pm 18.01$ \\
\hline
\end{tabular}

Table 4.11 Aqueductal CSF flow normality parameters obtained by optimized PCMRI. Negative CSF production represents flow in craniocaudal direction.

\subsection{Clinical Applications}

\subsubsection{Aqueductal CSF Flow in White Matter Disease and NPH}

\section{Adapted from:}

- N Flórez. L. Martí-Bonmatí. E Arana. J Forner. D Moratal. White Matter Disease does not Interfere with the Phase Contrast MR Imaging Diagnosis of Normal Pressure Hydrocephalus. Submitted to: Magn Reson Mater Phy.

NPH is clinically characterized by the triad of gait disturbance, dementia and urinary incontinence, presented with ventricular dilation and normal CSF pressure at lumbar puncture [112]. The comorbity of the NPH with various disorders as Alzheimer's disease [113], vascular dementia [56;114], cerebrovascular 


\section{Chapter 4: Results}

disease [115] and cerebral white matter lesions [95;116] makes difficult the preoperative selection of patients to be shunted. PC-MRI has described pathophysiologic changes in these patients, pointing to different biomarkers as hyperdynamic aqueductal CSF flow [58;87;117], reduced compliance of the subarachnoid spaces and blood flow alterations $[4 ; 6 ; 48]$.

White matter hyperintense lesions are common neuroimaging findings in elderly people. The casual relationship between white matter lesions and brain status is not clearly established, but they represent most probably the results of small vessel hypoxic ischemic events. These findings are directly related to increasing age and positively correlate with different pathologies such as dementia [118;119] and vascular risk factors [120;121]. These lesions are also prevalent in NPH patients [116;122]. In patients with ventricular dilatation and white matter lesions, it may be difficult to clearly differentiate by imaging findings NPH from isolated small vessels disease with white matter changes associated to volume loss. PC-MRI with flow quantification through the aqueduct of Sylvius is commonly used to diagnose NPH but the effects of hypoxic ischemic abnormalities on the calculated flow parameters have not been clearly defined.

The purpose of this work is to analyze by PC-MRI flow quantification dynamics of intracranial CSF flow through the aqueduct of Sylvius in an elderly population of normal volunteers, patients with white matter disease (WMD) and patients with NPH and white matter lesions (NPH-WML) to evaluate if white matter abnormalities modifies this imaging biomarker. Flow (maximum craniocaudal and caudocranial flow, mean flow stroke volume and CSF production), velocity (maximum craniocaudal and caudocranial velocity, mean velocity), temporal parameters (craniocaudal and caudocranial flow onset, craniocaudal flow duration, duration from $\mathrm{R}$ wave to maximum craniocaudal and caudocranial flow) and cross sectional area were evaluated.

The study population consisted of 30 adults. All were prospective and consecutively studied after reviewing the conventional MR imaging and clinical indications. All subjects gave informed consent for their studies to be anonymously used for research. 


\section{Chapter 4: Results}

There were 10 control subjects with mild ventricular dilatation and without evidence of white matter lesions at MR examination (6 female and 4 male; mean age \pm SD: $57 \pm 10$ years old, range: $43-75$ years). They had no history of neurological disease, vascular events or relevant risks factors. All control subjects were scanned because of mild headache history and were found to have minor ventricular dilatation.

Symptomatic patients were classified in two groups. There were 10 patients with white matter hypoxic ischemic lesions (5 female and 5 male; age: $67 \pm 12$ years old, range: 46-83 years). All of them were submitted for headache, migraine or mild cognitive. WMD was defined as hyperintensities on both short and long TE TSE (PD and T2-weighted) images with ventricular enlargement proportional to the subarachnoid space. All of them had WML grade 1 and 2 according to Bateman [95] (Figure 4.13). Mean follow-up period was two years to exclude any significant neurological disorder.

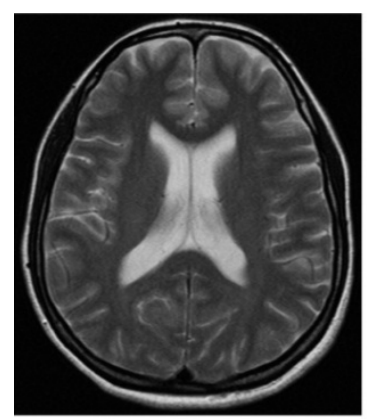

a

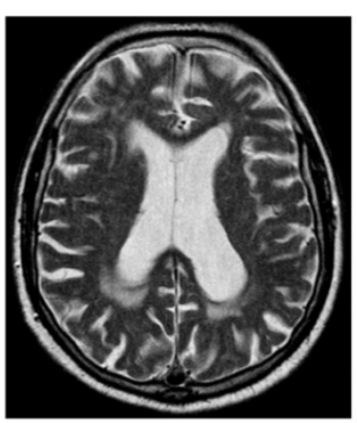

$\mathrm{b}$

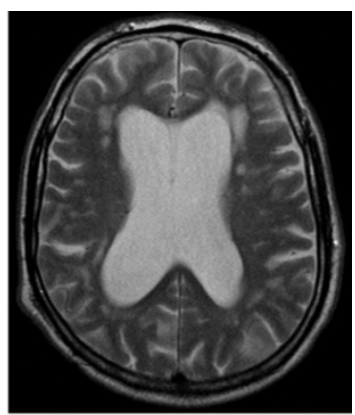

C

Figure 4.13 T2-weighted images showing: (a) Patient without evidence of WML.

(b) Patient with mild WMD and (c) patient with NPH and white matter hypoxic ischemic lesions.

The NPH-WML group included 10 patients (6 female and 4 male; age: 67 \pm 12 years old; range: $42-80$ years) with conventional MR imaging and clinical and imaging follow-up diagnosis of hydrocephalus at normal pressure. All of them had diffusely distributed focal white matter lesions at T2-weighted images. None of them were previously shunted and none was shunted before 4 months after the MR examination. 
All subjects were examined using a $1.5 \mathrm{~T}$ MR scanner using the acquisition protocol 1 in the same hourly stripe (14:00 to 18:00 hours). The study was complemented with $\mathrm{T} 2$ and PD weighted turbo SE images. The mean heart rate was not different among the three groups (volunteers: $73 \pm 11$ beats per minute (bpm), NPH: $73 \pm 10$ bpm, MWML: $67 \pm 9$ bpm; $p=0.52$ ).

All variables presented a normal distribution (test Kolmogorov-Smirnov, $p$ $\geq 0.05$ ). The One-way ANOVA followed by Student-Newman-Keuls test was used to compare the different parameters among the three groups. Null hypotheses were verified using a one-way test and $p$-values smaller than 0.05 were considered significant.

Patients with WMD had slightly higher calculated parameters than controls, but without statistical significance. Figure 4.14 graphically shows the Student-Newman-Keuls test results. These parameters differentiated the NPHWML patients from both control and WMD groups. All the flow amplitude parameters, with the exception of CSF production, presented very significant differences (Table 4.12), $p<0.001$. 

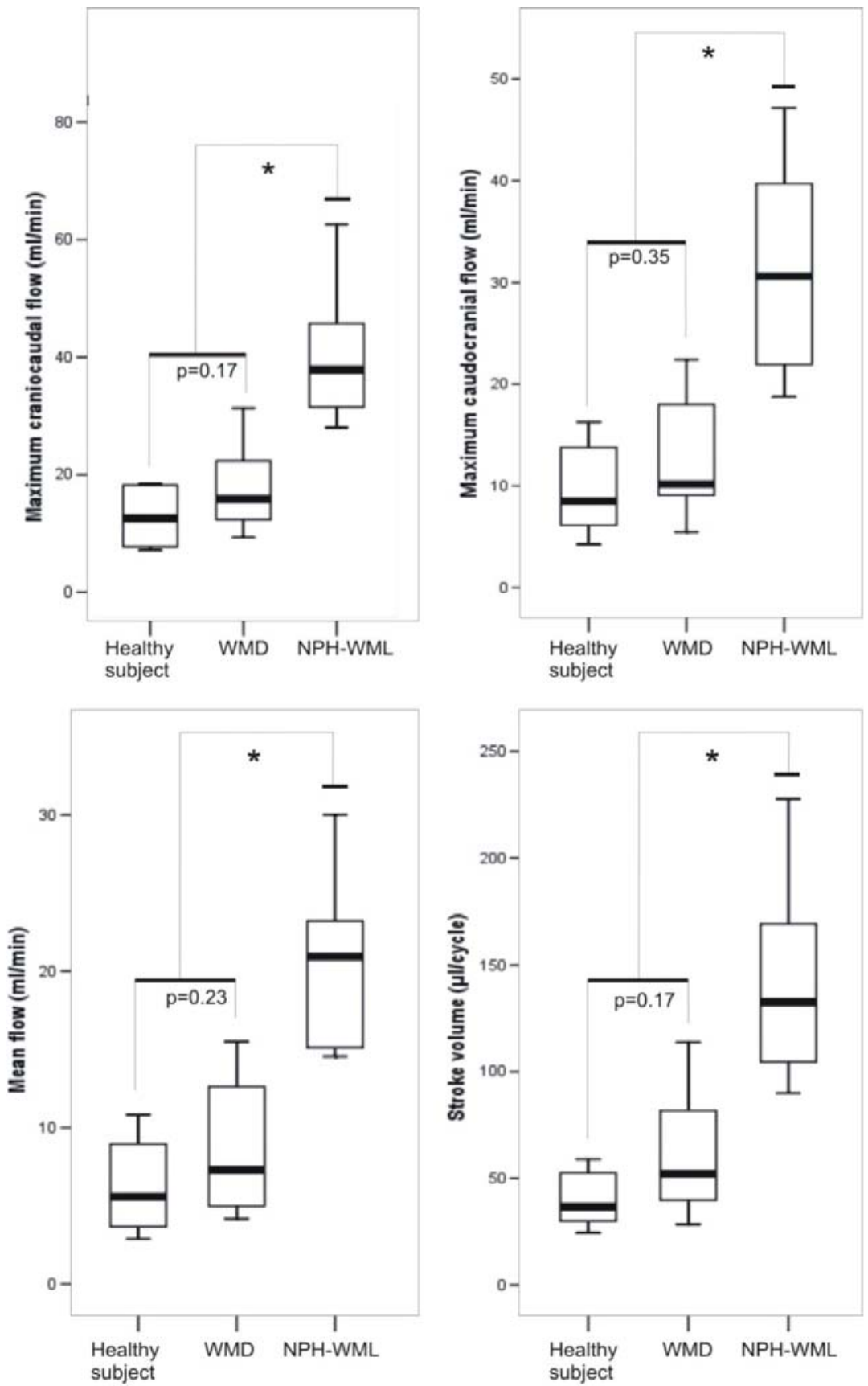

Figure 4.14 Student-Neuwman-Keuls tests for aqueductal CSF flow amplitude parameters. Asterisks indicate significantly different values between the groups ( $p$ $<0.001)$. 


\begin{tabular}{|c|c|c|c|c|}
\hline \multicolumn{2}{|c|}{ Parameters } & \multirow{2}{*}{$\begin{array}{c}\text { Mean } \pm \text { SD } \\
12.61 \pm 4.57\end{array}$} & \multirow{2}{*}{$\begin{array}{c}\begin{array}{c}\text { Range } \\
\min , \max \end{array} \\
7.15,18.45\end{array}$} & $p$ \\
\hline \multirow{3}{*}{$\begin{array}{l}\text { Maximum craniocaudal } \\
\text { flow (ml/min) }\end{array}$} & Control & & & \multirow{3}{*}{$<0.001$} \\
\hline & WMD & $17.79 \pm 7.19$ & $9.31,31.33$ & \\
\hline & NPH-WML & $39.80 \pm 10.93$ & $28.07,62.51$ & \\
\hline \multirow{3}{*}{$\begin{array}{l}\text { Maximum caudocranial } \\
\text { flow }(\mathrm{ml} / \mathrm{min})\end{array}$} & Control & $9.32 \pm 4.13$ & $4.24,16.27$ & \multirow{3}{*}{$<0.001$} \\
\hline & WMD & $12.21 \pm 5.61$ & $5.47,22.45$ & \\
\hline & NPH-WML & $31.22 \pm 9.61$ & $18.75,47.15$ & \\
\hline \multirow{3}{*}{$\begin{array}{l}\text { Mean flow } \\
(\mathrm{ml} / \mathrm{min})\end{array}$} & Control & $6.01 \pm 2.73$ & $2.87,10.83$ & \multirow{3}{*}{$<0.001$} \\
\hline & WMD & $8.28 \pm 4.08$ & $4.18,15.49$ & \\
\hline & NPH-WML & $20.58 \pm 5.13$ & $14.55,30.02$ & \\
\hline \multirow{3}{*}{$\begin{array}{l}\text { Stroke volume } \\
\quad(\mu \mathrm{l} / \text { cycle })\end{array}$} & Control & $40.07 \pm 12.83$ & $24.38,58.91$ & \multirow{3}{*}{$<0.001$} \\
\hline & WMD & $59.45 \pm 27.16$ & $28.57,113.67$ & \\
\hline & NPH-WML & $141.14 \pm 43.40$ & $89.85,227.72$ & \\
\hline \multirow{3}{*}{$\begin{array}{l}\text { CSF production } \\
(\mathrm{ml} / \mathrm{min})\end{array}$} & Control & $-0.40 \pm 0.20$ & $0.13,0.71$ & \multirow{3}{*}{0.37} \\
\hline & WMD & $-0.45 \pm 0.29$ & $0.08,1.40$ & \\
\hline & NPH-WML & $-0.60 \pm 0.39$ & $-1.09,1.40$ & \\
\hline
\end{tabular}

Table 4.12 Aqueductal CSF flow amplitude parameters for each one of the studied groups. p-value from one-way ANOVA test. Negative CSF production represents flow in craniocaudal direction.

CSF velocity amplitude parameters did not show significant differences $(p$ $\geq 0.05$ ) among the control group, subjects with WMD and those with NPH-WML. The obtained measures are shown in Table 4.13.

Regarding the temporal flow waveforms analysis, no statistical differences were found among the three studied groups (Table 4.14). Figure 4.15 shows the mean flow curves obtained for each group.

Also, the aqueduct area was different between control subjects and subjects with WMD compared to patients with NPH-WML, the later ones having larger 
areas $(5.34 \pm 1.58,6.78 \pm 1.53$ and $15.08 \pm 5.57$, respectively). The difference was highly significant between controls and patients with WMD as compared to NPHWML patients $(p<0.0001)$.

\begin{tabular}{|c|l|c|c|c|}
\hline \multicolumn{2}{|c|}{ Parameters } & Mean \pm SD & $\begin{array}{c}\text { Range } \\
(\text { min, max })\end{array}$ & \multirow{2}{*}{$p$} \\
\hline \multirow{2}{*}{$\begin{array}{c}\text { Maximum craniocaudal } \\
\text { velocity }(\mathrm{cm} / \mathrm{s})\end{array}$} & Control & $5.66 \pm 0.88$ & $4.40,7.06$ & \\
\cline { 2 - 4 } & WMD & $6.57 \pm 3.24$ & $3.06,14.23$ & \multirow{2}{*}{0.37} \\
\cline { 2 - 4 } & NPH-WML & $7.12 \pm 2.08$ & $3.75,9.77$ & \\
\hline \multirow{3}{*}{$\begin{array}{c}\text { Maximum caudocranial } \\
\text { velocity }(\mathrm{cm} / \mathrm{s})\end{array}$} & Control & $4.05 \pm 0.90$ & $2.98,5.73$ & \multirow{2}{*}{0.22} \\
\cline { 2 - 5 } & WMD & $5.00 \pm 2.72$ & $1.81,11.26$ & \\
\cline { 2 - 5 } & NPH-WML & $5.51 \pm 1.45$ & $3.39,7.86$ & \\
\hline \multirow{2}{*}{\begin{tabular}{c} 
Mean velocity $(\mathrm{cm} / \mathrm{s})$ \\
\cline { 2 - 5 }
\end{tabular}} & Control & $2.65 \pm 0.60$ & $1.80,3.73$ & \\
\cline { 2 - 5 } & WMD & $3.23 \pm 1.80$ & $1.32,7.54$ & \\
\cline { 2 - 4 } & NPH-WML & $3.71 \pm 0.95$ & $2.26,5.20$ & \\
\hline
\end{tabular}

Table 4.13 Aqueductal CSF velocity amplitude parameters for each one of the studied groups. p-values from one-way ANOVA test.

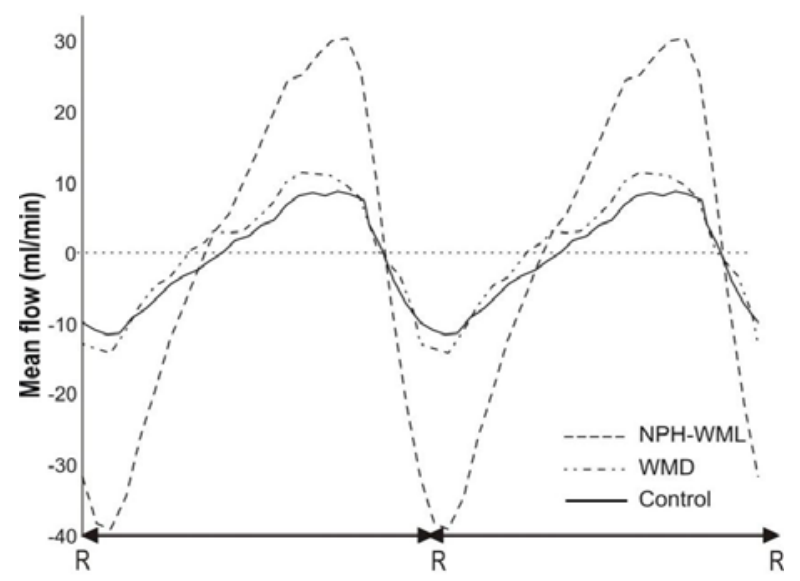

Figure 4.15 Mean cerebrospinal fluid flow waveforms obtained in each one of the three studied groups at the aqueduct of Sylvius. The graphic shows two complete cardiac cycles $(R-R)$. 


\begin{tabular}{|c|c|c|c|c|}
\hline \multicolumn{2}{|l|}{ Parameters } & Mean \pm SD & $\begin{array}{c}\text { Range } \\
(\min , \max )\end{array}$ & $p$ \\
\hline \multirow{3}{*}{$\begin{array}{l}\text { Craniocaudal flow onset } \\
\text { ( } \% \text { cardiac cycle })\end{array}$} & Control & $89.10 \pm 1.96$ & $85.21,92.05$ & \multirow{3}{*}{0.78} \\
\hline & WMD & $87.99 \pm 5.45$ & $79.18,95.22$ & \\
\hline & NPH-WML & $88.30 \pm 2.46$ & $85.74,91.90$ & \\
\hline \multirow{3}{*}{$\begin{array}{l}\text { Caudocranial flow onset } \\
\text { ( } \% \text { cardiac cycle })\end{array}$} & Control & $39.13 \pm 4.85$ & $31.34,48.34$ & \multirow{3}{*}{0.28} \\
\hline & WMD & $34.57 \pm 7.79$ & $19.85,45.49$ & \\
\hline & NPH-WML & $36.17 \pm 6.24$ & $25.90,45.68$ & \\
\hline \multirow{3}{*}{$\begin{array}{l}\text { Craniocaudal flow onset } \\
\text { (\% cardiac cycle })\end{array}$} & Control & $49.83 \pm 4.06$ & $42.47,56.29$ & \multirow{3}{*}{0.20} \\
\hline & WMD & $46.57 \pm 3.42$ & $40.67,51.40$ & \\
\hline & NPH-WML & $47.95 \pm 4.44$ & $39.78,54.76$ & \\
\hline \multirow{3}{*}{$\begin{array}{l}\mathrm{R} \text { wave to maximum craniocaudal } \\
\text { flow ( } \% \text { cardiac cycle })\end{array}$} & Control & $7.20 \pm 3.63$ & $1.59,12.90$ & \multirow{3}{*}{0.67} \\
\hline & WMD & $7.12 \pm 6.06$ & $0,11.27$ & \\
\hline & NPH-WML & $5.60 \pm 3.47$ & 0,20 & \\
\hline \multirow{3}{*}{$\begin{array}{l}\mathrm{R} \text { wave to maximum caudocranial } \\
\text { flow ( } \% \text { cardiac cycle })\end{array}$} & Control & $72.80 \pm 7.69$ & $56.45,80.79$ & \multirow{3}{*}{0.53} \\
\hline & WMD & $70.38 \pm 14.71$ & $32.80,82.79$ & \\
\hline & NPH-WML & $75.66 \pm 6.79$ & $59.49,83.77$ & \\
\hline
\end{tabular}

Table 4.14 Aqueductal CSF flow temporal parameters for each one of the studied groups. p-values from one-way ANOVA test.

\subsubsection{Intracranial Dynamic}

\subsubsection{In Healthy Volunteers}

\section{Adapted from:}

Flórez N, Moratal D, Martí-Bonmatí L, Forner J, Arana E. Dynamic relationships model of the craniospinal fluids in healthy volunteers using phase contrast magnetic resonance imaging. European Congress of Radiology (ECR), Wien, 2008. 
The first study was carried out in 10 healthy volunteers (6 males and 4 females) with a mean age of $27 \pm 5$ years old were scanned with a $3.0 \mathrm{~T}$ unit using the acquisition protocol 4 in the same hourly stripe (14:00 to 15:00 hours) to avoid circadian variations in the measurements.

The different parameters can be observed in Table 4.15 and Figure 4.16. The obtained mean waveforms in each one of the analyzed regions can be observed in Figure 4.17.

\begin{tabular}{|l|c|c|c|c|c|}
\hline \multicolumn{1}{|c|}{ Parameters } & $\begin{array}{c}\text { Internal } \\
\text { carotid } \\
\text { arteries }\end{array}$ & $\begin{array}{c}\text { Vertebral } \\
\text { arteries }\end{array}$ & C2C3 & $\begin{array}{c}\text { Aqueduct of } \\
\text { Sylvius }\end{array}$ & $\begin{array}{c}\text { Jugular } \\
\text { veins }\end{array}$ \\
\hline $\begin{array}{l}\text { Mean flow } \\
(\mathrm{ml} / \mathrm{min})\end{array}$ & $472 \pm 83$ & $185 \pm 55$ & $68 \pm 9$ & $5 \pm 3$ & $485 \pm 115$ \\
\hline $\begin{array}{l}\text { Mean amplitude } \\
\text { flow }(\mathrm{ml} / \mathrm{min})\end{array}$ & $394 \pm 99$ & $251 \pm 67$ & $293 \pm 65$ & $23 \pm 8$ & $351 \pm 109$ \\
\hline $\begin{array}{l}\text { Stroke volume } \\
(\mu \mathrm{l} / \mathrm{cycle})\end{array}$ & & $571 \pm 130$ & $34 \pm 20$ & \\
\hline $\begin{array}{l}\text { CSF production } \\
(\mathrm{ml} / \mathrm{min})\end{array}$ & & $-0.33 \pm 0.3$ & \\
\hline
\end{tabular}

Table 4.15 Amplitude parameters obtained from 10 healthy volunteers in each one of the regions included in the model. Negative CSF production represents flow in craniocaudal direction.

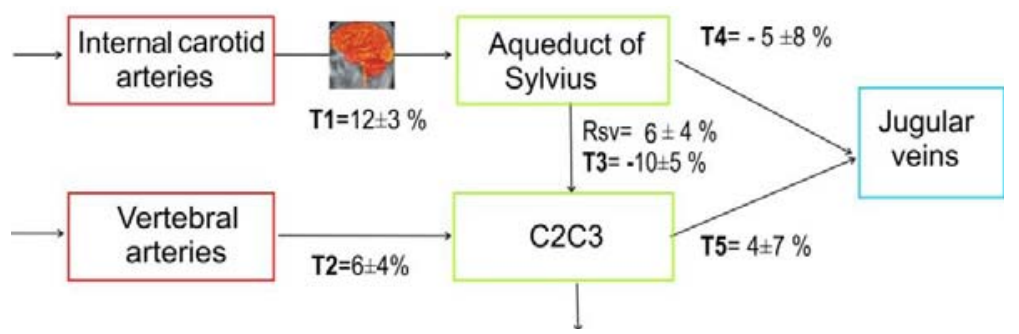

Figure 4.16 Temporal and amplitude relationships. Rsv: ratio of stroke volume, T1-T5: Percentages of cardiac cycle between the flow waveforms in respect to systolic peak. The negative value of T3 and T4 means a delay of aqueductal CSF flow 


\section{Chapter 4: Results}
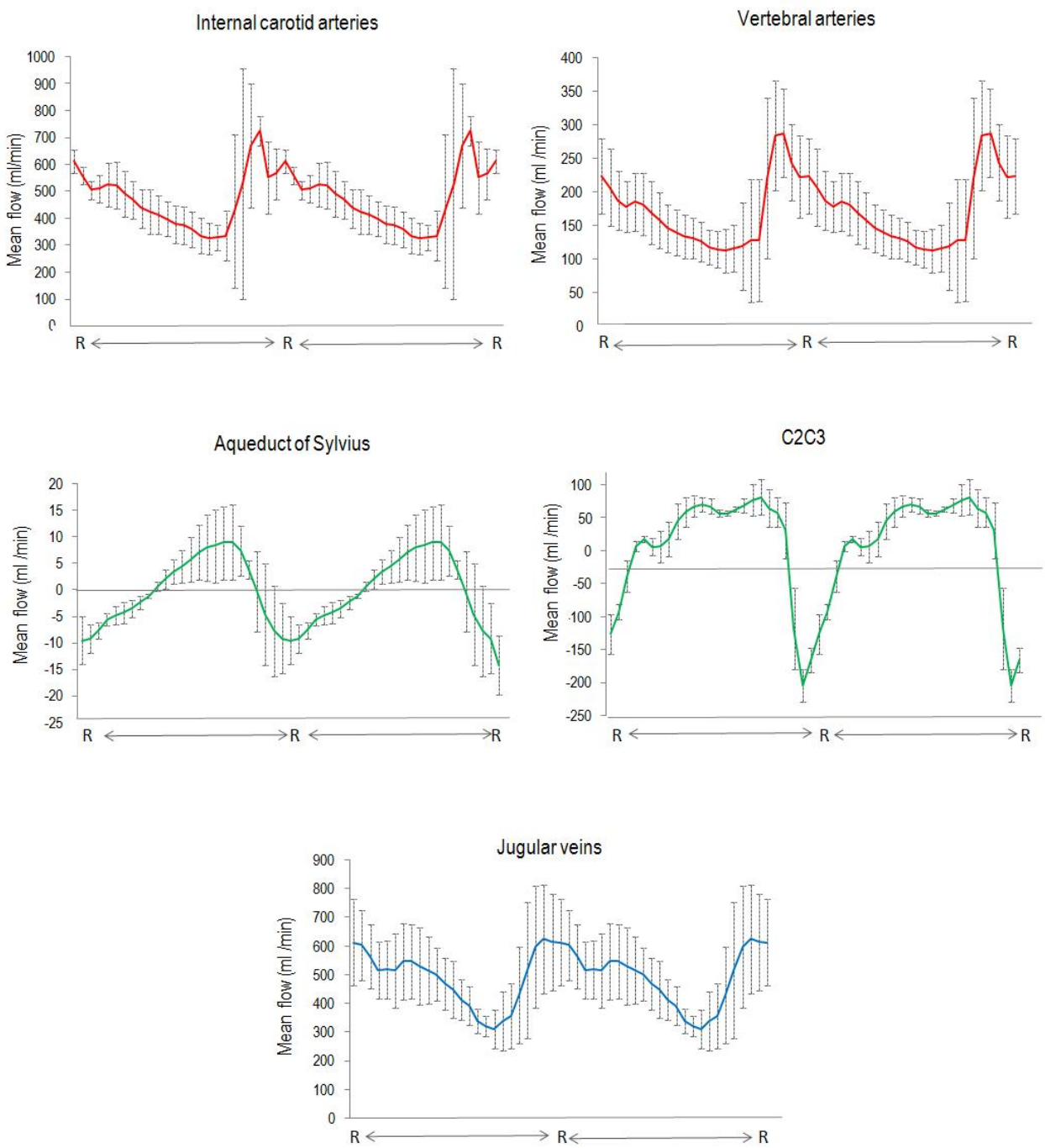

Figure 4.17 Mean flow curves obtained from 10 healthy volunteers. Two cardiac cycles are represented $(R-R)$. The venous flow is encoded with negative velocities. In the graphic the absolute velocities are represented. The bars represent 1 standard deviation. 


\section{Chapter 4: Results}

\section{Adapted from:}

Flórez N, Potayos C, Martí-Bonmatí L, Forner J, Moratal D. Temporal relationships between blood flow and cerebrospinal fluid in healthy subjects by means of phase-contrast magnetic resonance imaging. $8^{0}$ Congreso de la Sociedad Española de Base de Cráneo, Santander, 2008. [In Spanish]

The second study was carried out in 14 healthy subjects (8 men and 6 women) with age range from 24 to 38 years old $(27 \pm 4$ years, mean \pm standard deviation) were examined using the acquisition protocol 4 in the same hourly stripe (14:00 to $15: 00$ hours) to avoid circadian variations in the measurements. The quantified parameters are expressed in mean values and standard deviations in Table 4.16. The obtained mean waveforms in each one of the analyzed region can be observed in Figure 4.18.

\begin{tabular}{|l|c|c|c|c|c|}
\hline Parameters & $\begin{array}{c}\text { Arterial } \\
\text { input }\end{array}$ & $\begin{array}{c}\text { Aqueduct } \\
\text { of Sylvius }\end{array}$ & C2C3 & $\begin{array}{c}\text { Straight } \\
\text { sinus }\end{array}$ & $\begin{array}{c}\text { Superior } \\
\text { sinus }\end{array}$ \\
\hline $\begin{array}{l}\text { Mean flow } \\
(\mathrm{ml} / \mathrm{min})\end{array}$ & $660 \pm 104$ & $5 \pm 2$ & $75 \pm 12$ & $90 \pm 10$ & $320 \pm 90$ \\
\hline $\begin{array}{l}\text { Systolic volume } \\
(\mu \mathrm{l} / \mathrm{cycle})\end{array}$ & $1300 \pm 196$ & $34 \pm 18$ & $544 \pm 122$ & $58 \pm 18$ & $247 \pm 76$ \\
\hline $\begin{array}{l}\text { Delay } \\
(\% \text { cardiac cycle })\end{array}$ & & $25 \pm 13$ & $12 \pm 10$ & $22 \pm 4$ & $38 \pm 16$ \\
\hline $\begin{array}{l}\text { Compliance index } \\
\text { Pulsatility index }\end{array}$ & $1.03 \pm 0.15$ & $0.35 \pm 0.26$ & $1.42 \pm 0.33$ & $0.33 \pm 0.04$ & $0.39 \pm 0.10$ \\
\hline $\begin{array}{l}\text { Amplitude pressure } \\
\text { gradient }(\mathrm{mmHg} / \mathrm{cm})\end{array}$ & $0.31 \pm 0.08$ & $0.07 \pm 0.03$ & $0.07 \pm 0.02$ & $0.11 \pm 0.03$ & $0.09 \pm 0.03$ \\
\hline
\end{tabular}

Table 4.16 Amplitude and temporal parameters obtained from 14 healthy subjects. Arterial flow input is the sum of flows in the internal carotid and vertebral arteries. 


\section{Chapter 4: Results}

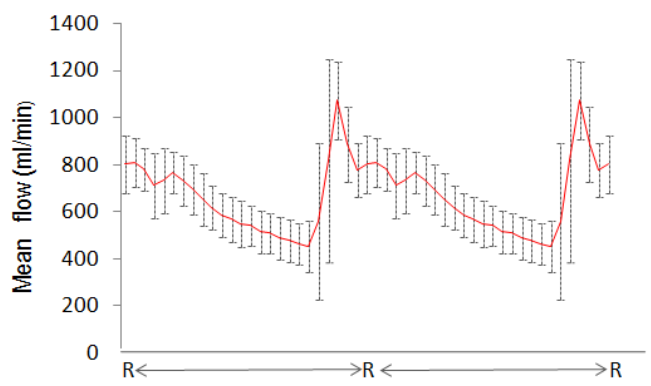

Internal carotid and

vertebral arteries

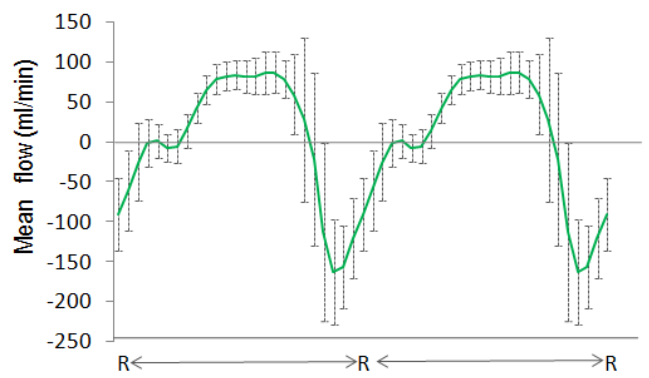

$\mathrm{C} 2 \mathrm{C} 3$

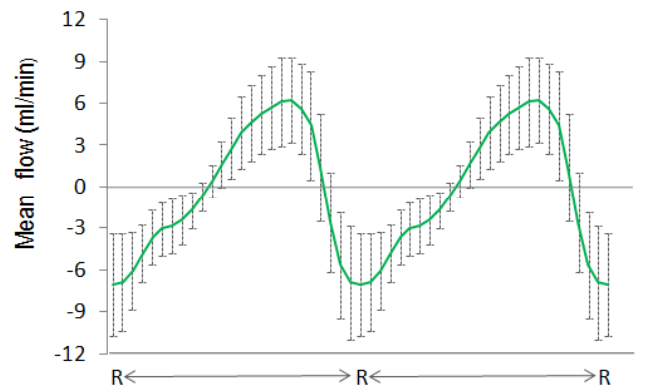

Aqueduct of Sylvius

Figure 4.18 Mean flow curves obtained from the fourteen healthy subjects studied. Two cardiac cycles $(R-R)$ are represented. The venous flow is encoded with negative velocities. In the graphic the absolute velocities are represented. The bars represent the standard deviation. 


\section{Chapter 4: Results}

The average ratio of cervical stroke volume to ventricular stroke volume was 5.26 $\pm 2.20 \%$ and the supratentorial production was $-0.24 \pm 0.19 \mathrm{ml} / \mathrm{min}$. Negative CSF production represents flow in craniocaudal direction.

\subsubsection{In Neurological Disorders}

The second study of the intracranial dynamic was applied in two different patients: the first one with Chiari I malformation (man of 50 years old) and the second one with NPH (man of 55 years old).

The Chiari I malformation is characterized by the displacement of the cerebellar tonsils more than $5 \mathrm{~mm}$ caudally through the foramen magmun with preserved fourth ventricle architecture [123]. These malformations are sometimes associated with spinal abnormalities such as syringomyelia (accumulation of fluid within the spinal cord), spina bifida (a malformation of the spinal cord), and occasionally with hydrocephalus [124] (Figure 4.19).

The Chari I malformation patient presented syringomyelia associated and the NPH patient presented mild white matter lesions. All of them were examined using the acquisition protocol 4 in the same hourly stripe (14:00 to 15:00 hours) to avoid circadian variations in the measurements.

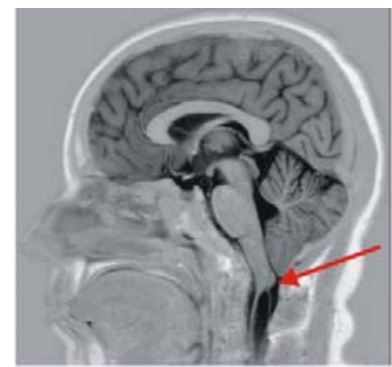

a

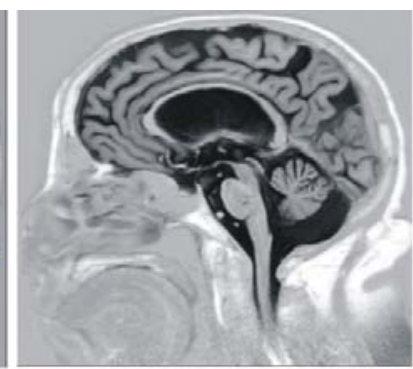

b

Figure 4.19 Sagittal slice of a T1 weighted turbo inversion recovery in a Chiari I malformation patient (a) and NPH patient (b). Chiari I malformation shows displacement of cerebellar tonsil below the upper margin of the foramen magnum. Note that there is no open connection between the cerebrospinal fluid (CSF) in the 
cranial (brain) compartment and the spinal compartment (arrow). Syringomyelia is present

By comparing the intracranial dynamic of the Chiari I patient with the mean parameters of the dynamic intracraneal obtained from 14 healthy volunteers (Table 4.16) disequilibrium in the arterial inflow, cervical CSF flow and venous flow in the straight sinus can be observed (Table 4.17). The arrows indicate increases or decreases when compared to reference limits established as the mean \pm 2 times the standard deviation.

\begin{tabular}{|c|c|c|c|c|c|}
\hline Parameters & $\begin{array}{l}\text { Arterial } \\
\text { input }\end{array}$ & $\begin{array}{l}\text { Aqueduct } \\
\text { of Sylvius }\end{array}$ & $\mathrm{C} 2 \mathrm{C} 3$ & $\begin{array}{l}\text { Straight } \\
\text { sinus }\end{array}$ & $\begin{array}{l}\text { Superior } \\
\text { sinus }\end{array}$ \\
\hline $\begin{array}{l}\text { Mean flow } \\
(\mathrm{ml} / \mathrm{min})\end{array}$ & $\begin{array}{r}369 \underset{\downarrow}{\downarrow} \\
660 \pm 104\end{array}$ & $\begin{array}{c}6 \\
5 \pm 2\end{array}$ & $\begin{array}{r}34 \downarrow \\
75 \pm 12\end{array}$ & $\begin{array}{c}99 \\
90 \pm 10\end{array}$ & $\begin{array}{c}289 \\
320 \pm 90\end{array}$ \\
\hline $\begin{array}{l}\text { Systolic volume } \\
(\mu \mathrm{l})\end{array}$ & $\begin{array}{r}778 \underset{\downarrow}{\downarrow} \\
1300 \pm 196\end{array}$ & $\begin{array}{c}40 \\
34 \pm 18\end{array}$ & $\begin{array}{r}221 \downarrow \\
544 \pm 122\end{array}$ & $\begin{array}{l}120 \boldsymbol{\top} \\
58 \pm 18\end{array}$ & $\begin{array}{c}279 \\
247 \pm 76\end{array}$ \\
\hline $\begin{array}{l}\text { Delay } \\
(\% \text { cardiac cycle })\end{array}$ & & $\begin{array}{c}20 \\
25 \pm 13\end{array}$ & $\begin{array}{c}16 \\
12 \pm 10\end{array}$ & $\begin{array}{c}16 \\
22 \pm 4\end{array}$ & $\begin{array}{c}12 \\
38 \pm 16\end{array}$ \\
\hline Compliance index & & $\begin{array}{c}18 \\
35 \pm 10\end{array}$ & $\begin{array}{c}2.5 \uparrow \\
1.10 \pm 0.45\end{array}$ & & \\
\hline Pulsatility index & $\begin{array}{c}1.23 \\
1.03 \pm 0.15\end{array}$ & $\begin{array}{c}0.62 \\
0.35 \pm 0.26\end{array}$ & $\begin{array}{r}0.15 \downarrow \\
1.42 \pm 0.33\end{array}$ & $\begin{array}{r}0.58 \quad \mathbf{T} \\
0.33 \pm 0.04\end{array}$ & $\begin{array}{c}0.42 \\
0.39 \pm 0.10\end{array}$ \\
\hline $\begin{array}{l}\text { Amplitude pressure } \\
\text { gradient }(\mathrm{mmHg} / \mathrm{cm})\end{array}$ & $\begin{array}{c}0.16 \\
0.31 \pm 0.08\end{array}$ & $\begin{array}{c}0.07 \\
0.07 \pm 0.03\end{array}$ & $\begin{array}{c}0.05 \\
0.07 \pm 0.02\end{array}$ & $\begin{array}{c}0.09 \\
0.11 \pm 0.03\end{array}$ & $\begin{array}{c}0.08 \\
0.09 \pm 0.03\end{array}$ \\
\hline
\end{tabular}

\begin{tabular}{|c|c|}
\hline Stroke volume ratio (\%) & $\begin{array}{c}18 \boldsymbol{\top} \\
5.26 \pm 2.20\end{array}$ \\
\hline $\begin{array}{l}\text { Supratentorial CSF production } \\
(\mathrm{ml} / \mathrm{min})\end{array}$ & $\begin{array}{c}-0.41 \\
-0.24 \pm 0.19\end{array}$ \\
\hline
\end{tabular}

Table 4.17 Intracranial dynamic in a Chiari I malformation patient (man of 50 years old) without syringomyelia. Negative CSF production represents flow in craniocaudal direction. 
By comparing the intracranial dynamic of the NPH patient with the means parameters of the dynamic intracranial obtained from fourteen healthy volunteers (Table 4.16) can be observed disequilibrium in the arterial inflow, aqueductal and cervical CSF flow and venous flow in the straight sinus (Table 4.18). The arrows indicate increases or decreases respect to reference limits established as the mean \pm 2 times the standard deviation.

\begin{tabular}{|c|c|c|c|c|c|}
\hline Parameters & $\begin{array}{l}\text { Arterial } \\
\text { input }\end{array}$ & $\begin{array}{l}\text { Aqueduct } \\
\text { of Sylvius }\end{array}$ & $\mathrm{C2C3}$ & $\begin{array}{l}\text { Straight } \\
\text { sinus }\end{array}$ & $\begin{array}{l}\text { Superior } \\
\text { sinus }\end{array}$ \\
\hline $\begin{array}{l}\text { Mean flow } \\
(\mathrm{ml} / \mathrm{min})\end{array}$ & $\begin{array}{r}389 \underset{\downarrow}{\downarrow} \\
660 \pm 104\end{array}$ & $\begin{array}{c}17 \uparrow \\
5 \pm 2\end{array}$ & $\begin{array}{c}81 \\
75 \pm 12\end{array}$ & $\begin{array}{r}54 \underset{\downarrow}{\downarrow} \\
90 \pm 10\end{array}$ & $\begin{array}{c}220 \\
320 \pm 90\end{array}$ \\
\hline $\begin{array}{l}\text { Systolic volume } \\
(\mu \mathrm{l})\end{array}$ & $\begin{array}{c}1100 \\
1300 \pm 196\end{array}$ & $\begin{array}{l}117 \boldsymbol{\uparrow} \\
34 \pm 18\end{array}$ & $\begin{array}{c}559 \\
544 \pm 122\end{array}$ & $\begin{array}{c}59 \\
58 \pm 18\end{array}$ & $\begin{array}{c}300 \\
247 \pm 76\end{array}$ \\
\hline $\begin{array}{l}\text { Delay } \\
\text { (\% cardiac cycle) }\end{array}$ & & $\begin{array}{c}23 \\
25 \pm 13\end{array}$ & $\begin{array}{c}3 \\
12 \pm 10\end{array}$ & $\begin{array}{c}15 \\
22 \pm 4\end{array}$ & $\begin{array}{c}15 \\
38 \pm 16\end{array}$ \\
\hline Compliance index & & $\begin{array}{r}8 \downarrow \\
35 \pm 10\end{array}$ & $\begin{array}{c}0.95 \\
1.10 \pm 0.45\end{array}$ & & \\
\hline Pulsatility index & $\begin{array}{c}1.16 \\
1.03 \pm 0.15\end{array}$ & $\begin{array}{c}0.1 \boldsymbol{\uparrow} \\
0.35 \pm 0.26\end{array}$ & $\begin{array}{r}0.6 \downarrow \\
1.42 \pm 0.33\end{array}$ & $\begin{array}{c}0.48 \uparrow \\
0.33 \pm 0.04\end{array}$ & $\begin{array}{c}0.58 \\
0.39 \pm 0.10\end{array}$ \\
\hline $\begin{array}{l}\text { Amplitude pressure } \\
\text { gradient }(\mathrm{mmHg} / \mathrm{cm})\end{array}$ & $\begin{array}{c}0.23 \\
0.31 \pm 0.08\end{array}$ & $\begin{array}{c}0.07 \\
0.07 \pm 0.03\end{array}$ & $\begin{array}{c}0.03 \\
0.07 \pm 0.02\end{array}$ & $\begin{array}{c}0.13 \\
0.11 \pm 0.03\end{array}$ & $\begin{array}{c}0.11 \\
0.09 \pm 0.03\end{array}$ \\
\hline
\end{tabular}

\begin{tabular}{|l|c|}
\hline Stroke volume ratio (\%) & $\uparrow 20$ \\
& $5.26 \pm 2.20$ \\
\hline Supratentorial CSF & -0.39 \\
production $(\mathrm{ml} / \mathrm{min})$ & $-0.24 \pm 0.19$ \\
\hline
\end{tabular}

Table 4.18 Intracranial dynamic in a NPH patient (man with 55 years old). Negative CSF production represents flow in craniocaudal direction. 
The figure 4.20 reflects the distribution of the pulsatility along of the craniospinal axis. The first flow volume displacement that occurs as consequence of the increment of arterial systolic volume is the blood flow volume through the SSS (14\% cc before than in the healthy subject), this first displacement is possibly occasioned by the reduction of the compliance. Following and simultaneously occurs the outflow through the ST and $\mathrm{C} 2 \mathrm{C} 3$ level. In the healthy subject, first occurred the displacements of CSF flow volume and afterward the exit of venous blood.
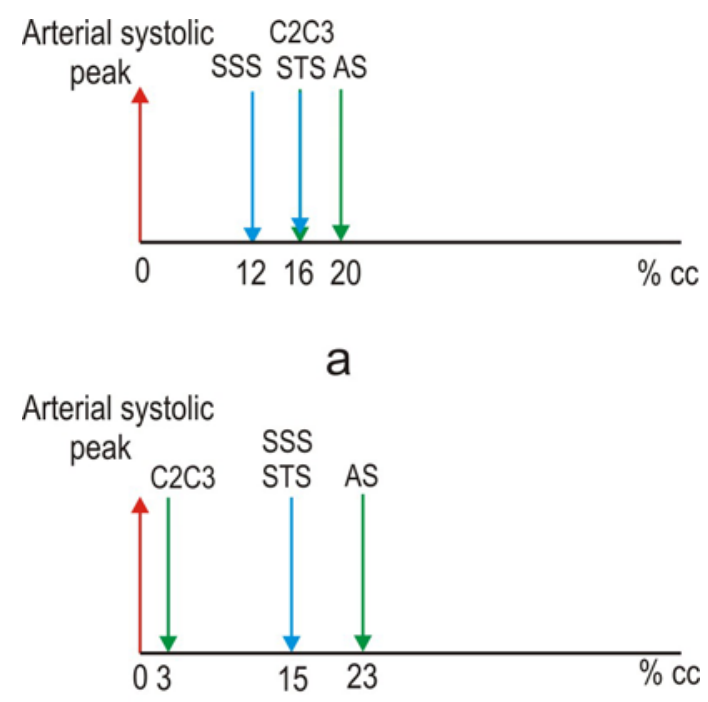

b

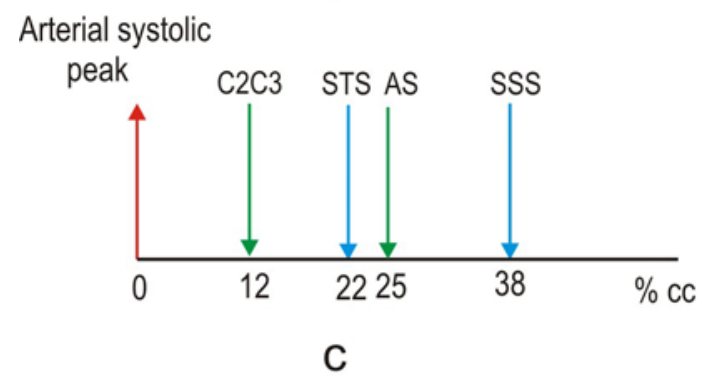

Figure 4.20 Temporal relationships of the intracranial fluid in a Chiari patient (a), a NPH patient (b) and fourteen volunteers (c). The x-axis represents the percentage of cardiac cycle (\% cc). AS: aqueduct of Sylvius, STS: straight sinus. 


\section{Chapter 5: Discussion}

\section{Discussion}

\subsection{Threshold Method}

A semiautomatic method that achieves reproducible quantitative analysis of flow has been developed. The results demonstrate that the agreement level obtained with the manual method $(\mathrm{ICC}=0.46)$ is insufficient, while the proposed method provides a very good agreement level $(\mathrm{ICC}=1.00)$. With this method, the variability was eliminated on its totality.

The parameters obtained with the semiautomatic method were higher than the values obtained with the manual method. This discrepancy can be attributed to the way the ROI is defined. The semiautomatic method uses temporal information and defines the ROI with variable shape according to the anatomy of the aqueduct; therefore the aqueduct is completely surrounded. The manual segmentation method defines circular ROIs from two points marked by the user: the localization is then dependent on the contrast to noise ratio and on the complexity of the image. In this case the aqueduct is not exactly surrounded.

A highly reproducible method is needed in the global evaluation of flow dynamic. From the obtained results it can be concluded that the developed semiautomatic method is highly reproducible.

Beside an adequate definition of the ROI, the correction of errors introduced by artefacts is necessary in order to obtain reliable measurements. In [82], Baledent et al. applies an aliasing correction to those visually detected aliased pixels. In [82], Baledent et al. applies a background correction manually selecting a ROI in the adjacent tissues to the region to analyze. In the developed methodology both artifacts are corrected; the entire sequence is analyzed, automatically detecting any aliased pixels and correcting it if necessary and a region is selected for the background correction.

Previous studies have used background baseline regions (which represent the apparent velocity in a region with no flow like in the medial temporo-occipital gyrus or anterior to the aqueduct in the midbrain) to correct eddy currents and 


\section{Chapter 5: Discussion}

slight brain motion but they have not detailed the relative value of the correction factor $[92 ; 94]$.

Although there were no statistical differences between measurements using any of the two different approaches that correct the background offset, with consistent agreement between observers, background correction is important to reduce inaccuracies. To be noted, the midbrain background offset correction showed higher difference between observers. Midbrain correction deviation is likely related to the ROI placed on the stationary tissue, as it is freely chosen by each observer. However, not every point of the brain suffers the same phase offset along the cycle. For these reasons, it may conclude that half moon correction measurements are more reproducible and therefore better.

Depending on the position slice and the anatomic distribution on the image of the structures to analyze, the background region must be carefully selected avoiding inaccuracies in measurements due to the inclusion of vascular structures. A half moon region is automatically selected surrounding the upper part of the ROI instead of a full moon region when the aqueduct is analyzed. This assures a parenchymal location avoiding any partial volume from vascular, noise or cistern structures. Nevertheless, the automatic half moon region must not be used in regions with influence of close vascular structures as, for example in the acquired images sequences to analyze vascular flow. For these images, the background region is semiautomatically defined.

The first step in order to correct the aliasing is to choose, during the acquisition, a $\mathrm{V}_{\mathrm{enc}}$ value greater than the expected maximum velocity. The correction methods presented in this thesis were developed taking into account that, if aliasing exist, it will be of first order.

It was not necessary to apply an aliasing correction to any of the normal subjects' data of the study due to the low flow velocities compared to the chosen velocity encoding. All subjects' data were completely and adequately analyzed. Aliasing is, however, quite relevant in a clinical setting of patients with an increase flow dynamic.

The aqueductal velocity results for the maximal mean systolic velocity $(5.27 \pm 1.3 \mathrm{~cm} / \mathrm{s})$ and the maximal mean diastolic velocity $(4.20 \pm 1.4 \mathrm{~cm} / \mathrm{s})$ 


\section{Chapter 5: Discussion}

reflect some variability in comparison to other studies [94;125]. Lee et al [94] obtained $3.7 \pm 1.6 \mathrm{~cm} / \mathrm{s}$ for the peak systolic velocity, while Marco et al [125] obtained maximal values of $4.5 \pm 1.9 \mathrm{~cm} / \mathrm{s}$ for systolic and $4.0 \pm 1.9 \mathrm{~cm} / \mathrm{s}$ for diastolic velocities. Our slightly different values are most probably caused by the improved background correction and the ROI definition in our series.

The aqueductal stroke volume values $(39.19 \pm 20.13 \mu \mathrm{l} /$ cycle $)$ are different in comparison to those obtained by Baledent et al. [82] (51 $\pm 25 \mu \mathrm{l} /$ cycle) but closer to the values of Kim et al. [62] (30.1 $\pm 19.8 \mu \mathrm{l} /$ cycle). The main difference with Baledent [82] is probably due to the difference of age. The age of our group was 40 \pm 18 years old while the age of the group analyzed by [82] was $27 \pm 4$ years old. As known, age influence the stroke volume [126].

Previous studies of flow quantification [82;87;94] have used similar parameters obtaining favorable results. However, we recognize that the voxel size should be ideally smaller. Therefore, the acquisition protocol was changed to a 0.33 $\mathrm{x} 0.33 \times 5 \mathrm{~mm}$ to improve the spatial resolution and the results.

With the appropriate evaluation tools, cine MR flow quantification by means of phase contrast sequences provides a reliable tool to quantify pulsed CSF flow. The developed method allows a generalization of the calculus of flow parameters with great consistency and independency of the operator.

\subsection{K-mean Method}

The need to improve the reproducibility and reliability of MRI-PC flow images through postprocessing led to develop a semiautomatic method that combine different temporal features of flow behavior as input attributes in an unsupervised k-means algorithm of classification. Segmentation techniques based upon temporal information of flow waveforms significantly improved the accuracy of ROI delineation.

The effectiveness of implemented k-means clustering is mainly attributed to the fact that attributes such as absolute velocity flow and fundamental frequency magnitude allow to clearly distinguish pulsatile flow regions from background tissues and noise. 


\section{Chapter 5: Discussion}

Alperin and Hoon Lee [84] proposed unbiased correlation threshold values of respectively 0.7 and 0.75 for segmentation of blood vessel lumens and CSF areas. In the developed method, these threshold values were automatically selected in a robust and reproducible way for each segmentation, improving the method robustness. Contrary to Alperin et al. [84] that used a simple boundary tracking method (nearest neighbor search) after applying the threshold value to define the ROI, we have selected the CSF flow pixels using k-means clustering with different temporal attributes of flow waveforms. The proposed method is another type of approach that permits the delineation of CSF regions even with complex and inhomogeneous pulsatile patterns. Depending on the slice position, cervical CSF flow area is not a single ROI as rachidian nerves can divide it into several functional compartments, namely posterior, anterior and lateral SAS, as shown in Figure 4.9. CSF flow in each compartment has its own behavior, close to the mean CSF flow waveform, but with a significant temporal shift [44]. In order to provide a better measurement accuracy, the proposed CSF segmentation algorithm in this work takes this morphological characteristic into account.

This partitioning phenomenon most probably explains the discrepancies found in the area segmented with the two methods at cervical level (table 5.3, ICC $=0.89$ ) in comparison with the aqueductal region (table $4.3, \mathrm{ICC}=0.94$ ) where the homogeneous pulsatile pattern that characterizes aqueductal flow facilitates the segmentation.

The reproducibility of the developed CSF segmentation algorithm was not affected by the initially selected seed point. The normalized standard deviation for cervical flow measurements and areas were respectively $3 \%$ and $4 \%$; these values are in agreement with the reproducibility results obtained in another study [82] where authors obtained a normalized standard deviation value of $4 \%$ for both cervical areas and flow measurements. The main advantage of the method developed herein lies in the fast ROI delineation, with great consistency and independence with regard to the operator.

A limitation of the method presented by Baledent et al. [82] was the difficulty of basilar artery pixels removal during pontine cistern flow measurements. Using the developed method in the 16 subjects, it was possible to delineate the 


\section{Chapter 5: Discussion}

pontine cistern. However, in 5 of those 16 subjects it was necessary to manually remove the fourth ventricle's CSF flow which was automatically selected joined to the pontine cistern area (Figure 4.5)

The redistribution of the pulsatibility along the craniospinal axis plays an important role in the regulation of the intracranial pressure. Quantify the flow dynamics in the different CSF flow pathways will contribute to establish biomarkers of neurological and cerebrovascular disease. The prepontine cistern is a considerable space on the ventral aspect of the pons. It contains the basilar artery, and is continuous behind with the subarachnoid cavity of the medulla spinalis, and with the cisterna cerebellomedullaris; and in front of the pons with the cistern interpeduncularis. Because of its complex anatomy it is difficult to segment this region to extract different flow parameters.

To our knowledge, CSF flow parameters measured in this region have not been published. Wagshul et al. [65] used PC-MRI to study the phase lag of CSF flow in the prepontine cistern respect to arterial inflow. They used a segmentation method based on [82] and used three selection criteria to the magnitude and the phase of the fundamental frequency of each temporal velocity pixel profile after a Fourier transform. Nevertheless for this method no specific validation has been published. With the developed method it is possible to easily delineate the pontine cistern removing the basilar artery (Figure 4.5) allowing a detailed study of CSF flow dynamic.

In this study, the baseline region was carefully selected close to the region being analyzed, systematically excluding vascular structures like epidural veins at cervical level or basilar artery at the intracranial level. The background correction applied to compensate phase dispersion did not significantly modify neither the cervical mean stroke volume (Table $4.4, \mathrm{p}=0.32$ ) nor the cervical net mean flow (Table 4.4, $p=0.69$ ). Indeed, the velocity offset is only a small ratio of CSF velocity and it also contains noise associated to brain motion [43]. Our results are in concordance with those found when the influence of the baseline region on aqueductal flow parameters was analyzed (Table 4.1).

In our studies, even with $\mathrm{V}_{\text {enc }}$ values slightly greater than the maximum flow velocity expected in order to avoid aliasing artefacts, this error was observed 


\section{Chapter 5: Discussion}

in 7 sequences ( 2 in the aqueduct, 2 in $\mathrm{C} 2 \mathrm{C} 3 \mathrm{SAS}$ and 3 in pontine cistern). Those artefacts were automatically detected and corrected. Using this correction, it has never been necessary to repeat the MR acquisition.

The distribution of CSF flow pulsatility in several regions of the craniospinal axis has been analyzed from different points of view in order to clarify some neurological disorders such as normal pressure hydrocephalus (NPH). Transfer functions and spatiotemporal relationships have been calculated so as to characterize the coupling of vascular flow with cervical SAS and ventricular CSF flows $[4 ; 40 ; 65]$; nevertheless the mechanisms of this pathology still remain unknown. Surgery of NPH is significantly risky and the response to treatment mainly depends upon an appropriate selection of the patients. Hyperdynamic aqueductal stroke volumes have been used as an NPH diagnosis test. Bradley et al. [58] proposed a cutoff of $42 \mu \mathrm{l} /$ cycle to predict a positive response to the treatment. However, this value is not fully reliable or reproducible, is also MRI acquisition and image processing dependent, limiting its clinical value in different centers. On the other hand, Kahlon et al. [127] found that aqueductal stroke volume is not useful for selecting patients with NPH symptoms to undergo shunt surgery. They divided the patients into three groups according to stroke volume range: low $(0-50 \mu \mathrm{l})$, middle $(51-100 \mu \mathrm{l})$, and high $(>100 \mu \mathrm{l})$ and did not found statistical difference in the improvement. These results highlight the importance to find reproducible biomarkers.

Baledent et al. [4] found different stroke volume ratios, defined as the ratio of aqueductal to cervical stroke volumes, for healthy volunteers and patient with communicating hydrocephalus. Wagshul [65] used this ratio, as well, to classify hydrocephalus patients. In the present study, the ratio has been assessed to $8 \%$ showing a slight discrepancy with the value of $5 \%$ obtained by Wagshul et al. [65]. Although the aqueductal stroke volume measured with our method $(33 \pm 20$ $\mu \mathrm{l} /$ cycle) was similar to Wagshul's value $(30.9 \pm 14.1 \mu \mathrm{l} /$ cycle $)$, cervical stroke volume measurements were quite different: $(383 \pm 133 \mu \mathrm{l} /$ cycle $)$ vs $(610 \pm 140$ $\mu \mathrm{l} /$ cycle). The reason for this discrepancy is unknown to us. No significant correlation could be found between the aqueductal and cervical stroke volumes. 
Bateman et al. [56] found that aqueductal stroke volumes could not differentiate early Alzheimer's disease from vascular dementia or NPH.

Whereas the direction of net flow was caudal for both the aqueduct and the pontine cistern, the direction was cranial in the $\mathrm{C} 2 \mathrm{C} 3$ space. Henry-Feugeas et al. [61] found two opposite directions in the upper cervical spaces: the net flow direction appeared to be caudal in the anterior space and cranial in the lateral space. Nilsson et al. [31] found that a cranial direction could be considered as a CSF flow displacement toward its main resorption sites at the cranial level. Nevertheless, we think that these results must be carefully considered as net flows are very small in comparison with the high standard deviations and larger pixel sizes in front of the aqueduct area.

Systolic velocity peaks in the three regions of interest were slightly higher than diastolic velocity peaks. At the $\mathrm{C} 2 \mathrm{C} 3$ level, velocity peaks were very close or higher than the chosen $\mathrm{V}_{\text {enc }}$ parameter. This was not a disadvantage in our analysis because as mentioned, the aliased pixels were automatically detected and corrected. The $\mathrm{V}_{\text {enc }}$ values set in our protocol were thought to maintain the best compromise between the signal to noise ratio and predicted velocity range.

The developed method allows carrying out, in a fast and reproducible way, CSF flow quantitative analysis in regions with complex and inhomogeneous flow patterns such as intracranial prepontine cistern and cervical subarachnoid spaces. A global understanding of the CSF dynamics should help in a better understanding of CSF flow disturbances like normal pressure hydrocephalus.

\subsection{Factors that Influence on the PC Quantitative Analysis of CSF}

\subsubsection{Influence of the MR Field Strength and Circadian Cycle}

High-field MRI at 3.0T has gained increasing acceptance for brain imaging. Diverse studies have been focused on the influence of field strength on image quality [19;103] and parameters extracted from MR image [102;128-130]. 


\section{Chapter 5: Discussion}

Nonetheless, to our knowledge, the influence on CSF flow parameters measured from PC-MRI sequences is unknown.

In this study, we demonstrate that CSF flow parameters measured at the aqueduct of Sylvius are in fact influenced by field strength, at least between 1.5 and 3T. Therefore, the range of normal values of these parameters should be adjusted to the field strength in order to improve the quantitative analysis interpretation of the CSF characteristics. The statistical difference found in the mean CSF flow measured in the same subject using two different 1.5 MR scanners allow confirmation of this influence.

The flow parameters obtained from 3.0T scanner were significantly higher than those obtained from 1.5T scanner. By taking into account that the same acquisition protocol was used in both MR units, the increment in flow parameters could be attributed to the SNR which linearly scales with the field strength $[103 ; 131]$.

Although the influence of MR main field strength was only analyzed on the aqueductal CSF flow parameters, this influence was most probably present in the quantification of blood flow parameters using PC-MRI as well. It seems therefore necessary to take into account this influence at the moment to compare results and establish reference values.

On the other hand, the circadian cycle significantly influenced the mean CSF flow. In the analyzed extreme hourly stripes (9:00-9:30 and 19:00-20:00) the curves presented peaks in the middle of the systole. For this reason the hourly stripe to carry out the acquisitions was established between the 11:00 and 18:00.

\subsubsection{Influence of the Subject's Age and Gender}

The CSF flow parameters measured at the aqueduct of Sylvius were not influenced by the subject's age. Nevertheless, as a tendency, all parameters decreased while the age increased. Few authors have studied the influence of aging on CSF flow. Barkhof et al. [92] and Gideon et al. [132] studied aqueductal velocity (maximum craniocaudal and caudocraneal velocity) and flow (maximum craniocaudal and caudocraneal flow) parameters in a young group (mean age 29 
years) and old group (mean age 69 years). They found no statistical differences either on velocity or flow parameters. Even more, these parameters presented an opposite tendency respect to our results. We have not a clear explanation for this discrepancy, but it could be attributed to technical and measurements conditions, which are the main limitations when the aqueductal CSF flow is studied.

Most recently, Stoquart-ElSankari et al. [126] studied the effect of ageing on both vascular and CSF cerebral flows, and on the dynamic coupling between these compartments. They did not found statistical differences in the aqueductal CSF flow parameters with the exception of the stroke volume, which was significantly different between the elderly (mean age 71 years) and young groups (mean age 27 years). Their results present the same tendency that the ones found in our study. The aqueductal CSF flow parameters decrease with the age. They found this tendency in both, blood and CSF flow along the craniospinal axis. This decrease is likely occasioned by aging itself, which is associated to a global cerebral atrophy [133] and changes in the mechanicals state of intracranial tissues [134].

To our knowledge the effect of gender on PC measurements has not been thoroughly studied. Our results reflect that gender do not statistically affect the aqueductal CSF flow parameters. As a trend, we noticed that all the measurement, except the CSF production, were higher in women. We have seen in our series that systole occupies a slightly greater percentage of the cardiac cycle in women than in men $(53.5 \%$ vs. $52 \%)$. It is important to study other physiologic variables that check these results.

\subsection{Clinical Application}

\subsubsection{Aqueductal CSF Flow in White Matter Disease and NPH}

The difficulty to diagnose NPH is associated to the variable presentation and progression of the disease, as well as its overlap and superimposition with other different neurological disorders. The distribution of the CSF pulsatibility in the craniospinal axis plays an important role to understand its pathophysiology. 


\section{Chapter 5: Discussion}

Therefore, it is indispensable to use adequate methodologies of analysis to increase the accuracy of the diagnosis.

NPH and WMD may share some imaging abnormalities, usually showing ventricular dilatation and periventricular hyperintensities. While several studies have used the quantification of PC-MR images to evaluate the dynamic of CSF and blood flow in patients with NPH, Alzheimer's disease and vascular dementias, they have been limited in patients with WMD [95]. The MR diagnosis technique should be methodologically accurate to allow a clear disease differentiation.

In our study, we have evaluated the flow dynamic at the aqueductal level in healthy subjects, WMD and NPH-WML patients, to evaluate if WML influence these parameters and have any impact in correctly clustering patients.

The maximum craniocaudal and the caudocranial flow, mean flow and stroke volume allow differentiating among groups. The results confirm the hyperdynamic aqueductal flow found in previous studies with NPH patients $[4 ; 64 ; 126 ; 135]$ and also suggest that hypoxic ischemic brain changes slightly but not significantly modify the CSF flow parameters in HNP-WML (Figure 4.14). Patients with WMD and those with NPH-WML did not overlap when mean flow and stroke volume were evaluated.

Luetmer et al. [87] proposed that mean CSF flow greater than $18 \mathrm{ml} / \mathrm{min}$ suggests idiopathic NPH. They found mean flow values (normal subject $=8.42 \pm$ $4.5 \mathrm{ml} / \mathrm{min} ; \mathrm{NPH}$ patients $=27.4 \pm 15.3 \mathrm{ml} / \mathrm{min}$ ) similar to our results. As CSF flow is related to patient's age and it has a circadian cycle $[31 ; 92 ; 126]$, normal values can slightly vary between series.

The stroke volume values obtained in healthy volunteers and NPH patients were respectively $22 \%$ and $28 \%$ lower than those measured by Baledent et al.[4] The different results can be mainly attributed to the acquisition and processing techniques, and age differences. Mean age in our study was higher (30 year older in healthy volunteers and 18 years older in NPH cases). The relationship between stroke volume and age is clearly established [126].

Gideon et al. [135] did not find a significant difference in the supratentorial CSF production between healthy volunteers $(0.68 \pm 0.31 \mathrm{ml} / \mathrm{min})$ and $\mathrm{NPH}$ patients $(0.60 \pm 0.59 \mathrm{ml} / \mathrm{min})$. We did also not find a significant difference. 


\section{Chapter 5: Discussion}

Interestingly, four NPH patients had a negative value in our study, indicating net flow in the caudocranial direction. Baledent et al.[4] attributed this behaviour to changes in the ventricular compartment and the transependymal CSF resorption present in patients with hydrocephalus.

The CSF secretion has not been accurately reported. This value presents a large variation of the results between invasive methods $(0.35-0.37 \mathrm{ml} / \mathrm{min})[27 ; 28]$ and imaging-based approaches $(0.30$ - $0.7 \mathrm{ml} / \mathrm{min})[26 ; 29 ; 30]$. The obtained CSF production values using both $\mathrm{V}_{\text {enc }}=20 \mathrm{~cm} / \mathrm{s}(0.42 \pm 0.70 \mathrm{ml} / \mathrm{min})$ and $\mathrm{V}_{\text {enc }}=15 \mathrm{~cm} / \mathrm{s}$ $(0.29 \pm 0.23 \mathrm{ml} / \mathrm{min})$ are in good agreement with theses values. Inaccuracies in the CSF production by means of PC-MRI may be attributed to the error propagation when one is deriving a small quantity from the subtraction of two large numbers [29]. High spatial resolution and adequate segmentation methods must be used in order to reliably measure the CSF production by means of PC-MRI.

CSF velocity parameters are higher in the NPH-WML patients compared with healthy volunteers and WMD patients. However, the differences are small and without statistical differences. Chang et al.[136] studied 10 normal volunteers $($ mean age $=58.5$ years old) and $16 \mathrm{NPH}$ patients (mean age $=65.2$ years old), the diagnosis of the NPH included also cases with periventricular WML. Our maximum craniocaudal velocity values are similar to those obtained by them $(6.22 \mathrm{~cm} / \mathrm{s}$ and $4.93 \mathrm{~cm} / \mathrm{s}$ for NPH patients and volunteers, respectively). In our study, WML do not significantly change the velocity parameters of the CSF at the aqueduct level.

Our maximum craniocaudal and maximum caudocranial velocity values are different to the values obtained by De Marco et al. [125] They found statistical differences between 36 healthy volunteers (maximum craniocaudal velocity $=4.5 \pm$ $1.9 \mathrm{~cm} / \mathrm{s}$ and maximum caudocranial velocity $=4.0 \pm 1.9)$ and $9 \mathrm{NPH}$ patients without WML (maximum craniocaudal velocity $=13.1 \pm 3.7 \mathrm{~cm} / \mathrm{s}$ and maximum caudocranial velocity $=10.3 \pm 2.4$ ). The differences found by De Marco et al. between volunteers and NPH patients most probably are due to the fact that the flow curve was calculated from the maximum velocities in each ROI along the cardiac cycle, while in this work the pixel's mean velocities were recorded to construct the curve. The possible loss of intracranial compliance with the age and its inverse behavior with the velocity could also explain the found differences (in 


\section{Chapter 5: Discussion}

our groups the mean age was not significantly different, while that of the volunteers group studied by De Marco et al. was 34 years younger than the one for NPH patients).

Although aqueductal flow parameters allowed distinguishing NPH-WML patients from normal subjects and WMD patients, the temporal parameters were not significantly different in this study. The craniocaudal flow duration was slightly shorter in WMD patient $(46.57 \% \pm 3.42)$ than in NPH patients $(47.95 \% \pm 4.44)$ and healthy volunteers $(49.83 \% \pm 4.06)$. Baledent et al [4]. found that the craniocaudal flow duration was significantly shorter in patients with hydrocephalus (48\%) than in volunteers (53\%). The degree to which the CSF fluid pulsates in the aqueduct is dependent on the strength of the arterial pressure pulse and the cerebral compliance. It seems therefore that age and parenchymal status condition may influence the temporal parameters.

The signal to noise ratio $(\mathrm{S} / \mathrm{N})$ is inversely proportional to $\mathrm{V}_{\text {enc }}$ value. For optimal noise performance the $\mathrm{V}_{\text {enc }}$ should be therefore always selected as small as possible. We chose a $\mathrm{V}_{\mathrm{enc}}=20 \mathrm{~cm} / \mathrm{s}$ for this first study although this value was later modified to $15 \mathrm{~cm} / \mathrm{s}$. We wanted to use a reproducible value for normal and pathologic subjects. By using a $\mathrm{V}_{\text {enc }}$ value lower than $15 \mathrm{~cm} / \mathrm{s}$ gave us aliasing for healthy subjects.

\subsubsection{Intracranial Dynamic}

A quantitative analysis of intracranial dynamic is possible with adequate segmentation methods that allow delineate different CSF spaces and vascular structures. In this thesis a quantitative evaluation of aqueductal CSF flow dynamic in healthy subjects and WMD and NPH-WML patients has been carried out. Our results suggest that WML does not significantly influence in mean flow and stroke volume. In our series, flow parameters are better biomarkers of NPH than temporal CSF parameters.

The aqueductal stroke volume has been considered as a biomarker of the $\mathrm{NPH}$; however the comorbidity of the NPH with various disorders as Alzheimer's disease, vascular dementia, cerebrovascular disease, and cerebral white matter 


\section{Chapter 5: Discussion}

lesion has limited its use. For example, Bateman et al.[56] found that the size of the aqueduct stroke volume depends on the arterial pulse volume and the relative compliance of the arterial tree and the brain. The aqueduct stroke volume cannot exclude significant comorbidity in NPH; they studied patients with Alzheimer, vascular dementia and NPH. Wagshul et al. [65] comments that questionable patients with clear signs of hydrocephalus have aqueductal flow in the normal range. They proposed that the stroke volume ratio took into account the model of redistribution of flow between the subarachnoid and ventricular spaces evidenced by Greitz [15]. Miyati et al.[48] found significant differences in the cerebral compliance between vascular dementia patients and NPH patients. These results suggest that the stroke volume is not enough for clinical diagnosis purposes; it is necessary to include different parameters that reflect the state of the intracranial dynamics.

The existence of CSF pulsations synchronous with the cardiac cycle and affected by venous pressure variations has been documented since the earliest studies on CSF. Several studies have been proposed to provide a better understanding of the intracranial dynamic. Some works have described hydraulic and electrical equivalence models of the intracranial dynamics and have tested them with simulated and real datasets $[40 ; 42 ; 50 ; 137]$. Other models assume that the cranial cavity can be divided into a set of compartments which are related by means of resistances and compliance [40;50;137-139]. Computational fluid dynamics models of the CSF flow inside the cranium have also been developed. Simulations for normal subject as well as for hydrocephalic patients have been compared using MRI analysis [140;141]. Other studies [7;40;142] have treated the cranium as a "black box". The blood volume measured in the internal carotid arteries (ICA) and vertebral arteries (VA) was considered as the input to the box and the displacement of blood flow volume through the jugular veins (JV) and CSF flow volume at spinal canal were the outputs of the system. In our opinion, the limitation of these studies is the underestimation of the true venous outflow since other venous structures such as the ophthalmic veins, the pterygoid plexus, and other venous channels were not taken into account. To correct this, the measured 


\section{Chapter 5: Discussion}

venous curve was scaled by a factor that forced the corrected average venous outflow to equal the average arterial inflow.

Although the obtained results in each one of the studies have been of great relevance, the understanding of the cerebral dynamic in diverse pathologies still remains unclear. It is therefore necessary to continue researching the hemohydrodynamic mechanism by means of adequate methodologies which allow establishing biomarkers of the illness that improve the diagnostic and follow-up evaluation.

Amplitude and temporal parameters that characterize the intracranial dynamic were quantified in healthy volunteers using reproducible acquisition protocols and adequate segmentation methods. These results will allow us to characterize imbalances in the intracranial dynamic occurred by diverse neurological and cerebrovascular diseases. It is important to emphasize that the obtained parameters are linked to the used specific protocol, since especially partial volume errors may differ significantly when e.g. different resolutions are used to obtain absolute values.

Much of the researches regarding the Chiari I malformation have been focused on the characterization of the cord displacement and CSF flow dynamic in diverse regions in the craniospinal junction (above and below the foramen magnum, anterior and posterior subarachnoid spaces and cerebellar tonsil) using midline sagittal $[143 ; 144]$ or axial [145-147] PC-MRI acquisitions. Significant elevation of peak systolic velocity in the CSF in the foramen magnum [146], reduced CSF velocity only dorsal to the spinal cord at the level of C2 [148] while duration of the CSF systole increased and the duration of CSF diastole decreased at C2C3 level [143] have been found. Few authors have applied the PC-MRI to thoroughly investigate the cerebral dynamic $[5 ; 149]$ in this pathology. They measured intracranial volume and pressure changes in order to calculate an intracranial compliance index. This parameter was significantly lower in the patient than in control subjects.

Our results show that this pathology may be associated with a decrease of the arterial inflow and an increment of the systolic volume and pulsatility index in the straight sinus. Nonetheless, the number of patients with an adequate clinical 


\section{Chapter 5: Discussion}

selection needs to be increased in order to fully characterize the intracranial dynamic and to obtain clear conclusions.

Age does not affect to the aqueductal CSF flow (Table 4.9); previous authors [122] have found an influence of the age on the blood and cervical CSF flow, therefore it will be interesting to characterize the parameters for different age ranges. 


\section{Chapter 6}

\section{Conclusions}

\subsection{Reviews of Thesis Objectives}

The comorbidity presents in diverse neurological disorders is one of the major problems at the moment to carry out a correct diagnosis. Therefore it is necessary to establish different imaging biomarkers that facilitate the diagnostic.

In this thesis, a methodology to study the intracranial flow dynamic within vascular structures and CSF spaces was developed. This methodology integrates dynamic semiautomatic segmentation techniques with background phase correction and aliased pixels detection and correction.

The manual segmentation of the region to analyze is one of the main sources of variability in the measurements. Based on the flow behavior, two semiautomatic segmentation methods were developed. The first method was implemented to analyze the flow in regions with parabolic and plane flow velocity profiles, as the aqueduct of Sylvius and main vascular structures. The second one allows studying flow in regions with complex shapes and inhomogeneous pulsatile flow patterns, as in the pontine cistern and subarachnoid spaces. Both methods are initialized by selecting a seed point inside the region to analyze on the magnitude or phase image. The obtained results reflect that both methods allow a generalization of the calculus of flow parameters with great consistency and independency of the operator. The reduction of the interobsever's variability was $100 \%$ and $97 \%$ for the first and second method, respectively.

The errors introduced by imperfect suppression of eddy currents or slight brain motion are corrected using an offset value calculated in regions where the brain should be static. Depending on the position slice and the anatomic distribution of the structures to be analyzed, the background region is selected 


\section{Chapter 6: Conclusions}

from a ROI surrounding tissue (automatically) or midbrain (semiautomatically). Although there were no statistical differences between measurements, these errors should be corrected in order to reduce inaccuracies.

Aliasing, other source of error in the flow quantification by PC-MRI, is automatically detected and corrected using the temporal information of flow within the defined ROI. The correction was implemented to correct aliased pixels with velocities smaller that $\left(1.80 \mathrm{x} \mathrm{V}_{\text {enc }}\right)$. This process is automatically applied without the user intervention making unnecessary to repeat the image sequence.

Because of the commitment between the acquisition protocol and the methodology to analyze the dynamic of flow, it is also important to take into account the influence of MR field strength on the measurement in order to establish reliable reference values. Almost all the parameters that characterize the CSF flow through the Aqueduct of Sylvius were slightly higher when they were obtained in the $3.0 \mathrm{~T}$ than at the $1.5 \mathrm{~T}$ MR machines. The obtained measurements with two machines of the same field (1.5T) did not have significant differences. These results highlight the importance to take in account the field strength.

Other factors that were studied but did not show influence on the flow parameters were age and gender. Nonetheless, both variables presented clear tendencies. As regard to age, almost all parameters decreased while age increased. Regarding gender, almost all parameter were higher in women than in men. This should be studied with more attention on a bigger sample. In this work these factors only were studied in the Aqueduct of Sylvius.

The circadian rhythm influences on the aqueductal mean flow. The mean flow waveforms obtained during the extreme hourly stripes (9:00 - 9:30 and 19:00 20:00) showed peaks at the beginning of the curve. The established hourly stripe in order to carry out the studies was from 11:00 to 18:00 hours and should be controlled.

An adequate methodology to carry out quick and reproducible blood and CSF flow quantitative analysis has been developed. Amplitude and temporal parameters that characterize the fluid dynamics in different vascular structures and CSF spaces have been established. This new approach to study cerebral fluids 
interactions could help to improve the understanding about the physiopathology of several cerebral diseases caused by CSF, blood and ICP alterations.

\subsection{On the Future Work}

Reference parameters of the intracranial dynamic will be obtained with our reproducible protocol and methodology. Patients with different neurological and cerebrovascular disease will be analyzed; longitudinal studies will be carried out in order to investigate the progression of the disease and to be able to establish predictors biomarkers.

A thoroughly investigation will be focused in multiple sclerosis (MS) patients. The MS is a demyelinating disease of CNS that commonly affects young adults between 20 and 50 years of age. There are diverse paraclinical explorations that complement its diagnosis: conventional and no-conventional MRI sequences, evoked potential tests and the study of CSF using lumbar punctures. Unfortunately, the diagnosis, severity and evolutionary prognosis remain obscure. The formation of sclerotic plaques during the course of the disease causes brain to lose its elasticity and the capability to adapt to volume changes. Therefore the characterization of the intracranial dynamic model in MS patients will allow to establish biomarkers that improve the diagnosis and follow-up of the illness. 


\section{Glossary}

\section{Glossary}

CNS central nervous system

WHO World Health Organization

$\mathrm{AD}$

Alzheimer's disease

VD vascular dementia

$\mathrm{NPH}$

normal pressure hydrocephalus

CSF

cerebrospinal fluid flow

MRI

magnetic resonance imaging

PC-MRI phase contrast magnetic resonance imaging

BCB blood-CSF barrier

$\mathrm{RF} \quad$ radiofrequency

FID free induction delay

WM white matter

GM gray matter

TE echo time

$\mathrm{V}_{\mathrm{enc}} \quad$ velocity encoding

$\mathrm{PP} \quad$ peripheral pulse

FOV field of view

ROI region of interest

SNR signal to noise ratio

CC correlation coefficient

FFT fast Fourier transform

ANOVA analysis of variance

df degree of freedom

$\mathrm{CV} \quad$ coefficient of variation

ICC intraclass correlation coefficient

WMD white matter disease

MS multiple sclerosis 


\section{References}

[1] World Health Organization. Neurological disorders: Public health challenges. February 27th, 2007

[2] N. Alperin, S. H. Lee, M. Mazda, S. G. Hushek, B. Roitberg, J. Goddwin, and T. Lichtor, "Evidence for the importance of extracranial venous flow in patients with idiopathic intracranial hypertension (IIH)," Acta Neurochir Suppl, vol. 95, pp. 129-132, 2005.

[3] N. Alperin, A. Sivaramakrishnan, and T. Lichtor, "Magnetic resonance imaging-based measurements of cerebrospinal fluid and blood flow as indicators of intracranial compliance in patients with Chiari malformation," J Neurosurg, vol. 103, no. 1, pp. 46-52, 2005.

[4] O. Baledent, C. Gondry-Jouet, M. E. Meyer, G. de Marco, D. Le Gars, M. C. Henry-Feugeas, and I. Idy-Peretti, "Relationship between cerebrospinal fluid and blood dynamics in healthy volunteers and patients with communicating hydrocephalus," Invest Radiol, vol. 39, no. 1, pp. 45-55, 2004.

[5] O. Baledent, C. Gondry-Jouet, S. Stoquart-Elsankari, R. Bouzerar, D. Le Gars, and M. E. Meyer, "Value of phase contrast magnetic resonance imaging for investigation of cerebral hydrodynamics," J Neuroradiol, vol. 33, no. 5, pp. 292-303, 2006.

[6] G. A. Bateman, "Vascular compliance in normal pressure hydrocephalus," AJNR Am. J Neuroradiol, vol. 21, no. 9, pp. 1574-1585, 2000.

[7] R. A. Bhadelia, A. R. Bogdan, R. F. Kaplan, and S. M. Wolpert, "Cerebrospinal fluid pulsation amplitude and its quantitative relationship 


\section{References}

to cerebral blood flow pulsations: a phase-contrast MR flow imaging study," Neuroradiology, vol. 39, no. 4, pp. 258-264, 1997.

[8] D. R. Enzmann and N. J. Pelc, "Normal flow patterns of intracranial and spinal cerebrospinal-fluid defined with phase-contrast cine MR imaging," Radiology, vol. 178, no. 2, pp. 467-474, 1991.

[9] R. L. Wolf, R. L. Ehman, S. J. Riederer, and P. J. Rossman, "Analysis of systematic and random error in MR volumetric flow measurements," Magn Reson Med, vol. 30, no. 1, pp. 82-91, 1993.

[10] "The brain: structure and function," www. cancerbackup. org. uk, 2008.

[11] Noback CR, "The human nervous system," McGraw-Hill, Inc., 1967.

[12] P. M Conn, "The Choroid Plexus-CSF Nexus," in Neuroscience in Medicine 2nd edition, pp. 160-195, 2009.

[13] K. Welch and V. Friedman, "The cerebrospinal fluid valves," Brain, vol. 83, pp. 454-469, 1960.

[14] G. Di Chiro, "Observations on the circulation of the cerebrospinal fluid," Acta Radiol Diagn (Stockh), vol. 5, pp. 988-1002, 1966.

[15] D. Greitz, "Cerebrospinal fluid circulation and associated intracranial dynamics. A radiologic investigation using MR imaging and radionuclide cisternography," Acta Radiol Suppl, vol. 386, pp. 1-23, 1993.

[16] D. Greitz and J. Hannerz, "A proposed model of cerebrospinal fluid circulation: observations with radionuclide cisternography," AJNR Am J Neuroradiol, vol. 17, no. 3, pp. 431-438, 1996.

[17] D. Greitz, T. Greitz, and T. Hindmarsh, "A new view on the CSFcirculation with the potential for pharmacological treatment of childhood hydrocephalus," Acta Paediatr, vol. 86, no. 2, pp. 125-132, 1997. 


\section{References}

[18] W.E. Dandy and K.D. Blackfan, "Internal hydrocephalus. An experimental, clinical and pathological study," Am J Dis Child, vol. 8, pp. 406-482, 1914.

[19] B. K. Rutt and D. H. Lee, "The impact of field strength on image quality in MRI," J. Magn Reson Imaging, vol. 6, no. 1, pp. 57-62, 1996.

[20] M. K. Hammock and T. H. Milhorat, "The cerebrospinal fluid: current concepts of its formation," Ann Clin Lab Sci, vol. 6, no. 1, pp. 22-26, 1976.

[21] T. H. Milhorat, "Choroid plexus and cerebrospinal fluid production," Science, vol. 166, no. 3912, pp. 1514-1516, 1969.

[22] H. F. Cserr, "Physiology of the choroid plexus," Physiol Rev, vol. 51, no. 2, pp. 273-311, 1971.

[23] M. B. Segal, "Extracellular and cerebrospinal fluids," J Inherit Metab Dis, vol. 16, no. 4, pp. 617-638, 1993.

[24] "Human Anatomy N261," http:// iupucanatomy. com/, 2009.

[25] P. D. Brown, S. L. Davies, T. Speake, and I. D. Millar, "Molecular mechanisms of cerebrospinal fluid production," Neuroscience, vol. 129, no. 4, pp. 957-970, 2004.

[26] T. Y. Huang, H. W. Chung, M. Y. Chen, L. H. Giiang, S. C. Chin, C. S. Lee, C. Y. Chen, and Y. J. Liu, "Supratentorial cerebrospinal fluid production rate in healthy adults: quantification with two-dimensional cine phase-contrast MR imaging with high temporal and spatial resolution," Radiology, vol. 233, no. 2, pp. 603-608, 2004. 


\section{References}

[27] C. May, J. A. Kaye, J. R. Atack, M. B. Schapiro, R. P. Friedland, and S. I. Rapoport, "Cerebrospinal fluid production is reduced in healthy aging," Neurology, vol. 40, no. 3 Pt 1, pp. 500-503, 1990.

[28] G. D. Silverberg, G. Heit, S. Huhn, R. A. Jaffe, S. D. Chang, H. BronteStewart, E. Rubenstein, K. Possin, and T. A. Saul, "The cerebrospinal fluid production rate is reduced in dementia of the Alzheimer's type," Neurology, vol. 57, no. 10, pp. 1763-1766, 2001.

[29] C. Thomsen, F. Stahlberg, M. Stubgaard, and B. Nordell, "Fourier analysis of cerebrospinal fluid flow velocities: MR imaging study. The scandinavian flow group," Radiology, vol. 177, no. 3, pp. 659-665, 1990.

[30] C. Nilsson, F. Stahlberg, P. Gideon, C. Thomsen, and O. Henriksen, "The nocturnal increase in human cerebrospinal fluid production is inhibited by a beta 1-receptor antagonist," Am J Physiol, vol. 267, no. 6 Pt 2, p. R1445-R1448, 1994.

[31] C. Nilsson, F. Stahlberg, C. Thomsen, O. Henriksen, M. Herning, and C. Owman, "Circadian variation in human cerebrospinal fluid production measured by magnetic resonance imaging," Am J Physiol, vol. 262, no. 1 Pt 2, p. R20-R24, 1992.

[32] D. Greitz, "Radiological assessment of hydrocephalus: new theories and implications for therapy," Neurosurg Rev, vol. 27, no. 3, pp. 145-165, 2004.

[33] D. Purves, D. Fitzpatrick, S.M. Williams, J.O. McNamara, G.J. Augustine, L.C. Katz, and A.S. LaMantia, "Neuroscience, 2nd edition". Sinauer Associates: Sunderland, MA, 2000.

[34] "The Merck manuals, online medical library," Neurologic Disorders, 2008. 


\section{References}

[35] "MedlinePlus medical encyclopedia," www.nlm.nih.gov/medlineplus/, 2008.

[36] "Resources: Anatomy for anaesthetists," www.frca.co.uk, 2008.

[37] "The free encyclopedia Wikipedia," www.wikipedia.org, 2008.

[38] E. H. Starling, "On the absorption of fluids from the connective tissue spaces," J. Physiol, vol. 19, no. 4, pp. 312-326, 1896.

[39] J. Gilroy, "Basic neurology, Third Edition". McGraw-Hill, 2008.

[40] N. Alperin, E. M. Vikingstad, B. Gomez-Anson, and D. N. Levin, "Hemodynamically independent analysis of cerebrospinal fluid and brain motion observed with dynamic phase contrast MRI," Magn Reson Med, vol. 35, no. 5, pp. 741-754, 1996.

[41] W. G. Bradley, "Magnetic resonance imaging in the evaluation of cerebrospinal fluid flow abnormalities," Magnetic Resonance Quarterly, vol. 8, no. 3, pp. 169-196, 1992.

[42] M. Egnor, L. Zheng, A. Rosiello, F. Gutman, and R. Davis, "A model of pulsations in communicating hydrocephalus," Pediatr Neurosurg, vol. 36, no. 6, pp. 281-303, 2002.

[43] D. R. Enzmann and N. J. Pelc, "Brain motion: measurement with phasecontrast MR imaging," Radiology, vol. 185, no. 3, pp. 653-660, 1992.

[44] M. C. Henry-Feugeas, I. Idy-Peretti, O. Baledent, A. Poncelet-Didon, G. Zannoli, J. Bittoun, and E. Schouman-Claeys, "Origin of subarachnoid cerebrospinal fluid pulsations: a phase-contrast MR analysis," Magn Reson Imaging, vol. 18, no. 4, pp. 387-395, 2000. 


\section{References}

[45] L. A. Steiner and P. J. Andrews, "Monitoring the injured brain: ICP and CBF," Br. J. Anaesth, vol. 97, no. 1, pp. 26-38, 2006.

[46] A. Marmarou, K. Shulman, and J. LaMorgese, "Compartmental analysis of compliance and outflow resistance of the cerebrospinal fluid system," J. Neurosurg, vol. 43, no. 5, pp. 523-534, 1975.

[47] N. Alperin, "MR-intracranial compliance and pressure: a method for noninvasive measurement of important neurophysiologic parameters," Methods Enzymol, vol. 386, pp. 323-349, 2004.

[48] T. Miyati, M. Mase, H. Kasai, M. Hara, K. Yamada, Y. Shibamoto, M. Soellinger, C. Baltes, and R. Luechinger, "Noninvasive MRI assessment of intracranial compliance in idiopathic normal pressure hydrocephalus," J Magn Reson Imaging, vol. 26, no. 2, pp. 274-278, 2007.

[49] G. Kellie, "Appearances observed in the dissection of two individuals death from cold and congestion of the brain," Trans Med-Chir Soc Edin, pp. 1-84, 1824.

[50] J. Kim, N. A. Thacker, P. A. Bromiley, and A. Jackson, "Prediction of the jugular venous waveform using a model of CSF dynamics," $A J N R$ Am J Neuroradiol, vol. 28, no. 5, pp. 983-989, 2007.

[51] N. Bloembergen, E. M. Purcell, and R. V. Pound, "Relaxation effects in nuclear magnetic resonance absorption," Physical Review, vol. 73, no. 7, pp. 679-712, 1948 .

[52] G. J. Stanisz, E. E. Odrobina, J. Pun, M. Escaravage, S. J. Graham, M. J. Bronskill, and R. M. Henkelman, "T1, T2 relaxation and magnetization transfer in tissue at 3T," Magn Reson. Med, vol. 54, no. 3, pp. 507-512, 2005. 


\section{References}

[53] B. O. Kjos, R. L. Ehman, M. Brant-Zawadzki, W. M. Kelly, D. Norman, and T. H. Newton, "Reproducibility of relaxation times and spin density calculated from routine MR imaging sequences: clinical study of the CNS," AJR Am. J. Roentgenol, vol. 144, no. 6, pp. 1165-1170, 1985.

[54] J. G. Sled and G. B. Pike, "Quantitative imaging of magnetization transfer exchange and relaxation properties in vivo using MRI," Magn Reson. Med, vol. 46, no. 5, pp. 923-931, 2001.

[55] G. E. Gold, B. Suh, A. Sawyer-Glover, and C. Beaulieu, "Musculoskeletal MRI at 3.0 T: initial clinical experience," AJR Am. J. Roentgenol, vol. 183, no. 5, pp. 1479-1486, 2004.

[56] G. A. Bateman, C. R. Levi, P. Schofield, Y. Wang, and E. C. Lovett, "The pathophysiology of the aqueduct stroke volume in normal pressure hydrocephalus: can co-morbidity with other forms of dementia be excluded?," Neuroradiology, vol. 47, no. 10, pp. 741-748,.2005.

[57] R. A. Bhadelia, A. R. Bogdan, and S. M. Wolpert, "Analysis of cerebrospinal fluid flow waveforms with gated phase-contrast MR velocity measurements," AJNR Am J Neuroradiol, vol. 16, no. 2, pp. 389400, 1995.

[58] W. G. Bradley, D. Scalzo, J. Queralt, W. N. Nitz, D. J. Atkinson, and P. Wong, "Normal-pressure hydrocephalus: evaluation with cerebrospinal fluid flow measurements at MR imaging," Radiology, vol. 198, no. 2, pp. 523-529, 1996.

[59] Y. N. Florez, D. Moratal, J. Forner, L. Marti-Bonmati, E. Arana, U. Guajardo-Hernandez, and J. Millet-Roig, "Semiautomatic analysis of phase contrast magnetic resonance imaging of cerebrospinal fluid flow through the aqueduct of Sylvius," Magn Reson Mater Phy, vol. 19, no. 2, pp. 78-87, 2006. 


\section{References}

[60] D. Greitz, A. Franck, and B. Nordell, "On the pulsatile nature of intracranial and spinal CSF-circulation demonstrated by MR imaging," Acta Radiol, vol. 34, no. 4, pp. 321-328, 1993.

[61] M. C. Henry-Feugeas, I. Idy-Peretti, B. Blanchet, D. Hassine, G. Zannoli, and E. Schouman-Claeys, "Temporal and spatial assessment of normal cerebrospinal fluid dynamics with MR imaging," Magn Reson Imaging, vol. 11, no. 8, pp. 1107-1118, 1993.

[62] D. S. Kim, J. U. Choi, R. Huh, P. H. Yun, and D. I. Kim, "Quantitative assessment of cerebrospinal fluid hydrodynamics using a phase-contrast cine MR image in hydrocephalus," Childs Nervous System, vol. 15, no. 9, pp. 461-467, 1999.

[63] T. Miyati, M. Mase, T. Banno, T. Kasuga, K. Yamada, H. Fujita, K. Koshida, S. Sanada, and M. Onoguchi, "Frequency analyses of CSF flow on cine MRI in normal pressure hydrocephalus," Eur Radiol, vol. 13, no. 5, pp. 1019-1024, 2003.

[64] W. R. Nitz, W. G. Bradley, A. S. Watanabe, R. R. Lee, B. Burgoyne, R. M. Osullivan, and M. D. Herbst, "Flow dynamics of cerebrospinal fluid: assessment with phase-contrast velocity MR imaging performed with retrospective cardiac gating," Radiology, vol. 183, no. 2, pp. 395-405, 1992.

[65] M. E. Wagshul, J. J. Chen, M. R. Egnor, E. J. McCormack, and P. E. Roche, "Amplitude and phase of cerebrospinal fluid pulsations: experimental studies and review of the literature," J Neurosurg, vol. 104, no. 5, pp. 810-819, 2006.

[66] R. M. Quencer, M. J. Post, and R. S. Hinks, "Cine MR in the evaluation of normal and abnormal CSF flow: intracranial and intraspinal studies," Neuroradiology, vol. 32, no. 5, pp. 371-391, 1990. 


\section{References}

[67] G. Greil, T. Geva, S. E. Maier, and A. J. Powell, "Effect of acquisition parameters on the accuracy of velocity encoded cine magnetic resonance imaging blood flow measurements," J Magn Reson Imaging, vol. 15, no. 1, pp. 47-54, 2002.

[68] F. R. Korosec and P. A. Turski, "Velocity and volume flow rate measurements using phase contrast magnetic resonance imaging," International Journal of Neuroradiology, vol. 3, no. 4, pp. 293-318, 1997.

[69] C. Tang, D. D. Blatter, and D. L. Parker, "Accuracy of phase-contrast flow measurements in the presence of Partial-Volume Effects," J Magn Reson Imaging, vol. 3, no. 2, pp. 377-385, 1993.

[70] C. J. G. Bakker, R. M. Hoogeveen, and M. A. Viergever, "Construction of a protocol for measuring blood flow by two-dimensional phase-contrast MRA ," J Magn Reson Imaging, vol. 9, no. 1, pp. 119-127, 1999.

[71] N. J. Pelc, M. A. Bernstein, A. Shimakawa, and G. H. Glover, "Encoding strategies for three-direction phase-contrast MR imaging of flow," J Magn Reson Imaging, vol. 1, no. 4, pp. 405-413, 1991.

[72] I. N. Bankman, T. Nizialek, I. Simon, O. B. Gatewood, I. N. Weinberg, and W. R. Brody, "Segmentation algorithms for detecting microcalcifications in mammograms," IEEE Trans Inf Technol Biomed, vol. 1, no. 2, pp. 141-149, 1997.

[73] J. K. Udupa, L. Wei, S. Samarasekera, Y. Miki, M. A. Van Buchem, and R. I. Grossman, "Multiple sclerosis lesion quantification using fuzzyconnectedness principles," IEEE Trans Med Imaging, vol. 16, no. 5, pp. 598-609, 1997.

[74] Y. Zhu and H. Yan, "Computerized tumor boundary detection using a Hopfield neural network," IEEE Trans Med Imaging, vol. 16, no. 1, pp. 55-67, 1997. 
[75] C. E. Byrum, J. R. MacFall, H. C. Charles, V. R. Chitilla, O. B. Boyko, L. Upchurch, J. S. Smith, P. Rajagopalan, T. Passe, D. Kim, S. Xanthakos, K. Ranga, and R. Krishnan, "Accuracy and reproducibility of brain and tissue volumes using a magnetic resonance segmentation method," Psychiatry Res, vol. 67, no. 3, pp. 215-234, 1996.

[76] P. Taylor, "Invited review: computer aids for decision-making in diagnostic radiology--a literature review," Br J Radiol, vol. 68, no. 813, pp. 945-957, 1995.

[77] V. S. Khoo, D. P. Dearnaley, D. J. Finnigan, A. Padhani, S. F. Tanner, and M. O. Leach, "Magnetic resonance imaging (MRI): considerations and applications in radiotherapy treatment planning," Radiother Oncol, vol. 42, no. 1, pp. 1-15, 1997.

[78] A. Goshtasby and D. A. Turner, "Segmentation of cardiac cine MR images for extraction of right and left ventricular chambers," IEEE Trans Med Imaging, vol. 14, no. 1, pp. 56-64, 1995.

[79] D. L. Pham, C. Xu, and J. L. Prince, "Current methods in medical image segmentation," Annu Rev Biomed Eng, vol. 2, pp. 315-337, 2000.

[80] C. Yuan, E. Lin, J. Millard, and J. N. Hwang, "Closed contour edge detection of blood vessel lumen and outer wall boundaries in black-blood MR images," Magn Reson Imaging, vol. 17, no. 2, pp. 257-266, 1999.

[81] S. Kozerke, R. Botnar, S. Oyre, M. B. Scheidegger, E. M. Pedersen, and P. Boesiger, "Automatic vessel segmentation using active contours in cine phase contrast flow measurements," J. Magn Reson Imaging, vol. 10, no. 1, pp. 41-51, 1999.

[82] O. Baledent, M. C. Henry-Feugeas, and I. Idy-Peretti, "Cerebrospinal fluid dynamics and relation with blood flow: A magnetic resonance study 


\section{References}

with semiautomated cerebrospinal fluid segmentation," Invest Radiol, vol. 36, no. 7, pp. 368-377, 2001.

[83] F. M. A. Box, A. Spilt, M. A. Van Buchem, R. J. van der Geest, and J. H. C. Reiber, "Automatic model-based contour detection and blood flow quantification in small vessels with velocity encoded magnetic resonance imaging," Invest Radiol, vol. 38, no. 9, pp. 567-577, 2003.

[84] N. Alperin and S. H. Lee, "PUBS: pulsatility-based segmentation of lumens conducting non-steady flow," Magn Reson Med, vol. 49, no. 5, pp. 934-944, 2003.

[85] I. Marshall, I. MacCormick, R. Sellar, and I. Whittle, "Assessment of factors affecting MRI measurement of intracranial volume changes and elastance index," Br. J. Neurosurg, vol. 22, no. 3, pp. 389-397, 2008.

[86] M. F. Quigley, B. Iskandar, M. E. Quigley, M. Nicosia, and V. Haughton, "Cerebrospinal fluid flow in foramen magnum: temporal and spatial patterns at MR imaging in volunteers and in patients with Chiari I malformation," Radiology, vol. 232, no. 1, pp. 229-236, 2004.

[87] P. H. Luetmer, Hus, J. ton, J. A. Friedman, G. R. Dixon, R. C. Petersen, C. R. Jack, R. L. McClelland, and M. J. Ebersold, "Measurement of cerebrospinal fluid flow at the cerebral aqueduct by use of phase-contrast magnetic resonance imaging: technique validation and utility in diagnosing idiopathic normal pressure hydrocephalus," Neurosurgery, vol. 50, no. 3, pp. 534-542, 2002.

[88] C. J. Lu, H. L. Kao, Y. Sun, H. M. Liu, J. S. Jeng, P. K. Yip, and Y. T. Lee, "The hemodynamic effects of internal carotid artery stenting: a study with color-coded duplex sonography," Cerebrovasc Dis, vol. 15, no. 4, pp. 264-269, 2003. 


\section{References}

[89] Y. Yang, D. G. Grosset, Q. Li, A. Shuaib, and K. R. Lees, "Turbulence and circulating cerebral emboli detectable at Doppler ultrasonography: a differentiation study in a stenotic middle cerebral artery model," $A J N R$ Am J Neuroradiol, vol. 23, no. 7, pp. 1229-1236, 2002.

[90] MacQueen J.B., "Some methods for classification and analysis of multivariate observations.,", Proceedings of $5^{\text {th }}$ Berkeley Symposium on Mathematical Statistics and Probability, Berkeley, University of California ed 1967, pp. 281-297.

[91] C. B. Henk, S. Grampp, J. Koller, M. Schoder, H. Frank, U. Klaar, G. Gomischek, and G. H. Mostbeck, "Elimination of errors caused by firstorder aliasing in velocity encoded cine-MR measurements of postoperative jets after aortic coarctation: in vitro and in vivo validation," European Radiology, vol. 12, no. 6, pp. 1523-1531, 2002.

[92] E. Barkhof, M. Kouwenhoven, P. Scheltens, M. Sprenger, P. Algra, and J. Valk, "Phase-contrast cine MR imaging of normal aqueductal CSF Flow. Effect of aging and relation to CSF void on modulus MR," Acta Radiol, vol. 35, no. 2, pp. 123-130, 1994.

[93] N. J. Pelc, "Flow quantification and analysis methods.," MRI Clinics of North America, vol. 3, no. 3, pp. 413-424, 1995.

[94] J. H. Lee, H. K. Lee, J. K. Kim, H. J. Kim, J. K. Park, and C. G. Choi, "CSF flow quantification of the cerebral aqueduct in normal volunteers using phase contrast cine MR imaging," Korean J Radiol, vol. 5, no. 2, pp. 81-86, 2004.

[95] G. A. Bateman, "Pulse wave encephalopathy: a comparative study of the hydrodynamics of leukoaraiosis and normal pressure hydrocephalus," Neuroradiology, vol. 44, no. 9, pp. 740-748, 2002. 


\section{References}

[96] R. G. Gosling and D. H. King, "Arterial assessment by Doppler-shift ultrasound," Proc. R. Soc. Med, vol. 67, no. 6 Pt 1, pp. 447-449, June1974.

[97] S. N. Urchuk and D. B. Plewes, "MR measurements of pulsatile pressure gradients," J. Magn Reson Imaging, vol. 4, no. 6, pp. 829-836, 1994.

[98] J. M. Bland and D. G. Altman, "Statistical methods for assessing agreement between two methods of clinical measurement," Lancet, vol. 1, no. 8476, pp. 307-310, 1986.

[99] J. L. Fleiss, The design and analysis of clinical experiments. New York: Wiley, 1986.

[100] M. A. Bernstein, J. Huston, III, C. Lin, G. F. Gibbs, and J. P. Felmlee, "High-resolution intracranial and cervical MRA at 3.0T: technical considerations and initial experience," Magn Reson Med, vol. 46, no. 5, pp. 955-962, 2001.

[101] B. L. Schmitz, A. J. Aschoff, M. H. Hoffmann, and G. Gron, "Advantages and pitfalls in 3T MR brain imaging: a pictorial review," AJNR Am J Neuroradiol, vol. 26, no. 9, pp. 2229-2237, 2005.

[102] W. A. Willinek, M. Born, B. Simon, H. J. Tschampa, C. Krautmacher, J. Gieseke, H. Urbach, H. J. Textor, and H. H. Schild, "Time-of-flight MR angiography: comparison of 3.0-T imaging and 1.5-T imaging initial experience," Radiology, vol. 229, no. 3, pp. 913-920, 2003.

[103] W. A. Willinek and H. H. Schild, "Clinical advantages of 3.0 T MRI over 1.5 T," Eur J Radiol, vol. 65, no. 1, pp. 2-14, 2008.

[104] M. A. Bernstein, J. Huston, III, and H. A. Ward, "Imaging artifacts at 3.0T," J Magn Reson Imaging, vol. 24, no. 4, pp. 735-746, 2006. 


\section{References}

[105] C. M. Collins and M. B. Smith, "Signal-to-noise ratio and absorbed power as functions of main magnetic field strength, and definition of "90 degrees" RF pulse for the head in the birdcage coil," Magn Reson Med., vol. 45, no. 4, pp. 684-691, 2001.

[106] Z. B. Redzic, J. E. Preston, J. A. Duncan, A. Chodobski, and J. Szmydynger-Chodobska, "The choroid plexus-cerebrospinal fluid system: from development to aging," Curr Top Dev Biol, vol. 71, pp. 1-52, 2005.

[107] G. D. Silverberg, G. Heit, S. Huhn, R. A. Jaffe, S. D. Chang, H. BronteStewart, E. Rubenstein, K. Possin, and T. A. Saul, "The cerebrospinal fluid production rate is reduced in dementia of the Alzheimer's type," Neurology, vol. 57, no. 10, pp. 1763-1766, 2001.

[108] J. E. Preston, "Ageing choroid plexus-cerebrospinal fluid system," Microsc. Res. Tech, vol. 52, no. 1, pp. 31-37, 2001.

[109] M. Matteis, E. Troisi, B. C. Monaldo, C. Caltagirone, and M. Silvestrini, "Age and sex differences in cerebral hemodynamics: a transcranial Doppler study," Stroke, vol. 29, no. 5, pp. 963-967, 1998.

[110] R. A. Raine, N. A. Black, T. J. Bowker, and D. A. Wood, "Gender differences in the management and outcome of patients with acute coronary artery disease," J Epidemiol Community Health, vol. 56, no. 10, pp. 791-797, 2002.

[111] A. Cellerino, D. Borghetti, and F. Sartucci, "Sex differences in face gender recognition in humans," Brain Res Bull, vol. 63, no. 6, pp. 443449, 2004.

[112] R. D. Adams, C. M. Flisher, S. Hakim, R. G. Ojemann, and W. H. Swett, "Symptomatic occult hydrocephalus with "normal" cerebrospinal fluid pressure: a treatable syndrome," $N$ Engl J Med, vol. 273, pp. 117$126,1965$. 


\section{References}

[113] S. Savolainen, L. Paljarvi, and M. Vapalahti, "Prevalence of Alzheimer's disease in patients investigated for presumed normal pressure hydrocephalus: a clinical and neuropathological study," Acta Neurochir. (Wien), vol. 141, no. 8, pp. 849-853, 1999.

[114] G. A. Bateman, "Pulse wave encephalopathy: a spectrum hypothesis incorporating Alzheimer's disease, vascular dementia and normal pressure hydrocephalus," Med Hypotheses, vol. 62, no. 2, pp. 182-187, 2004.

[115] G. A. Bateman, "The pathophysiology of idiopathic normal pressure hydrocephalus: cerebral ischemia or altered venous hemodynamics?," AJNR Am J Neuroradiol, 2007.

[116] W. G. Bradley, Jr., A. R. Whittemore, A. S. Watanabe, S. J. Davis, L. M. Teresi, and M. Homyak, "Association of deep white matter infarction with chronic communicating hydrocephalus: implications regarding the possible origin of normal pressure hydrocephalus," AJNR Am J Neuroradiol, vol. 12, no. 1, pp. 31-39, 1991.

[117] J. Forner, N. Florez, M. C. Valero, L. Marti-Bonmati, D. Moratal-Perez, J. Piquer, L. Elso, and E. Arana, "Assessment of reliable quantification of the dynamics of cerebrospinal fluid by magnetic resonance imaging in idiopathic normal pressure hydrocephalus," Neurologia, vol. 22, no. 4, pp. 213-220, 2007. Spanish.

[118] L. Pantoni and J. H. Garcia, "The significance of cerebral white matter abnormalities 100 years after Binswanger's report. A review," Stroke, vol. 26, no. 7, pp. 1293-1301, 1995.

[119] Y. Y. Sitoh, Y. Y. Sitoh, and S. Sahadevan, "Clinical significance of cerebral white matter lesions in older Asians with suspected dementia," Age and Ageing, vol. 33, no. 1, pp. 65-71, 2004. 


\section{References}

[120] M. M. Breteler, J. C. van Swieten, M. L. Bots, D. E. Grobbee, J. J. Claus, J. H. van den Hout, H. F. van, H. L. Tanghe, P. T. de Jong, G. J. van, "Cerebral white matter lesions, vascular risk factors, and cognitive function in a population-based study: the Rotterdam Study," Neurology, vol. 44, no. 7, pp. 1246-1252, 1994.

[121] A. Lindgren, A. Roijer, O. Rudling, B. Norrving, E. M. Larsson, J. Eskilsson, L. Wallin, B. Olsson, and B. B. Johansson, "Cerebral lesions on magnetic resonance imaging, heart disease, and vascular risk factors in subjects without stroke. A population-based study," Stroke, vol. 25, no. 5, pp. 929-934, 1994.

[122] J. K. Krauss, J. P. Regel, W. Vach, M. Orszagh, F. D. Jungling, M. Bohus, and D. W. Droste, "White matter lesions in patients with idiopathic normal pressure hydrocephalus and in an age-matched control group: a comparative study," Neurosurgery, vol. 40, no. 3, pp. 491-495, 1997.

[123] A. D. Elster and M. Y. Chen, "Chiari I malformations: clinical and radiologic reappraisal," Radiology, vol. 183, no. 2, pp. 347-353, 1992.

[124] V. S. Caviness, "The Chiari malformations of the posterior fossa and their relation to hydrocephalus," Dev Med Child Neurol, vol. 18, no. 1, pp. 103-116, 1976.

[125] G. de Marco, I. Idy-Peretti, A. Didon-Poncelet, O. Baledent, F. Onen, and M. C. Feugeas, "Intracranial fluid dynamics in normal and hydrocephalic states: systems analysis with phase-contrast magnetic resonance imaging," J Comput Assist Tomogr, vol. 28, no. 2, pp. 247-254, 2004.

[126] S. Stoquart-Elsankari, O. Baledent, C. Gondry-Jouet, M. Makki, O. Godefroy, and M. E. Meyer, "Aging effects on cerebral blood and 


\section{References}

cerebrospinal fluid flows," J. Cereb. Blood Flow Metab, vol. 27, no. 9, pp. 1563-1572, 2007.

[127] B. Kahlon, M. Annertz, F. Stahlberg, and S. Rehncrona, "Is aqueductal stroke volume, measured with cine phase-contrast magnetic resonance imaging scans useful in predicting outcome of shunt surgery in suspected normal pressure hydrocephalus?," Neurosurgery, vol. 60, no. 1, pp. 124129, 2007.

[128] L. Marti-Bonmati, R. Sanz-Requena, and A. berich-Bayarri, "Pharmacokinetic MR analysis of the cartilage is influenced by field strength," Eur J Radiol, vol 67, no. 3, pp. 448-452 2008

[129] T. Sommer, M. Hackenbroch, U. Hofer, A. Schmiedel, W. A. Willinek, S. Flacke, J. Gieseke, F. Traber, R. Fimmers, H. Litt, and H. Schild, "Coronary MR angiography at $3.0 \mathrm{~T}$ versus that at $1.5 \mathrm{~T}$ : initial results in patients suspected of having coronary artery disease," Radiology, vol. 234, no. 3, pp. 718-725, 2005.

[130] A. Vidal, Y. Bureau, T. Wade, J. D. Spence, B. K. Rutt, A. Fenster, and G. Parraga, "Scan-rescan and intra-observer variability of magnetic resonance imaging of carotid atherosclerosis at $1.5 \mathrm{~T}$ and $3.0 \mathrm{~T}, "$ Phys Med Bio, vol. 53, no. 23, pp. 6821-6835, 2008.

[131] J. Lotz, R. Doker, R. Noeske, M. Schuttert, R. Felix, M. Galanski, M. Gutberlet, and G. P. Meyer, "In vitro validation of phase-contrast flow measurements at $3 \mathrm{~T}$ in comparison to $1.5 \mathrm{~T}$ : precision, accuracy, and signal-to-noise ratios," J. Magn Reson. Imaging, vol. 21, no. 5, pp. 604$610,2005$.

[132] P. Gideon, C. Thomsen, F. Stahlberg, and O. Henriksen, "Cerebrospinal fluid production and dynamics in normal aging: a MRI phase-mapping study," Acta Neurol. Scand, vol. 89, no. 5, pp. 362-366, 1994. 


\section{References}

[133] T. Greitz, "Effect of brain distension on cerebral circulation," Lancet, vol. 1, no. 7600, pp. 863-865, 1969.

[134] S. J. Uftring, D. Chu, N. Alperin, and D. N. Levin, "The mechanical state of intracranial tissues in elderly subjects studied by imaging CSF and brain pulsations," Magn Reson. Imaging, vol. 18, no. 8, pp. 991-996, 2000.

[135] P. Gideon, F. Stahlberg, C. Thomsen, F. Gjerris, P. S. Sorensen, and O. Henriksen, "Cerebrospinal fluid flow and production in patients with normal pressure hydrocephalus studied by MRI," Neuroradiology, vol. 36, no. 3, pp. 210-215, 1994.

[136] L. H. Chang, C. Y. Chen, M. Y. Chen, T. Y. Huang, and H. W. Chung, "Normal and abnormal cerebrospinal fluid dynamics evaluated by optimized cine phase-contrast MR imaging," Chin J Radiology, vol. 25, pp. 191-195, 2000.

[137] K. Ambarki, O. Baledent, G. Kongolo, R. Bouzerar, S. Fall, and M. E. Meyer, "A new lumped-parameter model of cerebrospinal hydrodynamics during the cardiac cycle in healthy volunteers," IEEE Trans Biomed Eng, vol. 54, no. 3, pp. 483-491, 2007.

[138] T. Takemae, Y. Kosugi, J. Ikebe, Y. Kumagai, K. Matsuyama, and H. Saito, "A simulation study of intracranial pressure increment using an electrical circuit model of cerebral circulation," IEEE Trans Biomed Eng, vol. 34 , no. 12 , pp. 958-962, 1987.

[139] G. C. Agarwal, B. M. Berman, and L. Stark, "A lumped parameter model of the cerebrospinal fluid system," IEEE Trans Biomed Eng, vol. 16 , no. 1 , pp. 45-53, 1969.

[140] A. A. Linninger, C. Tsakiris, D. C. Zhu, M. Xenos, P. Roycewicz, Z. Danziger, and R. Penn, "Pulsatile cerebrospinal fluid dynamics in the 


\section{References}

human brain," IEEE Trans Biomed Eng, vol. 52, no. 4, pp. 557-565, 2005.

[141] A. A. Linninger, M. Xenos, D. C. Zhu, M. R. Somayaji, S. Kondapalli, and R. D. Penn, "Cerebrospinal fluid flow in the normal and hydrocephalic human brain," IEEE Trans Biomed Eng, vol. 54, no. 2, pp. 291-302, 2007.

[142] D. R. Enzmann and N. J. Pelc, "Cerebrospinal fluid flow measured by phase-contrast cine MR," AJNR Am J Neuroradiol, vol. 14, no. 6, pp. 1301-1307, 1993.

[143] R. A. Bhadelia, A. R. Bogdan, S. M. Wolpert, S. Lev, B. A. Appignani, and C. B. Heilman, "Cerebrospinal fluid flow waveforms: analysis in patients with Chiari I malformation by means of gated phase-contrast MR imaging velocity measurements," Radiology, vol. 196, no. 1, pp. 195$202,1995$.

[144] B. Liu, Z. Y. Wang, J. C. Xie, H. B. Han, and X. L. Pei, "Cerebrospinal fluid dynamics in Chiari malformation associated with syringomyelia," Chin Med. J. Engl, vol. 120, no. 3, pp. 219-223, 2007.

[145] E. Hofmann, M. Warmuth-Metz, M. Bendszus, and L. Solymosi, "Phasecontrast MR imaging of the cervical CSF and spinal cord: volumetric motion analysis in patients with Chiari I malformation," AJNR Am. J Neuroradiol., vol. 21, no. 1, pp. 151-158, 2000.

[146] V. M. Haughton, F. R. Korosec, J. E. Medow, M. T. Dolar, and B. J. Iskandar, "Peak systolic and diastolic CSF velocity in the foramen magnum in adult patients with Chiari I malformations and in normal control participants," AJNR Am J Neuroradiol, vol. 24, no. 2, pp. 169$176,2003$. 


\section{References}

[147] B. J. Iskandar and V. Haughton, "Age-related variations in peak cerebrospinal fluid velocities in the foramen magnum," J Neurosurg, vol. 103, no. 6 Suppl, pp. 508-511, 2005.

[148] R. A. Armonda, C. M. Citrin, K. T. Foley, and R. G. Ellenbogen, "Quantitative cine-mode magnetic resonance imaging of Chiari I malformations: an analysis of cerebrospinal fluid dynamics," Neurosurgery, vol. 35, no. 2, pp. 214-223, 1994.

[149] N. Alperin, K. Kulkarni, F. Loth, B. Roitberg, M. Foroohar, M. F. Mafee, and T. Lichtor, "Analysis of magnetic resonance imaging-based blood and cerebrospinal fluid flow measurements in patients with Chiari I malformation: a system approach," Neurosurg Focus., vol. 11, no. 1, p. E6, 2001. 


\section{Publications}

\section{Thesis related publications}

Publication in journals

JCR (SCI) indexed journals

- Flórez YN, Moratal D, Forner J, Marti-Bonmatí L, Arana E, GuajardoHernandez U, Millet-Roig J. Semiautomatic analysis of phase contrast magnetic resonance imaging of cerebrospinal fluid flow through the aqueduct of Sylvius. Magn Reson Mater Phy 2006; 19(2):78-87

- Forner J, Flórez N, Valero-Merino C, Martí-Bonmatí L, Moratal D, Piquer J, Elso L, Arana E. Assessment of reliable quantification of the dynamics of cerebrospinal fluid by magnetic resonance imaging in idiopathic normal pressure hydrocephalus. Neurología,22:213-220,2007

- $\quad$ Flórez N, Bouzerar R, Moratal D, Meyer M.E, Martí-Bonmatí L, Balédent O. Quantitative analysis of cerebrospinal fluid flow by means of unsupervised clustering k-means using phase contrast magnetic resonance imaging. Medical Image Analysis. Submitted.

- $\quad$ Flórez N, Martí-Bonmatí L, Arana E, Forner J, Moratal D. Analyses of the dynamic of the cerebrospinal fluid flow through of the aqueduct of Sylvius in normal volunteers, patients with normal pressure hydrocephalus and patients with mild white matter lesions using phase contrast MR imaging. Magn Reson Mater Phy. Submitted 
Other journals (non-JCR-SCI- indexed journals)

- J Forner, N Flórez, E Arana, L Martí-Bonmatí, D Moratal. Diagnóstico de hidrocefalia normopresiva con medición de flujo LCR en el acueducto. Revista Clínica Quirón y Medicina, 11: 25-27, 2005.

- J Forner, L Martí-Bonmatí, E Arana, N Flórez, D Moratal, Signo Radiológico: Vacío del Flujo en Imágenes RM en el Tercer Ventrículo de Pacientes con Hidrocefalia Normotensiva. Revista Argentina de Radiología, 71:199-220, 2007

- Flórez N, Martí-Bonmatí L, Forner J, Moratal D, Arana E. Normal Values of the Cerebrospinal Fluid Flow Dynamics in the Aqueduct of Sylvius by means of an Optimized Analysis of Phase Contrast Magnetic Resonance. Radiología, 51:38-44, 2009;

Publications in Conference Proceedings

International Conference Proceedings

- $\quad$ Flórez N, Moratal D, Arana E, Martí-Bonmatí L, Millet J. Analysis of Phase-Contrast Magnetic Resonance Imaging of Cerebrospinal fluid flow. A software to define the optimum region of interest. International Congress of Computational Bioengineering, Zaragoza 2003.

- $\quad$ Flórez N, Martí-Bonmatí L, Arana E, Moratal D, Millet J. Automatic flow measurement of cerebrospinal fluid by $\mathrm{MR}$ in aqueduct of Sylvius. European Congress of Radiology, Wien 2004.

- Moratal D, Flórez N, Forner J, Arana E, Martí-Bonmatí L, Millet J. Partial volume effect and aliasing correction in PC-MRI analysis of 
cerebrospinal fluid flow. European Society for Magnetic Resonance in Medicine and Biology - 21st Annual ESMRMB Meeting, Copenhague 2004.

- Flórez N, Martí-Bonmatí L, Moratal D, Forner J, Arana E, Millet J. Interobserver variability in quantitative analysis of cerebrospinal flow using phase contrast magnetic resonance imaging. European Society for Magnetic Resonance in Medicine and Biology -22st Annual ESMRMB Meeting, Basel, 2005.

- Flórez N, Moratal D, Forner J, Arana E, Martí-Bonmatí L, Millet J. Seed method, a method to carry out semiautomatic quantitative analysis of Cerebrospinal Fluid Flow through the Aqueduct of Sylvius using Phase Contrast Magnetic Resonance Imaging. European Congress of Radiology (ECR), Wien 2006.

- Flórez N, D. Moratal, J. Forner, E. Arana, L. Martí-Bonmatí. Influence of the MR Field Strength on the PC Quantitative Analysis of Cerebrospinal Fluid Flow within the Aqueduct. European Society for Magnetic Resonance in Medicine and Biology -23st Annual ESMRMB Meeting Warsaw, 2006.

- Arana E, Forner J, Flórez N, Martí-Bonmatí L, Moratal D, Millet J. Flow measurements and Evans index in normal pressure hydrocephalus and white matter lesions. Join annual meeting ISMRM (International Society for Magnetic Resonance in Medicine - ESMRMB (European Society for Magnetic Resonance in Medicine and Biology, Berlin 2007

- Flórez N, Moratal D, Martí-Bonmatí L, Forner J, Arana E. Dynamic relationships model of the craniospinal fluids in healthy volunteers using phase contrast magnetic resonance imaging. European Congress of Radiology (ECR), Wien 2008. 
- Flórez N, Martí-Bonmatí L, Forner J, Arana E, Moratal D. Cerebrospinal Flow Dynamics in White Matter Disease evaluated by optimized Cine Phase Contrast MR Imaging. European Society for Magnetic Resonance in Medicine and Biology-25st Annual ESMRMB Meeting Valencia 2008.

\section{National Conference Proceedings}

- Flórez N, Martí-Bonmatí L, Arana E, Forner J, Moratal D, Millet J. Análisis del flujo del líquido cefalorraquídeo en el acueducto de Silvio por RM. XXVII Congreso de la SERAM (Sociedad Española de Radiología Médica, Bilbao, 2004.

- Flórez N, Moratal D, Forner J, Martí-Bonmatí L, Arana E, Millet J. Corrección de la variabilidad de resultados en análisis cuantitativos de flujo en imágenes de resonancia magnética por contraste de fase. XXII Congreso Anual de la Sociedad Española de Ingeniería Biomédica (CASEIB, Santiago de Compostela 2004.

- Flórez N, Moratal D, Forner J, Arana E, Poyatos C, Martí-Bonmatí L. Optimización de la cuantificación de los parámetros del flujo de líquido cefalorraquídeo medidos a través del acueducto de Silvio mediante imágenes de RM de contraste de fase. XXVII Congreso Nacional de la Seram, XXIII Congreso Internacional de Radiología CIR, Zaragoza 2006.

- Martí-Bonmatí L, Flórez N, Moratal D, Forner J, Arana E. Diferencias en la dinámica del líquido cefalorraquídeo en el acueducto de Silvio en sujetos normales, pacientes con hidrocefalia normopresiva y pacientes con afectación hipóxico-isquémica. XXIX Congreso Nacional de la SERAM, Sevilla 2008 . 
- $\quad$ Flórez N, Potayos C, Martí-Bonmatí L, Forner J, Moratal D. Relaciones temporales del flujo sanguíneo y el líquido cefalorraquídeo en sujetos sanos mediante cuantificación de imágenes de RM en contraste de fase. $8^{\circ}$ Congreso de la Sociedad Española de Base de Cráneo, Santander 2008 


\section{APPENDIX 1 Flujómetro}

Flujómetro is a friendly image post-processing tool that serves of support to carry out quantitative analysis of the flow dynamics in the main vessels and CSF spaces. This tool integrates the different segmentation and corrections methods developed in this thesis. The different parameters that characterize the behavior of the flow are calculated and finally exported to a file in three different formats: .xls, .txt and .pdf. The two first are used for statistical analysis and the last one is the report for the clinician.

The tool has been implemented using MATLAB R7 (The MathWorks, Inc., Natick, MA, USA) and taking advantage of the compiler toolbox an executable file is created in order to work independently from MATLAB.

Flujómetro was registered at the Center for Technology Transfer (Centre de Transferència Tecnològica) of the Universitat Politècnica de València with registration number CTT-007804, in December 2006. Next, the main functions of Flujómetro are briefly described.

\section{Main windows menus}

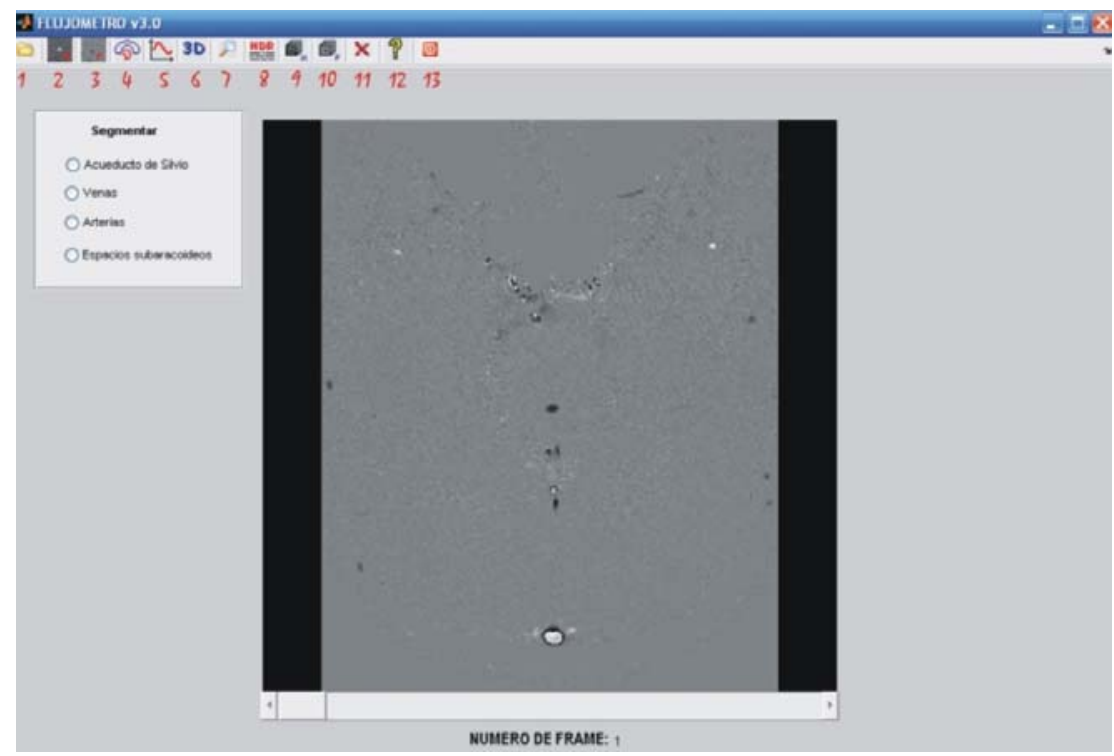

Figure A.1 Main window of Flujómetro 
1. Opening image sequences. The tool classifies the images sequences and allows the user to select the sequence to analyze (Figure A.2). DICOM (Digital Imaging and Communication in Medicine) is the image format supported by the software.

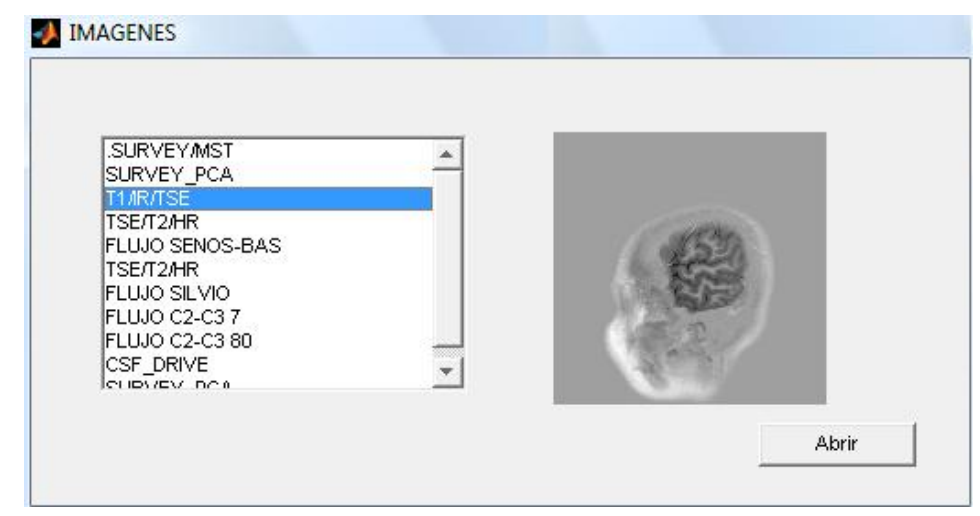

Figure A.2 Image sequences classified

2. Modulo image. With the slider located in the lower part it is possible to visualize each one of the images of the module sequence.

3. Phase image or velocity map. Just like the previous menu permits to visualize the images of phase.

4. Segmentation. This menu allows to mark a point within the region to analyze in order to carry out the delineation of the ROI. Flujómetro is designed to segment four different regions (arteries, veins, aqueduct of Sylvius and CSF spaces). The process is initialized by selecting a seed point inside the region to analyze on the magnitude or phase image.

- Aqueduct of Sylvius. Three ROIs are automatically selected; the red region is used to calculate the velocity parameters, the yellow region for the flow parameters and the blue halfmoon is used for the background correction.

- Veins and arteries. It allows to select the desired veins and arteries in only one step. The vessels to analyze are selected marking a point with the left button of the mouse. The right button finishes the selection. 


\section{ANNEX 1: Flujómetro}

The tool was implemented for veins with positive velocities (pixels of clear intensities) and arteries with negative velocities (pixels with dark intensities). If the intensity encoding is not known then it is necessary to try with both options.

- Subarachnoidian spaces. The region automatically selected using the kmean method is showed in the main image; two more images appear to the right side of the main image. The right upper image contains the two classes and the right lower image represents the discarder class. Any of these two images can be selected by the user when the automatically segmented region is incorrect. When this menu is selected the options to delete or to select regions on the main image appears on the left side of the window (Figure A.3).

The information about area, number of pixels and encoding velocity are shown in each one of the segmentations.

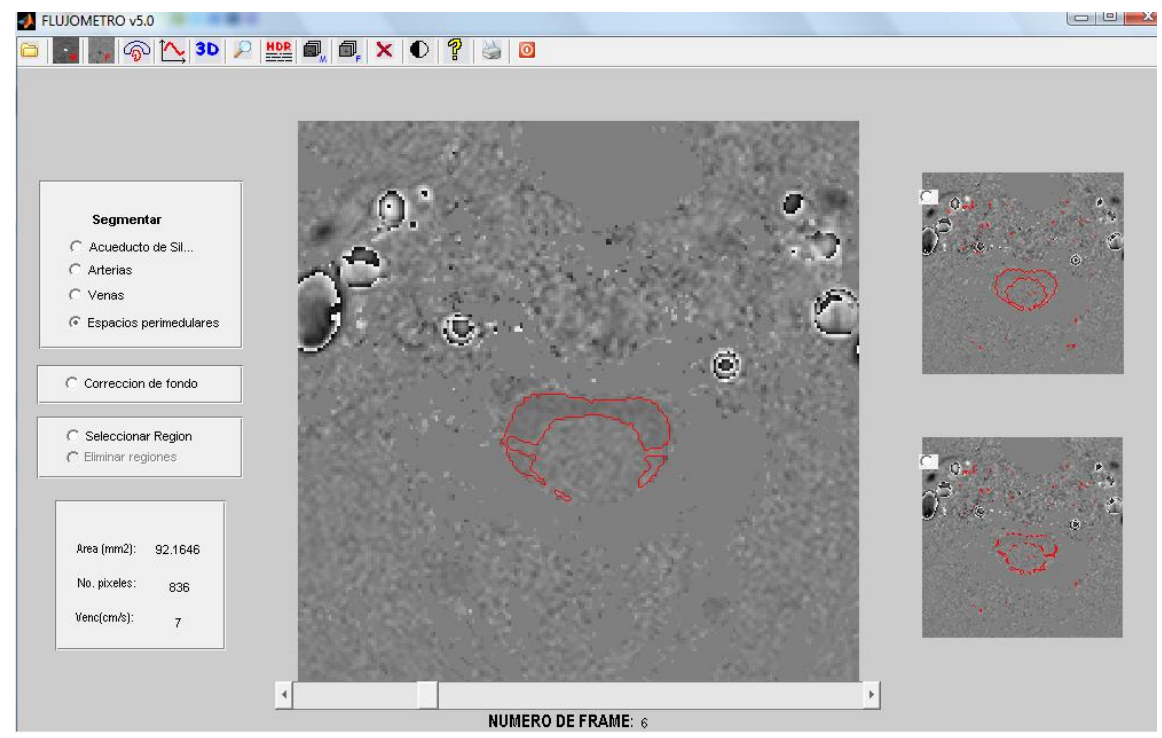

Figure A.3 K-mean segmentation method used at spinal space C2C3.

The background correction is activated for all regions to exception of the aqueduct of Sylvius; in this region the method automatically selects the background region to carry out the correction. A phase image appears in a new 
window. Here the user selects a point in the midbrain. A circular ROI is then built with $42 \mathrm{~mm}^{2}$ area using that selected point as its centre

5. Quantitative analysis. The main calculated parameters are shown in a second window (Figure A.4). The selected region and the velocity curve are also presented. The flow and stroke volume waveforms can be visualized using the menu of the upper part.

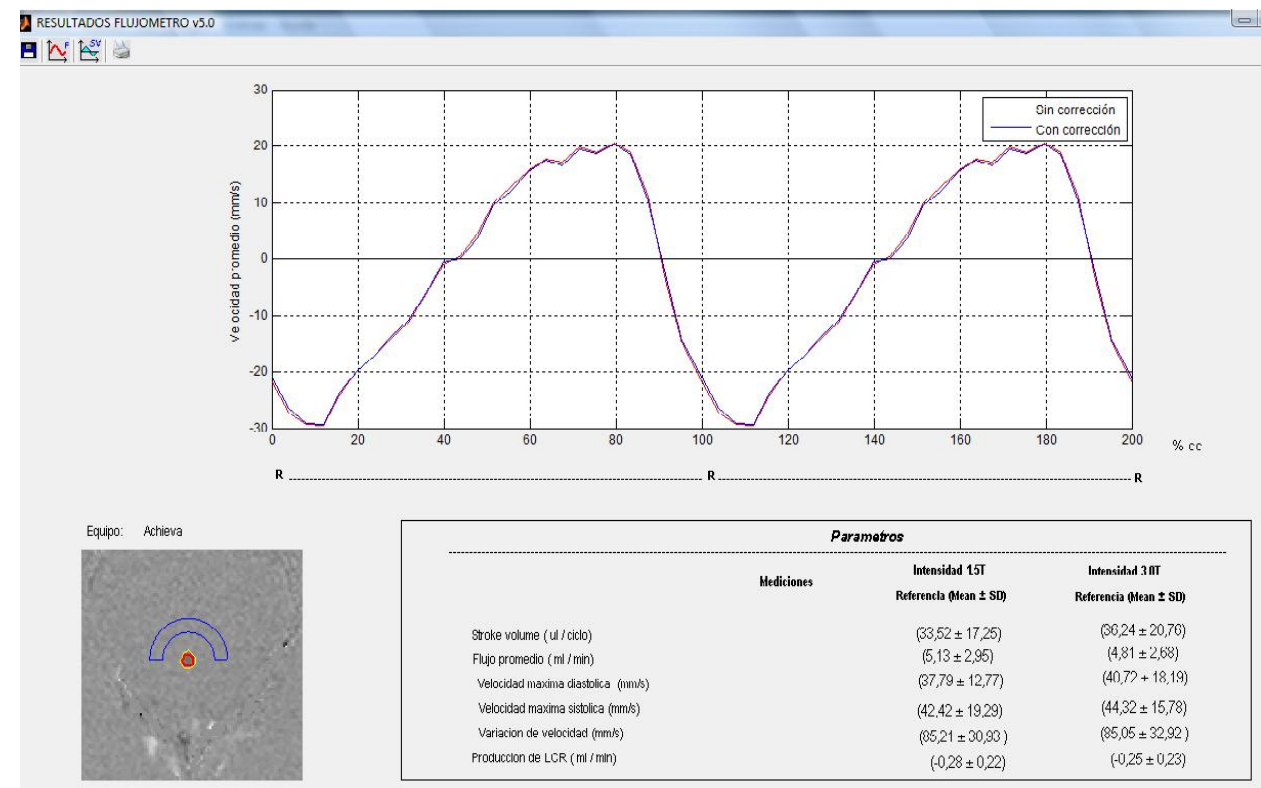

Figure A.4 Results window.

6. This function allows to visualize the region to analyze in $3 \mathrm{D}$. 


\section{ANNEX 1: Flujómetro}

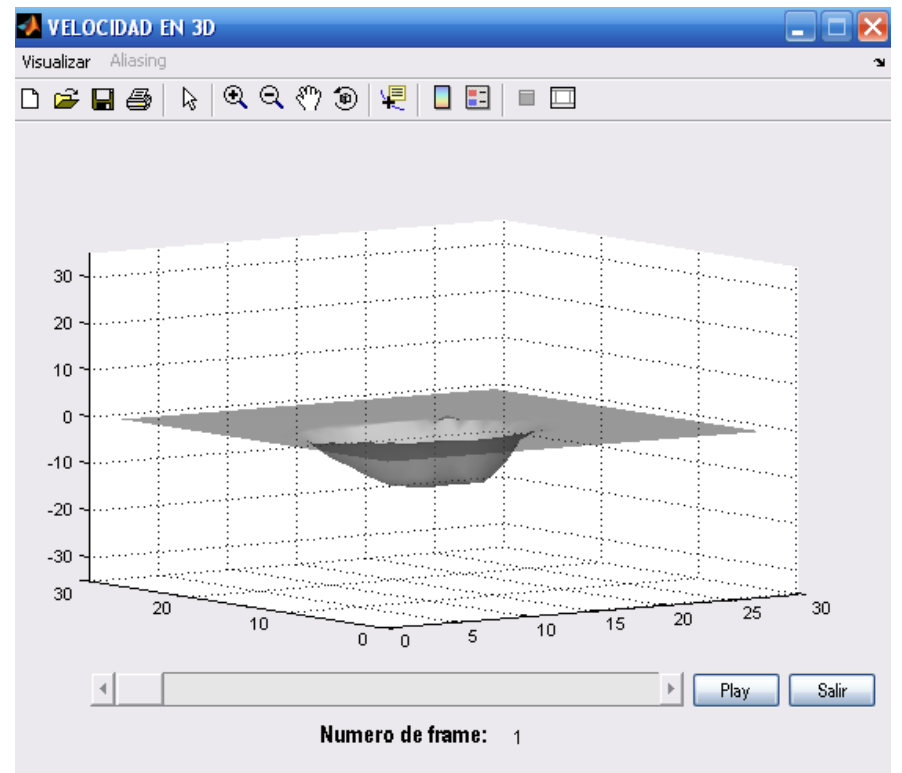

Figure A.5 A 3D visualization of the flow motion.

In this window the Aliasing menu is automatically activated if this artifact is detected and corrected. The sequence with and without correction can be observed. A 3D visualization of the flow motion during the cardiac cycle allows a visual analysis of the aliasing correction.

7. Zoom.

8. Header DICOM. With this function it is possible to consult the image header info.

9. Modulo images sequence. All sequence is visualized in a video.

10. Phase images sequence. All sequence is visualized in a video.

11. Delete. It permits to eliminate the segmentation carried out and to be able to carry out a new one.

12. Help. Window that permits to consult a detailed handbook about the main function of the Flujómetro.

13. Exit 


\section{Reports}

The save menu of the results windows allows to select the name of the region that has been segmented (Figure A.4). Next a folder with the name of the patient is created in a predetermined path. The results are exported in .txt and .pdf files. The user can print the selected inform or to create the intracranial dynamic report, which uses five .txt files (Aqueduct of Sylvius, C2C3, arteries, straight sinus, sagittal superior sinus) (Figure A.6).

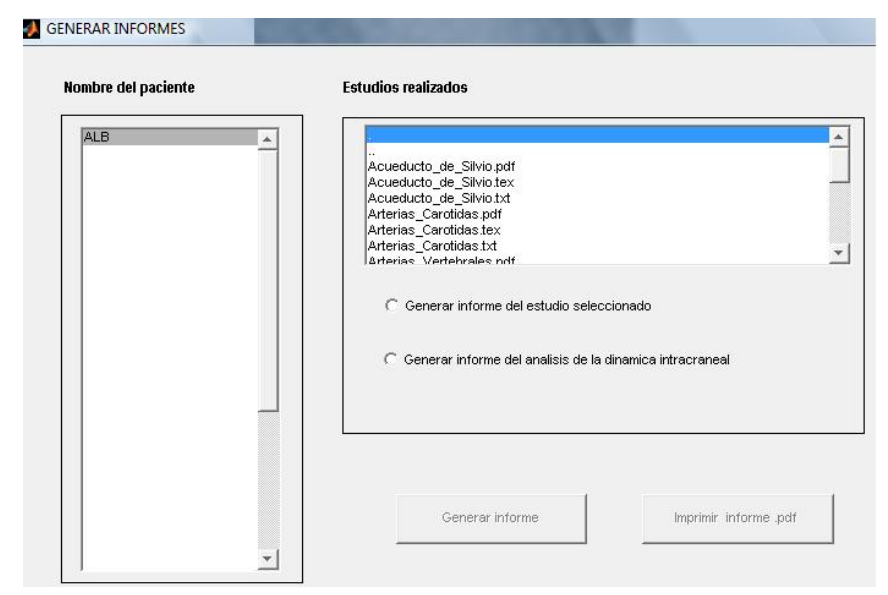

Figure A.6 Report windows. 
Report generated for the regions

\section{Análisis de flujo}

Nombre: $\mathrm{xxx}$

Equipo: $x x x$

Fecha del estudio: $\mathrm{xxx}$

ID: $\mathrm{xxx}$

\begin{tabular}{||l||l||}
\hline \multicolumn{1}{|c|}{ Parámetros } & Mediciones \\
\hline Volumen por ciclo $(\mu \mathrm{l} /$ ciclo $)$ & \\
\hline Flujo promedio $(\mathrm{ml} / \mathrm{min})$ & \\
\hline Velocidad máxima sistólica $(\mathrm{cm} / \mathrm{s})$ & \\
\hline Velocidad máxima diastólica $(\mathrm{cm} / \mathrm{s})$ & \\
\hline Variación de velocidad $(\mathrm{cm} / \mathrm{s})$ & \\
\hline
\end{tabular}

\section{Curva de volumen de flujo}

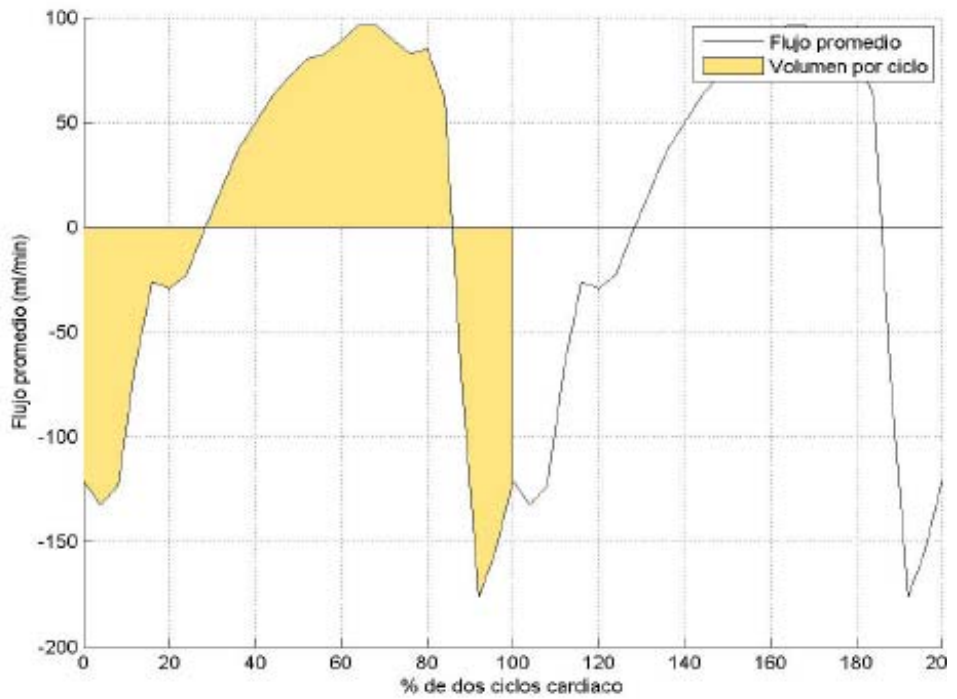

Volumen por ciclo (Stroke volume) [ul/ciclo]: Valor promedio del volumen de flujo desplazado durante un ciclo cardiaco, independientemente del sentido, calculado como la integral de la curva de flujo, medido en el área total del acueducto.

Flujo promedio (Mean flow) [mL/min]: Promedio del valor absoluto del flujo en ambos sentidos, medido en el área total del acueducto.

Velocidad máxima (maximum velocity) [cm/s]: Máxima velocidad a través del ciclo cardiaco.

Velocidad mínima (minimum velocity) [cm/s]: Mínima velocidad a través del ciclo cardiaco.

Variación de velocidad (Difference in velocities) $[\mathrm{cm} / \mathrm{s}]$ : Amplitud de velocidad calculada como la diferencia entre la velocidad máxima y la velocidad mínima. 


\section{Relaciones dinámicas de los fluidos intracraneales}

Nombre: $\mathrm{xxx}$

Fecha del estudio: $\mathrm{xxx}$

ID: $\mathrm{xxx}$

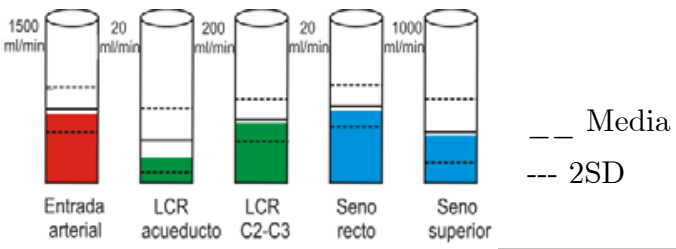

Mediciones de amplitud (Valores de referencia) ${ }^{*}$

\begin{tabular}{|c|c|c|c|c|c|}
\hline Parameters & $\begin{array}{l}\text { Entrada } \\
\text { arterial }\end{array}$ & $\begin{array}{l}\text { Acueducto } \\
\text { de Silvio }\end{array}$ & $\mathrm{C2C3}$ & Seno recto & $\begin{array}{c}\text { Seno } \\
\text { superior }\end{array}$ \\
\hline Flujo promedio $(\mathrm{ml} / \mathrm{min})$ & $\begin{array}{c}\mathrm{xxx} \\
660 \pm 104\end{array}$ & $\begin{array}{c}\mathrm{xxx} \\
5 \pm 2\end{array}$ & $\begin{array}{c}\mathrm{xxx} \\
75 \pm 12\end{array}$ & $\begin{array}{c}\mathrm{xxx} \\
90 \pm 10\end{array}$ & $\begin{array}{c}\mathrm{xxx} \\
320 \pm 90\end{array}$ \\
\hline $\begin{array}{l}\text { Volumen sistólico } \\
(\mu \mathrm{l}) \\
\end{array}$ & $\begin{array}{c}\mathrm{xxx} \\
1300 \pm 196\end{array}$ & $\begin{array}{c}\mathrm{xxx} \\
34 \pm 18 \\
\end{array}$ & $\begin{array}{c}\mathrm{xxx} \\
544 \pm 122 \\
\end{array}$ & $\begin{array}{c}\mathrm{xxx} \\
58 \pm 18\end{array}$ & $\begin{array}{c}\mathrm{xxx} \\
247 \pm 76\end{array}$ \\
\hline $\begin{array}{l}\text { Tiempos } \\
(\% \text { ciclo cardíaco })\end{array}$ & & $\begin{array}{c}\mathrm{xxx} \\
25 \pm 13\end{array}$ & $\begin{array}{c}\mathrm{xxx} \\
12 \pm 10\end{array}$ & $\begin{array}{c}\mathrm{xxx} \\
22 \pm 4\end{array}$ & $\begin{array}{c}\mathrm{xxx} \\
38 \pm 16\end{array}$ \\
\hline Indice de complianza & & $\begin{array}{c}\mathrm{xxx} \\
35 \pm 10\end{array}$ & $\begin{array}{c}\mathrm{xxx} \\
1.10 \pm 0.45\end{array}$ & & \\
\hline Índice de pulsatibilidad & \begin{tabular}{cc}
\multicolumn{2}{c}{$\mathrm{xxx}$} \\
$1.08 \quad 0.15$
\end{tabular} & $\begin{array}{c}\mathrm{xxx} \\
0.35 \pm 0.26\end{array}$ & $\begin{array}{c}\mathrm{xxx} \\
1.42 \pm 0.33\end{array}$ & $\begin{array}{c}\mathrm{xxx} \\
0.33 \pm 0.04\end{array}$ & $\begin{array}{c}\mathrm{xxx} \\
0.39 \pm 0.10\end{array}$ \\
\hline $\begin{array}{l}\text { Amplitud del gradiente de } \\
\text { presión }(\mathrm{mmHg} / \mathrm{cm})\end{array}$ & $\begin{array}{c}\mathrm{xxx} \\
0.31 \pm 0.08\end{array}$ & $\begin{array}{c}\mathrm{xxx} \\
0.07 \pm 0.03\end{array}$ & $\begin{array}{c}\mathrm{xxx} \\
0.07 \pm 0.02\end{array}$ & $\begin{array}{c}\mathrm{xxx} \\
0.11 \pm 0.03\end{array}$ & $\begin{array}{c}\mathrm{xxx} \\
0.09 \pm 0.03\end{array}$ \\
\hline
\end{tabular}

\section{Parámetros derivados (Valores de referencia) ${ }^{*}$}

\begin{tabular}{|l|c|}
\hline Relación de volumen por ciclo $(\%)$ & $\mathrm{xxx}$ \\
& $5.26 \pm 2.20$ \\
\hline Producción supratentorial & $\mathrm{xxx}$ \\
$(\mathrm{ml} / \mathrm{min})$ & $-0.24 \pm 0.19$ \\
\hline
\end{tabular}
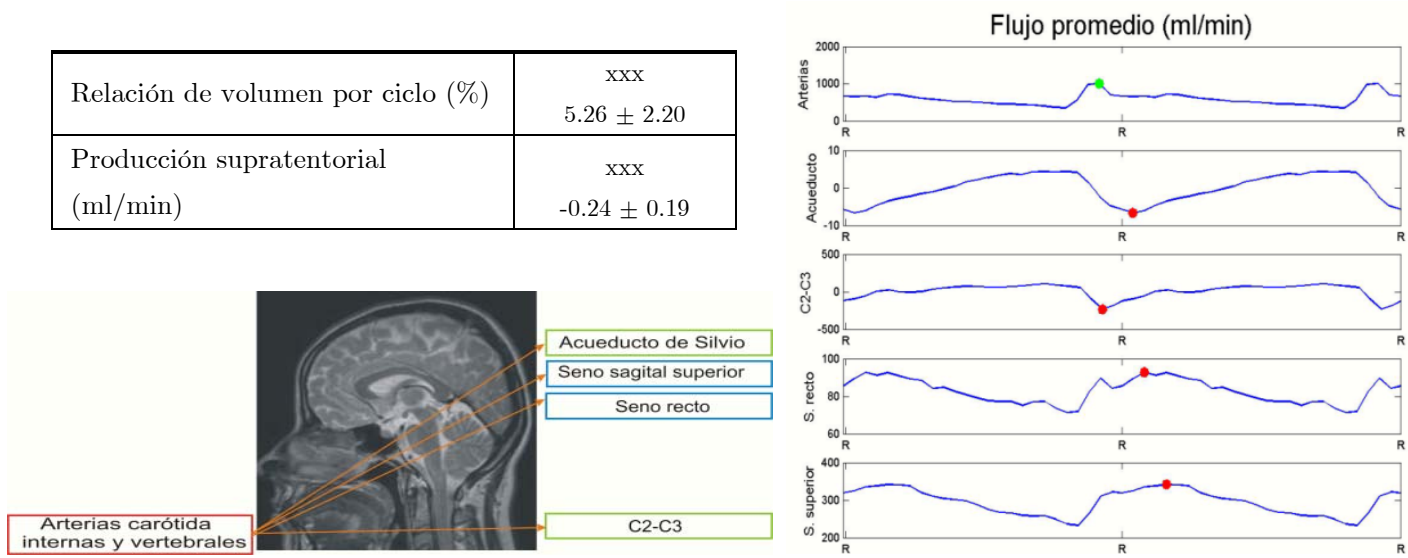

\footnotetext{
${ }^{*}$ Valor de referencia calculados de una serie propia (ENE-2008), con una intensidad de campo de 3T.
} 